\title{
Recovery of Fresh Water Resources from Desalination of Brine Produced During Oil and Gas Production Operations
}

\section{Final Report}

This project has been jointly funded by the U.S. Department of Energy, National Energy Technology Laboratory (No. DE-FC26-03NT15427) and the Global Petroleum Research Institute (Texas Engineering Experiment Station) Texas A\&M University.

\section{Performance Period}

September 30, 2003 - December 29, 2006

Principal Investigators

David B. Burnett, Director of Technology GPRI

Mustafa Siddiqui. M.S. Petroleum Engineering

Harold Vance Department of Petroleum Engineering

Texas A\&M University

3116 TAMU

College Station, Texas 77843-3116 


\section{SCLAI MERS}

\section{U.S. Department of Energy Disclaimer}

This report was prepared as an account of work sponsored by an agency of the United State Government. Neither the United States Government nor any agency thereof, nor any of their employees, makes any warranty, express or implied, or assumes any legal liability or responsibility for the accuracy, completeness, or usefulness of any information, apparatus, product, or process disclosed, or represents that its use would not infringe privately owned rights. Reference herein to any specific commercial product, process, or service by trade name, trademark, manufacturer, or otherwise does not necessarily constitute or imply its endorsement, recommendation, or favoring by the United States Government or any agency thereof. The views and opinions of authors expressed herein do not necessarily state or reflect those of the United States Government or any agency thereof.

\section{GPRI Disclaimer}

The material in this Report is intended for general information only. Any use of this material in relation to any specific application should be based on independent examination and verification of its unrestricted applicability for such use and on a determination of suitability for the application by professionally qualified personnel. No license under any GPRI, patents or other proprietary interest is implied by the publication of this Report. Those making use of or relying upon the material assume all risks and liability arising from such use of reliance. 


\title{
ABSTRACT \\ Recovery of Fresh Water Resources from Desalination of Brine Produced During Oil and Gas Production Operations \\ A Global Petroleum Research Institute Report \\ U.S. DOE DE-FC26-03NT15427 \\ Performance Period
}

September 30, 2003 - December 29, 2006

\begin{abstract}
Management and disposal of produced water is one of the most important problems associated with oil and gas (O\&G) production. O\&G production operations generate large volumes of brine water along with the petroleum resource. Currently, produced water is treated as a waste and is not available for any beneficial purposes for the communities where oil and gas is produced. Produced water contains different contaminants that must be removed before it can be used for any beneficial surface applications. Arid areas like west Texas produce large amount of oil, but, at the same time, have a shortage of potable water.
\end{abstract}

A multidisciplinary team headed by researchers from Texas A\&M University has spent more than six years is developing advanced membrane filtration processes for treating oil field produced brines The government- industry cooperative joint venture has been managed by the Global Petroleum Research Institute (GPRI).

The goal of the project has been to demonstrate that treatment of oil field waste water for re-use will reduce water handling costs by $50 \%$ or greater. Our work has included (1) integrating advanced materials into existing prototype units and (2) operating short and long-term field testing with full size process trains. Testing at A\&M has allowed us to upgrade our existing units with improved pre-treatment oil removal techniques and new oil tolerant $R O$ membranes. We have also been able to perform extended testing in "field laboratories" to gather much needed extended run time data on filter salt rejection efficiency and plugging characteristics of the process train.

The Program Report describes work to evaluate the technical and economical feasibility of treating produced water with a combination of different separation processes to obtain water of agricultural water quality standards. Experiments were done for the pretreatment of produced water using a new liquid-liquid centrifuge, organoclay and microfiltration and ultrafiltration membranes for the removal of hydrocarbons from produced water. The results of these experiments show that hydrocarbons from produced water can be reduced from $200 \mathrm{ppm}$ to below $29 \mathrm{ppm}$ level. Experiments were also done to remove the dissolved solids (salts) from the pretreated produced water using desalination membranes. Produced water with up to 45,000 ppm total dissolved solids (TDS) can be treated to agricultural water quality water standards having less than 500 ppm TDS. 
The Report also discusses the results of field testing of various process trains to measure performance of the desalination process. Economic analysis based on field testing, including capital and operational costs, was done to predict the water treatment costs. Cost of treating produced water containing 15,000 ppm total dissolved solids and 200 ppm hydrocarbons to obtain agricultural water quality with less than 200 ppm TDS and 2 ppm hydrocarbons range between $\$ 0.5-1.5$ /bbl.

The contribution of fresh water resource from produced water will contribute enormously to the sustainable development of the communities where oil and gas is produced and fresh water is a scarce resource. This water can be used for many beneficial purposes such as agriculture, horticulture, rangeland and ecological restorations, and other environmental and industrial application. 


\section{TABLE OF CONTENTS}

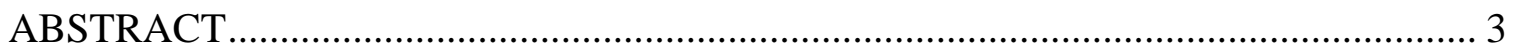

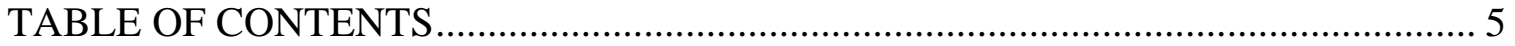

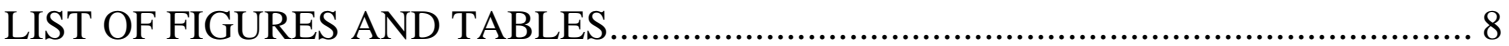

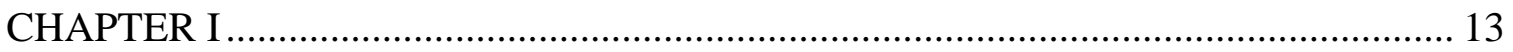

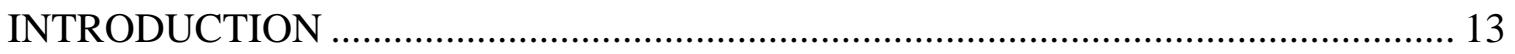

Produced Water - A Headache for the Oil and Gas Industry......................................... 13

Fresh Water - A Problem for West Texas and Other Arid Regions ................................. 14

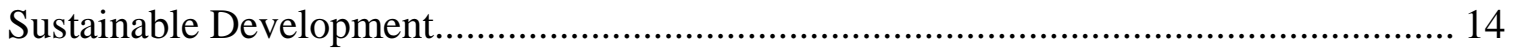

Sustainable Development Through Beneficial Use of Produced Water .......................... 15

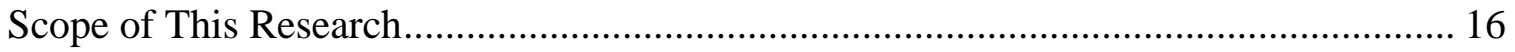

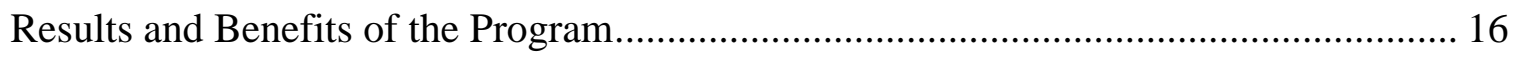

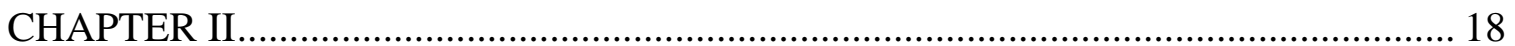

BACKGROUND AND LITERATURE REVIEW .................................................... 18

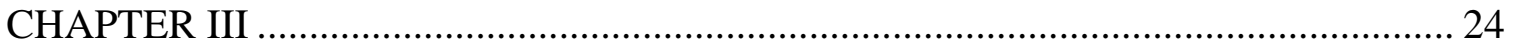

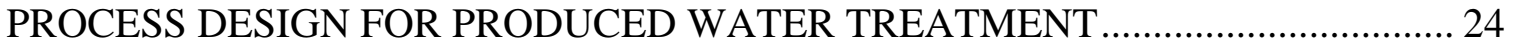

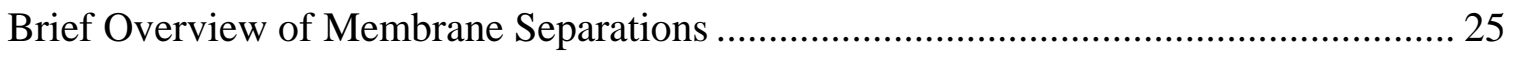

Process Design for the Produced Water Treatment ...................................................... 27

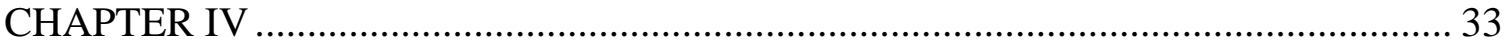

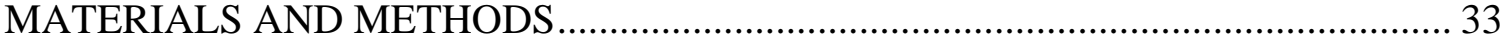

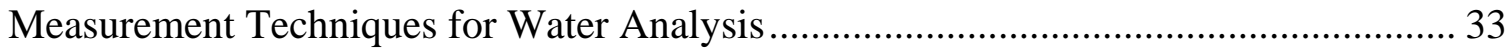

Removal of Hydrocarbons From Produced Water by CINC Centrifuge .......................... 34

Removal of Hydrocarbons From Produced Water by ET-1 Organoclay.......................... 37

Screening of Membranes for the Removal of Hydrocarbons From Produced Water and

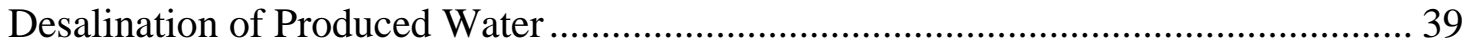

Experiments With SWC-1-4040 Membrane for Desalination of Produced Water........... 46

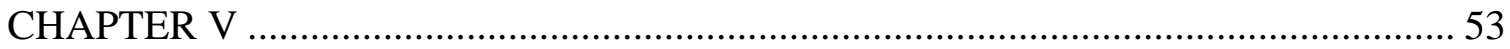

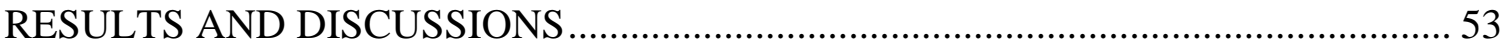

Removal of Hydrocarbons From Produced Water.......................................................... 53

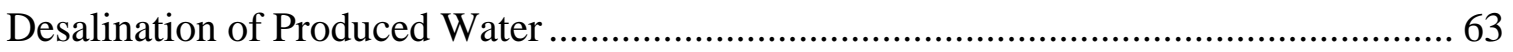




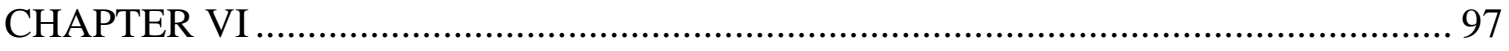

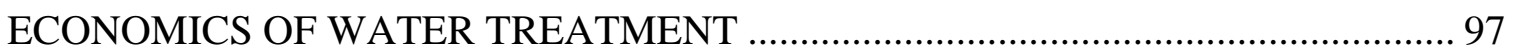

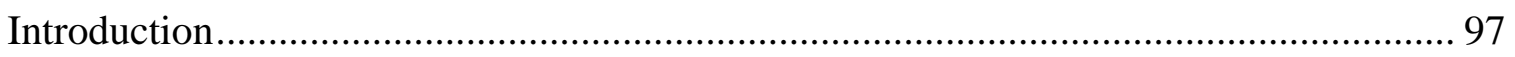

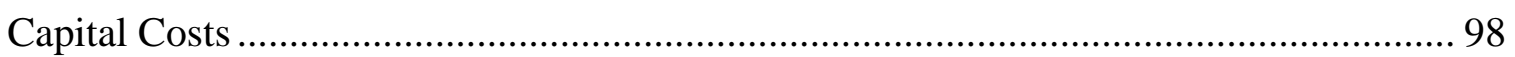

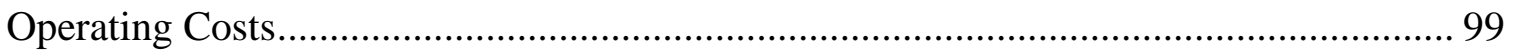

Total Water Treatment Costs ................................................................................... 106

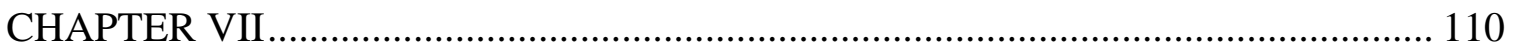

CONCLUSIONS AND RECOMMENDATIONS ………........................................ 110

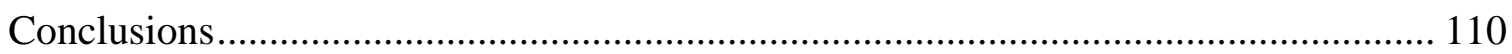

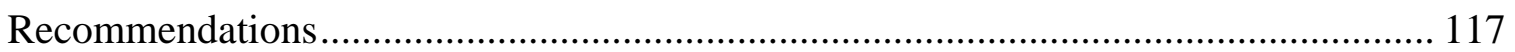

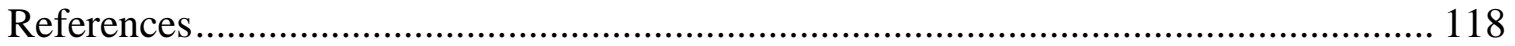

BASICS OF PRODUCED WATER MANAGEMENT .............................................. 131

Water Production in Onshore Oil and Gas Operations in Texas .................................... 131

Water Produced During Drilling Operations .................................................................. 131

Water Produced from Well Fracturing Operations.......................................................... 132

Water Produced During Production Operations …………............................................. 133

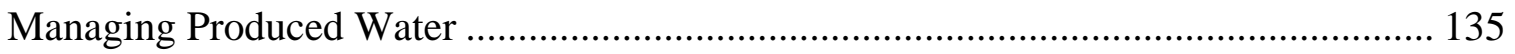

Produced Water Volumes and Composition................................................................... 135

Brackish Water Produced in Texas Oil and Gas Wells ................................................. 136

Uncertainties with Regulatory Issues..................................................................... 142

Costs of Managing Produced Water ............................................................................ 142

POTENTIAL FOR THE DESALINATION OF PRODUCED BRINE .......................... 143

Produced water desalination (PWDS) technology............................................................ 143

Reverse Osmosis Desalination for Oil Field Brine ...................................................... 144

Pre-Treatment of Oil Field Brine .............................................................................. 145

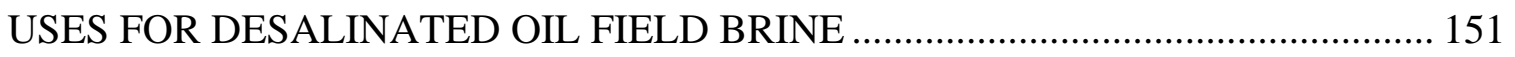

Beneficial Use of Desalinated Oil Field Brine ……….................................................. 151

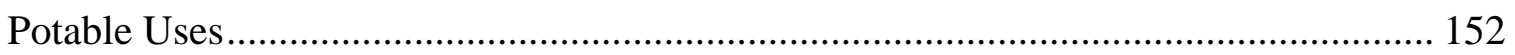

Discharge to Supplement In-Stream Flow or Rangeland Habitat Enhancement............. 153

Restoring Rangeland Habitat ................................................................................... 154

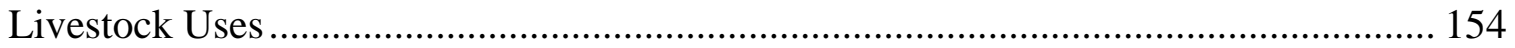

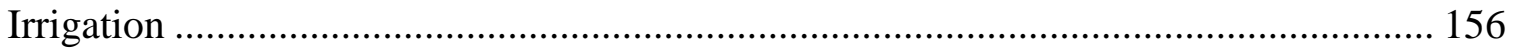

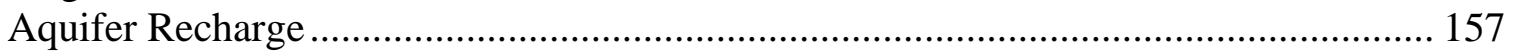

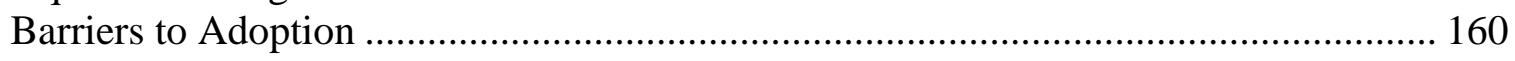

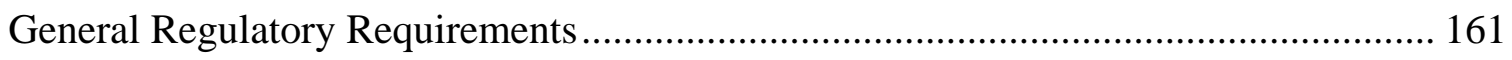

WATER RESOURCES ASSOCIATED WITH UNCONVENTIONAL O\&G

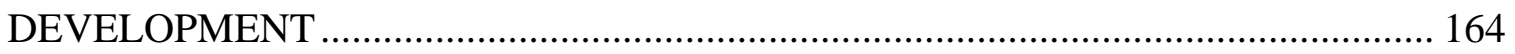

Water Resources Used in Energy Production.................................................................. 165 
Burnett \& Siddiqui. “Recovery of Fresh Water Resources

The Social Cost of Energy Production........................................................................... 167

RECOMMENDATIONS FOR THE ADVANCEMENT OF DESALINATION

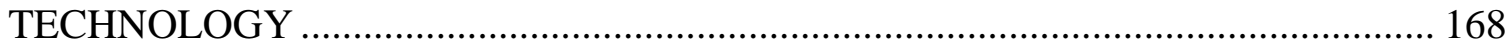

Collaboration with State Agencies........................................................................... 168

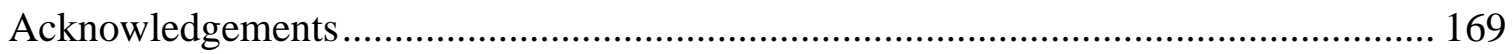

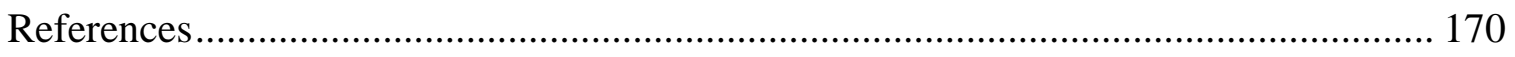




\section{LIST OF FIGURES AND TABLES}

Fig. 3.1-Pressure-driven membrane separation processes. ......................................... 25

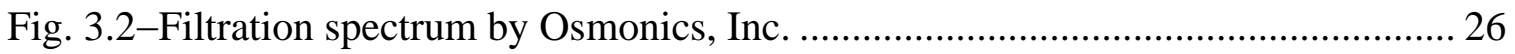

Fig. 3.3-Possible Produced Water Treatment Train -1 ............................................. 29

Fig. 3.4-Possible Produced Water Treatment Train -2 ................................................ 29

Fig. 3.5-Possible Produced Water Treatment Train - 3............................................. 30

Fig. 3.6-Possible Produced Water Treatment Train - 4.............................................. 30

Fig. 3.7-Proposed Produced Water Treatment Method \# 1. .......................................... 31

Fig. 3.8-Proposed Produced Water Treatment Method \# 2. .......................................... 32

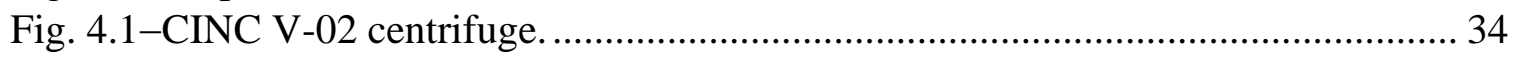

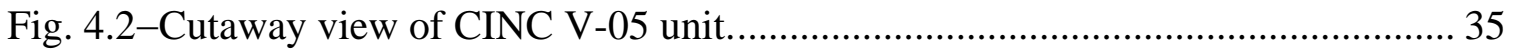

Fig. 4.3-Conversion of rpm to G-force published by CINC ....................................... 37

Fig. 4.4-A schematic of crossflow filtration. ............................................................ 43

Fig. 4.5-NIRO-XP pilot plant membrane unit. ...................................................... 45

Fig. 5.1-Effect of centrifuge rotor speed on TOC concentration of the produced water exiting the centrifuge. (Feed flow rate $=0.155 \mathrm{lit} / \mathrm{min}$. Temperature $=75^{\circ}, 90^{\circ}$ and

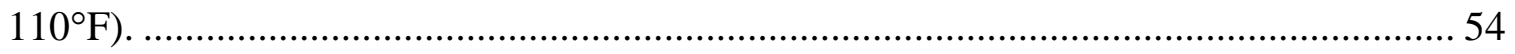

Fig. 5.2-TOC concentration of the produced water entering and exiting the organoclay

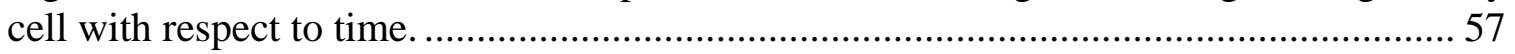

Fig. 5.3-Reduction in hydrocarbons from produced water by membranes..................... 59

Fig. 5.4-Concentration of TDS in permeate of the selected membranes. ......................... 60

Fig. 5.5-Flux across membranes at their maximum operating pressures........................ 61

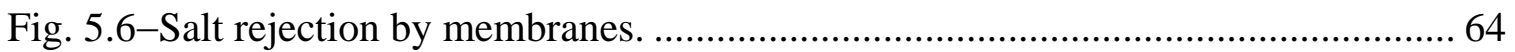

Fig. 5.7-Flux across membranes at maximum salt rejection.......................................... 64

Fig. 5.8-Hydrocarbon concentration in permeate of AFC80, AFC99 and SWC-1-4040

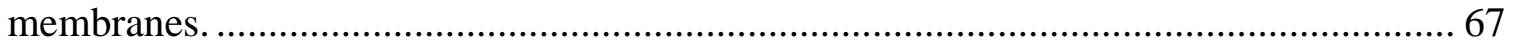

Fig 5.9-Effect of pressure on flux with clean water feed. (Feed flow rate $=8,11$ and 14 gpm. Run 1, Run 2 and Run 3 show the difference in flux at $8 \mathrm{gpm})$.......................... 69

Fig. 5.10-Effect of pressure on flux with clean water feed. (Feed flow rate = 8, 11 and 14 gpm. Flux normalized @ 95² F)................................................................................ 70

Fig 5.11-Effect of pressure on recovery with clean water feed. (Feed flow rate = 8, 11 and 14 gpm. Flux normalized @ 95² F)........................................................................ 71 Fig. 5.12-Effect of pressure on flux with 15,000 ppm TDS produced water feed. (Feed flow rate $=8,11$ and 14 gpm. Flux normalized @ 95² F)............................................. 72 Fig. 5.13-Effect of pressure on recovery with 15,000 ppm TDS produced water feed. (Feed flow rate = 8, 11 and 14 gpm. Recovery normalized @ 95 ${ }^{\circ} \mathrm{F}$ ).............................. 73 Fig. 5.14-Effect of pressure on total dissolved solids (TDS) in permeate with 15,000 ppm TDS produced water feed. (Feed flow rate $=8,11$ and $14 \mathrm{gpm}$ ). ................................ 75 Fig. 5.15-Effect of pressure on flux with 30,000 and 45,000 ppm TDS produced water feed. $($ Feed flow rate = 8, 11 and 14 gpm. Flux normalized @ 95 F)............................ 77 Fig. 5.16-Effect of pressure on recovery with 30,000 and 45,000 ppm TDS produced water feed. (Feed flow rate = 8, 11 and 14 gpm. Recovery normalized @ 95 F)........... 78 
Fig. 5.17-Effect of pressure on total dissolved solids (TDS) in permeate with 30,000 ppm TDS produced water feed. (Feed flow rate $=8,11$ and 14 gpm). .............................. 79 Fig. 5.18-Effect of pressure on total dissolved solids (TDS) in permeate with 45,000 ppm TDS produced water feed. (Feed flow rate $=8,11$ and $14 \mathrm{gpm}$ ).

Fig. 5.19-Effect of pressure on flux with clean water and produced water (15,000, 30,000 and 45,000 ppm TDS) feed. (Feed flow rate = 8, 11 and 14. Flux normalized @ 95 F). 81 Fig. 5.20-Effect of pressure on total dissolved solids (TDS) in permeate with produced water (15,000, 30,000 and 45,000 ppm TDS) feed. (Feed flow rate = 8, 11 and $14 \mathrm{gpm}$ ).

Fig. 5.21-Effect of pressure on energy required per gallon permeate obtained with 15,000 ppm TDS produced water feed. (Feed flow rate $=8,11$ and $14 \mathrm{gpm}$ ). 85

Fig 5.22-Effect of time on flux across SWC-1-4040 membrane for fouling profile. (15,000 ppm TDS and 40 ppmC TOC produced water. Flux normalized @ 95 F)....

Fig 5.23-Effect of time on flux for fouling profile on log-log scale. (15,000 ppm TDS and 40 ppmC TOC produced water. Operating pressure $=550$ psi. Feed flow rate $=10$ gpm. Flux normalized @ 95 F). 88

Fig. 5.24-Effect of time on salt concentration in the permeate for fouling profile. $(15,000$ ppm TDS and 40 ppmC TOC produced water. Operating pressure $=550$ psi. Feed flow rate $=10 \mathrm{gpm})$.

Fig. 5.25-Effect of time on TOC concentration in the permeate for fouling profile. (15,000 ppm TDS and 40 ppmC TOC produced water. Operating pressure $=550$ psi. Feed flow rate $=10$ gpm). 90

Fig. 5.26-Effect of concentrating produced water on flux. (Operating pressure $=550$ psi. Feed flow rate $=10 \mathrm{gpm})$. 91

Fig. 5.27-Effect of concentrating produced water on the salt concentration in permeate. (Operating pressure $=550$ psi. Feed flow rate $=10 \mathrm{gpm}$ ). 92 Fig. 5.28-Effect of pressure on flux with clean water feed before and after membrane cleaning. (Feed flow rate $=11 \mathrm{gpm})$.

Fig. 5.29-Effect of pressure on flux with 15,000 ppm TDS produced water feed before and after membrane cleaning. (Feed flow rate $=11 \mathrm{gpm}$ ). 94

Fig. 5.30-Effect of pressure on salt concentration in permeate before and after membrane cleaning. (15,000 ppm TDS produced water feed. Feed flow rate = $11 \mathrm{gpm}$ ). 95 


\section{Recovery of Fresh Water Resources from Desalination of Brine Produced During Oil and Gas Production Operations}

\section{EXECUTIVE SUMMARY}

The Texas A\&M GPRI Desalination Program is described in two Sections, as described in the original program deliverables.

Section 1 Advanced Processes for Treatment of Produced Brine

Section 2 Field Demonstration of Produced Brine Treatment and Re-Use for Beneficial Purposes

A multidisciplinary team has spent more than six years is developing advanced membrane filtration processes for treating oil field produced brines and flow back water from fracturing fluids produced during gas well completion operations in the Barnett Shale. The team consists of academic researchers at Texas A\&M University and a government- industry cooperative joint venture under the guidance of the Global Petroleum Research Institute (GPRI).

The project has included an A\&M program studying the beneficial re-use of produced water resources from oil and gas operations ${ }^{1}$. Our goal of that part of the project has been to demonstrate that treatment of oil field waste water for re-use will reduce water handling costs by $50 \%$ or greater. Our work has included (1) integrating advanced materials into existing prototype units and (2) operating short and long-term field testing with full size process trains. Testing at A\&M has allowed us to upgrade our existing units with improved pre-treatment oil removal techniques and new oil tolerant $R O$ membranes. We have also been able to perform extended testing in "field laboratories" to gather much needed extended run time data on filter salt rejection efficiency and plugging characteristics of the process train.

This project is the first comprehensive study of the treatment and reuse of oilfield brine for beneficial purposes. There are two major deliverables coming from our work.

\section{Section 1: Advanced Processes for Treatment of Produced Brine}

\section{Section 2: Field Demonstration of Produced Brine Treatment and Re-Use for Beneficial} Purposes

Section 1 represents a Final Report describing the technology we have developed to treat oil field produced brine in a cost effective manner. It contains background information on the types of produced water and the various ways of removing contaminants from brine.

Section 2 describes the A\&M Desalination team work with mobile field pre-treatment and desalination units to determine the cost effectiveness of membrane treatment and to measure the conditions where such treatments could be adopted by the O\&G industry.

The two Desalination Sections provide a set of documented engineering reports describing technology used to treat produced water and reuse it in an environmentally beneficial manner. These reports describe the economics of beneficial use of produced 
water and its potential impacts on production, using the results of a series of tests at different field locations under different conditions.

The Final Report describes the technical and economical feasibility of treating produced water with a combination of different separation processes to obtain water of agricultural water quality standards. Experiments were done for the pretreatment of produced water using a new liquid-liquid centrifuge, organoclay and microfiltration and ultrafiltration membranes for the removal of hydrocarbons from produced water. The results of these experiments show that hydrocarbons from produced water can be reduced from $200 \mathrm{ppm}$ to below 29 ppm level. Experiments were also done to remove the dissolved solids (salts) from the pretreated produced water using desalination membranes. Produced water with up to 45,000 ppm total dissolved solids (TDS) can be treated to agricultural water quality water standards having less than 500 ppm TDS.

The Report also discusses the results of field testing of various process trains to measure performance of the desalination process. Economic analysis based on field testing, including capital and operational costs, was done to predict the water treatment costs. Cost of treating produced water containing 15,000 ppm total dissolved solids and 200 ppm hydrocarbons to obtain agricultural water quality with less than 200 ppm TDS and 2 ppm hydrocarbons range between $\$ 0.5-1.5$ /bbl. 


\section{SECTION 1: ADVANCED PROCESSES FOR THE TREATMENT OF PRODUCED BRINE}

Management and disposal of produced water is one of the most important problems associated with oil and gas (O\&G) production. O\&G production operations generate large volumes of brine water along with the petroleum resource. Currently, produced water is treated as a waste and is not available for any beneficial purposes for the communities where oil and gas is produced. Produced water contains different contaminants that must be removed before it can be used for any beneficial surface applications. Arid areas like west Texas produce large amount of oil, but, at the same time, have a shortage of potable water.

The Texas A\&M Desalination Program is described in two reports. Section 1 describes work to evaluate the technical and economical feasibility of treating produced water with a combination of different separation processes to obtain water of agricultural water quality standards. Experiments were done for the pretreatment of produced water using a new liquid-liquid centrifuge, organoclay and microfiltration and ultrafiltration membranes for the removal of hydrocarbons from produced water. The results of these experiments show that hydrocarbons from produced water can be reduced from $200 \mathrm{ppm}$ to below $29 \mathrm{ppm}$ level. Experiments were also done to remove the dissolved solids (salts) from the pretreated produced water using desalination membranes. Produced water with up to 45,000 ppm total dissolved solids (TDS) can be treated to agricultural water quality water standards having less than 500 ppm TDS.

Finally an economic analysis, including capital and operational costs, was done to predict the water treatment costs. Cost of treating produced water containing 15,000 ppm total dissolved solids and 200 ppm hydrocarbons to obtain agricultural water quality with less than 200 ppm TDS and 2 ppm hydrocarbons range between \$0.5-1.5/bbl.

The contribution of fresh water resource from produced water will contribute enormously to the sustainable development of the communities where oil and gas is produced and fresh water is a scarce resource. This water can be used for many beneficial purposes such as agriculture, horticulture, rangeland and ecological restorations, and other environmental and industrial application. 


\section{CHAPTER I INTRODUCTION}

\section{Produced Water - A Headache for the Oil and Gas Industry}

Management and disposal of Produced Water is one of the most important problems associated with oil and gas (O\&G) production. O\&G production operations generate large volumes of brine water along with the petroleum resource. Disposing of this byproduct is costly because of its makeup and large volumes that must be handled. The volume of the produced water can easily exceed the volume of hydrocarbon production by ten times over the economic life of an oil or gas field.

With volumes of this magnitude, the disposal of produced water associated with oil and gas production becomes expensive for the operator and affects the economics of the reservoir and the environment. In Texas alone more than 4-million barrels of water (150,000,000 gallons) are produced every day. ${ }^{1}$ Water management today is an important area for the industry. ${ }^{2-14}$ Costs associated with produced water management may take a significant portion from the profits of a company and may cause other technological and environmental complications.

The preferred method for the disposal of produced water is one that adequately protects the environment and is of the lowest cost to the operator. Regulatory and monetary constraints often limit the options available to the operator. Subsurface water shut off and downhole oil/water separation $^{3-17}$ are some of the methods to stop water production. Other methods of water management include using the produced water for pressure maintenance of the reservoir or for enhanced oil recovery (EOR) purposes on the same or nearby field. ${ }^{5,}$, 10, 18, 19

On-shore the most common way for water management is to re-inject the water into water disposal wells that may be on the same field. If not, the water has to be transported to other nearby wastewater disposal re-injection wells. The cost of produced water disposal may be as much as $\$ 4.00 / \mathrm{bbl}$ if the produced water has to be transported to disposal sites that are not in the field.

The costs associated with produced water disposal play a significant role in the economics of the reservoirs. Cost-effective management of produced water improves the profitability of natural gas and oil producers by reducing the costs associated with the disposal of produced water. The industry has made large investments in produced water management and disposal. Oil companies such as Shell, ChevronTexaco and others have dedicated produced water management teams or departments for this purpose. 


\section{Fresh Water - A Problem for West Texas and Other Arid Regions}

The Texas Commission on Environmental Quality (TCEQ) estimates that by the year 2050, fresh water needs in the state of Texas will increase by more than twenty percent. ${ }^{20}$ West Texas is arid with little fresh water resources, but with huge oil and gas production and associated brine production. This situation is the same for many oil and gas producing regions all over the world where substantial amounts of oil and gas are produced along with the associated produced water e.g. Middle East and the Central Asian Republics.

New technologies have evolved in the field of oil-water separation and desalination that can be used to remove the contaminants from produced water. Over the past years the oil industry has looked into ways of using this produced water for beneficial uses to reduce the amount of water to be re-injected into the ground hence saving on produced water disposal costs. ${ }^{21-27}$

Doran et $a l^{25,26}$ and Miller et $a l^{22}$ conducted pilot plant studies for converting produced water to beneficial use quality. Settle et $\mathrm{al}^{24}$ looked into ways of using plants to treat the water and using it for beneficial purposes. Gurden et $\mathrm{al}^{27}$ looked into ways of removing contaminants from produced water using "Reed bed Technology" in Oman and then using this water for agricultural purposes. Most of the work done in the field of produced water treatment involved large investments in capital and big infrastructure. Due to these reasons large volumes of produced water production over long periods of operation are necessary to economically justify these projects.

At the same time, work has been done in the past few years in the field of membrane technologies and separation science for different purposes. ${ }^{28-30}$ Now new technologies, especially in the area of membranes, are available for waste water and sea-water desalination that may be applied to produced water treatment and desalination. However, little work has been has been done in the field of produced water use for beneficial purposes by applying these technologies for this problem and to economically justify the water treatment process.

The regulations ${ }^{31-33}$ governing the disposal of produced water have become more stringent over the years. Discharge of produced water is not allowed on land and in streams and rivers where the produced water can come in contact with the surface water. At the present there are no clear-cut laws and regulations in the United States dealing with the beneficial use of produced water.

\section{Sustainable Development}

"Development that meets the needs of present generations without compromising the ability of future generations to meet their own needs" is the definition of sustainable development given by the Brundtland Commission set up by the United Nations. ${ }^{16}$ 
"Economic growth, the alleviation of poverty, and sound environmental management are mutually consistent to these objectives" are some of the underlying principles of sustainable development that have also been mentioned in the Brundtland Commission's report. $^{34}$ These are some of the criteria that have to be addressed for the sustainable development of communities.

Sustainable development and social responsibility are concepts only recently embraced by the oil industry. Social responsibility, contribution to the society and environment where the company operates ${ }^{35-44}$ are amongst some of the important factors that are looked at by the investors today, apart from the profits the company makes, while judging a company for investment. Being a good corporate citizen is more important today than it has ever been in the past. It is for these reasons that currently the industry invests in sustainable development of the communities and the environment where they operate.

Two important elements mutually consistent with the objectives of sustainable development are the availability of energy and water. The oil and gas industry is in a unique position to provide both these key elements to the communities where they operate. The operating companies already provide the energy infrastructure to the communities where they operate. At the same time these companies are in a position to provide water in their areas of operation where there is a scarcity of water.

The contribution of this resource will contribute enormously to the sustainable development of these communities where oil and gas is produced. This water can be used for many beneficial purposes such as agriculture, horticulture, rangeland and ecological restorations, and other environmental and industrial applications.

\section{Sustainable Development Through Beneficial Use of Produced Water}

The Global Petroleum Research Institute (GPRI) in the Department of Petroleum Engineering at Texas A\&M University in conjunction with the Texas Water Resources Institute (TWRI) at Texas A\&M University formed an interdisciplinary faculty team to study the beneficial use of petroleum produced water in the oil and gas industry. With the support of TWRI, the Department of Petroleum Engineering at A\&M has partnered with the Chemical Engineering Department, the International Agriculture Department, Rangeland and Ecology Management, Soil and Crop Sciences, Department of Sociology, and the Wildlife and Fisheries Departments to create a truly multi-disciplinary team for looking into all aspects of this project. Substantial support from industry and the federal government has been received in the form of grants and sponsorships to support the project.

This research project brings the concept and new technology to the treatment of produced water for beneficial use produced from oil and gas operations. This effort is part of an endeavor to enhance the concepts of sustainable development in the oil and gas industry and producing activity. 


\section{Scope of This Research}

Currently produced water is treated as a waste. Re-injection for pressure maintenance and improved recovery is the only option available to producers. Produced water contains different contaminants which include suspended oil and grease, organics, dissolved and suspended solids, salts and various other contaminants. These contaminants may also include heavy metals and naturally occurring radioactive metals (N.O.R.M.s). Before produced water could be considered for any beneficial surface application, these contaminants must be removed.

Our approach to the design of a cost effective treatment process has been to remove the different contaminants including salts from produced water so that the treated water can meet the criteria for clean water and/or agricultural water standards. The goal was to select technologies that can be used to treat the produced water in a manner that is cost effective and economically justified. Our estimates are that these technologies will be used in the future to treat about $10-25 \%$ of the total produced water at mature onshore fields in the state of Texas. This treated water may be used for agriculture, rangeland, ecological, and environmental restorations and add value to oil and gas operations.

The objectives of the first phase of the desalination program were to create a preliminary process design of the prototype portable units for the treatment of produced water to agriculture standards for use in oil field operations. The steps used in the design of the produced water treatment unit are as follows:

1) To evaluate through literature survey different commercially available oil/water separation technologies for the oil and gas industry.

2) Evaluate the performance various pretreatment steps including CINC centrifuge for oil-water separations prior to using membranes during lab experiments. This is a new type of centrifuge that has been introduced recently in the oil industry for oil/water separations.

3) Conduct lab experiments on an organoclay to determine its efficiency in removing hydrocarbons from the produced water as a pretreatment step for the produced water before it passes through the membranes.

4) Select and screen membranes for the removal of hydrocarbons and desalination.

5) Perform optimization experiments on the selected membrane for the desalination of the produced water to agricultural water standards.

\section{Results and Benefits of the Program}

We believe that this study demonstrates that treatment of produced water to agricultural water quality standards is technically possible and economically justifiable. This study serves as a critical first step of the ongoing project at Texas A\&M University that 
demonstrates and proves the hypothesis that produced water can be treated and used beneficially; and that produced water is a valuable resource for the oil and gas industry rather than being a waste. The goals of this project have been:

1) To design and construct prototype portable units for the treatment of produced water to agriculture water standards for use in oil field operations.

2) To measure the performance of these prototype units in field tests.

3) To prove that on site produced water treatment is technically possible and economically justifiable at the current time in oil \& gas production operations.

4) To measure the impact of treated produced water in the creation of wildlife habitat and rangeland restoration, and monitor the effects of the treated produced water on the native soils, plants and wild life.

5) To create a program to effect change in the regulations governing the beneficial use of treated oilfield brine for use as a resource to the community and public.

6) To determine the socio-ecological, social and economic impact of the treated produced water on the communities where the treated produced water is used.

7) To create a program promoting the technology to broader markets and areas of application.

The results of this study should provide the initial data for the conceptual and process design of the portable produced water treatment units to be used in oil field operations. We believe that between 10 to $25 \%$ of the produced water (depending on the nature of the produced water) can be treated and recovered as fresh water at mature onshore fields in the state of Texas. The treated produced water will benefit both the industry and the society. This treated water will play a significant role in the sustainable development of communities where oil and gas are produced and fresh water is a scarce resource. The treated water can be used for different ecological applications such as habitat and rangeland restoration, agricultural, horticulture, livestock or industrial use.

The benefit to the oil and gas industry will be the economic savings on produced water disposal, which equates to reduced operating costs for operators. Savings will be derived from a more effective use of capital, expense and resources to produce petroleum rather than paying the cost of disposal. Also the treated water can be considered as value added to the exploration and production cycle as this water is used for beneficial purposes instead being considered as a waste and thrown away. 


\section{CHAPTER II}

\section{BACKGROUND AND LITERATURE REVIEW}

Salt water that is produced along with the hydrocarbons during oil and gas production is commonly known as produced water or brine in the oil industry. The Environmental Protection Agency $^{45}$ (EPA) in CFR Title 40: Protection of Environment, CHAPTER I PART 435 gives the official definition of produced water as:

"Produced water means the water (brine) brought up from the hydrocarbon-bearing strata during the extraction of oil and gas, and can include formation water, injection water, and any chemicals added downhole or during the oil/water separation process ".

Discharge of produced water to the surface waters and seawaters is prohibited under the Clean Air and Water Act until certain criteria are met. ${ }^{45}$ CFR Title 40.1 defines the maximum allowable petroleum hydrocarbon concentration in produced water that can be discharged to seawaters is $29 \mathrm{ppm}$. For discharge of produced water to surface waters there is no defined limit on the concentration of hydrocarbons in the produced water, but the petroleum hydrocarbon concentration has to be below the $29 \mathrm{ppm}$ limit.

Disposal and management of produced water is by and far the biggest problem associated with oil and gas (O\&G) production. Large volumes of produced water are generated in O\&G production operations along with the petroleum resource. Disposing of this byproduct is costly because of the large volumes that must be handled makeup and the makeup of produced water.

The volume of the produced water can easily exceed the volume of hydrocarbon production by ten times over the economic life of an oil or gas field. With volumes of this magnitude, the disposal of produced water associated with oil and gas production becomes expensive for the operator and affects the economics of the reservoir and the environment.

In Texas alone more than 4-million barrels of water (150,000,000 gallons) are produced every day. ${ }^{1}$ Water management today is an important area for the industry. ${ }^{2-14}$ Lyngbeak et al. ${ }^{2}$ concluded that to handle the ever-increasing amounts of produced water with time, steps require to be taken to improve, upgrade and increase the capacity of produced water handling facilities.

Ukpohor et $a .^{3}{ }^{3}$ studied the possible detrimental effect produced water discharged in offshore and onshore areas in Nigeria. They concluded that if effective produced water treatment technologies are not employed by the various operating companies to treat the water, the discharge of produced water will become a cause of serious environmental hazards to plant and animals and a big problem for the operating companies. Lawerence et al. ${ }^{4,5}$ also did a comprehensive study of different scenarios for the cost-effective and environmentally acceptable methods for disposal of produced water. They concluded that 
additional surface water discharge opportunities might exist where beneficial use such as irrigation or watering livestock is possible and where treatment will ensure that the release to surface waters will not violate water quality standards.

Success of many oilfields depends upon efficient disposal of produced water. Willde et $a .^{7}$ studied the effects of underestimating the production rates and quality of produced water in oil fields in Oman. This led to complications as higher water injection rates than expected were required for subsurface disposal of produced water as more produced water had to be disposed off than capacity. This in turn affected the economics of the produced water injection wells and oil production from the field.

New and novel ways are being used to decide which method to use for the management of produced water. Decision analysis is a framework for conducting integrated reservoir management. It integrates reservoir engineering, environmental impact assessment, environmental regulations, geochemistry, geological studies, process design, risk analysis, quality control and financial appraisals with the aim of maximizing the return on investment. Evans ${ }^{8}$ demonstrated the success of using decision analysis tools for carrying out a thorough and logical evaluation of alternative strategies for produced water handling and disposal.

Georgie et al. ${ }^{13}$ presented how environmental issues have become a major concern in the O\&G industry with increased volume of produced water being handled in the North Sea. The importance of environmental concerns of produced water disposal have become more important with the possibility of further reduction in the oil content allowed in the discharged water in the North Sea.

The costs associated with produced water management may take a significant portion from the profits of a company and may cause other technological and environmental complications. The preferred method for the disposal of produced water is one that adequately protects the environment and is of the lowest cost to the operator. Regulatory and monetary constraints often limit the options available to the operator. New methods and techniques are being employed by companies to address the issue of produced water handling and use of alternative options is also being investigated. Some of the methods employed for the disposal of produced water are:

Produced Water Re-injection (PWRI): The most common route and method for disposal of produced water in the oil and gas industry onshore in Western Europe and North America has been ground disposal. Discharging the produced water overboard into the sea has been the most common method of disposal and is still the preferred route in offshore production. The produced water may be re-injected in the same reservoir for pressure maintenance of the reservoir or for EOR purposes on the same or nearby field., $6,10,18,19$ If the produced water is not consumed for EOR or pressure maintenance then the produced water is re-injected into water disposal wells. Water disposal wells may be located on the same field or the produced water has to be transported to other nearby wastewater disposal re-injection wells, which becomes very costly for the operator. 
Subsurface Water Shut Off: Subsurface water shut off from the water producing zones and downhole oil/water separation ${ }^{3-17}$ are some of the methods to stop water production. Water shut off in multi-perforated zones in the well can be used as a means to reduce the water production. This technique is used to block off the water zone in wells and maintains the production from the oil rich zones. This technique is only applicable in multi-perforated zones and where it is clear that one perforated zone is producing a high water rate.

Downhole Separation: Down hole separation is a means to separate and allow the water to flow back to the reservoir without bringing it up to the surface. Suitable oil water separation units are placed inside the well and must be installed during well operation. Fluids are separated close to the producing formation and the produced water is reinjected through well branches without producing the produced water to the surface.

The costs associated with produced water disposal play a significant role in the economics of the reservoirs. Cost-effective management of produced water improves the profitability of natural gas and oil producers by reducing the costs associated with the disposal of produced water. The regulations ${ }^{31-33}$ governing the disposal of produced water have become also become more stringent over the years.

Due to the changes in regulations the industry has made large investments in produced water management and disposal, especially in oil-water separation technologies. 4, 5, 9, 46-64 This new technology in oil water separations is also being applied now to newer onshore fields to meet the onshore disposal criteria. ${ }^{47,54,58-60}$ Different technologies that are being employed in the industry for oil/water separations are:

Hydrocyclone Technology: For example, hydrocyclones, 9, 13, 21, 46, 47, 50, 52, 54, 56, 58, 59, 60, 62 have proven to be effective in high pressure and medium pressure oil systems. This technology is now considered to be the most reliable for offshore applications in meeting the required level of oil for discharge. Hydrocyclones have limitations in low-pressure systems. The efficiency of oil removal with a hydrocyclone unit becomes less due to the fact that there is not enough pressure in the system to drive the water. Consequently the water has to be pumped and as a result the produced water becomes more difficult to clean. Small oil droplets and the use of different chemicals, makes the hydrocyclone option not very effective in a number of gas condensate systems. Also small density difference between the oil and water phase solid particles present in the feed reduced the efficiency of hydrocyclones.

Centrifuge Technology: Centrifuges $9,13,46,48,50,52-55,64$ are considered to be effective for specific applications. Centrifuges can be used to treat low pressure produced water streams as well as treating oily water streams from the drain systems. Oily water streams are difficult to treat due to the different waste streams and chemicals which have been routed to the drain systems and which make the dispersed oil more stable within the water phase. Centrifuge units were not widely used offshore due to due to the technology limitations in terms of handling high pressure and gassy water, as well capacity of the individual units, cost and reliability. 
Coalescing Units, Plate Separators and Gas (air) Induced Flotation Technology: Coalescing media, plate separators and produced water using flotation, ${ }^{14,23,46,49-54,56,60,64}$ and other coalescing technology has been used extensively in the oil industry for produced water treatment to separate oil from water. Apart from these technologies API separators are the most common equipment utilized in the oil industry for oil water separation. Coagulation, dissolved air flotation and flocculation separation technologies have been used extensively in the chemical industry for oil/water separation. These are old and proven technologies, but the main disadvantages of these processes are their limitation and overall reliability in achieving the $29 \mathrm{ppm}$ or less required oil in water concentration for discharge, use of chemicals, interference due to variable flow and sensitivity due to motion.

Filtration and Membrane Separation Technology: Membrane technology has proven to be very effective for desalination applications and oil water separations in other industries. ${ }^{28-}$ 30, 61 This technology has been used for treating small amounts of produced water onshore. Utilization of this technology for oil water separation in the oil industry has been very limited and with limited success due to the to operability, maintenance and reliability issues involved and understanding of the technology. Also the use of membrane systems creates a waste stream that can generate additional problems in processing for the operator.

Other Alternative New Technologies: There are other technologies that have been introduced in the past few years and are still under evaluation. ${ }^{51,53,54,56,57,60,62,63 \text { Some }}$ small scale tests that have been carried out on laboratory scale have been very promising. However, limited field assessment under specific conditions has not been very successful. Growth of oil droplet size ${ }^{53}$ for better oil-water separation using different oil/water separation technologies has also been tested. Pre-coalescing hydrocyclone ${ }^{56}$ and airsparged hydrocyclone, ${ }^{62}$ increase the effectiveness of the normal hydrocyclone unit, have also been studied. The use of hydrocyclones in series and three phase hydrocyclones ${ }^{60}$ has also been tested for the effective oil water separation.

Doyle and Brown ${ }^{57}$ studied the use of organoclay for the removal of dispersed oil from water by adsorption and performed limited field tests with this technology. For onshore operation, vaporization of water using large surface area exposure of water on water ponds is another option. Boysen et al. ${ }^{61}$ looked into the commercial feasibility of using freeze thaw and evaporation process to treat produced water. This approach may cause environmental impacts relevant to the atmosphere as well as life around the ponds.

Removal of Dissolved Oil from Produced Water: The technology for removing soluble components from produced water has not been fully assessed and utilized till date. Such technology does exist offshore, and it has been used onshore only with a certain degree of success. The technology for removing soluble components can be based on extraction, precipitation, oxidation process or per-vaporation system. All these technologies require relatively large facilities to handle the large volume of produced water offshore. Most of these technologies involve the use of other chemicals and solvents, use of additional 
power, as well as producing a concentrated waste stream. Activated carbon has been used in the chemical industry for a long time for the removal of dissolved organics from waste streams. Some new technologies that are available today for the removal of dissolved hydrocarbon components from the produced water are MPPE system from Akzo Nobel, ${ }^{65}$ pertraction technology ${ }^{66}$ and surfactant modified zeolites.

Removal of oil from produced water and produced water treatment are not a simple processes. Kahtib, ${ }^{9}$ Georgie, ${ }^{13}$ Hughes et al., ${ }^{46}$ Bansal et al., ${ }^{51}$ Wim et al., ${ }^{52}$ and Arnold et $a .^{54}$ all concluded that choosing a single effective equipment may not be the best solution for oil water separation in reducing the hydrocarbons concentration in the produced water below the required discharge limit of $29 \mathrm{ppm}$. A more practical approach to achieve this goal is the use of a combination of conventional and new technologies for oil water separation to meet lower discharge levels. For each individual option, there are different levels of efficiency and field achievements of the selective technology. The successful application of the different technologies can be a combination of different categories.

The Texas Commission on Environmental Quality (TCEQ) estimates that by the year 2050, fresh water needs in the state of Texas will increase by more than twenty percent. ${ }^{20}$ West Texas is arid with little fresh water resources, but with huge oil and gas production and associated brine production. This situation is the same for many oil and gas producing regions globally where huge amounts of oil and gas are produced along with the associated produced water e.g. Middle East and the Central Asian Republics.

The Texas Commission on Environmental Quality (TCEQ) classifies ground water in four broad categories: fresh water, slightly saline water, moderately saline water and very saline water. ${ }^{67}$ Fresh water is defined as water having less than $1000 \mathrm{ppm}$ total dissolved solids present and this water can be used for irrigation. Fresh water for irrigation is further classified in two groups that are Class 1 and Class 2 water. Class 1 water is water with less than 500 ppm total dissolved solids (TDS) and Class 2 water is water with dissolved solids between $500-1000$ ppm range.

Over the past couple of years the oil industry has looked into ways of using this produced water for beneficial uses and to reduce the amount of water to be re-injected into the ground hence saving water disposal costs. ${ }^{21-27}$ Doran et $a l^{25,26}$ and Miller et $a l^{22}$ conducted pilot plant studies for converting produced water to beneficial use quality. Both these studies involved large initial capital investments for the building of water treatment plants and were aimed at treating large quantities of produced water. The pay back period for the investment was about 20 years and 10 years respectively. Economics were based on the assumption that the wells would keep on producing for long time and economics were unfeasible for treating small quantities of produced water. The maximum amount of dissolved solids present in the produced water that could be treated by these plants was limited to 8000 ppm TDS. Both these studies also reported complications with the use of membranes as the membranes got fouled very quickly. These studies were done more than five years back and since then there has been no reported progress on the fate of the pilot plant experiments and whether the full-scale water treatment plants were ever built. 
Settle et $a l^{24}$ looked into ways of using plants to reduce the volume of produced water that needed to be disposed off. Plants with high salt tolerance were planted to process the produced water. These plants would consume the produced water and hence the final volume of produced water that needs to be disposed off is small. One of the major concerns was the soil contamination by highly saline produced water and therefore the ground where these plants were planted needed to be lined so that salt leaching did not take place.

Gurden et $a l^{27}$ looked into ways of removing contaminants from produced water using "Reedbed Technology" in Oman and then using this water for agricultural purposes. Gurden et al used reeds for the removal of hydrocarbons from the produced water. Then they used this treated water beneficially for growing salt tolerant crops. One of the problems associated with this method is that as the reeds process the produced water, the salinity of the water increases, therefore a seal between the plants and the groundwater is needed so that the ground water does not gets contaminated.

Most of the work done in the area of beneficial use of produced water involved treating large quantities of produced water to make the process economically feasible. None of the work previously done is geared towards treating small quantity of produced water with small modular water treatment units and then using this treated water for beneficial use.

New technologies have evolved in the field of separations for oil-water separation and desalination that can be used to remove the contaminants from produced water. Work has been done in the past few years in the field of membrane technologies and separation science for different purposes. ${ }^{50-52}$ Membrane technology has been extensively used in the fields of seawater desalination, wastewater purification and removal of contaminants in different chemical industries. There are also a number of pretreatment technologies and methods available for the removal of suspended solids from water before it is processed through membranes. ${ }^{28-30}$ These include back washable filters, bag filters, depth filters, media filters, screens and strainers, etc. One of the new technologies that can remove suspended solids is the back washable disk filter manufactured by Essco. This filter can remove particles up to 5 microns in size without itself being consumed. Whenever the media gets full it is washed automatically of all the debris and the filter is ready to be used again. These new technologies may be applied to produced water treatment and desalination.

Various technologies and equipment exist and have been proven to be very effective in removing one kind of contaminant. This equipment is being used in the industry for a particular purpose but has never been combined with other technologies to see how effective it is to treat oilfield-produced water to agricultural water quality standards. 


\section{CHAPTER III}

\section{PROCESS DESIGN FOR PRODUCED WATER TREATMENT}

Produced water contains various contaminants that may be dissolved or suspended in the produced water. The contaminants in produced water include oil and grease (hydrocarbons), other organics, salts, silt, sediments and other solids. Different metals and heavy metals such as iron, copper, barium, strontium, cadmium, chromium, lead, mercury, zinc, etc. and naturally occurring radioactive metals (N.O.R.M.) may also be present in the produced water.

The level of contaminants present in the produced water varies from one field to the next. Composition of containments also depends on what kind of oil processing and separation facilities are employed on the field. Suspended and dissolved hydrocarbons can be present in the range of $50-500 \mathrm{ppm}$. The amount of dissolved solids present in the produced water can vary in the range of 200-100,000 ppm depending on the field where the water is produced. Dissolved salts of sodium, calcium, potassium, magnesium, manganese, etc. may be present as chlorides, carbonates, bicarbonates, nitrates or sulfates, etc. Apart from these contaminants different chemicals employed for O\&G production may also be present in the produced water.

Different contaminants and salts present in the produced water have to be removed from the produced water to treat the produced water to irrigation quality water. One of the most common methods these days to remove dissolved solids (salts) from water is the use of reverse osmosis membrane. RO membranes can be used for the desalination of produced water but before these membranes are used it is important to remove the other contaminants from produced water that can damage these membranes. RO membranes will be used in this study for the removal of dissolve solids (salts) from the produced water). Pretreatment is the process of removal of harmful contaminants and suspended solids from the water that can damage the membrane prior to the processing of water by membranes. Produced water needs pretreatment before it can is passed through the membranes. The aim of the pretreatment process is to reduce the oil and grease contents and the larger solid particles from the water in order to prevent membrane fouling.

Pretreatment of feed one of the most important steps in successful membrane operation and performance. Pretreatment, in many cases, determines the overall plant performance. The purpose of pretreatment is to guard against feed upsets, remove suspended and colloidal materials, prevent scaling from precipitation of sparingly soluble salts, and to prevent biological growth. In short pretreatment is done to minimize fouling of membranes. The importance of pretreatment cannot be underestimated as it guards against the fouling of membranes and extend the membrane life. Today seawater desalination utilizing RO has become common. ${ }^{68}$ Many state-of-art techniques are available for the pretreatment of seawater RO applications that may also be applied to produced water. 
The amount of pretreatment required on a feed depends upon the nature of the feed stream, membrane material, membrane configuration, and the goal of the separation. Contaminants, fouling agents present in the feed, and the membrane in question determine the method of pretreatment

\section{Brief Overview of Membrane Separations}

Solid-liquid and liquid-liquid membrane filtration may be defined as the separation of dissolved solutes in a liquid stream based primarily on size difference by a membrane. Membranes act as selective barriers to retain certain components while allowing other components to pass through.

Pressure driven membrane separation processes include reverse osmosis (RO), nanofiltration (NF), ultrafiltration (UF) and microfiltration (MF). Classification of the pressure driven membrane separation processes i.e. MF, UF, NF and RO, is based on the size of rejected particle. The amount of hydraulic pressure applied to speed the transport process across the membrane also distinguishes the different pressure driven separation process from one another. Retention characteristics of the four pressure driven membrane separation processes, microfiltration, ultrafiltration, nanofiltration and reverse osmosis are shown in Fig. 3.1. The nature of the membranes controls the components that are permeated and those that are retained by it. Different common particles that can be separated using membrane filtration are shown in Fig 3.2.

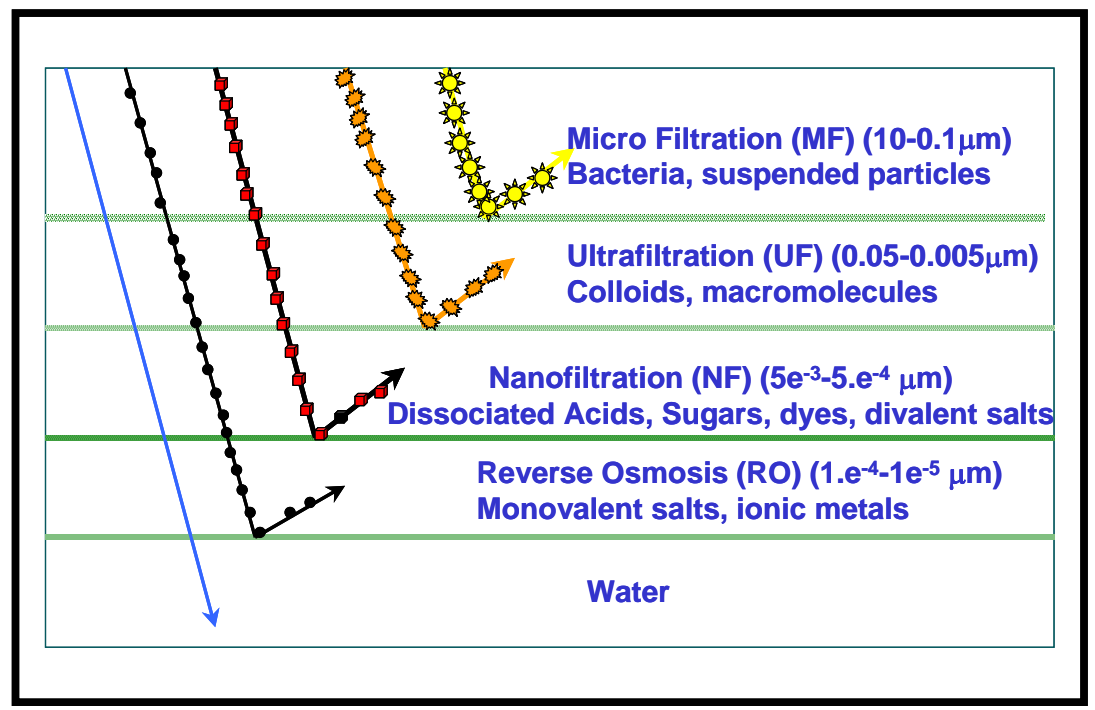

Fig. 3.1-Pressure-driven membrane separation processes. 


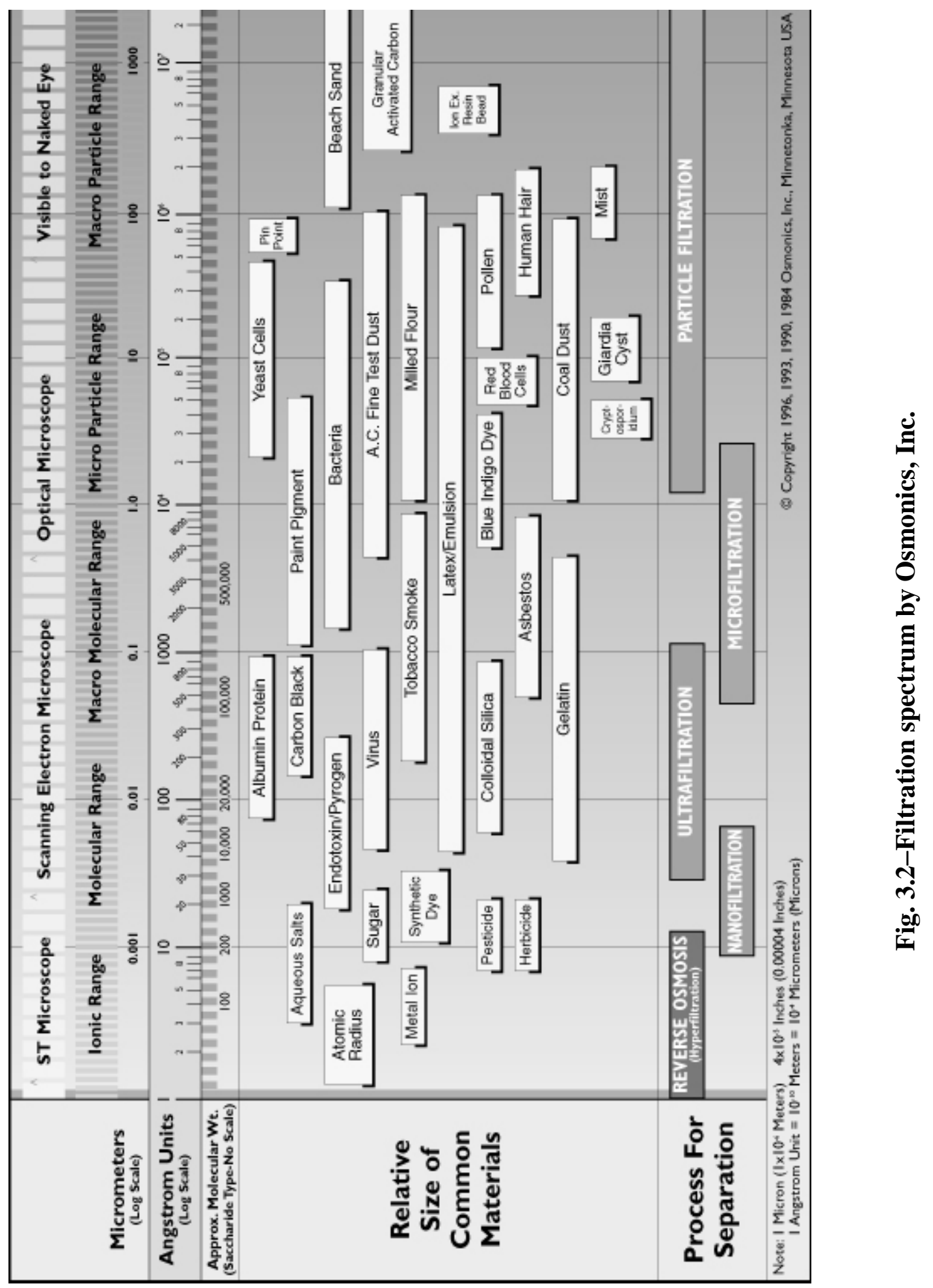


Membranes today are manufactured from a variety of different materials including stainless steel, aluminum, carbon, ceramics, polymers and composite (polymeric and inorganic), etc. materials.

Different membrane configurations are available each having its own advantages and disadvantages. The four main configurations for polymeric membranes are tubular, plate and frame, hollow fiber and spiral. Each configuration has its own advantages and disadvantages. Comparison of different membrane configurations is done in Table 3.1. Most inorganic membranes are tubular. Spiral membranes, made from flat sheet membranes, are one of the most compact and inexpensive designs available today. They pack a large surface area in a very small volume.

\section{Process Design for the Produced Water Treatment}

There are a number of options available for the treatment of produced water for fresh agricultural water quality standards as defined by TCEQ. Treatment of produced water consists of removing the suspended oil and grease (hydrocarbons), dissolved hydrocarbons (BTEX, VOC, etc.), suspended solids and other contaminants, and finally the removal of salts from the produced water by membrane desalination. Suspended and dissolved hydrocarbons, and suspended solids can be removed by a combination of methods and technologies described earlier. Some different options that may be used for the treatment of produced water are shown in the Figs. 3.3, 3.4, 3.5, and 3.6. 
TABLE 3.1-COMPARISON OF DIFFERENT MEMBRANE CONFIGURATIONS.

\begin{tabular}{|c|c|c|c|c|}
\hline & $\begin{array}{c}\text { Tubular } \\
\text { Membranes }\end{array}$ & $\begin{array}{l}\text { Hollow Fiber } \\
\text { Membranes }\end{array}$ & $\begin{array}{c}\text { Spiral } \\
\text { Membranes }\end{array}$ & Plate \\
\hline $\begin{array}{l}\text { Membrane } \\
\text { Diameter }\end{array}$ & $\begin{array}{c}0.25-1 " \\
(6-25 \mathrm{~mm})\end{array}$ & $40 \mu \mathrm{m}-3 \mathrm{~mm}$ & 2-12" & $0.5-1 \mathrm{~mm}$ \\
\hline Length & $\begin{array}{c}4-20 \\
(1.2-3 \mathrm{~m})\end{array}$ & $\begin{array}{c}0.6-3.6 \\
(0.18-1.2 \mathrm{~m})\end{array}$ & $\begin{array}{c}0.5-6 \\
(0.15-1.8 \mathrm{~m})\end{array}$ & $\begin{array}{c}0.3-2 \\
(10-60 \mathrm{~cm})\end{array}$ \\
\hline Prefiltration & $\begin{array}{l}\text { May help } \\
\text { performance }\end{array}$ & Yes & Yes & $\begin{array}{l}\text { May help } \\
\text { performance }\end{array}$ \\
\hline Particle Size & $600-2500 \mu \mathrm{m}$ & $20-300 \mu \mathrm{m}$ & $56-300 \mu \mathrm{m}$ & $600-2500 \mu \mathrm{m}$ \\
\hline Cleaning & $\begin{array}{l}\text { Easy } \\
\text { Sponge Balls, } \\
\text { etc. }\end{array}$ & $\begin{array}{l}\text { Backflushing } \\
\text { and Lumen- } \\
\text { flushing }\end{array}$ & $\begin{array}{l}\text { Problems with } \\
\text { spacers }\end{array}$ & $\begin{array}{l}\text { May be some } \\
\text { channeling }\end{array}$ \\
\hline Velocity and Flow & $\begin{array}{l}2-6 \mathrm{~m} / \mathrm{s} \\
\text { Turbulent }\end{array}$ & $\begin{array}{l}0.5-2 \mathrm{~m} / \mathrm{s} \\
\text { Laminar }\end{array}$ & Turbulent & $\begin{array}{l}\text { Both laminar } \\
\text { and turbulent }\end{array}$ \\
\hline Flux & $\begin{array}{l}\text { Highest flux } \\
\text { under } \\
\text { polarization- } \\
\text { limited } \\
\text { conditions }\end{array}$ & Good & $\begin{array}{l}\text { Lowest Flux } \\
\text { under } \\
\text { polarization } \\
\text { limited } \\
\text { conditions }\end{array}$ & Good \\
\hline Operating Pressure & Low - High & Low - High & Low - High & Low - High \\
\hline $\begin{array}{l}\text { Ease of Membrane } \\
\text { Replacement }\end{array}$ & Possible in Field & Possible in Field & Possible in Field & No \\
\hline $\begin{array}{l}\text { Energy } \\
\text { Consumption }\end{array}$ & Highest & Moderate & Lowest & Moderate \\
\hline Floor Space & Highest & Compact & Compact & High \\
\hline $\begin{array}{l}\text { Surface Area to } \\
\text { Volume Ratio }\end{array}$ & Lowest & Highest & Highest & Moderate \\
\hline Capital Cost & High & Mid-high & Lowest & Moderate \\
\hline Costs $\left(\$ / m^{2}\right)$ & $300(0.5 ")$ & 600 & 75 & Inexpensive \\
\hline $\begin{array}{l}\text { Operating Cost } \\
\text { Cost per unit } \\
\text { volume Permeate }\end{array}$ & Low - High & Low - Moderate & Lowest & Moderate \\
\hline $\begin{array}{l}\text { Membrane } \\
\text { Replacement Cost }\end{array}$ & Moderate & High & Low & Moderate \\
\hline Key Factor & High flow rate & Prefiltration & Prefiltration & $\begin{array}{c}\text { Tolerance to } \\
\text { colloidals/large } \\
\text { particles }\end{array}$ \\
\hline
\end{tabular}




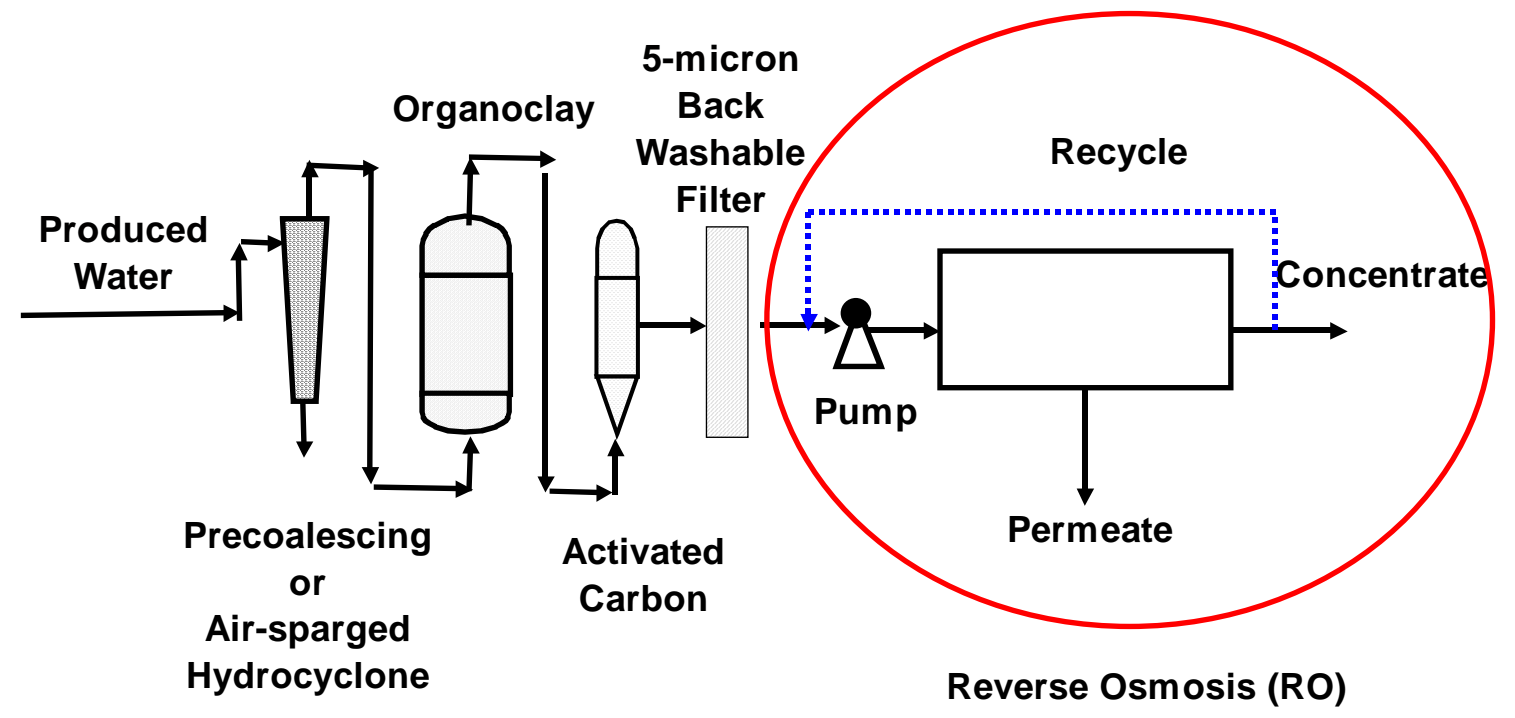

Fig. 3.3-Possible Produced Water Treatment Train - 1.

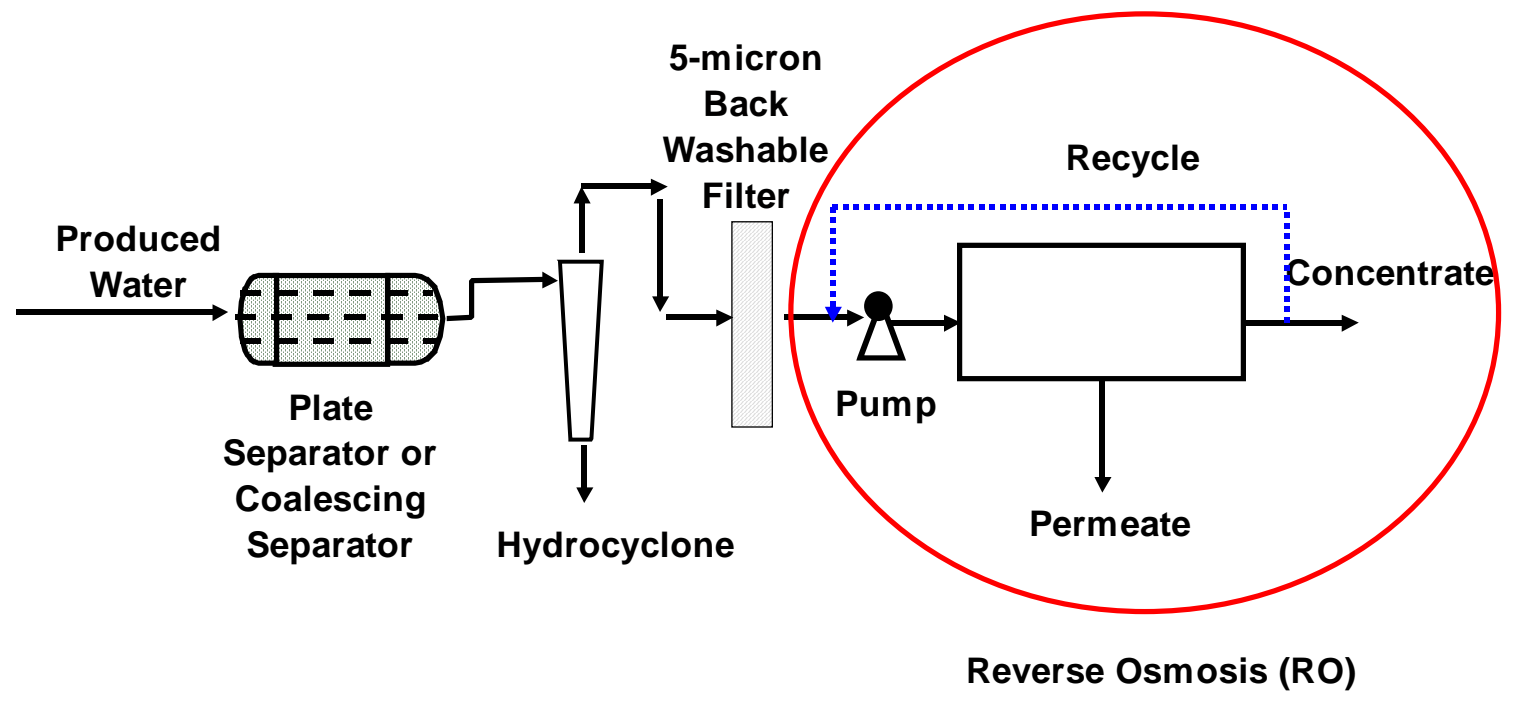

Fig. 3.4-Possible Produced Water Treatment Train - 2 . 


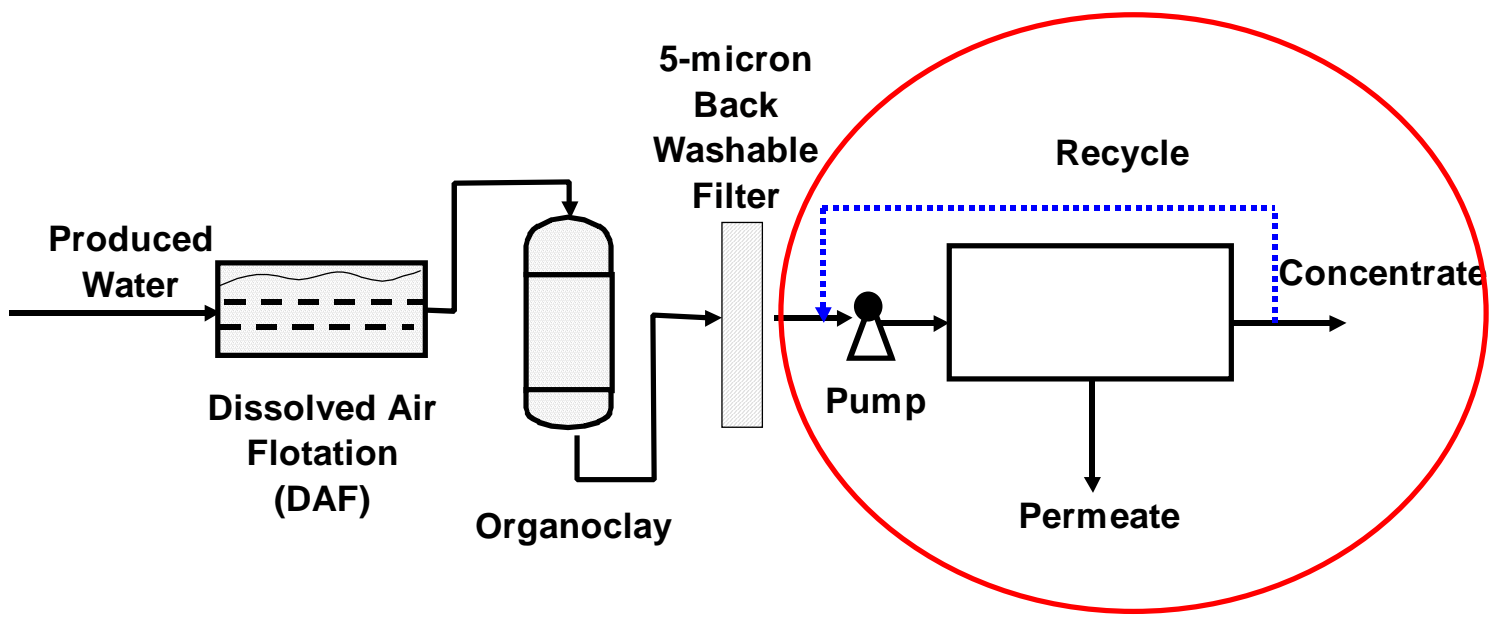

Reverse Osmosis (RO)

Fig. 3.5-Possible Produced Water Treatment Train - 3.

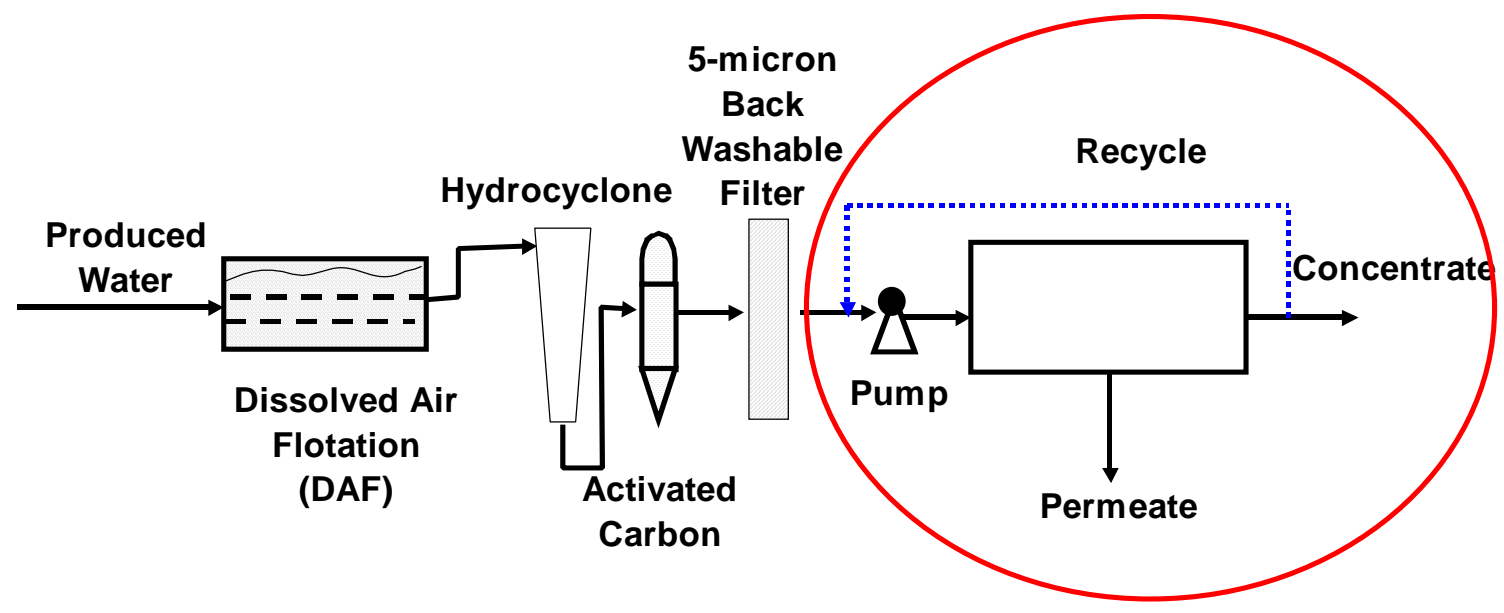

Reverse Osmosis (RO)

Fig. 3.6-Possible Produced Water Treatment Train - 4.

\section{Proposed Treatment Process for Produced Water}

Two treatment methods were selected for the treatment of produced water to agricultural water quality water standards. Brief description of these two produced water treatment methods is given below and schematic is shown in Figs. 3.7 and 3.8. 


\section{Produced Water Treatment Method \# 1}

The first method consists of pretreating produced water with a new liquid/liquid centrifuge (CINC centrifuge) for primary removal of larger suspended hydrocarbon particles followed by organoclay for secondary removal of smaller suspended and dissolved hydrocarbons. This is followed by the granular activated carbon, if necessary, for the removal of any other dissolved hydrocarbons that may be present. This treated produced water, without the hydrocarbons, is then passed through a 5-micron backwashable filter to remove the larger suspended solids. Salts are then removed from the produced water using reverse osmosis desalination membranes.

Fig. 3.7-Proposed Produced Water Treatment Method \# 1.

\section{Produced Water Treatment Method \# 2}

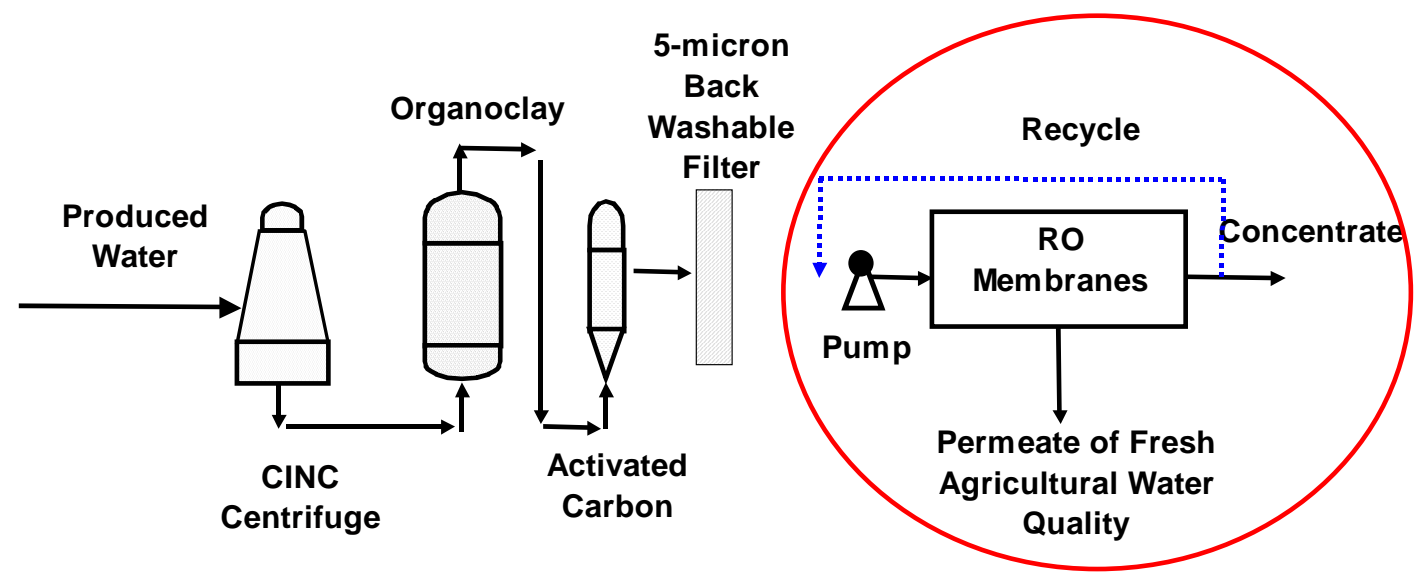

Reverse Osmosis (RO) System

In the second method the produced water is first pretreated with the liquid/liquid centrifuge (CINC centrifuge) for primary removal of larger suspended hydrocarbon particles. After this the produced water is processed through tubular ultrafiltration membranes for the removal of suspended solids and hydrocarbons present in the produced water. The produced water is then processed by reverse osmosis desalination membranes for the removal of salts from the produced water. 


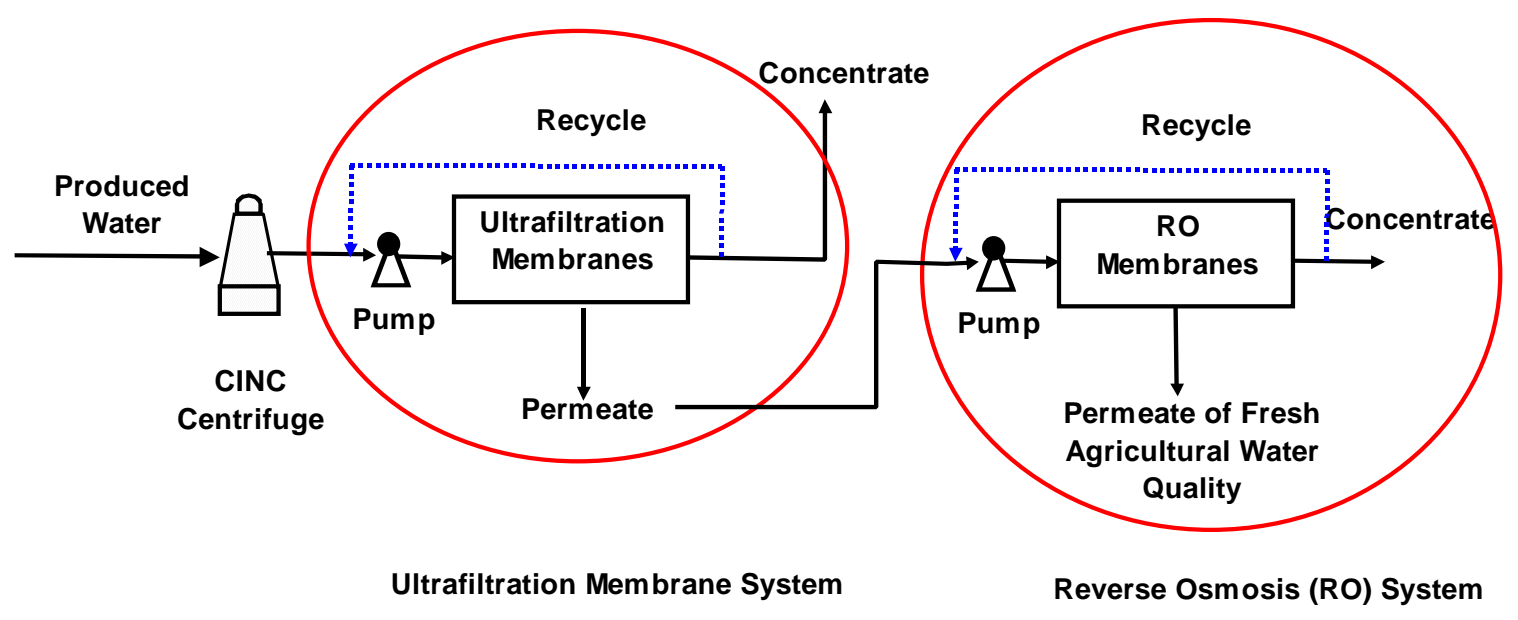

Fig. 3.8-Proposed Produced Water Treatment Method \# 2. 


\section{CHAPTER IV}

\section{MATERIALS AND METHODS}

\section{Measurement Techniques for Water Analysis}

\section{Total Organic Carbon (TOC) Measurement}

An easy and approximate method used in the industry for determining the amount of hydrocarbons present in a fluid is the Total Organic Carbon (TOC) analysis. TOC gives the total amount of organic carbon present in a sample. TOC analysis are usually expressed in parts per million of Carbon (ppmC) basis. TOC analyses were done on produced water (feed) and permeate samples to determine the amount of hydrocarbons present in them. Forty ml fluid samples were collected in glass bottles. These samples were then analyzed for hydrocarbons using OI Analytical TOC-700 Total Organic Carbon Analyzer. Some samples were also sent to private analytical laboratories for confirmation of TOC results obtained by the TOC-700 analyzer and independent analysis.

\section{Total Dissolved Solids (TDS) and Conductivity Measurements}

Total Dissolved Solids (TDS) refers to the total amount of dissolved solids present in a liquid. Total dissolved solids present in a water sample is found by performing analytical experiments on the water and determining the quantity of each ion species present in the water. The amount of all the ions present in the water is then totaled to obtain the TDS. TDS is expressed as parts per million (ppm).

A quick way to approximately calculate the TDS in water is by conductivity analysis. The amount of conductivity of water (or a fluid) can be directly related to the approximate amount of solids present in the water (fluid). Units of measurement of conductivity are micro Siemens per centimeter $(\mu \mathrm{S} / \mathrm{cm})$ or micromhos per centimeter ( $\mu \mathrm{mhos} / \mathrm{cm})$. Both these units are the same and often used interchangeably. Conductivity is related to the amount of solids present in a fluid by the following equation:

\section{TDS $(\mathrm{ppm})=0.7 *$ Conductivity $(\mu \mathrm{s} / \mathrm{cm}$ or $\mu \mathrm{mhos} / \mathrm{cm}$.}

Conductivity readings of the produced water and permeate samples were taken to determine the amount of total dissolved solids (or total solids) present in them. Conductivity readings were taken using EP-10 Conductivity Meter manufactured by Myron Company. Some of the samples were sent to Texas A\&M University's Soil and 
Crop Water and Forage testing lab for independent analytical analysis of dissolved solids. These analyses also confirmed the accurateness of the conductivity readings.

\section{Removal of Hydrocarbons From Produced Water by CINC Centrifuge}

A new kind of liquid/liquid low speed centrifuge was tested to evaluate its performance in reducing the concentration of hydrocarbons from produced water, as a pretreatment step before the produced water is passed through membranes for desalination. CINC V02 and CINC V-05 centrifuges manufactured by CINC industries were evaluated for their efficiency in removing the hydrocarbons from the produced water. V-02 is a small lab scale bench top centrifuge used for liquid-liquid separations. This centrifuge is used to determine applicability of this technology to this specific liquid mixture. Optimum operating parameters were determined using V-02 and V-05 centrifuges at different RPM, flow rate and temperature.

The CINC centrifuge uses centrifugal force to separate immiscible liquids of different densities. CINC V-02 centrifuge is shown in Fig. 4.1. The fluid stream, containing the two liquids to be separated, enters into the annular mixing zone. The process fluids are homogenized in the annular mixing zone, and then directed by the bottom vanes towards the rotor inlet. the cutaway view of CINC V-02 unit is shown in Fig. 4.2. The selfpumping rotor moves fluids axially up its diameter, where the generated centrifugal force (from 50 to $500 \mathrm{G}$-force) separates the two liquid phases as they flow through the rotor. The outlet ports allow for direct gravity outflow of the two separated liquid phases from the CINC unit.

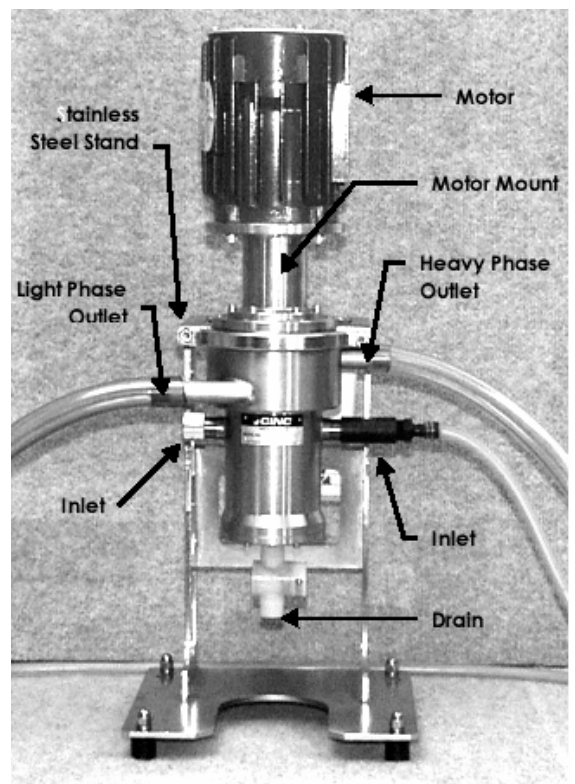

Fig. 4.1-CINC V-02 centrifuge. 
The efficiency of the flow and phase separation of the CINC centrifuge is controlled by the rotor RPM and the heavy phase weir plate. Both of these can be adjusted to allow for rapid and efficient separation of any two immiscible fluids. These two parameters are optimized for a process dependent upon the ratio, flow rate, density difference and viscosity (at the process temperature) of the process fluids.

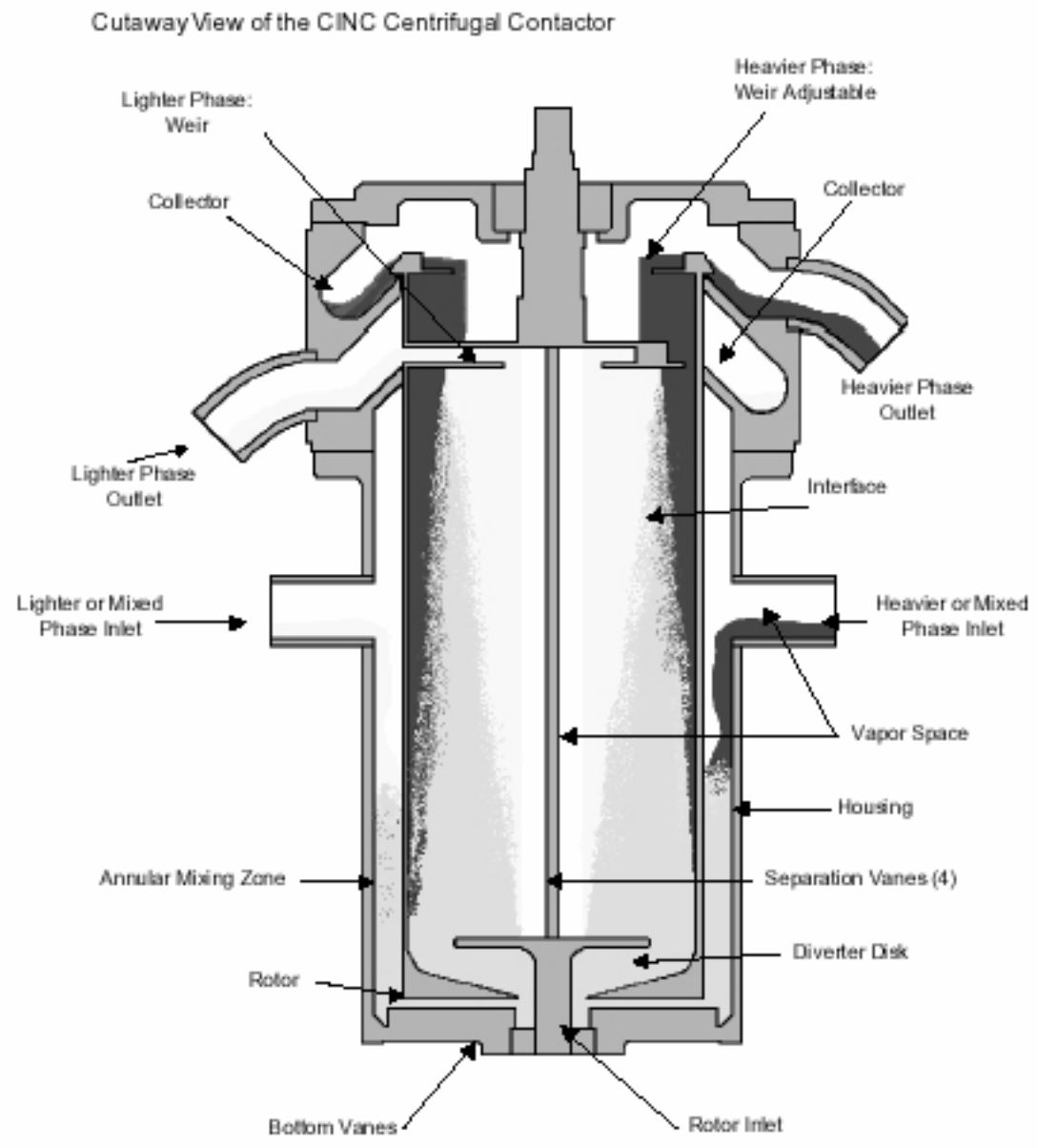

Fig. 4.2-Cutaway view of CINC V-05 unit.

Droplet size, density difference between the two phases and fluid viscosity are fixed by the process stream and operation temperature. Parameter that can readily be changed and controlled when optimizing the CINC centrifuge are the rotor angular velocity $(\omega)$ and fluid residence time while in the rotor. Fluid residence time is directly controlled by feed rate. Lowering the feed rate can improve the quality of both separated phases by allowing more time to achieve efficient separation. 
High angular speed $(\omega)$ results in higher centrifugal force (G-Force) inside the rotor, it also results in more mixing in the annulus, and therefore smaller droplet size (d). As a result of this, an increase in the angular speed sometimes results in no improvement in separation efficiency as the increased angular velocity $(\omega)$ may be offset by a decrease in droplet size (d). This should be determined for each set of application conditions and the fluids processed.

\section{Experimental Procedure}

Produced water with hydrocarbon concentration of 200 ppmC TOC was run through the V-02 centrifuge at different flow rates, temperatures and rotor angular velocities. The centrifuge was initially run at a temperature of $75^{\circ} \mathrm{F}$ and rotor speed of $4000 \mathrm{rpm}$, corresponding to roughly $430 \mathrm{G}$-force at the rotor walls. This is the maximum rotor speed recommended by the manufacturer. The conversion of rotor rpm to G-force for the CINC centrifuge is given in Fig. 4.3, published by CINC industries. The produced water feed was initially dark gray in color. The flow rate across the centrifuge was adjusted unit a visual confirmation was obtained, when the water phase at the output side of the centrifuge became yellowish in color, that the centrifugal separation is effective. Visual confirmation was obtained at a feed flow rate of $0.460 \mathrm{lit} / \mathrm{min}$

Operating conditions of the centrifuge were varied to see the effectiveness of the separation with change in operation parameters. Produced water was passed through the centrifuge at 75,90 and $110^{\circ} \mathrm{F}$ temperature. Four different flow rates were used to see the effect of resonance time. These flow rates were $0.155 \mathrm{lit} / \mathrm{min}, .260 \mathrm{lit} / \mathrm{min}, 350 \mathrm{lit} / \mathrm{min}$ and $0.460 \mathrm{lit} / \mathrm{min}$ giving feed resonance time between 50 to 20 seconds in the centrifuge. Four different centrifuge speeds were selected to see the effect of rotor rpm on decreasing the TOC concentration in the produced water. The selected rotor speeds were 3400,3600 , 3800 and 4000 rpm corresponding to 300, 340, 380 and 430 G-force at the rotor wall. 


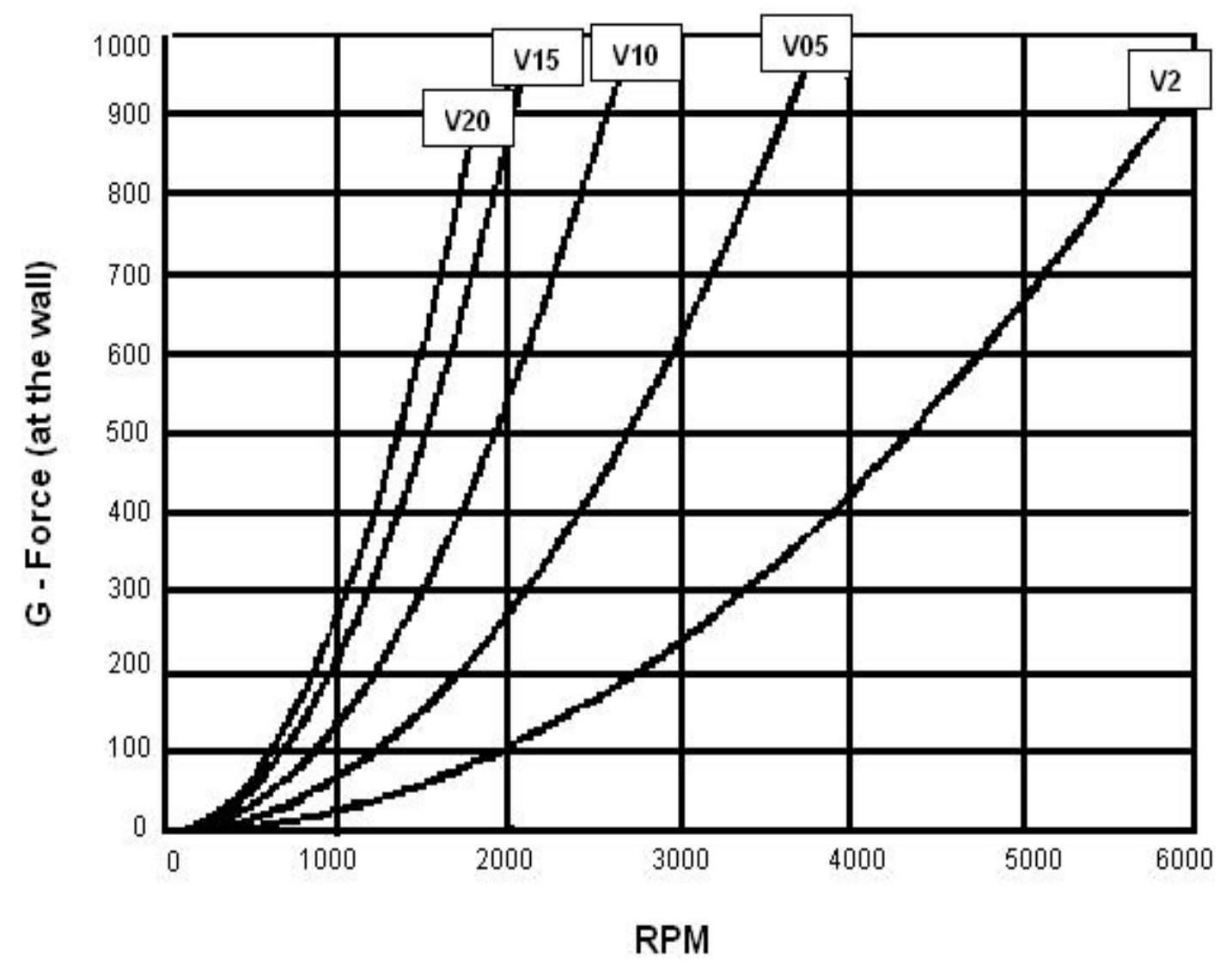

Fig. 4.3-Conversion of rpm to G-force published by CINC.

\section{Removal of Hydrocarbons From Produced Water by ET-1 Organoclay}

Aqua Technology's ET-1 organoclay was tested in the lab for its efficiency in removing hydrocarbons from produced water as a pretreatment step before the produced water is passed through desalination membrane. Produced water was initially run through centrifuge to lower the concentration of hydrocarbons and remove some of the suspended solids present in it. This produced water was then passed through ET-1 organoclay to determine the effectiveness of ET-1 organoclay in the removal of organics from produced water.

Aqua technology's ET-1 organoclay is composed of modified Bentonite clay, modified Montmorillonite, and a propriety high molecular weight cationic polymer. The resulting formulated organoclay has a surface that is organophilic and organics are removed from water by adsorption. Some of the properties of ET-1 organoclay, as claimed by the manufacturer, in the removal of hydrocarbons from the produced water are: 
- ET-1 organoclay can adsorb up to 60- 70\% hydrocarbon by weight.

- ET-1 organoclay can remove insoluble and dispersed hydrocarbons. However removal of dissolved hydrocarbons like benzene, toluene, ethylbenzene, and xylene (BTEX) is not very effective.

- ET-1 organoclay can tolerate concentration spikes that might result from separator or treater upsets and accidental oil carry-over from storage tanks.

- Hydrocarbons adsorbed by ET-1 organoclay do not desorb.

\subsubsection{Experimental Procedure}

Produced water collected from the water disposal facility was run twice through the CINC V-05 centrifuge to remove some of the suspended oil and. The TOC concentration of the produced water after being processed by the centrifuge was about $80 \mathrm{ppm}$. This treated produced water with $80 \mathrm{ppm}$ TOC concentration was used to determine the efficiency of Aqua Technology's ET1 organoclay in removing the hydrocarbons from the produced water.

ET-1 organoclay was first washed in running water to flush out the fine particles and dust that might have been present in it. It was then immersed in water for 24 hours to hydrate the organoclay so it would function properly. The organoclay was then packed in a 500ml cylindrical cell, which was then closed from top and bottom. Peristaltic pump were used to pump the produced water through the organoclay packed cell. The produced water was run through the organoclay cell in an up flow condition i.e. the produced water entered the cell from bottom exited from the top. The up flow configuration of the feed was used to eliminate the possibility of fluid channeling through the organoclay or increased pressure differential due to clay compaction in the cell due to downward feed flow.

Resonance time is defined as the total time that the feed is in contact with the organoclay in the container, from the entrance to exit. The manufacturer recommends that the resonance time of the feed with the organoclay should be between 3-6 minutes for maximum efficiency in removing the organics.

It was assumed that the cell packed with the ET1 organoclay had 30\% porosity (based on spherical particle size and uniform distribution). This gives pore volume $\mathrm{V}_{\mathrm{p}}$ of

$\mathrm{V}_{\mathrm{p}}=$ porosity $*$ Cell Volume

$\mathrm{V}_{\mathrm{p}}=0.3 * 500 \mathrm{ml}$

$\mathrm{V}_{\mathrm{p}}=150 \mathrm{ml}$ 
For 3-6 minute resonance time for the produced water with the organoclay, the required flow rate is

$\mathrm{Q}_{\mathrm{l}}=150 \mathrm{ml} / 6 \mathrm{~min} \quad$ and $\quad \mathrm{Q}_{\mathrm{h}}=150 \mathrm{ml} / 3 \mathrm{~min}$

$\mathrm{Q}_{\mathrm{l}}=25 \mathrm{ml} / \mathrm{min} \quad$ and $\quad \mathrm{Q}_{\mathrm{h}}=50 \mathrm{ml} / \mathrm{min}$

Where $\mathrm{Q}_{\mathrm{l}}$ and $\mathrm{Q}_{\mathrm{h}}$ are the minimum and maximum feed flow rates through the organoclay packed cell. Based on these calculations the flow rate of the produced water through the organoclay packed cell was kept at $35 \mathrm{ml} / \mathrm{min}$. This gave a resonance time (contact time) of $4.28 \mathrm{~min}$ (approximately $4 \mathrm{~min} 15 \mathrm{sec}$ ) for the produced water with the organoclay for the removal of hydrocarbons from the produced water.

\section{Screening of Membranes for the Removal of Hydrocarbons From Produced Water and Desalination of Produced Water}

Experiments were done on selected membranes to screen them for their efficiency in removing the hydrocarbon and dissolved solids (salts) from the produced water. There were three main objectives for the screening of membranes. These were:

1. Screen membranes for their efficiency in reducing the hydrocarbon contents of the produced water.

2. Determine which membranes would lower the hydrocarbon content of the produced water below the maximum allowable discharge limit of 29 ppmC TOC for produced water, as set by the EPA in Title 40.1 and the suggested 15 ppmC TOC for discharge to surface waters.

3. Screen the efficiency of the selected membranes for the removal of dissolved solids (salts) for desalination of produced water and determine which membrane would lower the salt concentration of the produced water to Class 1 and Class 2 agricultural water quality standards as defined by TCEQ.

Nine different membranes were selected to determine their efficiency in removing hydrocarbons and salts from the produced water. These membranes were selected in consultation with the faculty and industry based on their experience with membrane separation processes in different industrial applications. Selection criterion for the membranes was based on the ability of the membrane to handle hydrocarbons and other organics, hydrophilicity, resistance to fouling by organics (oil), and rejection of dissolved solids. 
Membranes that were selected for screening included one spiral, three ceramic, and five tubular membranes. The tubular membranes selected were AFC30, AFC80, AFC99, FP100 and FP200, which are all manufactured by PCI Membranes. The three ceramic membranes included AH1347, AH1393, and \#19, which are manufactured by Corning. The spiral membrane selected was SWC-1-4040 and this membrane is manufactured by Hydraunatics. All tests were performed on standard commercial size elements so that the results obtained from the experiments could easily be scaled up to actual field test unit. Specifications of these membranes are given in Table 4.1.

Membranes FP-100, FP-200, \#19, AH1347, AH1393 and AFC30 were primarily selected to evaluate their performance in removing the hydrocarbons from the produced water below the maximum allowable discharge limit of 29 ppmC TOC for produced water set by EPA in Title 40.1, and below the recommended hydrocarbon concentration limit of 15 ppmC TOC for discharge of produced water to surface waters.

The secondary purpose of using these membranes was the removal of finer suspended solids from the produced water before produced water is passed through desalination membrane for the removal of salts from the produced water. Desalination membranes usually do not tolerate organics very well and get fouled quickly. Similarly if suspended solids greater than 5-microns in size are not removed, the feed channel of desalination membranes may be blocked. AFC30 was also evaluated to determine its efficiency in removing the salts from the produced water

Membranes AFC80, AFC99 and SWC-1-4040 were evaluated primarily to determine their salt rejection characteristics (desalination) and determine if they can reduce the salt concentration to either Class 1 or Class 2 irrigation quality water standard as defined by the Texas Commission on Environmental Quality (TCEQ). These membranes were studied for their performance in lowering the TOC concentration of the produced water as well.

\subsubsection{Experimental Procedure}

Produced Water was collected from produced water disposal facility located outside of College Station in Brazos County. This facility is used for the disposal of produced water that is collected from the oil wells surrounding the College Station area. The produced water was pretreated using CINC V-05 centrifuge to reduce the oil contents and remove the larger solid particles from the water, as described in the previous chapter.

The hydrocarbon concentration of the processed produced water was 110 ppmC TOC, after being processed by the centrifuge and the total dissolved solids (TDS) concentration of was about 45,000 ppm. This produced water was used as feed for the membranes to determine their efficiency in removing the hydrocarbons and salts from the produced water. 
NIRO-XP pilot plant membrane unit was used to process the produced water across the membranes using crossflow filtration. The membranes were run at their respective operating conditions. The three ceramic membranes, \#19, AH1347 and AH1373, were operated at an average trans-membrane pressure of 13.5 psi. FP100 and FP200 were operated at an average trans-membrane pressure of 42 psi. AFC30, AFC80, AFC99 and SWC-1-4040 membranes were operated at a maximum pressure of 800 psi.

Produced water with 45,000 ppm TDS was used for the to process through the membranes for two purposes. One was that 45,000 ppm TDS is the maximum salt concentration in the produced water that would be treated for the scope of this project. Second, when produced water of 15,000 ppm TDS concentration is processed, the concentrate gets richer in TDS and it needs to be determined that how much recovery is possible and what will be the TDS concentration in the permeate obtained and will this be within the desired TDS content of the permeate. 


\begin{tabular}{|c|c|c|c|c|c|c|c|c|c|c|}
\hline 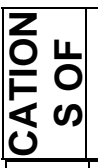 & 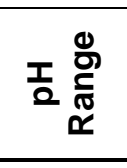 & $\underset{丶}{\stackrel{7}{1}}$ & $\stackrel{\vec{J}}{\overrightarrow{1}}$ & $\stackrel{m}{\rightarrow}$ & $\begin{array}{l}\text { ने } \\
\text { ம் } \\
\text { - }\end{array}$ & $\begin{array}{l}\text { ने } \\
\text { ம் } \\
\text { - }\end{array}$ & 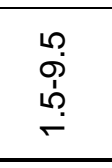 & 官 & نْ & 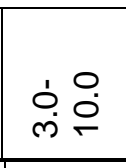 \\
\hline & 爻 & $\begin{array}{l}\text { II } \\
\stackrel{\circ}{8} \\
\stackrel{8}{8}\end{array}$ & 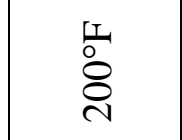 & 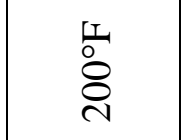 & $\begin{array}{l}1 \\
0 \\
0 \\
0 \\
1 \\
-1\end{array}$ & $\begin{array}{l}1 \\
0 \\
0 \\
0 \\
\end{array}$ & $\begin{array}{l}\text { II } \\
\text { 品 } \\
\text { 守 }\end{array}$ & 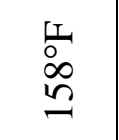 & $\begin{array}{l}\text { 도 } \\
0 \\
0 \\
\\
\end{array}$ & $\begin{array}{l}I I \\
\text { Oे } \\
\text { M } \\
\text { = }\end{array}$ \\
\hline & $\begin{array}{l}\dot{x} \\
\dot{\mathbb{I}} \\
\Sigma\end{array}$ & $\begin{array}{l}\bar{n} \\
\stackrel{2}{\circ} \\
\stackrel{+}{*}\end{array}$ & $\begin{array}{l}\bar{n} \\
\stackrel{2}{\circ} \\
\text { o }\end{array}$ & $\begin{array}{l}\bar{n} \\
\stackrel{0}{\circ} \\
\text { o }\end{array}$ & 㗂 & $\stackrel{\circ}{\stackrel{\circ}{\circ}}$ & 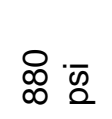 & 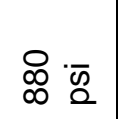 & 品 & 육 \\
\hline & 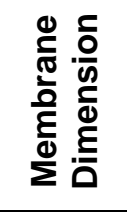 & 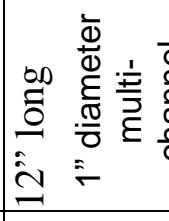 & 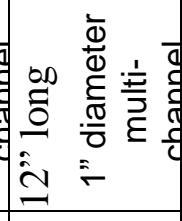 & 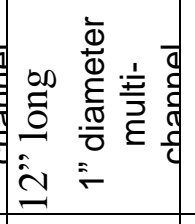 & 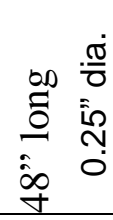 & 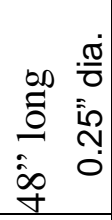 & 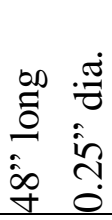 & 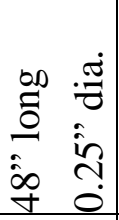 & 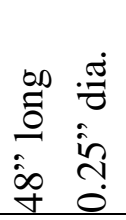 & $\begin{array}{c}\hat{\hat{O}} \\
\rtimes \\
\hat{y} \\
\hat{\dot{y}}\end{array}$ \\
\hline & 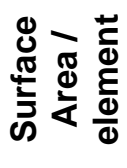 & 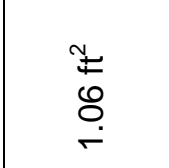 & $\begin{array}{l}\underset{\Xi}{ \pm} \\
\stackrel{+}{+}\end{array}$ & $\begin{array}{l}\underset{ \pm}{ \pm} \\
\underset{-}{+}\end{array}$ & 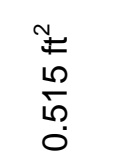 & \begin{tabular}{l}
\multirow{7}{\pm}{} \\
10 \\
10 \\
0 \\
0
\end{tabular} & \begin{tabular}{l}
\multirow{7}{\pm}{} \\
10 \\
17 \\
10 \\
0
\end{tabular} & $\begin{array}{l}70 \\
10 \\
10 \\
0 \\
0\end{array}$ & 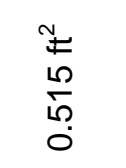 & $\begin{array}{l}\underset{1}{N} \\
0\end{array}$ \\
\hline & 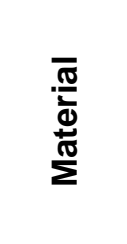 & 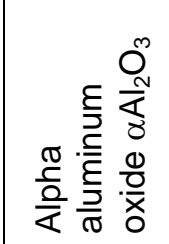 & 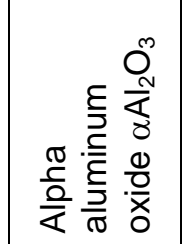 & 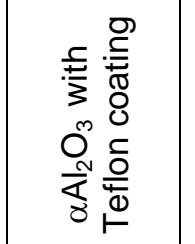 & $\stackrel{\text { 岁 }}{\stackrel{2}{0}}$ & $\stackrel{\frac{1}{0}}{\stackrel{0}{0}}$ & $\begin{array}{l}\frac{0}{0} \\
\frac{0}{E} \\
\frac{0}{\lambda} \\
\frac{0}{0}\end{array}$ & $\begin{array}{l}\frac{0}{.0} \\
\frac{O}{E} \\
\frac{0}{2} \\
\frac{0}{0} \\
0\end{array}$ & $\begin{array}{l}\frac{0}{0} \\
\frac{0}{E} \\
\frac{0}{2} \\
\frac{0}{0} \\
0\end{array}$ & 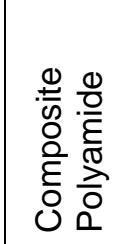 \\
\hline & 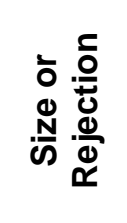 & $\begin{array}{c}\frac{c}{0} \\
\stackrel{U}{U} \\
E \\
N \\
0\end{array}$ & 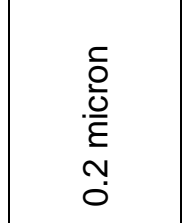 & 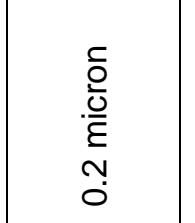 & \begin{tabular}{l}
8 \\
8 \\
\hdashline
\end{tabular} & 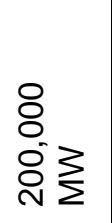 & 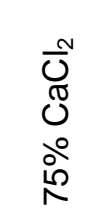 & $\begin{array}{l}\overline{0} \\
2 \\
0 \\
0 \\
\infty\end{array}$ & 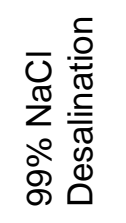 & 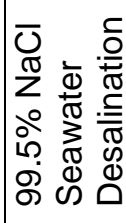 \\
\hline & $\stackrel{\Perp}{\stackrel{\Xi}{2}}$ & 흘 & & 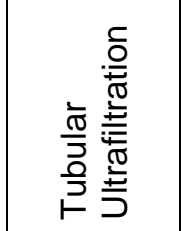 & & & 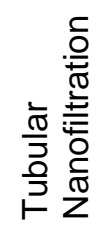 & 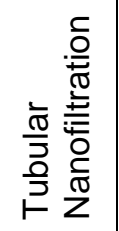 & 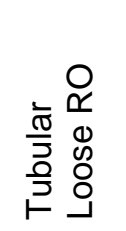 & 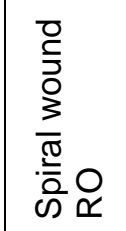 \\
\hline & 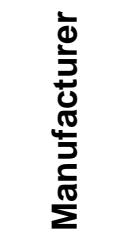 & 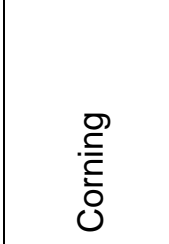 & 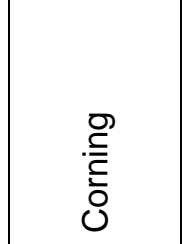 & 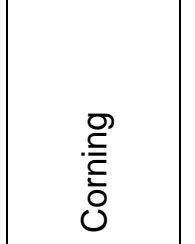 & $\bar{\searrow}$ & $\bar{\circlearrowright}$ & $\bar{Q}$ & $\bar{\chi}$ & $\bar{\chi}$ & 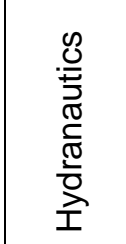 \\
\hline & 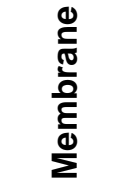 & $\stackrel{9}{\rightarrow}$ & 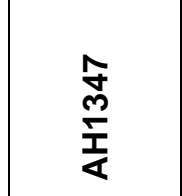 & 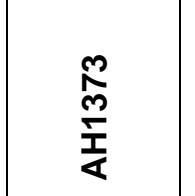 & $\begin{array}{l}8 \\
\text { 언 } \\
\text { ㄴ. }\end{array}$ & $\begin{array}{l}\text { 오․ } \\
\text { î }\end{array}$ & 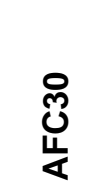 & 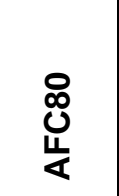 & 㝵 & 仓ं \\
\hline
\end{tabular}




\subsubsection{Crossflow Filtration}

Crossflow filtration consists of pumping the feed over the surface of the membrane, parallel to the surface of the membrane and along the length of the membrane. A schematic of crossflow filtration is shown in Fig 4.4. $\mathrm{P}_{\mathrm{i}}, \mathrm{P}_{\mathrm{o}}$ and Pp refer to the inlet, outlet and permeate pressures respectively. The pressure gradient across the membrane forces part of the solvent and some particles smaller than the pores of the membrane through the membrane, while the larger particles/molecules are retained. Hence one feed stream is split into two product streams.

The retained stream is referred to as retentate or concentrate. Larger particles/molecules are retained in the retentate stream by the membrane. The stream going through the membrane is called permeate, which is depleted of the large particles present in the original stream. Major part of the feed stream flows over the surface of the membrane to the outlet as retentate, which is usually recycled through the system or passed across more membranes. 69

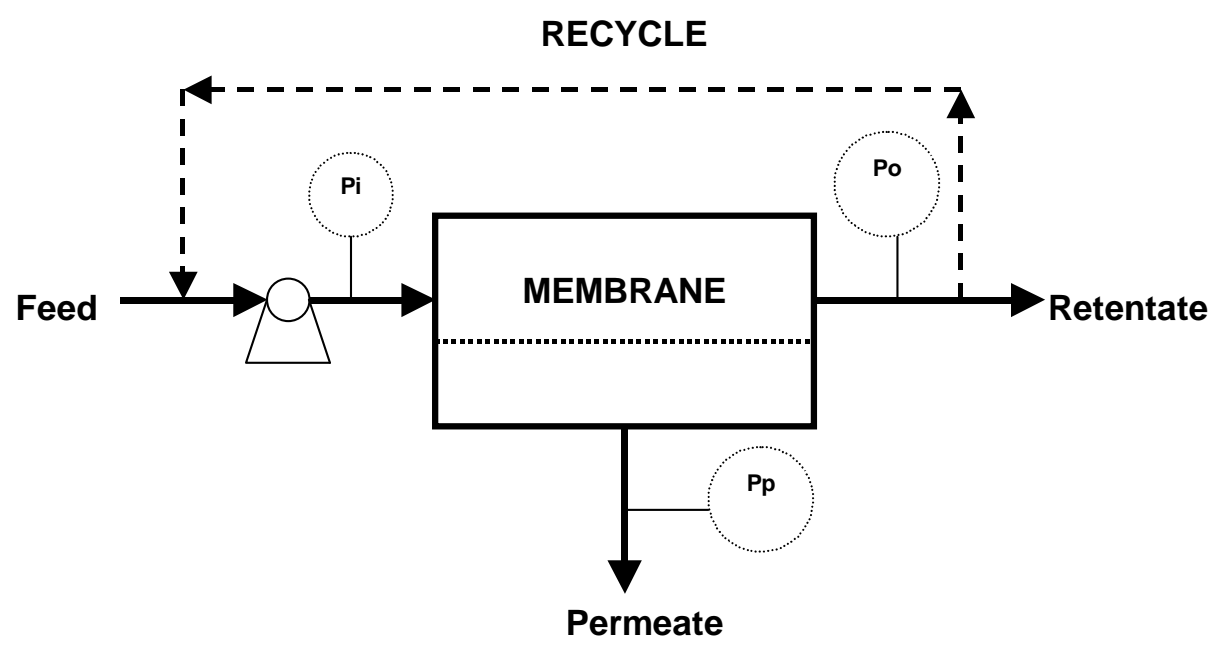

Fig. 4.4-A schematic of crossflow filtration.

\subsubsection{Operation of NIRO-XP Pilot Plant Membrane Unit}

Experiments on all the membranes were conducted using NIRO-XP pilot plant membrane unit. It is shown in Fig. 4.5. NIRO-XP is equipped with spiral, tubular and ceramic housings and therefore all types of membranes can be screened using this pilot plant unit. NIRO-XP unit is used for determining the operational parameters of membranes that are scaled up directly to industrial level. This unit was used for the screening of all the membranes. 
NIRO-XP is equipped with a centrifugal pump for feed flow, and a positive displacement diaphragm pump for pressure build up. Two needle valves are provided to regulate the pressure across the membranes. A gate valve regulates the fluid flow rate. The unit has a feed tank of 14 gallons capacity. The fluid holdup in the plumbing of the unit is approximately 3 gallons. Therefore, the total fluid in the system is about 17 gallons during operation. Maximum flow rate through the system is $40 \mathrm{gpm}$ and the maximum pressure for the system is 1000 psi.

Two Halliburton MC-II Flow Analyzer liquid flow meters were placed in the system to measure the flow rates at different points in the system. One flow meter was placed before the membrane housing near the feed entrance to the membrane, to measure the inlet feed rate. The second flow meter was placed at the feed exit of the membrane housing to measure the concentrate flow rate at the outlet. Permeate flow rate was measured manually to accurately measure the permeate flow rate. Permeate samples were collected in a graduated cylinder and the time for collection was measured using a stopwatch. Flow rate was obtained by dividing the volume of permeate collected by the time over which permeate was collected.

Pressure gauges at the feed entrance and the concentrate exit side of the membrane housing were mounted to record at the entrance and exit of the feed and concentrate across the membrane. Pressure on the permeate side of the membrane was atmospheric pressure. The average of the feed and concentrate pressure gives the average transmembrane or operating pressure. A digital thermometer was used to record the fluid temperature in the feed tank. This temperature was assumed to be uniform throughout the system. 


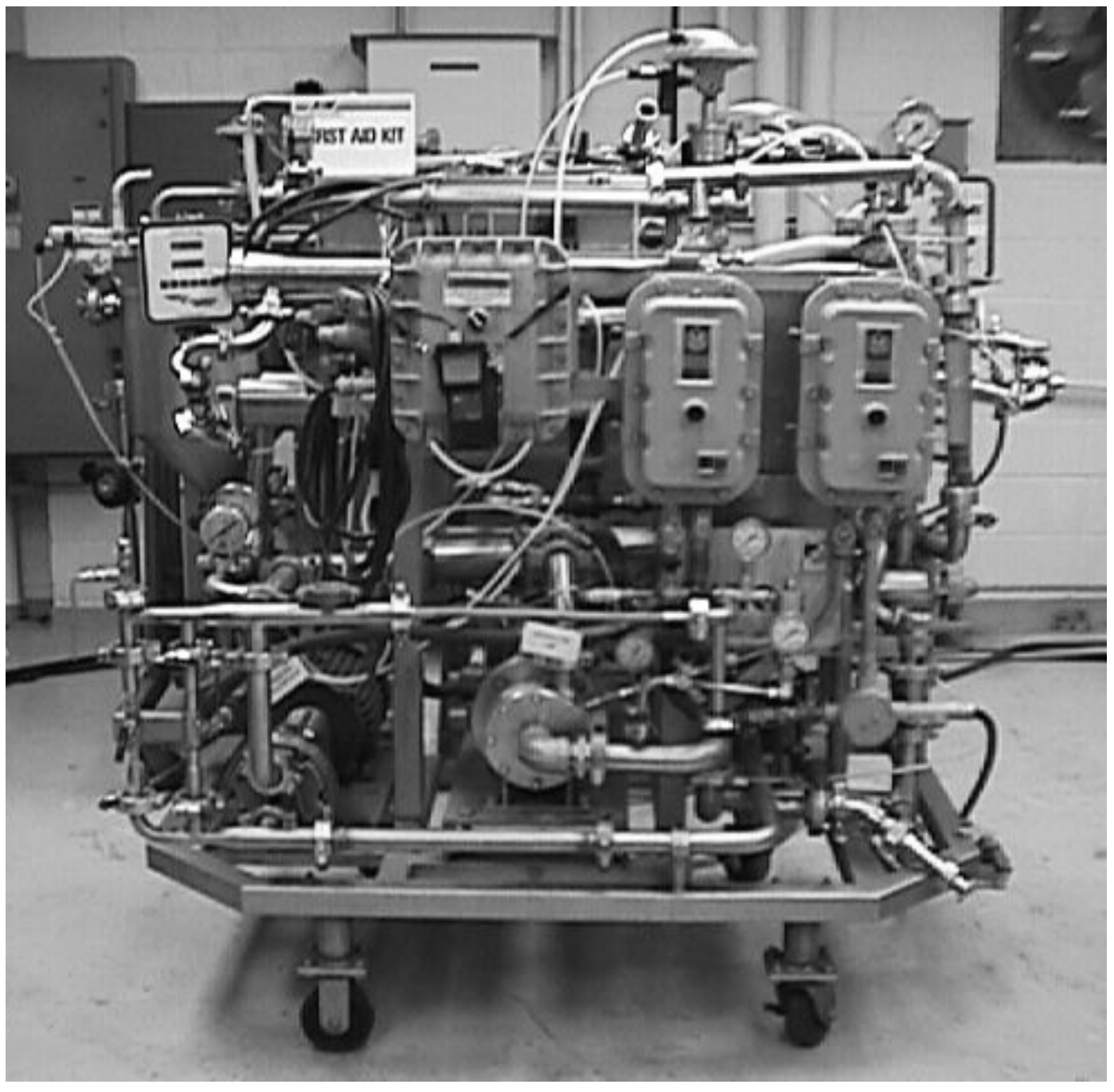

Fig. 4.5-NIRO-XP pilot plant membrane unit. 


\section{Experiments With SWC-1-4040 Membrane for Desalination of Produced Water}

SWC-1-4040 membrane was selected for further tests for the desalination of produced water to agricultural water quality standards. A standard commercial $4 \times 40$ membrane element (4 inch diameter and 40 inches long) was chosen for experiments so that the results obtained from the experiments could easily be scaled up to actual field test unit.

Different tests performed on SWC-1-4040 membrane included: a) performing clean water flux experiments, and b) determining the efficiency of SWC-1-4040 in removing dissolved solids from produced water of different concentrations and corresponding fluxes at different pressures and selected flow rates. Tests were conducted with produced water having concentrations of 15,000 ppm, 30,000 ppm and 45,000 ppm total dissolved solids (TDS) respectively.

Experiments were performed on SWC-1-4040 membrane at 3 constant feed flow rates of 8, 11 and $14 \mathrm{gpm}$ (0.1143, 0.1572 and $0.2000 \mathrm{gpm} / \mathrm{ft}^{2}$ membrane surface area) across the membrane surface. $8 \mathrm{gpm}$ and $14 \mathrm{gpm}$ correspond to the minimum and maximum recommended flow rates by the manufacturer across SWC-1-4040 membrane. Maximum pressure of 800 psi was applied to the membrane due to equipment limitations.

Dividing the feed flow rate by the surface area of the membrane being used gives the normalized flow rate on gpm per square foot membrane area basis. This is helpful in adjusting the feed flow rate if the same membrane in a different configuration is used.

Produced water was taken from a produced water disposal facility near College Station in the Brazos County. This produced water contained about 46,000 ppm dissolved and suspended solids and about 200 ppm TOC. Gravitational settling of produced water was done to allow the heavier suspended solids to settle and be removed. Produced water was passed twice through the CINC centrifuge to remove suspended oil and grease particles present in it.

The produced water was then passed through 0.2 micron ceramic membrane to further reduce the hydrocarbon concentration. Any feed that is to be passed through a spiral RO membrane should first be passed at least through a 5 micron filter (or $<5$ micron) to remove large suspended solids as these may clog space between feed channels and as well physically damage the membrane. Therefore the ceramic membrane performed two functions: 1) it further removed the hydrocarbons and decreased the TOC concentrations in the produced water after the centrifuge, and 2) removed the larger suspended solids from the feed.

Pretreated produced water obtained after passing through the ceramic membranes was 45,000 ppm in dissolved solids (TDS) and $120 \mathrm{ppmC}$ in TOC. This produced water was used for the testing the performance of the SWC-1-4040 membrane. For additional tests at lower concentrations of TDS, the produced water obtained from the ceramic membranes with 45,000 ppm TDS, was blended with distilled water to obtain produced water with 30,000 ppm and 15,000 ppm TDS. Analytical tests were done these produced 
waters to determine the impurities present in them. The analytical test results are given in Table 4.2.

\subsubsection{Clean Water Flux Experiments}

"Clean water flux" experiments are experiments done on each test membrane with distilled water (ideally zero or < 100 TDS). These experiments are very important as they form the benchmark of all subsequent experiments that are done with the actual feed. These experiments are conducted on brand new membranes that have never been used. The aim of these experiments is:

\begin{tabular}{|l|r|r|r|r|r|r|r|r|}
\hline \multicolumn{2}{|c|}{ TABLE 4.2-DISSOLVED SOLIDS IN PRODUCED WATER OF DIFFERENT } \\
CONCENTRATIONS.
\end{tabular}




\begin{tabular}{|l|r|r|r|l|r|r|r|r|r|}
\hline TAF & & & 19 & & & 38 & & & 57 \\
\hline GPG & & & 824 & & & 1639 & & & 2459 \\
\hline SAR & & & 58 & & & 70 & & & 105 \\
\hline $\begin{array}{l}\text { Percent Sodium } \\
\text { (SSP) }\end{array}$ & & & 88 & & & 59 & & & 89 \\
\hline Phosphorus & & 10.12 & & & 12.01 & & & 18.02 & \\
\hline Copper, Dissolved & & $<0.01$ & & & $<0.01$ & & & $<0.01$ & \\
\hline Zinc & & 0.02 & & & 0.01 & & & 0.01 & \\
\hline
\end{tabular}

a) Determine if there is any membrane compaction.

b) Determine the flux across the membrane at different pressures and selected flow rates.

c) Determine the membrane resistance at selected flow rates.

d) Determine the efficiency of membrane cleanings that will be done later, as the membrane is used and fouls.

e) Indicate fouling characteristics of the membrane with the feed stream.

Clean water flux is the maximum flux across a membrane that is possible for a particular membrane. Fluxes obtained with the actual feed are always less than the clean water flux as the feed has impurities present. If the flux with the actual feed with dissolved impurities is found to be more than the clean water flux, then this may show a problem with the membrane integrity. Therefore the membrane and its module should be further tested to determine if the membrane is installed properly or is damaged.

Experiments were done at 3 constant feed flow rates of 8, 11 and 14 gpm $(0.1143,0.1572$ and $0.2000 \mathrm{gpm} / \mathrm{ft}^{2}$ membrane surface area) across the membrane surface. $8 \mathrm{gpm}$ and 14 gpm correspond to the minimum and maximum recommended flow rates by the manufacturer across SWC-1-4040 membrane. Transmembrane pressure from 100 to 800 psi was applied in 100 psi increments.

Membrane compaction is determined by increasing the transmembrane pressure from zero to the maximum allowable limit (limited either by the membrane or the equipment), at a fixed flow rate and noting the permeate flow rates at predetermined pressures. The pressure is then released and the permeate flow rate is noted at the pre-selected pressures again. The flux is then calculated and normalized, and compared at corresponding pressures for the pressure increase and decrease runs. If the fluxes are the same then the membrane has not compacted. However if the fluxes are different from each other then the membrane is said to have compacted. This procedure is done three times and the fluxes are compared to determine if there has been any membrane compaction. All membranes compress to some extent initially. 


\subsubsection{Experiments with 15,000, 30,000 and 45,000 TDS Concentration Produced Water}

Experiments were conducted with produced water of 15,000 ppm, 30,000 ppm and 45,000 ppm TDS concentration using constant flow rates of 8, 11 and $14 \mathrm{gpm}$ (corresponding to $0.1143,0.1571$ and 0.2000 gallon per minute flow rate per square foot membrane area). Hydrocarbon concentration in the produced water was 40, 80 and 120 ppmC TOC for the 15,000, 30,000 and 45,000 ppm TDS concentration produced water, respectively.

These experiments were done to determine the permeate flux across the membrane for produced water of different concentrations at different flow rates as the pressure is varied. Percent permeate recovery from the feed, salt concentrations in permeate, and percent salt rejection for different concentration of produced water was studied at selected flow rates by varying the pressure. Different dissolved solids present in the produced water of 15,000 ppm, 30,000 ppm and 45,000 ppm TDS concentrations are given in Table 4.2.

Pressure was increased from 100 psi to 800 psi with 100 psi pressure increments for $15,000 \mathrm{ppm}$ TDS produced water. Permeate started flowing when the applied pressure was 300 psi that corresponded to nearly twice the osmotic pressure for 15,000 ppm TDS produced water, which is approximately $150 \mathrm{psi}$. The maximum pressure applied across the membrane was $800 \mathrm{psi}$, limited due to equipment limitations. All fluxes were normalized to $95^{\circ} \mathrm{F}$.

The osmotic pressures for the 30,000 ppm TDS produced water is about $300 \mathrm{psi}$, and approximately 450 psi for 45,000 ppm TDS produced water. Permeate started flowing when the applied pressure reached 500 psi, both for 30,000 ppm and 45,000 ppm TDS produced water. Applied transmembrane pressure was varied from 550 psi to 800 psi for data collection. The maximum pressure applied across the membrane was $800 \mathrm{psi}$.

\subsubsection{Membrane Fouling}

Fouling is the term used to describe undesirable formation of deposits on the surface of the membrane and consequent reduction of flux and membrane selectivity. Fouling occurs when the rejected solids are not transported from the surface of the membrane back to the bulk stream. As a result, dissolved salts, suspended solids and microorganisms accumulate at the membrane surface. The following processes are the main causes for fouling:

- Inorganic deposits (scaling)

- Organic molecule adsorption (organic fouling) 
- Particle deposition (colloidal fouling)

- Microbial adhesion and growth (biofouling)

All of these different types of fouling processes frequently occur at the same time in RO process and tend to decrease the performance of the membranes. The combined effect of fouling is an increase in operating and maintenance cost of the RO system. Consequences of fouling are:

- Increased cleaning and maintenance costs of the RO system.

- Deterioration in the product water quality (permeate quality) i.e. increase in the passage of dissolved materials (salts) in permeate (decreased salt rejection).

- Decline in flux over time.

- Increase in transmembrane and differential pressure (feed pressure and $\Delta \mathrm{P}$ ) with time.

- $\quad$ Reduced membrane life.

Fouling can be classified is of two kinds: 1) temporary fouling and 2) permanent or irreversible fouling. Membrane cleaning processes and techniques can reverse temporary fouling and restore the RO system to previous operating conditions. Permanent or irreversible fouling cannot be corrected as the membrane is permanently spoiled and a permanent change in operating conditions takes place. Temporary fouling can become irreversible or permanent if it is allowed to go unchecked. Nearly all feed components foul the membrane to some extent. The nature and extent of membrane fouling depends strongly on the physical and chemical nature of the membrane and the feed and their interaction.

All membranes are permanently fouled to some extent the first time that they are used and then this fouling slows down as these membranes are utilized. This can be measured by performing clean water tests after each run with the actual feed (produced water in this case). Clean water flux as well as flux for the actual feed keeps on decreasing over time as the membrane is used. This flux may be restored to original value (for clean water and the actual feed) by employing proper cleaning methods for the membrane.

Fouling and cleaning studies were done on SWC-1-4040 membrane using produced water feed of 15,000 ppm TDS and 40 ppmC TOC hydrocarbon concentration, at a feed flow rate of $10 \mathrm{gpm}$ and at an operating transmembrane pressure of 550 psi. Produced water was processed through the membrane for a total of 41.5 hours (2485 minutes) of operation.

Fouling tests were performed by measuring time versus permeate flux, salt concentrations in permeate, percent salt rejection and hydrocarbon rejection with SWC-1-4040 
membrane. All the experiments conducted during the fouling tests, are divided in two parts, which are: series "Foul 1" and series "Foul 2". The reason for his is because after 11.5 hours (685 minutes) of operation there was a system upset. "Foul 1" refers to the data taken from prior to system upset and "Foul 2" refers to the data taken after system was restored to the operating conditions.

\subsubsection{Volume Concentration Ratio (VCR)}

Recovery across a single membrane is limited. In actual operations the total recovery desired is often more than the recovery across single membrane. In such case there may be two or more membranes arranged in series, one after the other, depending on how much overall recovery is required. The concentrate/reject from the first membrane becomes the feed for the second membrane and so on.

Volume Concentration Ratio experiments are done in order to determine the flux across the membrane as the salt concentration in the feed increases. VCR is also referred to as the volume "concentration factor" $(X)$. The rejection data is also presented as a function of VCR to determine the salt rejection efficiency, as the feed is concentrated. Volume concentration ration (VCR) is defined as:

$\mathrm{VCR}=\mathrm{V}_{\mathrm{o}} / \mathrm{V}_{\mathrm{R}}$

Where

$\mathrm{V}_{\mathrm{o}}=$ Initial feed Volume

$\mathrm{V}_{\mathrm{R}}=$ Retentate Volume

Volume concentration Ratio experiments were done on SWC-1-4040 membrane with a produced water feed of 15,000 ppm TDS and $40 \mathrm{ppmC}$ TOC. This experiment was conducted at 550 psi operating pressure and 10 gpm feed flow rate.

\subsubsection{Membrane Cleaning}

Correct membrane cleaning method is required to ensure that all undesirable materials deposited on the membrane surface, causing membrane fouling, are removed. A good membrane cleaning procedure is one that restores the membrane close to its original condition, i.e. the flux and rejection are restored to their initial conditions. Appropriate membrane cleaning method was determined for SWC-1-4040 membrane.

The SWC-1-4040 membrane was cleaned twice. The first time was during the fouling profile experiment. This was necessitated because after 11.5 hours (685 minutes) of operation during the fouling profile run, there was a system upset. Oil leaked into the system and deposited on the membrane surface, fouling the membrane. 
During the first membrane cleaning cycle a very aggressive membrane cleaning method was used. "Big Red" a commercial detergent was added to the water (125 $\mathrm{ml}$ for 17 gallons of water) and this water was allowed to circulate through the system for about an hour. This water was drained and the system was flushed with clean water. This process was repeated three times. Sodium Hydroxide $(\mathrm{NaOH})$ was then added to the system and the $\mathrm{pH}$ was increased to 11 at a temperature of $95^{\circ} \mathrm{F}$. This water was allowed to circulate through the system for 30 minutes. This process was also repeated thrice but still there was a thin oil sheen present on the water coming out of the system. This showed that there was still some oil present on the surface of the membrane.

After this an enzyme based cleaner called "Terg-A-Zyme" was used to clean the membrane. A $0.75 \%$ solution (7.5 g/lit) was prepared with the enzyme cleaner and run through the system for 30 minutes. The system was then flushed with clean water. The water coming out at the exit of the membrane did not show any traces of oil on the surface. This showed that the oil from the surface of the membrane had been removed successfully. Clean water flux was then taken at $11 \mathrm{gpm}$ feed flow rate from 100 to 800 psi pressure with 100 psi pressure increments. This flux was compared to the clean water flux that was taken with the new membrane to see if the membrane cleaning was effective.

After this produced water with 15,000 ppm TDS and 40 ppmC TOC was run through the system. Flux readings were taken at different pressures at $11 \mathrm{gpm}$ feed flow rate. These flux readings were compared to the flux taken at the same conditions before the membrane was fouled. This was done in order to determine if the membrane cleaning procedure was effective, and if the flux and salt rejection was restored.

After all the experiments had been performed on the membrane the membrane was cleaned the second time prior to storage. Cleaning was done again with "Big Red" commercial detergent by adding $100 \mathrm{ml}$ of Big Red to 17 gallons of clean water. This water was run through the system for 30 minutes and the system flushed. $\mathrm{NaOH}$ was then added to clean water to achieve a $\mathrm{pH}$ of 11 . This water was run for 30 minutes and the system was flushed with clean water. Clean water flux readings at feed flow rate of 11 gpm and different pressures were taken. These readings were compared to the original clean water flux readings and the clean water flux after the first membrane cleaning. 


\section{CHAPTER V}

\section{RESULTS AND DISCUSSIONS}

\section{Removal of Hydrocarbons From Produced Water}

\subsubsection{Removal of Hydrocarbons From Produced Water by CINC Centrifuge}

The effect of changing the centrifuge rotor speed on the TOC concentration of the produced water exiting the centrifuge at a feed flow rate of $0.155 \mathrm{lit} / \mathrm{min}$, at temperatures of 75,90 and $110^{\circ} \mathrm{F}$ is shown in Fig. 5.1. The graph was plotted at the minimum feed flow rate through the centrifuge, as this flow rate gives the maximum resonance time for the produced water in the centrifuge, and hence the maximum oil/water separation efficiency by the centrifuge. It is seen from the figure that the TOC concentration of the exiting produced water decreased from 170 to $143 \mathrm{ppmC}$ TOC at $75^{\circ} \mathrm{F}$, and from 150 to $131 \mathrm{ppmC}$ TOC at $90^{\circ} \mathrm{F}$, as the rotor speed is increased from 3400 to $4000 \mathrm{rpm}$. At $110^{\circ} \mathrm{F}$ temperature it was observed that the maximum separation efficiency of the produced water processed by the centrifuge was at $3400 \mathrm{rpm}$ with TOC concentration of about 130 ppmC TOC, of the processed water and as the rotor speed was increased the TOC concentration of the exiting produced water increased to about $132 \mathrm{ppmC}$ TOC.

TOC concentration of the produced water exiting the centrifuge at different operating conditions is given in Table 5.1. Statistical analysis was done on the TOC results obtained to determine if there exist any significant difference in the TOC concentration of the produced water exiting the centrifuge, as the operating conditions are changed. The average TOC concentration of the produced water exiting the centrifuge was $143.09 \pm$ 10.66 ppmC TOC. The maximum TOC concentration of the produced water processed by the centrifuge was $169.69 \mathrm{ppmC}$ TOC and the minimum TOC concentration was 129.80 ppmC TOC. The average hydrocarbon removal efficiency of the centrifuge from the produced water was about $30 \%$ only. 


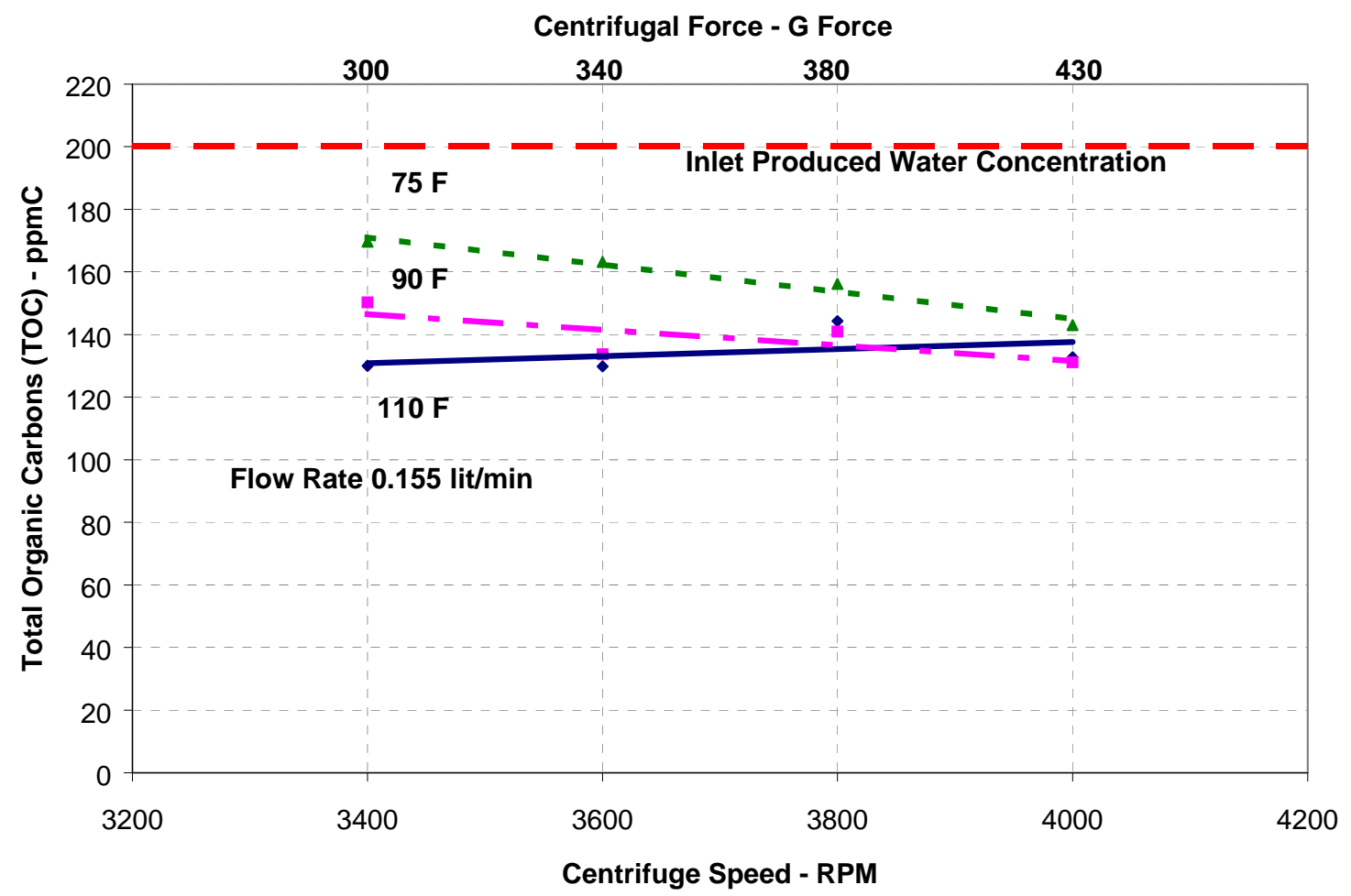

Fig. 5.1-Effect of centrifuge rotor speed on TOC concentration of the produced water exiting the centrifuge. (Feed flow rate $=0.155 \mathrm{lit} / \mathrm{min}$. Temperature $=75^{\circ}, 90^{\circ}$ and $\left.110^{\circ} \mathrm{F}\right)$.

CINC V-05 centrifuge was used after V-02 to process the produced water. Operating parameters for the V-05 centrifuge were determined by scaling up the operating parameters of V-02 using, the figures and methods provided by the manufacturer. These figures are given in the company web site. Problems were encountered when V-05 centrifuge was used to process the produced water. V-05 centrifuge was unable to decrease the hydrocarbon concentration of the produced water by $30 \%$ to about 140 ppmC TOC, as the V-02 had done. The produced water exiting the centrifuge had to be passed twice through the centrifuge to lower the TOC concentration to about $140 \mathrm{ppmC}$. 
TABLE 5.1-TOC CONCENTRATION OF THE PRODUCED WATER EXITING CINC V-02 CENTRIFUGE.

\begin{tabular}{|c|c|c|c|}
\hline $\begin{array}{l}\text { Centrifuge Rotor } \\
\text { Speed } \\
(\mathrm{rpm})\end{array}$ & $\begin{array}{c}\text { Feed Flow Rate } \\
\text { (lit/min) }\end{array}$ & $\begin{array}{c}\text { Temperature } \\
\left({ }^{\circ} \mathrm{F}\right)\end{array}$ & $\begin{array}{l}\text { TOC Concentration of } \\
\text { Exiting Produced Water } \\
\text { (ppmC TOC) }\end{array}$ \\
\hline 3400 & 0.155 & 75 & 169.69 \\
\hline 3400 & 0.155 & 90 & 150.22 \\
\hline 3400 & 0.155 & 110 & 129.99 \\
\hline 3400 & 0.260 & 110 & 137.45 \\
\hline 3400 & 0.350 & 110 & 138.05 \\
\hline 3400 & 0.460 & 110 & 141.42 \\
\hline 3600 & 0.155 & 75 & 163.20 \\
\hline 3600 & 0.155 & 90 & 133.69 \\
\hline 3600 & 0.155 & 110 & 129.80 \\
\hline 3800 & 0.155 & 75 & 156.17 \\
\hline 3800 & 0.155 & 90 & 140.94 \\
\hline 3800 & 0.155 & 110 & 144.28 \\
\hline 3800 & 0.260 & 110 & 150.80 \\
\hline 4000 & 0.155 & 75 & 142.98 \\
\hline 4000 & 0.155 & 90 & 131.10 \\
\hline 4000 & 0.155 & 110 & 131.33 \\
\hline 4000 & 0.260 & 90 & 143.07 \\
\hline 4000 & 0.260 & 110 & 149.87 \\
\hline 4000 & 0.350 & 90 & 141.59 \\
\hline 4000 & 0.350 & 110 & 152.33 \\
\hline 4000 & 0.460 & 90 & 136.48 \\
\hline 4000 & 0.460 & 110 & 145.31 \\
\hline \multicolumn{3}{|c|}{$\begin{array}{c}\text { Produced Water Feed (Inlet) Hydrocarbon } \\
\text { Concentration }\end{array}$} & 200 ppmC TOC \\
\hline \multicolumn{2}{|c|}{ Average } & & 143.09 \\
\hline \multicolumn{2}{|c|}{ Maximum } & & 169.69 \\
\hline \multicolumn{2}{|c|}{ Minimum } & & 129.80 \\
\hline \multicolumn{2}{|c|}{ Standard Deviation } & & 10.66 \\
\hline \multicolumn{2}{|c|}{ Coefficient of Variance } & & $7.45 \%$ \\
\hline
\end{tabular}

To simulate different field conditions for various kinds of produced water, different samples of produced water were collected from field with different TOC concentrations 
and processed by CINC V-05 centrifuge. The separation efficiency of the V-05 for the processing of different feeds was poor. The feed had to be passed at least twice to get a hydrocarbon removal efficiency of about 30\%. This was shown when feeds with TOC concentration of $140 \mathrm{ppmC}$ TOC and $170 \mathrm{ppmC}$ TOC were processed through the V-05. Both the feeds had to be centrifuged twice to get a hydrocarbon removal efficiency of about 30 percent.

\subsubsection{1. $\quad \underline{\text { Conclusions }}$}

The hydrocarbon removal efficiency of both the CINC V-02 and V-05 centrifuges was less than expected. Although CINC centrifuges perform well in other oil/water separation applications, as documented by the manufacturer, the centrifuge did not perform well for the applications of this project. It was decided not to use the CINC centrifuge as part of the water treatment process train. The V-05 centrifuge was only used in the lab for the pretreatment of the produced water for the membranes. Other method for the removal of suspended hydrocarbons from the produced water as discussed in the Chapter II should be investigated and used.

\subsubsection{Removal of Hydrocarbons From Produced Water by ET-1 Organoclay}

The produced water was run through the ET-1 organoclay packed cell for 24 hours. The results of this test are given in Fig. 5.2 and Table 5.2. The average inlet hydrocarbon concentration of the produced water was $80 \mathrm{ppmC}$ TOC. It is seen from Fig. 5.2 that during the 24 hour test period, the TOC concentration of the produced water at the outlet remained below 20 ppmC TOC. The hydrocarbon removal efficiency of the ET-1 organoclay from the produced water was about 75\%. This suggests that the ET-1 organoclay is effective in taking out the organics from produced water when the resonance time is kept between 3-6 minutes.

Another important note is that the concentration of hydrocarbons should be lowered as much as possible using conventional treatment methods before the produced water is passed through the organoclay. Minimizing hydrocarbon concentration in the feed reduces the frequency of replacing the organoclay, as organoclay is a consumable media that needs to be replaced when it reaches its saturation limit. This in turn reduces the replacement cost of the media and improves the economics of water treatment. 


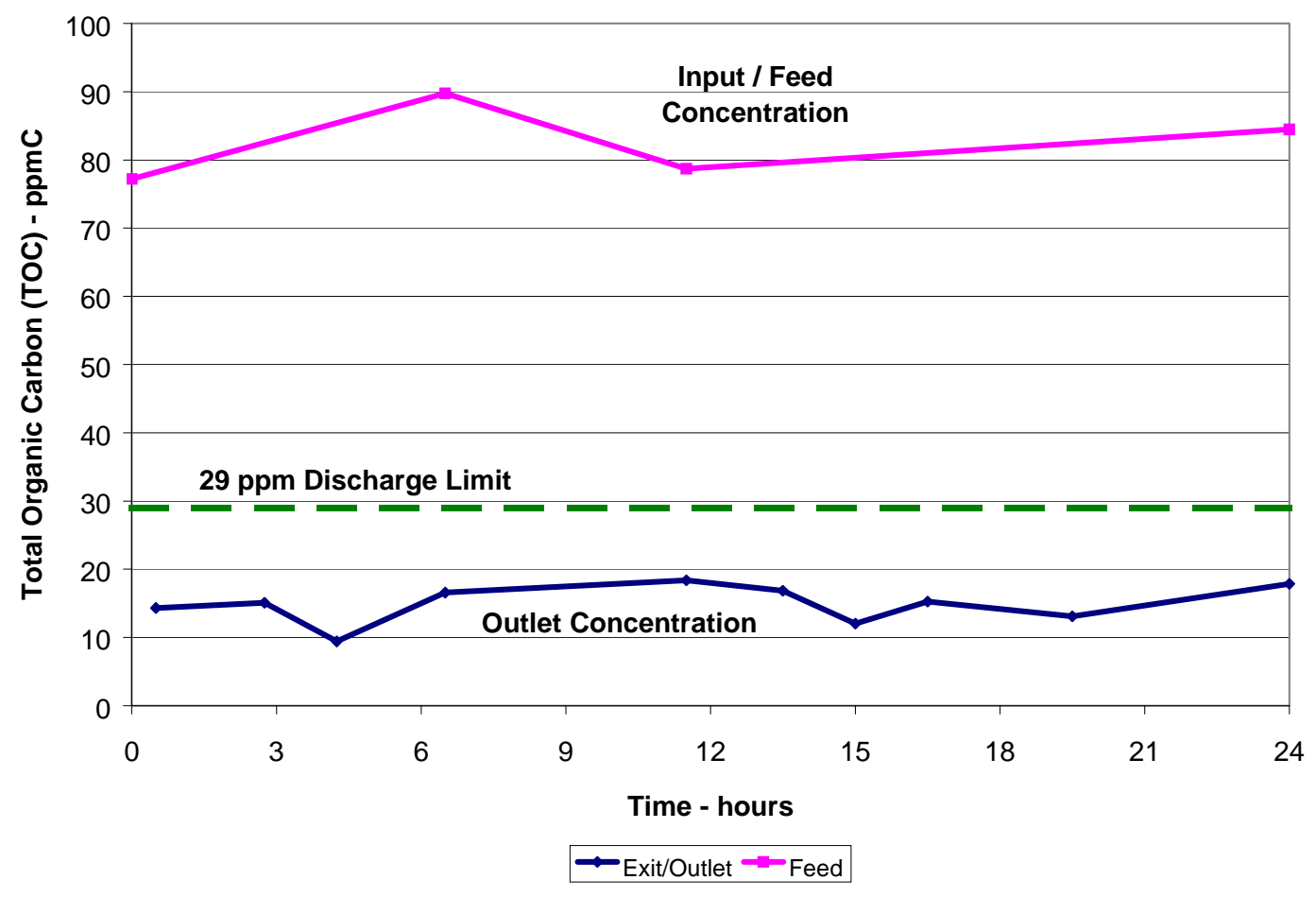

Fig. 5.2-TOC concentration of the produced water entering and exiting the organoclay cell with respect to time.

TABLE 5.2-TOC CONCENTRATION OF PRODUCED WATER ENTERING AND EXITING THROUGH THE ORGANOCLAY CELL.

\begin{tabular}{|l|c|c|c|c|}
\hline \multicolumn{1}{|c|}{ Sample } & $\begin{array}{c}\text { Time } \\
\text { (hours) }\end{array}$ & $\begin{array}{c}\text { TOC Concentration } \\
\text { (ppmC) }\end{array}$ & $\begin{array}{c}\text { Flow Rate } \\
\text { (ml/min) }\end{array}$ & $\begin{array}{c}\text { Resonance Time } \\
\text { (Contact Time) } \\
\text { (min) }\end{array}$ \\
\hline Outlet/Exit & & & & \\
\hline & $0: 00$ & & 35 & 4.29 \\
\hline OC-1 & $0: 30$ & 14.33 & 37 & 4.05 \\
\hline OC-2 & $2: 45$ & 15.06 & 36 & 4.17 \\
\hline OC-3 & $4: 15$ & 9.42 & 35 & 4.29 \\
\hline OC-4 & $6: 30$ & 16.58 & 35 & 4.29 \\
\hline OC-5 & $11: 30$ & 18.37 & 35 & 4.29 \\
\hline OC-6 & $13: 30$ & 16.88 & 35 & 4.29 \\
\hline OC-7 & $15: 00$ & 12.04 & 32 & 4.69 \\
\hline
\end{tabular}




\begin{tabular}{|l|c|c|c|c|}
\hline OC-8 & $16: 30$ & 15.26 & 33 & 4.55 \\
\hline OC-9 & $19: 30$ & 13.09 & 33 & 4.55 \\
\hline OC-10 & $24: 00$ & 17.85 & 33 & 4.55 \\
\hline \multicolumn{5}{|l|}{} \\
\hline Feed/Inlet & & 77.20 & & \\
\hline Feed 1 & $0: 00$ & 89.76 & & \\
\hline Feed 2 & $6: 30$ & 78.70 & & \\
\hline Feed 3 & $11: 30$ & 84.46 & & \\
\hline Feed 4 & $24: 00$ & & & \\
\hline
\end{tabular}

\subsubsection{1. $\quad \underline{\text { Conclusions }}$}

The produced water with 80 ppmC TOC hydrocarbon concentration was run through the ET-1 organoclay packed cell for 24 hours. During the 24 hour test period, the TOC concentration of the produced water at the outlet remained below $20 \mathrm{ppmC}$ TOC. The hydrocarbon removal efficiency of the ET-1 organoclay from the produced water was about $75 \%$. This suggests that the ET-1 organoclay is effective in taking out the organics from produced water when the resonance time is kept between 3-6 minutes.

There were about 20 ppmC TOC hydrocarbons still present in the produced water exiting the organoclay cell. To remove these hydrocarbons another container of organoclay should be used in series to remove the hydrocarbons to the minimum level.

\subsubsection{Screening of Membranes for the Removal of Hydrocarbons from Produced Water}

Produced water with hydrocarbon concentration of 110 ppmC TOC and 45,000 ppm TDS, was run through the selected membranes at their respective operating conditions. Hydrocarbon (TOC) concentrations in the produced water after being processed by the membranes and the corresponding percentage reduction in the TOC by the membranes are given in Fig. 5.3.

The three ceramic membranes, \#19, AH1347 and AH1373, were operated at an average trans-membrane pressure of 13.5 psi. Permeate obtained from the \#19 had a TOC concentration of about $93 \mathrm{ppmC}$, reducing the TOC concentration in the produced water by $15 \%$. AH1347 and AH1373 were able to reduce the hydrocarbon concentration of the produced water by about $20 \%$, giving TOC concentration of $89 \mathrm{ppmC}$ in the permeate. The amount of organics present in the produced water after passing through these membranes was still above the required maximum allowable discharge limit of 29 ppmC. 
FP100 and FP200 were operated at an average trans-membrane pressure of 42 psi. Both these membranes did not prove effective in removing the hydrocarbons from the produced water. FP100 and FP200 reduced the TOC content of the produced water to only 98 and 99 ppmC respectively.

AFC30 proved a little better in removing the hydrocarbons from the produced water. The hydrocarbon concentration of the produced water processed by AFC30 membrane had a TOC concentration of 68 ppmC, giving a rejection of about 38\%. The concentration of hydrocarbons in the produced water processed by AFC30 was still above the required maximum allowable value of 29 ppmC.

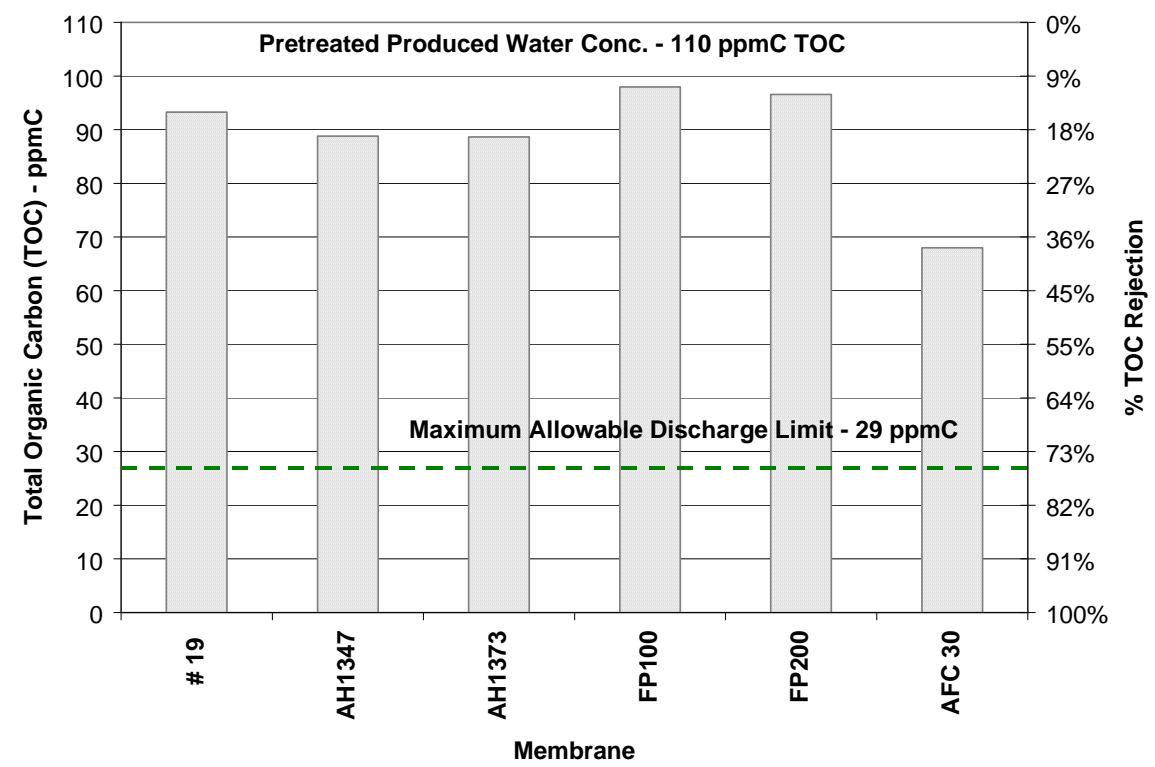

Fig. 5.3-Reduction in hydrocarbons from produced water by membranes.

Fig. 5.4 gives the concentration of the TDS in permeates obtained from the different membranes and the maximum salt rejection that could be obtained by these membranes at their respective operating parameters. The salt concentration of the produced water feed passed across the membranes was $45,000 \mathrm{ppm}$ in suspended and dissolved solids. Fig. 5.5 gives the flux obtained across different membranes at the maximum salt rejection by these membranes.

Permeate obtained from \# 19, AH1347, AH1373 microfiltration membranes and FP100 and FP200 ultrafiltration membranes reduced the salt concentration to 42,5000 ppm TDS, which is only about $5.5 \%$ salt rejection. This was as expected because these membranes are microfiltration and ultrafiltration membranes and were primarily tested for their efficiency in removing the hydrocarbons from the produced water. These membranes however were efficient in removing the suspended solids from the produced water. 


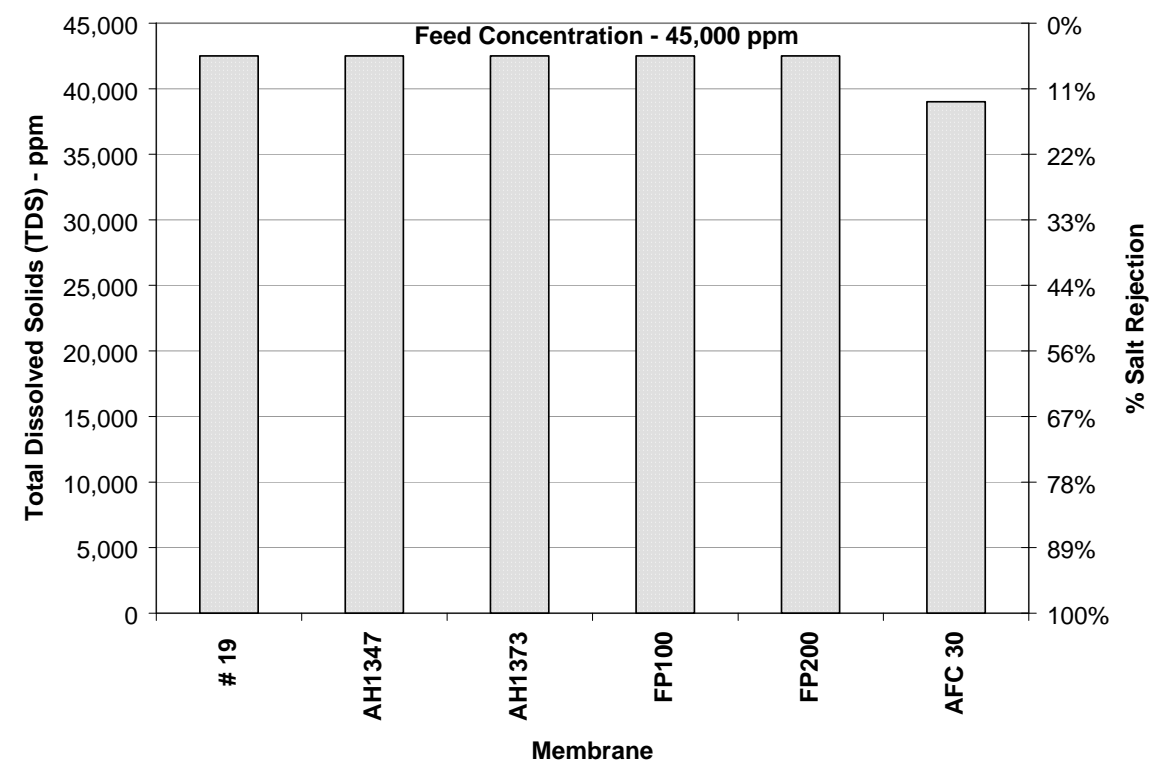

Fig. 5.4-Concentration of TDS in permeate of the selected membranes.

Table 5.3 gives the flux, hydrocarbon rejection and salt rejection across different membranes at their operating conditions. Although salt rejection from the produced water by FP100, FP200, \# 19, AH1347 and AH1373 membranes was quite similar and the TOC rejection levels varied a little, there was a big difference in the flux obtained across the membranes at these rejection levels. Flux across FP200 was the highest at 168 GFD (gal/ft ${ }^{2} /$ day). FP200 is the loosest membrane amongst all the membranes so this result is as expected

When the produced water fluxes across the three ceramic membranes are compared, (which are all same in size and have similar TOC rejections) it is observed that there exists a big difference in the flux across these membranes. Flux across \#19 membrane is about 133 GFD, which is the highest for the three ceramic membranes at same rejection levels, and same operating conditions as seen from Table 5.3. Flux across AH1347 is about 48 GFD and flux across AH1373 is about 66 GFD, which are about one third and half as compared to the flux across \#19 membrane. This shows that the salt rejection and the TOC rejection of by different membranes can be quite similar but the flux across the membrane can be very different from one membrane to the other. 


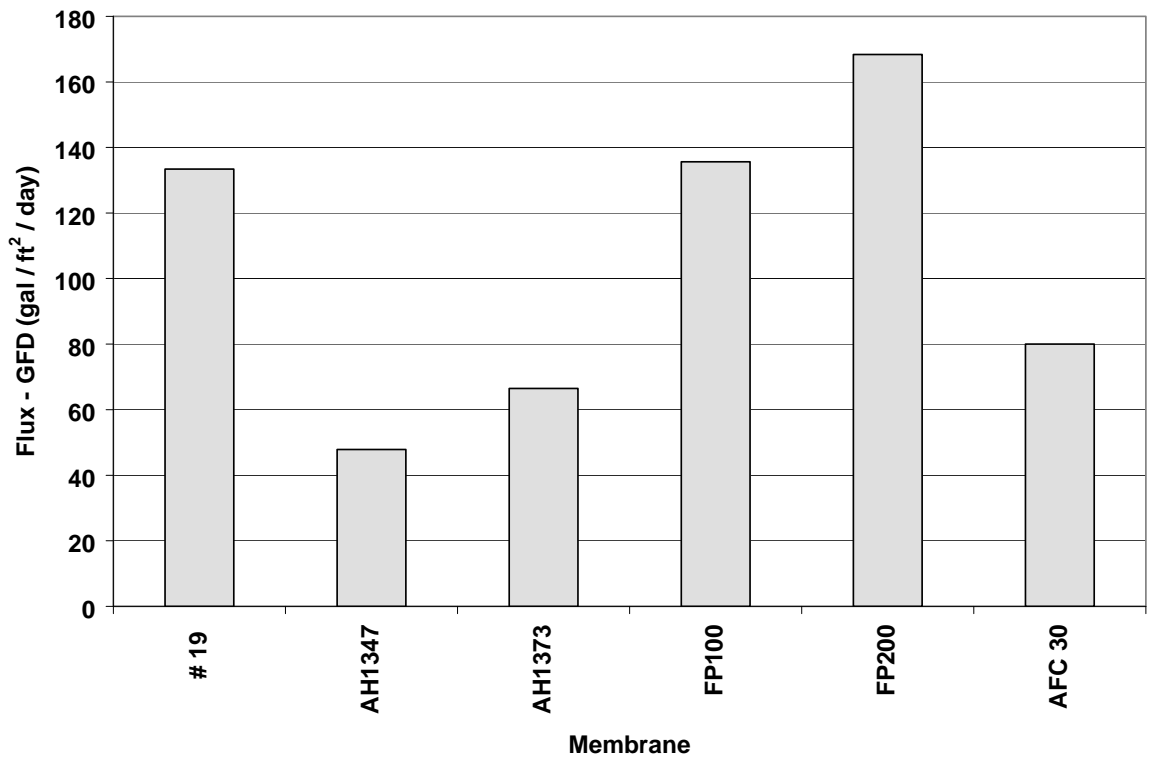

Fig. 5.5-Flux across membranes at their maximum operating pressures.

AFC30 reduced the TDS concentration of the produced water to only 39,000 ppm, which is about $13 \%$ salt rejection. Performance of AFC30 was not satisfactory as it was expected that AFC30 would remove more salts from the produced water, as it is a loose NF membrane. 


\begin{tabular}{|c|c|c|c|c|c|c|}
\hline \multicolumn{7}{|c|}{$\begin{array}{l}\text { TABLE 5.3-FLUX, HYDROCARBON AND SALT REJECTION ACROSS SELECTED } \\
\text { MEMBRANES. } 110 \text { PPMC TOC AND 45,000 PPM TDS PRODUCED WATER. FLUX } \\
\text { NORMALIZED @ } 95^{\circ} \mathrm{F} .\end{array}$} \\
\hline Membrane & $\begin{array}{l}\text { Operating } \\
\text { Pressure } \\
\text { (psi) }\end{array}$ & $\begin{array}{c}\text { Flux } \\
\text { GFD } \\
\text { (gal//ft'/day) }\end{array}$ & $\begin{array}{l}\text { Total } \\
\text { Dissolved } \\
\text { Solids (TDS) } \\
\quad(p p m)\end{array}$ & $\begin{array}{c}\% \text { Salt } \\
\text { Rejection }\end{array}$ & $\begin{array}{c}\text { TOC } \\
\text { (ppmC) }\end{array}$ & $\begin{array}{c}\% \text { TOC } \\
\text { Rejection }\end{array}$ \\
\hline \# 19 & 13.5 & 140.413 & 42,500 & $5.56 \%$ & & \\
\hline \# 19 & 13.5 & 133.392 & 42,500 & $5.56 \%$ & 93 & $15.18 \%$ \\
\hline $\mathrm{AH} 1347$ & 13.5 & 47.841 & 42,500 & $5.56 \%$ & & \\
\hline $\mathrm{AH} 1347$ & 13.5 & 47.841 & 42,500 & $5.56 \%$ & 89 & $19.29 \%$ \\
\hline $\mathrm{AH} 1373$ & 13.5 & 66.445 & 42,500 & $5.56 \%$ & & \\
\hline $\mathrm{AH} 1373$ & 13.5 & 66.445 & 42,500 & $5.56 \%$ & 89 & $19.43 \%$ \\
\hline FP100 & 42 & 156.317 & 42,500 & $5.56 \%$ & & \\
\hline FP100 & 42 & 135.605 & 42,500 & $5.56 \%$ & 98 & $10.95 \%$ \\
\hline FP200 & 42 & 161.054 & 42,500 & $5.56 \%$ & 93 & $15.45 \%$ \\
\hline FP200 & 42 & 168.337 & 42,500 & $5.56 \%$ & 97 & $12.22 \%$ \\
\hline AFC 30 & 310 & 77.106 & 39,000 & $13.33 \%$ & 56 & $48.92 \%$ \\
\hline AFC 30 & 310 & 74.037 & 39,000 & $13.33 \%$ & 67 & $39.10 \%$ \\
\hline AFC 30 & 510 & 93.521 & 39,000 & $13.33 \%$ & 73 & $33.43 \%$ \\
\hline AFC 30 & 510 & 79.985 & 39,000 & $13.33 \%$ & 68 & $38.21 \%$ \\
\hline AFC 30 & 510 & 72.368 & 39,000 & $13.33 \%$ & & \\
\hline
\end{tabular}

\subsubsection{1. $\quad$ Conclusions}

Produced water with hydrocarbon concentration of 110 ppmC TOC and 45,000 ppm TDS, was run through the selected membranes at their respective operating conditions. The amount of organics present in the produced water after passing through \# 19, AH1347, AH1373, FP100 and FP200 and AFC30 membranes was above the required maximum allowable discharge limit of 29 ppmC. Hence these membranes were ineffective in reducing the hydrocarbon concentration in the produced water to the required level.

Salt rejection across AFC30 was not as expected although it is a loose nanofiltration membrane. Although salt rejection from the produced water by FP100, FP200, \# 19, AH1347 and AH1373 membranes was quite similar (about 42,5000 ppm TDS, 5.5\% salt rejection) and the TOC rejection levels varied a little, there was a big difference in the flux obtained across the membranes at these rejection levels. This shows that the salt rejection and the TOC rejection of by different membranes can be quite similar but the flux across the membrane can be very different from one membrane to the other. This is one of the reasons why proper selection of the membrane is a difficult procedure. 
Based on the experimental results it was decided not to use any of the selected membranes for the removal of hydrocarbons from the produced water. It was decided that the hydrocarbons should be removed from the produced water using a combination of organoclay with one of the other oil/water separation techniques discussed literature review section for the pilot treatment unit.

Although there have been developments in the removal of hydrocarbons from produced water by membranes and new membranes are available for this purpose, but the costs associated with the use of these new membranes does not justify the use of these membranes for this project. The use of these membranes for the removal of hydrocarbons is justified by the volumes of produced water to be processed and other operational limitations such as weight of equipment, footprint of equipment, etc.

\section{Desalination of Produced Water}

\subsubsection{Screening of Membranes for Desalination of Produced Water}

TDS concentration in permeates obtained from the different membranes and the maximum salt rejection that could be obtained by these membranes at their respective operating parameters is presented in Fig. 5.6. Salt concentration of the produced water feed passed across the membranes was 45,000 ppm TDS. Flux obtained across different membranes at the maximum salt rejection by these membranes is given in Fig. 5.7. 


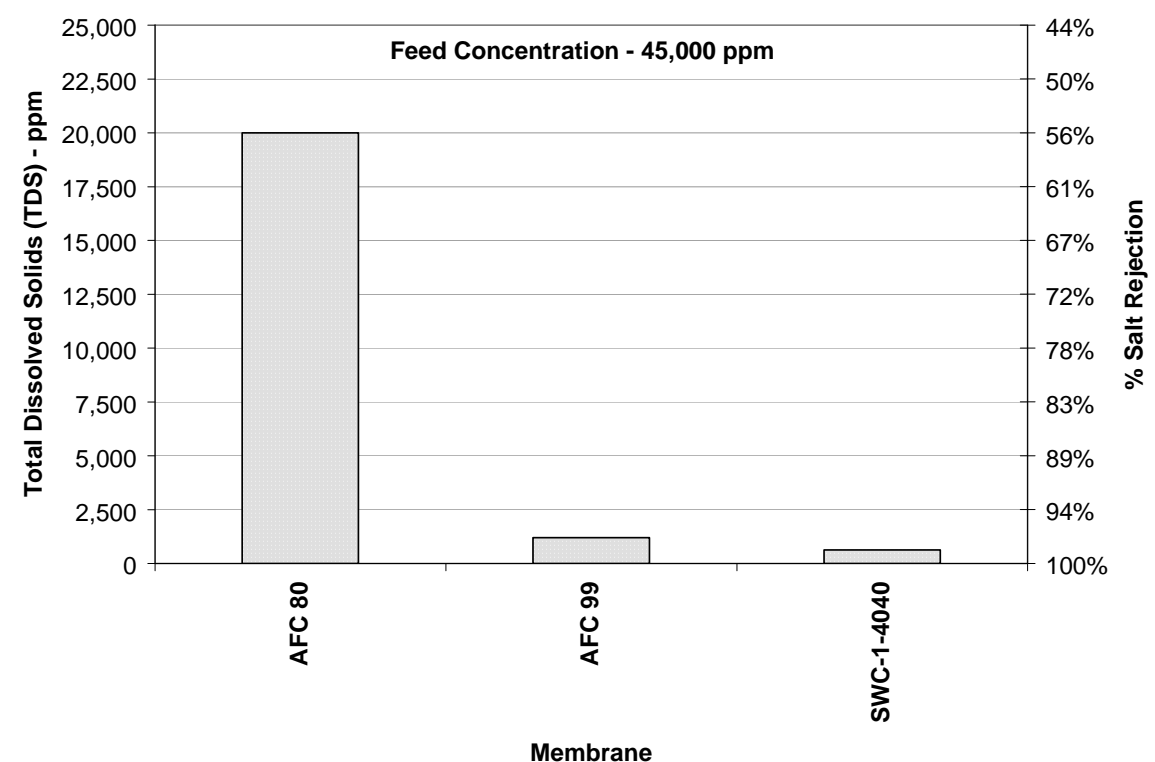

Fig. 5.6-Salt rejection by membranes.

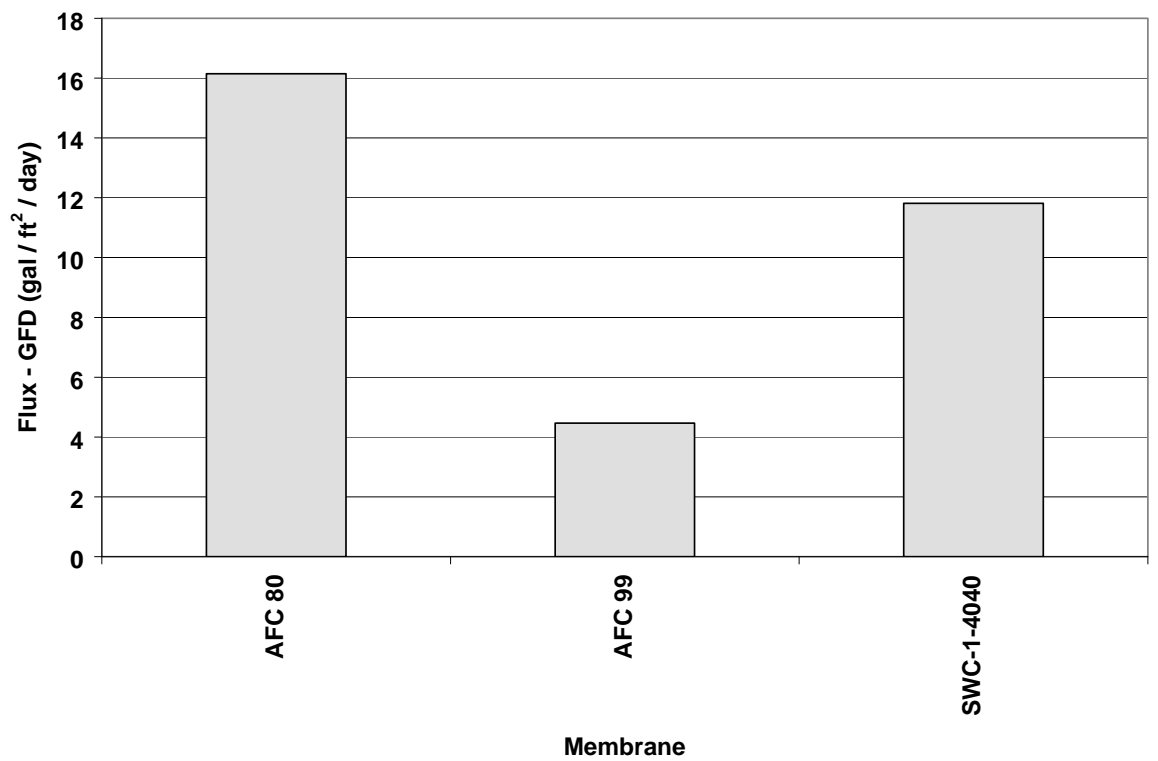

Fig. 5.7-Flux across membranes at maximum salt rejection.

Flux, TOC rejection and salt rejection across different membranes at their operating conditions at their operating conditions are presented in Table 5.4. Permeate obtained from AFC80 membrane had 20,000 ppm TDS concentration, which gave about 55\% 
reduction in dissolved solids in the permeate of the produced water. Maximum reduction in the TDS concentration of the produced water by AFC99 membrane was $97.4 \%$, giving salt concentration of about 1100 ppm TDS in the permeate. SWC-1-4040 membrane was able to give the best salt rejection amongst all the membranes. SWC-1-4040 was able to reduce the salt concentration of the produced water to about $630 \mathrm{ppm}$ TDS, giving $98.4 \%$ salt rejection.

The salt rejection by AFC99 was satisfactory and according to the membrane specifications, but it was observed that the flux across AFC99 dropped significantly in short time as the produced water was processed through the membrane, as shown in Table 5.4. This showed that there might be fouling problems associated with AFC99. Flux obtained at an operating pressure of 800 psi across AFC99 and SWC-1-4040 was about 5 GFD and 11.5 GFD respectively. This showed that not only the salt rejection by SWC-1-4040 was better but also the flux obtained across SWC-1-4040 was nearly twice that of AFC99.

The salt rejection by AFC 80 was 55\% and about $98 \%$ by SWC-1-4040 at operating pressure of 800 psi. This shows a difference of about $40 \%$ salt rejection between these two membranes. At the same pressure the flux across AFC80 was about 16 GFD and 11.5 GFD across SWC-1-4040, which shows that the flux across SWC-1-4040 was about 30\% less than AFC80. This comparison shows that although the difference in salt rejection between the two membranes is almost twice, the difference in flux across these membranes is only $30 \%$ at the same operating conditions.

AFC80, AFC99 and SWC-1-4040 membranes proved to be the most effective in removing the hydrocarbons from the produced water. Hydrocarbon concentration in permeate of different membranes is shown in Fig. 5.8. All of these membranes reduced the hydrocarbon content of the produced water to below the maximum allowable TOC discharge limit of 29 ppmC. AFC80 and AFC99 lowered the TOC concentration of the produced water to $4 \mathrm{ppmC}$ and $10 \mathrm{ppmC}$, while SWC-1-4040 reduced the organics to 2 ppmC TOC. This gave TOC reduction of about 96\% for AFC80, 90\% for AFC99 and 98\% for SWC-1-4040. AFC99 and SWC-1-4040 membranes are not intended for the removal of hydrocarbons from the produced water. They are desalination membranes and are designed for the removal of dissolved solids from the produced water.

\begin{tabular}{|c|c|c|c|c|c|c|}
\hline \multicolumn{7}{|c|}{$\begin{array}{l}\text { TABLE 5.4-FLUX, SALT AND TOC REJECTION ACROSS SELECTED } \\
\text { MEMBRANES. } 110 \text { PPMC TOC AND 45,000 PPM TDS PRODUCED WATER. FLUX } \\
\text { NORMALIZED @ } 95^{\circ} \mathrm{F} .\end{array}$} \\
\hline Membrane & $\begin{array}{l}\text { Operating } \\
\text { Pressure } \\
\text { (psi) }\end{array}$ & $\begin{array}{c}\text { Flux } \\
\text { GFD } \\
\text { (gal/ft' } / \text { day) }\end{array}$ & $\begin{array}{l}\text { Total } \\
\text { Dissolved } \\
\text { Solids (TDS) } \\
\text { (ppm) }\end{array}$ & $\begin{array}{c}\% \text { Salt } \\
\text { Rejection }\end{array}$ & $\begin{array}{c}\text { TOC } \\
\text { (ppmC) }\end{array}$ & $\begin{array}{c}\% \text { TOC } \\
\text { Rejection }\end{array}$ \\
\hline AFC 80 & 310 & 8.139 & 16,000 & $64.44 \%$ & 64 & $41.45 \%$ \\
\hline AFC 80 & 310 & 7.404 & 17,000 & $62.22 \%$ & 44 & $59.89 \%$ \\
\hline
\end{tabular}


Burnett \& Siddiqui. “Recovery of Fresh Water Resources

\begin{tabular}{|c|c|c|c|c|c|c|}
\hline AFC 80 & 510 & 13.638 & 11,500 & $74.44 \%$ & 22 & $79.59 \%$ \\
\hline AFC 80 & 510 & 14.854 & 13,000 & $71.11 \%$ & 25 & $77.39 \%$ \\
\hline AFC 80 & 510 & 13.331 & & & & \\
\hline AFC 80 & 790 & 15.235 & & & & \\
\hline AFC 80 & 810 & 16.147 & 20,000 & $55.56 \%$ & 4 & $96.36 \%$ \\
\hline AFC 80 & 810 & 18.092 & & & & \\
\hline AFC 80 & 790 & 15.827 & 25,000 & $44.44 \%$ & 5 & $95.45 \%$ \\
\hline AFC 80 & 810 & 15.827 & & & 2 & $98.18 \%$ \\
\hline AFC 80 & 810 & 15.651 & & & & \\
\hline AFC 99 & 790 & 8.189 & & & & \\
\hline AFC 99 & 790 & 7.848 & & & & \\
\hline AFC 99 & 810 & 8.468 & 1,100 & $97.56 \%$ & 10 & $90.91 \%$ \\
\hline AFC 99 & 810 & 5.866 & & & & \\
\hline AFC 99 & 790 & 4.469 & 1,200 & $97.33 \%$ & 4 & $96.36 \%$ \\
\hline AFC 99 & 810 & 4.469 & & & 4 & $96.00 \%$ \\
\hline AFC 99 & 810 & 4.051 & & & & \\
\hline SWC-1-4040 & 550 & 4.047 & 1,400 & $96.89 \%$ & 2 & $98.18 \%$ \\
\hline SWC-1-4040 & 550 & 3.913 & 1,260 & $97.20 \%$ & 2 & $98.18 \%$ \\
\hline SWC-1-4040 & 700 & 8.695 & 770 & $98.29 \%$ & 2 & $98.18 \%$ \\
\hline SWC-1-4040 & 800 & 11.816 & 630 & $98.60 \%$ & 2 & $98.18 \%$ \\
\hline
\end{tabular}

\subsubsection{1. $\quad \underline{\text { Conclusions }}$}

The selection of the membranes for the treatment of the produced water is not an easy process. Membranes that give high flux may not give high salt rejection or hydrocarbon rejection. Similarly membranes that have high salt rejection characteristics have a low flux. Also membranes that give high salt rejections may not give high hydrocarbon rejection. 


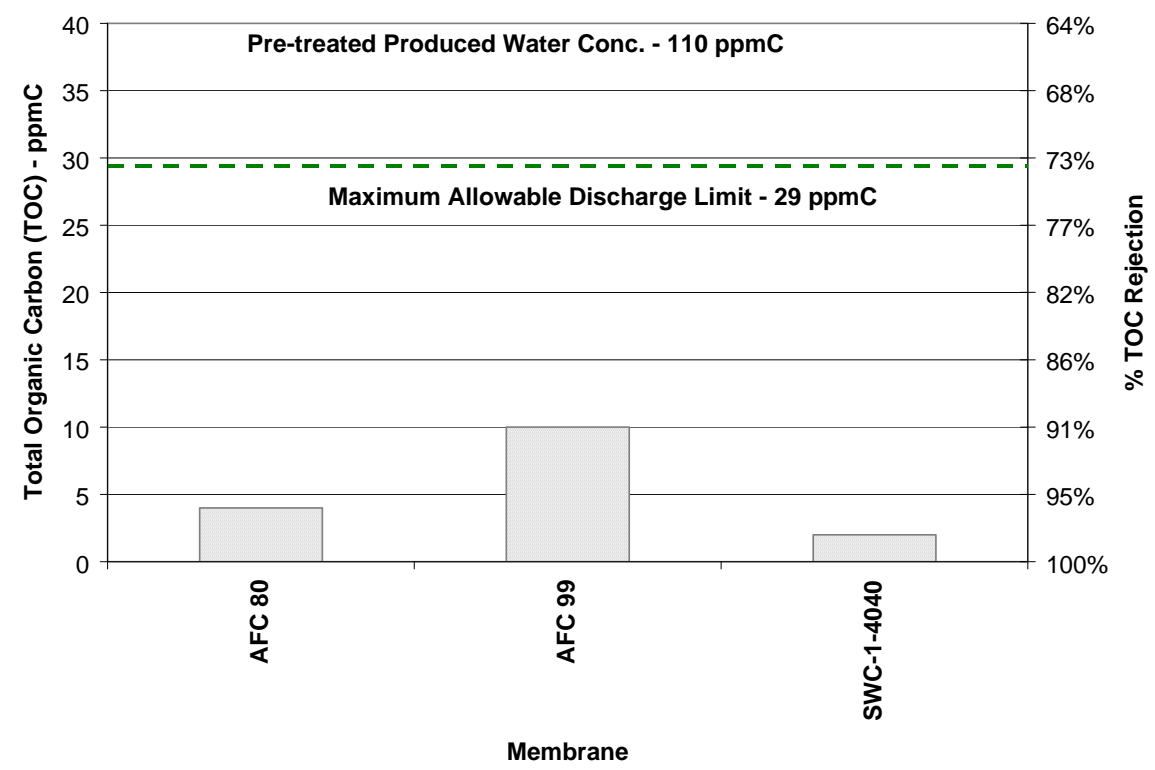

Fig. 5.8-Hydrocarbon concentration in permeate of AFC80, AFC99 and SWC-14040 membranes.

Flux obtained across AFC80 membrane was very small compared to the salt rejection by the membrane. This flux would have been acceptable if the salt rejection by AFC80 was higher. AFC80 was able to remove the hydrocarbons concentration below the maximum allowable discharge limit of 29 ppmC TOC.

Salt rejection by AFC99 membrane was according to the membrane specifications but the flux across the membrane was very low. AFC99 was able to remove the organics from the produced water below the required levels. However AFC99 showed problems with handling the produced water with hydrocarbons in it, as it was seen that the flux across AFC99 decreased very quickly over a short period of time, showing that it had fouling problems.

SWC-1-4040 gave the best salt rejection characteristics and a good flux at the same time. Hydrocarbon removal efficiency of SWC-1-4040 very good as it was able to remove the organics from the produced water below the maximum allowable limit of 29 ppmC TOC. At the same time SWC-1-4040 membrane did not show any severe fouling problems during the screening process as AFC99 did.

AFC80, AFC99 and SWC-1-4040 are all desalination membranes and not meant for the removal of organics. The reason for running organics through these membranes was to establish that if there was a system upset or breakdown, would these membranes be able 
to handle the organics without any damage to the membranes and not pass any organics in the permeate.

Based on the results of the membrane screening experiments it was decided to use SWC1-4040 for the desalination of produced water and further tests were performed on this membrane.

\subsubsection{Experiments With SWC-1-4040 Membrane for the Desalination of Produced Water}

SWC-1-4040 membrane was selected for further tests for the desalination of produced water to agricultural water quality standards based on the results discussed in previous section. A standard commercial 4x40 membrane element (4 inch diameter and 40 inches long) was chosen for experiments so that the results obtained from the experiments could easily be scaled up to actual field test unit.

After the screening and reviewing the performances of selected membranes in removing dissolved solids and organics, as discussed earlier, SWC-1-4040 was selected for further tests for the desalination of produced water. Other key criteria in the selection of SWC-14040, over other competing membranes of different companies, were previous working knowledge and familiarity of the faculty and other industry professionals with Hydranautic products.

\subsubsection{1. $\quad$ Experiments with Clean Water}

Effect of pressure on flux with clean water at $8 \mathrm{gpm}$ feed flow rate is shown in Fig 5.9. The pressure was increased from 100 psi to 800 psi and then decreased. This was done thrice to see if there is any membrane compaction. As seen from the graphs that when the pressure was increased the first time (Run 1) the fluxes between 500 to 800 psi are more than when the pressure was increased the second and third time (Run 2 and Run 3). This shows that there was some initial membrane compaction during the first pressure increase run. This initial membrane compaction is normal when the membrane is used for the first time. During the $2^{\text {nd }}$ and $3^{\text {rd }}$ pressure increase runs the fluxes across the membrane were close to each other, at same pressures. This showed that there was no more membrane compaction.

Similar tests were done at $11 \mathrm{gpm}$ and $14 \mathrm{gpm}$ but the flux remained constant at any particular pressure, at constant flow rate. This again showed that there was no further membrane compaction and the membrane was acceptable for further testing.

The effect of pressure on flux of clean water across the SWC-1-4040 membrane is shown in Fig. 5.10. All fluxes were normalized to $95^{\circ} \mathrm{F}$. It can be seen from Fig. 5.10 that there is a linear relationship between the applied pressure and the flux. As the pressure is 
increased the flux across the membrane increases at constant flow rates of 8, 11 and 14 gpm. This is as expected. It was also observed that at any constant pressure, the flux decreased with increase in the feed flow rate across the membrane. The difference in the flux was more obvious at pressures higher than 500 psi. At pressures lower than 500 psi, the flux at a fixed pressure at constant flow rates of 8,11 and 14 gpm were very close to each other.

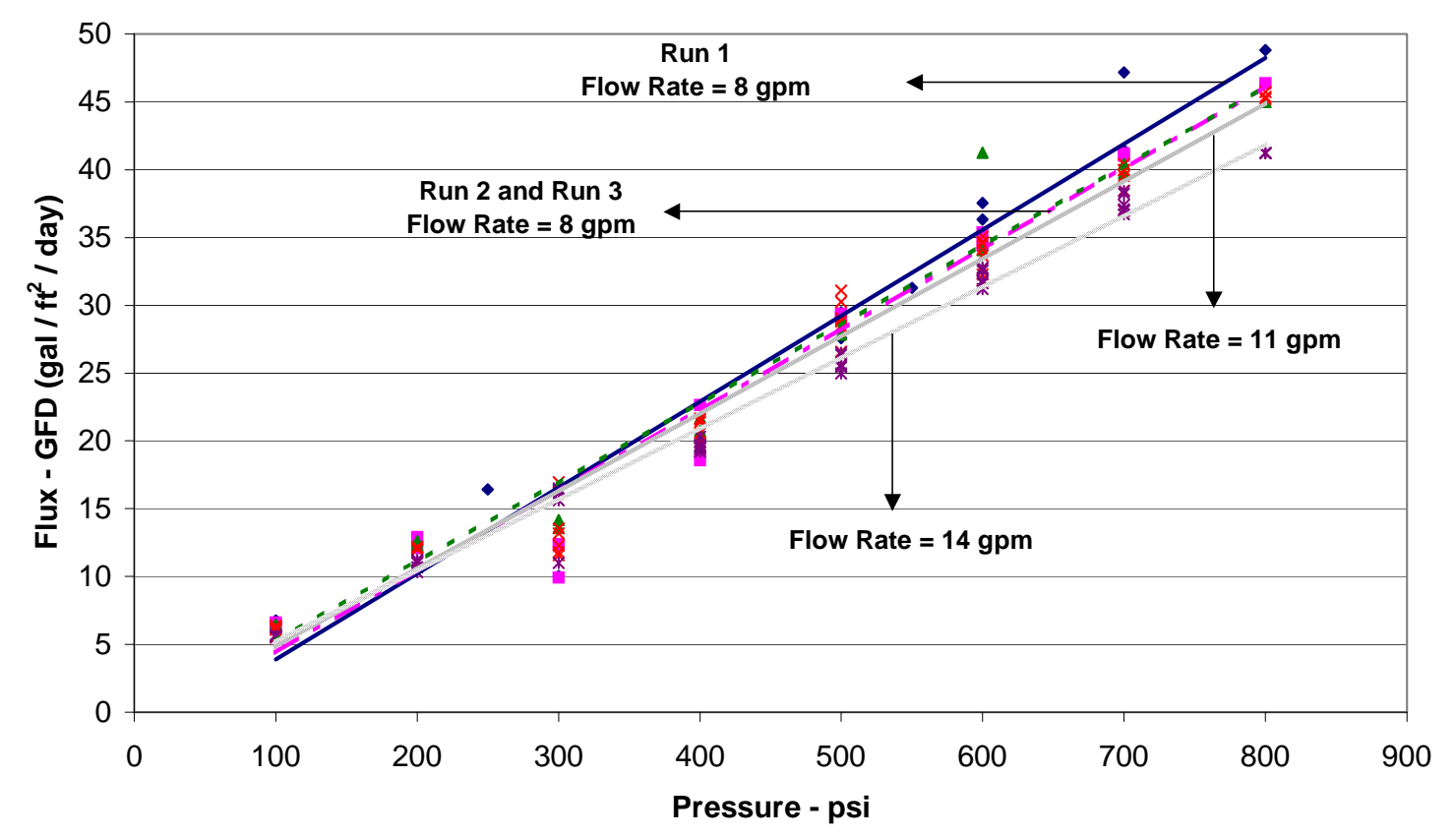

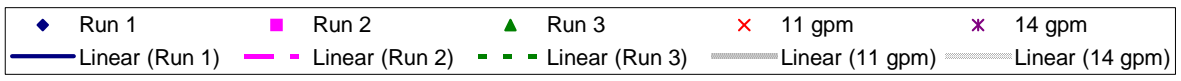

Fig 5.9-Effect of pressure on flux with clean water feed. (Feed flow rate $=8,11$ and 14 gpm. Run 1, Run 2 and Run 3 show the difference in flux at 8 gpm).

Percent recovery of clean water from the feed stream as the pressure is changed at constant flow rates of 8, 11 and 14 gpm is shown Fig. 5.11. Maximum recovery, corresponding to the maximum flux of approximately $47 \mathrm{GFD}$ (gal/ft ${ }^{2} /$ day) at a flow rate of 8 gpm and 800 psi pressure, is about $28.0 \%$. At any fixed pressure as the flow rate was increased the recovery decreased. The difference in amount of recovery between 8,11 and 14 gpm flow rates (at a fixed pressure) increased for pressures higher than 500 psi. 


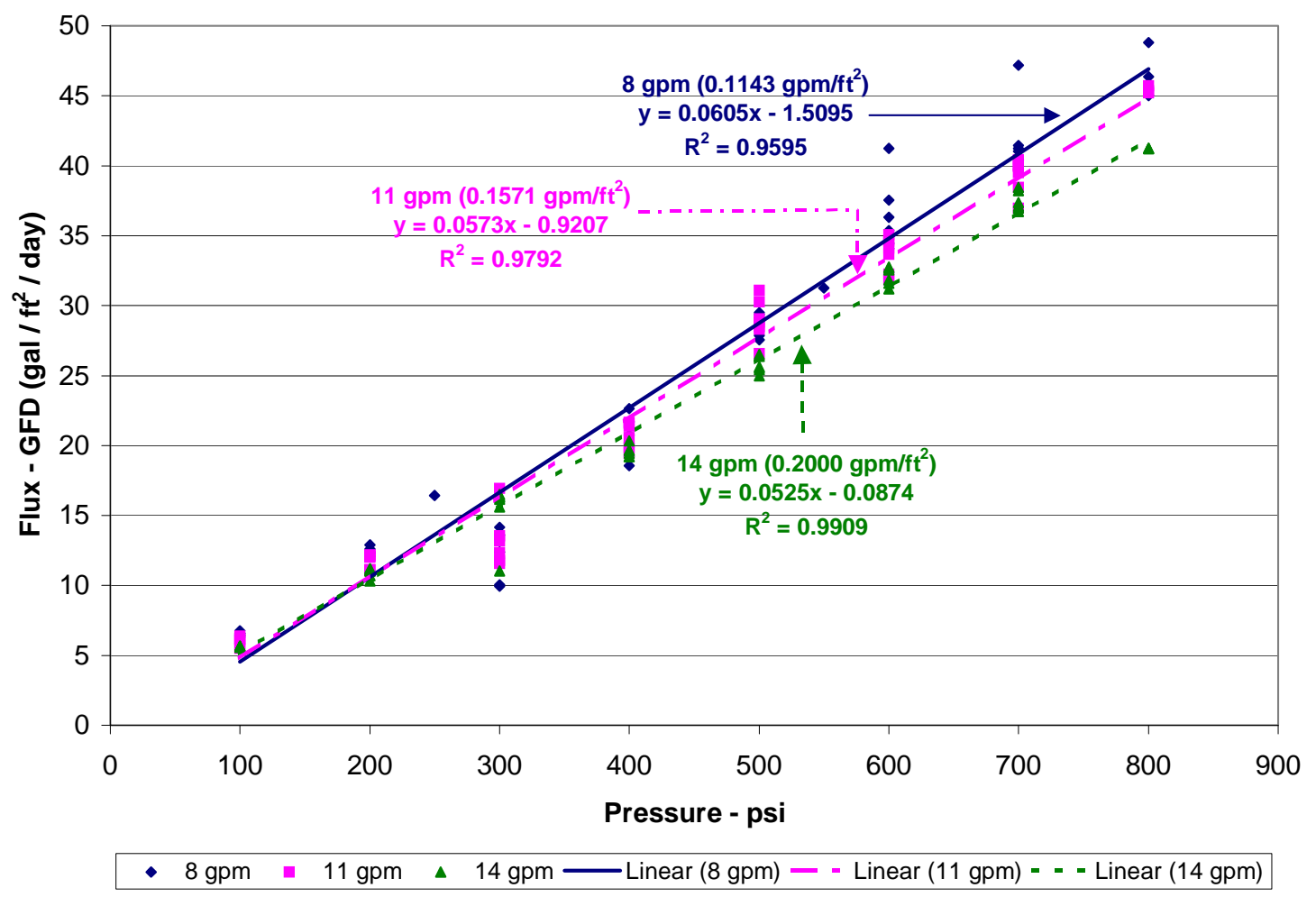

Fig. 5.10-Effect of pressure on flux with clean water feed. (Feed flow rate $=8,11$ and 14 gpm. Flux normalized @ 95 F).

Membrane resistance at a constant flow rates is found from the linear relationship between pressure and flux. A straight line is plotted through the pressure vs. flux graph (Fig. 5.9) at a constant flow rate. The inverse of the slope of this line is the resistance of the membrane at that flow rate. Membrane resistances at 8, 11 and $14 \mathrm{gpm}$ flow rates are presented in Table 5.5. It is seen from the table that the membrane resistance increases as the feed flow rate across the membrane is increased. 


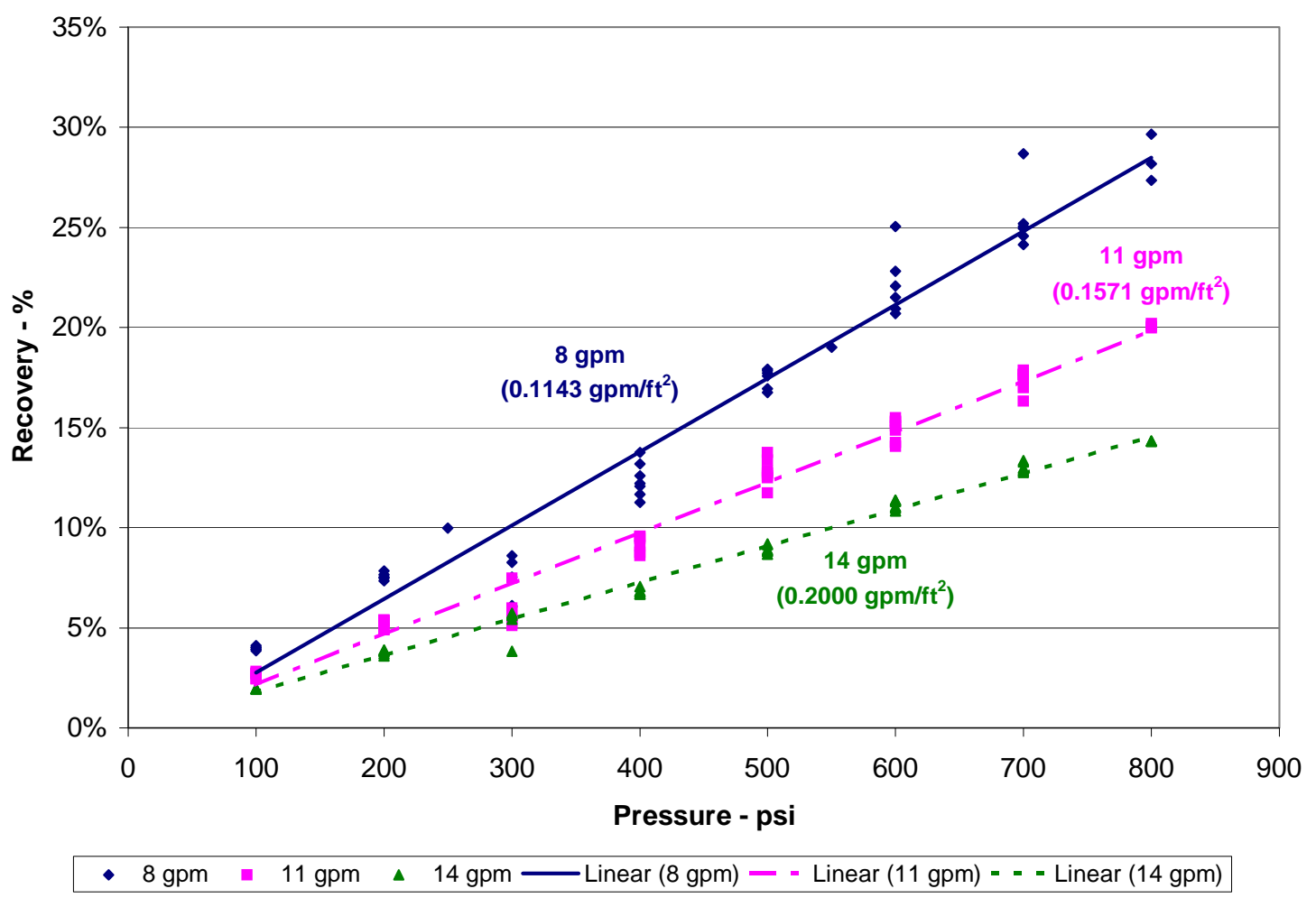

Fig 5.11-Effect of pressure on recovery with clean water feed. (Feed flow rate = 8, 11 and 14 gpm. Flux normalized @ 95 F).

TABLE 5.5-EFFECT OF FEED FLOW RATE ON MEMBRANE RESISTANCE.

\begin{tabular}{|c|c|c|}
\hline $\begin{array}{c}\text { Flow Rate } \\
\text { (gpm) }\end{array}$ & $\begin{array}{c}\text { Slope } \\
\text { (GFD/psi) }\end{array}$ & $\begin{array}{c}\text { Membrane Resistance } \\
\text { (psi/GFD) }\end{array}$ \\
\hline 8 & 0.0605 & 16.5289 \\
\hline 11 & 0.0573 & 17.4520 \\
\hline 14 & 0.0525 & 19.0476 \\
\hline
\end{tabular}

\subsubsection{2. $\quad$ Experiments With 15,000 ppm TDS Produced Water}

Results of the flux across the SWC-1-4040 membrane and the corresponding recovery at the selected flow rates, rates as the pressure was varied are presented in Fig. 5.12 and Fig. 5.13. It is seen that the flux as well as the recovery at $8 \mathrm{gpm}$ flow rate is the highest at any fixed pressure. The flux and recovery, at any constant pressure, at $11 \mathrm{gpm}$ flow rate is lower than at $8 \mathrm{gpm}$, and at $14 \mathrm{gpm}$ flow rate the flux and the recovery is the least. 
Burnett \& Siddiqui. “Recovery of Fresh Water Resources

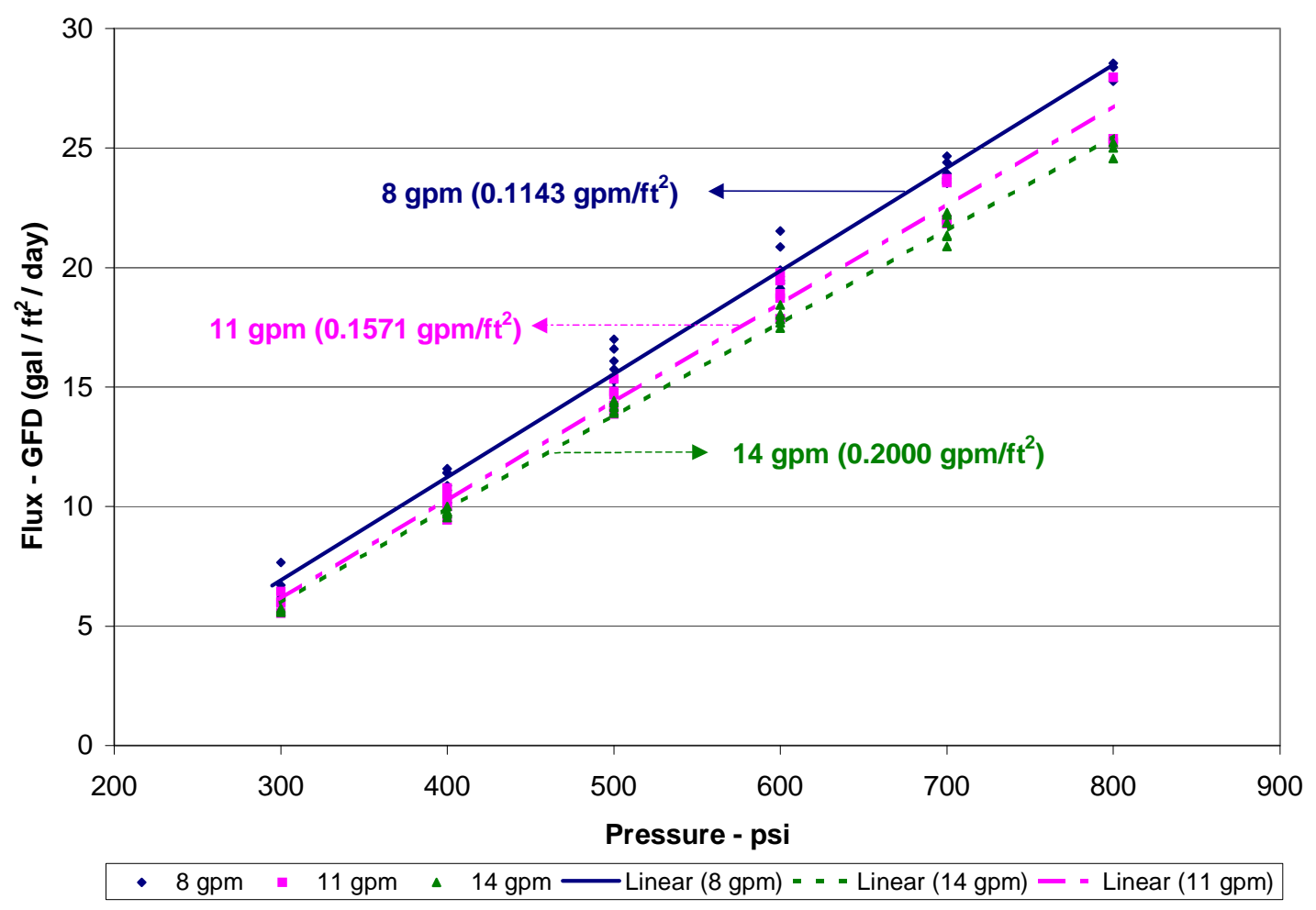

Fig. 5.12-Effect of pressure on flux with 15,000 ppm TDS produced water feed.

(Feed flow rate = 8, 11 and 14 gpm. Flux normalized @ 95 F). 
From Fig. 5.12 and Fig. 5.13 it is seen that the flux and recovery at the selected flow rates of 8,11 and 14 gpm increased linearly with the increase in pressure. This shows a linear relationship between pressure and flux and, pressure and recovery. The maximum permeate flux obtained across the membrane was about $28 \mathrm{GFD}$ (gal/ $\mathrm{ft}^{2} / \mathrm{day}$ ) corresponding to $17.0 \%$ recovery at a pressure of 800 psi and 8 gpm feed flow rate. Maximum flux obtained at $11 \mathrm{gpm}$ was $26.5 \mathrm{GFD}$ and at $14 \mathrm{gpm}$ was $25 \mathrm{GFD}$ at a pressure of 800 psi. These fluxes correspond to about $11 \%$ and $8 \%$ recovery respectively.

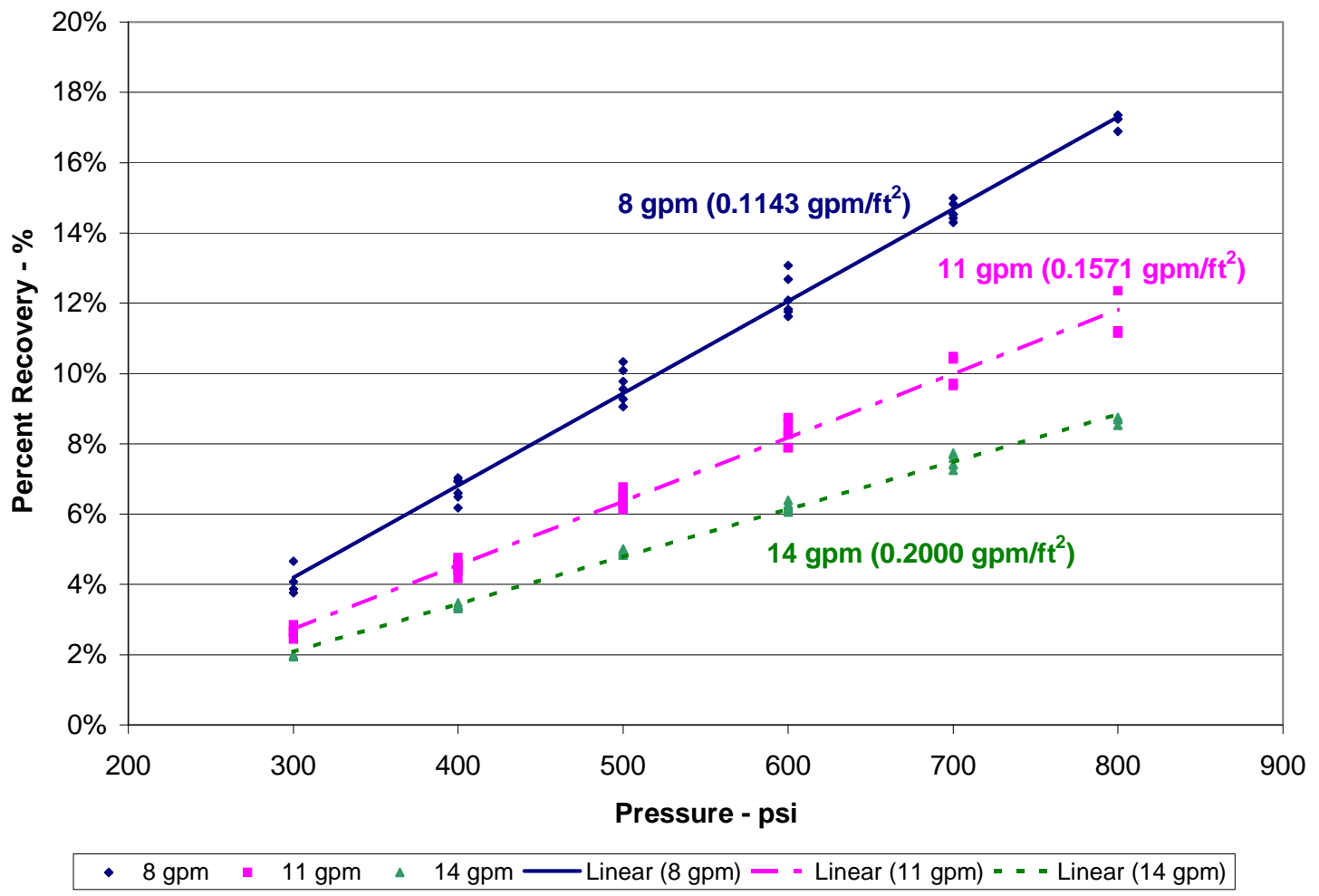

Fig. 5.13-Effect of pressure on recovery with 15,000 ppm TDS produced water feed.

(Feed flow rate = 8, 11 and 14 gpm. Recovery normalized @ 95 F). 
The difference in flux was 5.5\% between $8 \mathrm{gpm}$ and $11 \mathrm{gpm}$ flow rates (at $800 \mathrm{psi}$ ) and the corresponding difference in recovery was about 6\%. Similarly the difference in flux was $5.5 \%$ and recovery was $3.0 \%$ between $11 \mathrm{gpm}$ and $14 \mathrm{gpm}$ flow rates (at $800 \mathrm{psi}$ ). It is seen that the difference in flux and recovery at 8, 11 and 14 gpm flow rates, at a constant pressure, decreases as the pressure is decreased from 800 psi to 300 psi. It was observed that at 300 psi the flux at all the flow rates was the nearly the same, and the difference in the recoveries was relatively small.

The concentration of salts (dissolved solids) in the permeate determine the quality of water and the purposes it can be used. Texas Commission on Environmental Quality (TCEQ) defines fresh water for agricultural standards as "water having less than 500 ppm of dissolved solids". The aim of this project was to obtain permeate of fresh water quality standard. The efficiency of reverse osmosis is determined by the amount of dissolved solids rejected from the feed by the membrane and passing to the permeate. The effect of the pressure on amount of salts present in the permeate and percent salt rejection by the membrane at the selected feed flow rates of 8, 11 and 14 gpm is shown in Fig. 5.14.

It is seen from Fig. 5.14 that as the pressure is increased the amount of salt concentration in the permeate decreases at all flow rates. Maximum salt rejection achieved is about 99.4\%at 800 psi at 8 gpm flow rate. This corresponds to approximately 85 ppm TDS in the permeate at 800 psi and 8 gpm. Similarly at 11 and 14 gpm flow rate and 800 psi pressure, the TDS present in the permeate is less than 95 ppm with more than $99.3 \%$ salt rejection by the membrane.

The fact that the TDS concentration in the permeate of $8 \mathrm{gpm}$ is lower than the salt concentration in the permeate of 11 and 14 gpm flow rates, at constant pressure, is due to the fact that the water flow rate (permeate rate) across the membrane, hence the flux, is highest for $8 \mathrm{gpm}$ feed flow rate. The same is true if permeate of $11 \mathrm{gpm}$ is compared to permeate obtained at $14 \mathrm{gpm}$, at the same pressure. 


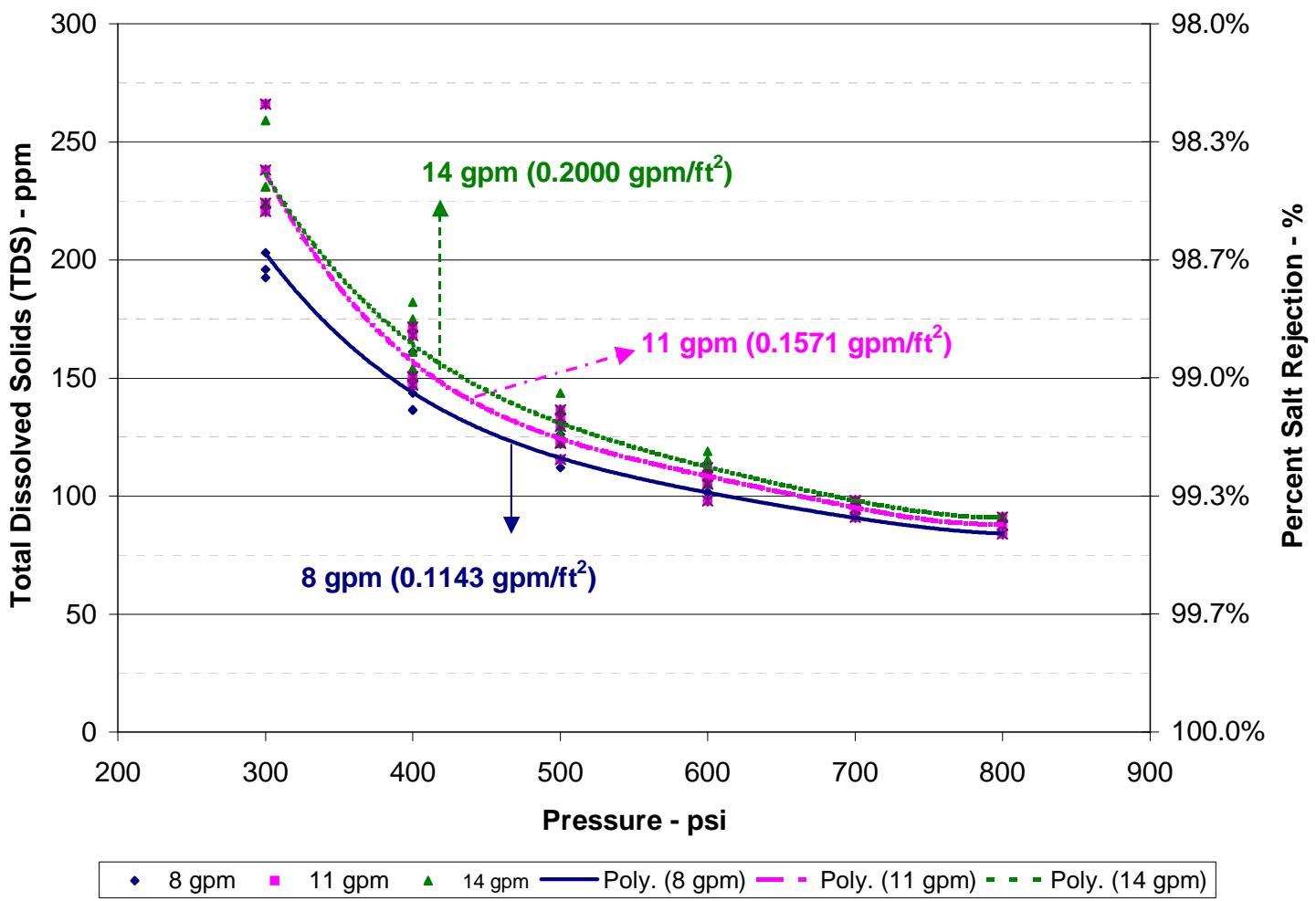

Fig. 5.14-Effect of pressure on total dissolved solids (TDS) in permeate with 15,000 ppm TDS produced water feed. (Feed flow rate $=8,11$ and $14 \mathrm{gpm}$ ).

It can be seen from Fig. 5.14 that the salt rejection increases with increase in pressure at any constant flow rate, which is as expected. As pressure is increased from 300 psi to 400 psi and then to 500 psi the difference in the amount of TDS in the permeate and the corresponding salt rejection is significant at all flow rates. When the pressure was increased from 500 psi to 800 psi, there was not a big difference in TDS concentration in the permeates and the corresponding salt rejections. The pressure vs. TDS and salt rejection curves starts to flatten out after 600 psi as seen from the Fig. 5.14.

Minimum salt rejection obtained across the membrane is $98.4 \%$ with TDS of about 250 ppm at 14 gpm flow rate and 300 psi pressure. Salt rejection and the TDS present in the permeated water for the selected flow rates of 8, 11 and 14 gpm and pressures between 300 and 800 psi, are between the minimum and maximum values of $98.4 \%$ and 250 TDS, and $99.4 \%$ and 85 TDS. The quality of all the permeated water at all the selected pressures and flow rates is within the fresh water quality standards i.e. less than 500 ppm TDS.

\subsubsection{3. $\quad$ Experiments With 30,000 ppm and 45,000 ppm TDS Produced Water}


The effect of pressure on flux across the SWC-1-4040 membrane at the selected flow rates of 8,11 and $14 \mathrm{gpm}$ for 30,000 ppm and 45,000 ppm TDS produced water is shown in Fig. 5.15. All fluxes were normalized to $95^{\circ} \mathrm{F}$. As the pressure was increased the flux as well as the recovery increased showing a linear relationship between pressure and flux and pressure and recovery, for both the 30,000 ppm and 45,000 ppm TDS produced water.

It is observed from Fig. 5.15 that for the 30,000 ppm TDS produced water, the flux was nearly the same (8.20 GFD) at 550 psi pressure for 8, 11 and $14 \mathrm{gpm}$ feed flow rates across the membrane. As the pressure was increased from 550 to 800 psi a slight difference in flux is observed between 8,11 and $14 \mathrm{gpm}$ flow rates. Flux at the maximum pressure of 800 psi for 8 gpm flow rate was 16.30 GFD, for 11 gpm the flux was 16.01 GFD, and for $14 \mathrm{gpm}$ the flux was 15.74 GFD.

Although there is not a significant difference in flux at 8, 11 and 14 gpm flow rates at a constant pressure, there however is a significant difference in the recoveries at these flow rates for the 30,000 ppm TDS produced water. At 550 psi and 8 gpm the recovery is $5.0 \%$, while at the same pressure but 11 gpm flow rate the recovery is $3.6 \%$ and only $2.8 \%$ recovery at $14 \mathrm{gpm}$ flow rate. The difference in recoveries at constant pressure increased for different flow rates at higher flow rates. Recovery was $9.9 \%$ at 800 psi and $8 \mathrm{gpm}$ flow rate, which was the highest. For $11 \mathrm{gpm}$ flow rate recovery was $7.1 \%$, while for 14 gpm flow rate the recovery was $5.5 \%$ at 800 psi pressure. 


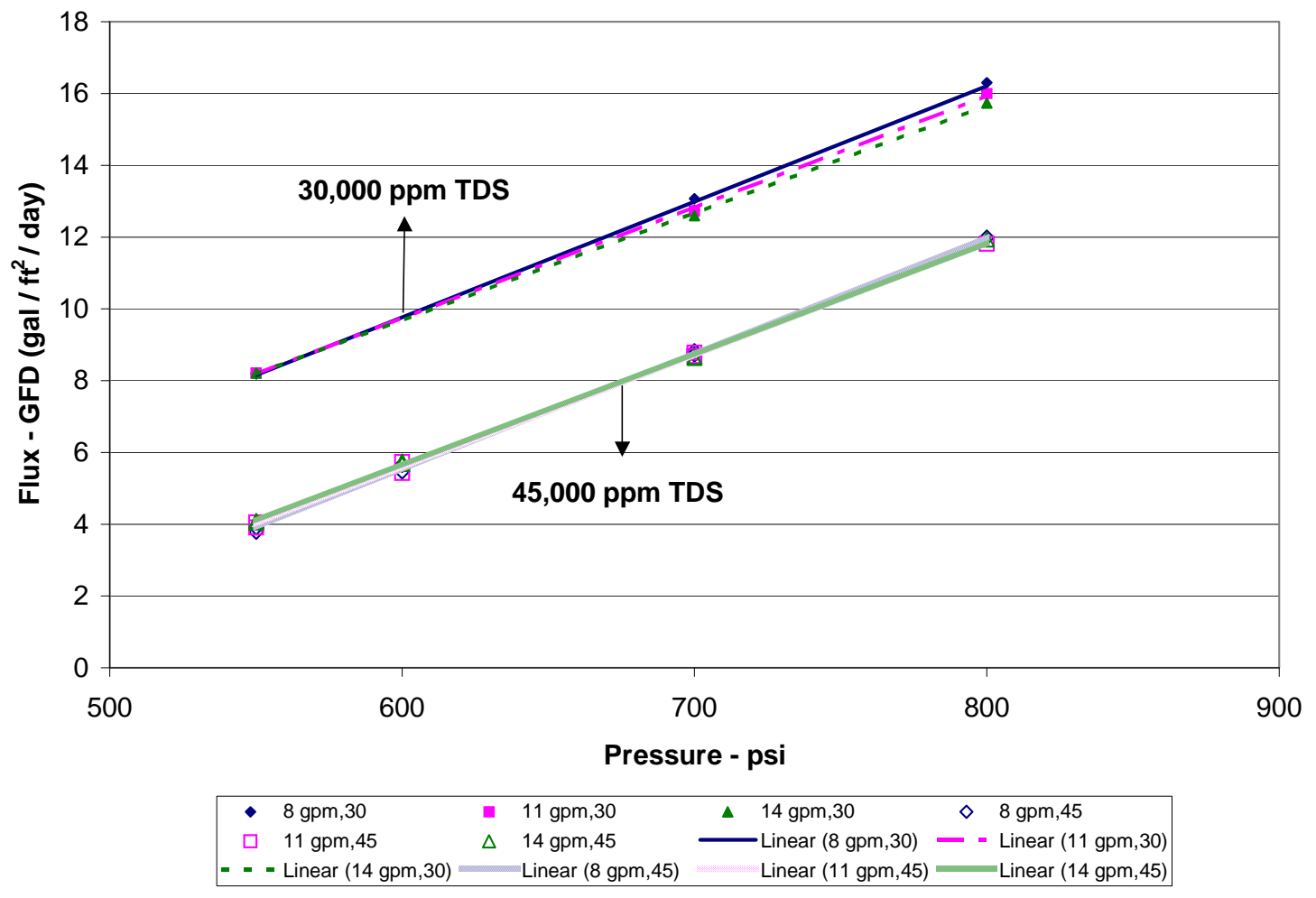

Fig. 5.15-Effect of pressure on flux with 30,000 and 45,000 ppm TDS produced water feed. (Feed flow rate = 8, 11 and 14 gpm. Flux normalized @ 95%).

From Fig. 5.16 it is seen that for the 45,000 ppm TDS produced water the flux remains identical at all the selected flow rates at any fixed pressure. Minimum flux was about 4.0 GFD at 550 psi, and the maximum flux was about 11.9 GFD at 800 psi. However there is a difference in the recoveries at 8,11 and $14 \mathrm{gpm}$ flow rates at any fixed pressure. Recovery decreases as the flow rate is increased at a fixed pressure. 


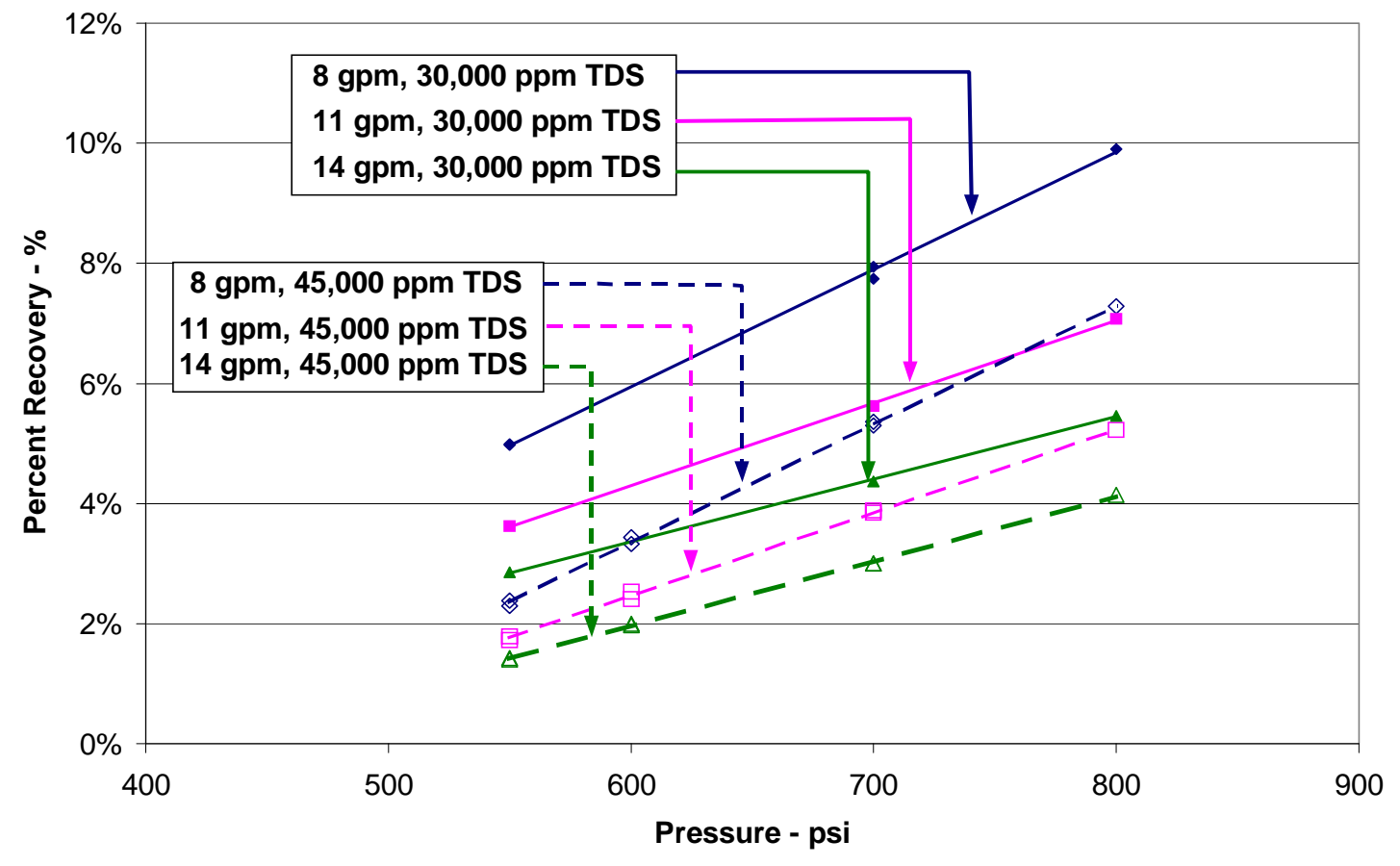

Fig. 5.16-Effect of pressure on recovery with 30,000 and 45,000 ppm TDS produced water feed. (Feed flow rate = 8, 11 and 14 gpm. Recovery normalized @ 95 F).

The recovery at $550 \mathrm{psi}$ is $2.4 \%$ for $8 \mathrm{gpm}, 1.8 \%$ for $11 \mathrm{gpm}$, and $1.4 \%$ for $14 \mathrm{gpm}$ feed flow rate. At 800 psi the recovery is $7.3 \%$ for $8 \mathrm{gpm}, 5.2 \%$ for $11 \mathrm{gpm}$, and $4.1 \%$ for gpm feed flow rate across the membrane. These differences in recoveries with the same flux at different flow rate are because the calculation of recovery is based on the ratio of permeate rate to the feed flow rate across the membrane as discussed before.

The effect of pressure on total dissolved solids (TDS) in the permeate and percent salt rejection for 30,000 ppm and 45,000 ppm TDS produced water at the selected flow rates of 8,11 and 14 gpm is shown in Figs. 5.17 and 5.18. It is seen from both the figures that the amount of dissolved solids in the permeate decrease and the salt rejection increases as the pressure is increased. It is also observed that the salt rejection and the concentration of salts present in the permeate is approximately the same at any constant pressure at the selected flow rates of 8, 11 and 14 gpm. 


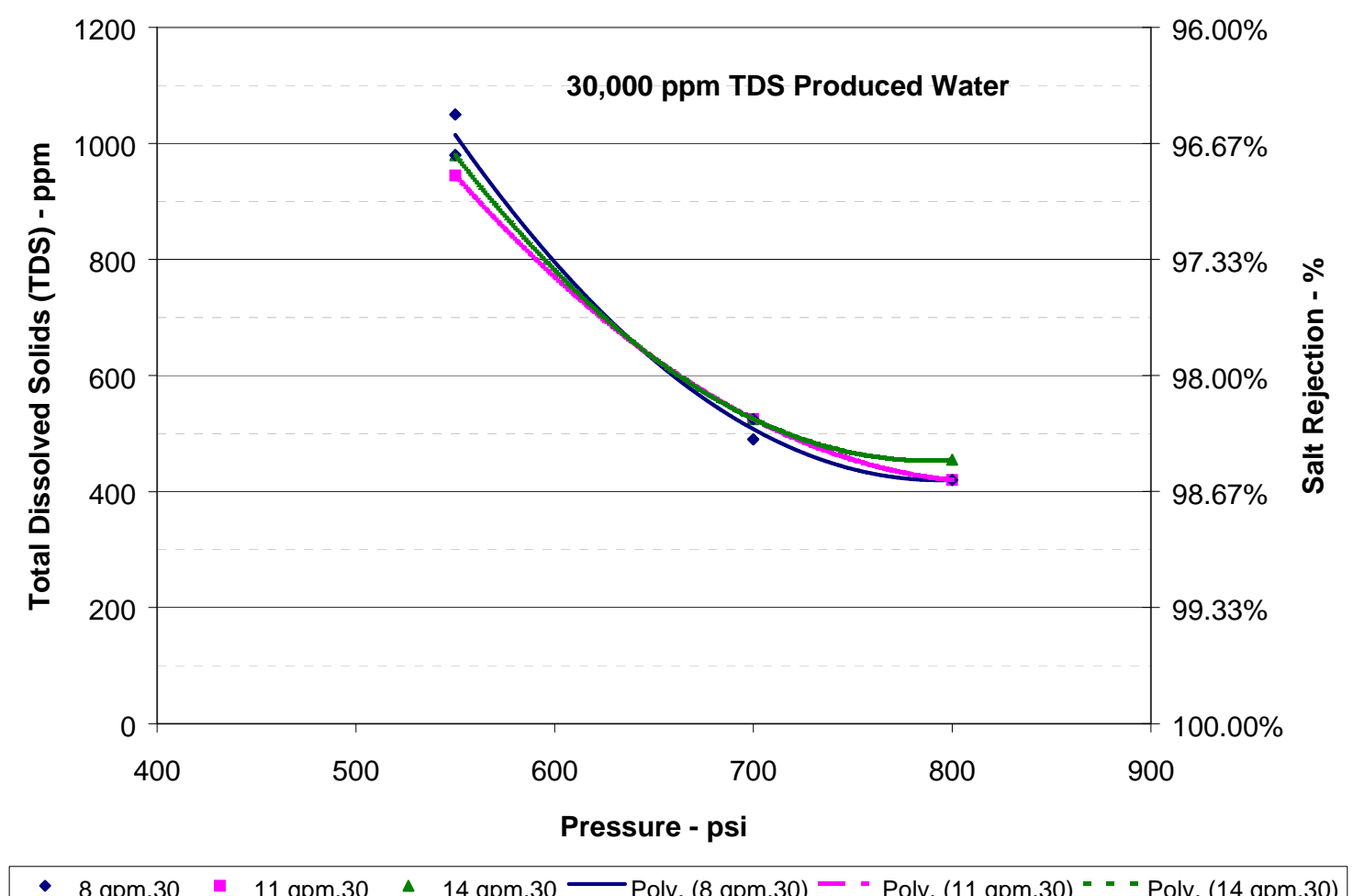

Fig. 5.17-Effect of pressure on total dissolved solids (TDS) in permeate with 30,000 ppm TDS produced water feed. (Feed flow rate = 8, 11 and 14 gpm).

Maximum salt rejection and minimum salt concentration in the permeate is at $800 \mathrm{psi}$ for both the produced waters. For 30,000 ppm TDS produced water maximum salt rejection is $98.6 \%$ corresponding to about $430 \mathrm{ppm}$ TDS in the permeate, which is the minimum salt concentration. The minimum TDS concentration in the permeate is of 45,000 TDS produced water is about $640 \mathrm{ppm}$ TDS corresponding to $98.6 \%$ salt rejection.

At 550 psi the TDS concentration is about $1000 \mathrm{ppm}$ for 30,000 ppm TDS produced water. This corresponds to about $96.5 \%$ salt rejection. For the 45,000 ppm TDS produced water salt concentration in the permeate is about $1400 \mathrm{ppm}$ TDS corresponding to about 96.8\% salt rejection. Although the salt concentration in permeate of 30,000 TDS produced water is less than the permeate of $45,000 \mathrm{ppm}$ produced water (at $550 \mathrm{psi}$ ), yet the salt rejection by the membrane is higher for 45,000 TDS produced water. This is because salt rejection is calculated by dividing the amount of salts rejected by the membrane by the total solids present in the feed. 


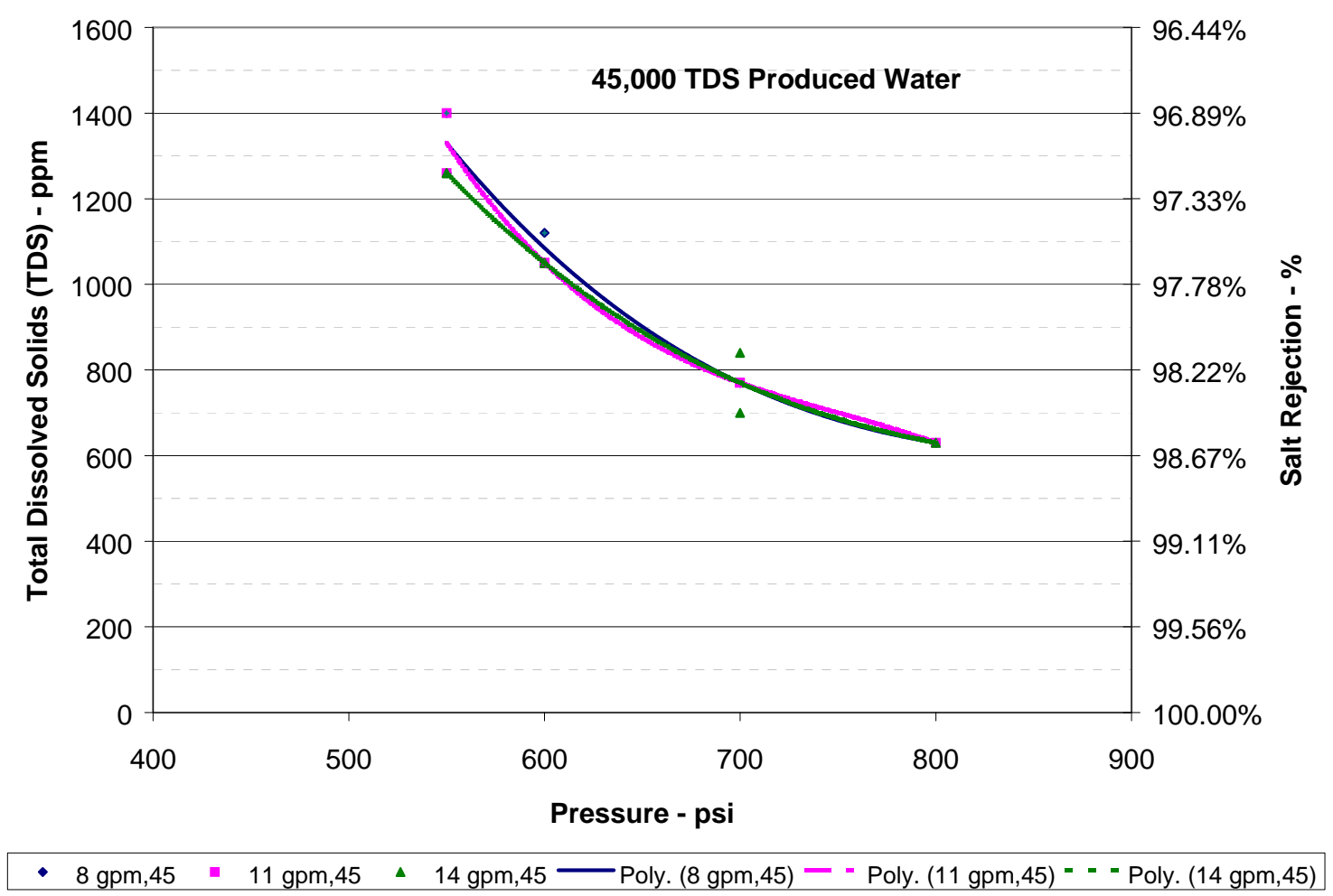

Fig. 5.18-Effect of pressure on total dissolved solids (TDS) in permeate with 45,000 ppm TDS produced water feed. (Feed flow rate $=8,11$ and $14 \mathrm{gpm}$ ).

\subsubsection{Comparison of Flux and Permeate Quality of 15,000 ppm, 30,000 ppm and 45,000 ppm TDS Produced Water}

The Flux for clean water feed and produced water feeds with 15,000 ppm, 30,000 ppm and 45,000 ppm TDS is compared as the pressure is varied in Fig. 5.19. As discussed previously the flux varies as the feed flow rate is changed at constant pressure for clean water and produced water of 15,000 ppm TDS. For the 30,000 ppm and 45,000 ppm TDS produced water feed the flux at different flow rates remains constant at fixed pressure. This shows that as the feed increases in salt concentration, difference in flux obtained at different flow rates will become smaller, at a constant pressure, and will eventually become the same at all flow rates.

From Fig. 5.19 it can also be seen that as the concentration of dissolved solids (salts) in the feed is increased the flux becomes less at any fixed pressure. It is also observed that as the concentration of salts increases in the water the minimum pressure to obtain permeate flow across the SWC-1-4040 membrane also increases. This is explained by the fact that as TDS concentration is increased the osmotic pressure also increases and more pressure is required to overcome the osmotic pressure and obtain permeate across the 
membrane. The relationship between pressure and flux is linear for all concentrations of feed and flux increases as the pressure is increased.

For produced water feed with concentration of salts other than experimented with, the flux across the membrane at any pressure may be found by linear interpolation using Fig. 5.20. This will give an approximate working value of the flux at the desired pressure. Similarly flux for feed flow rates other then the ones experimented with, can also be found by interpolation.

The effect of pressure on the salt concentration in the permeate stream for produced water feeds of 15,000 ppm, 30,000 ppm and 45,000 ppm TDS concentrations is shown in Fig. 5.20. It is observed that for all concentration feeds as the pressure is increased the TDS concentration in the permeate decreases. It is also observed that as the salt concentration in the produced water is increased, the amount of solids passing through the membrane into the permeate also increases at any fixed pressure. The minimum total dissolved solids concentration in the permeate is obtained at 800 psi for all feed produced water concentrations.

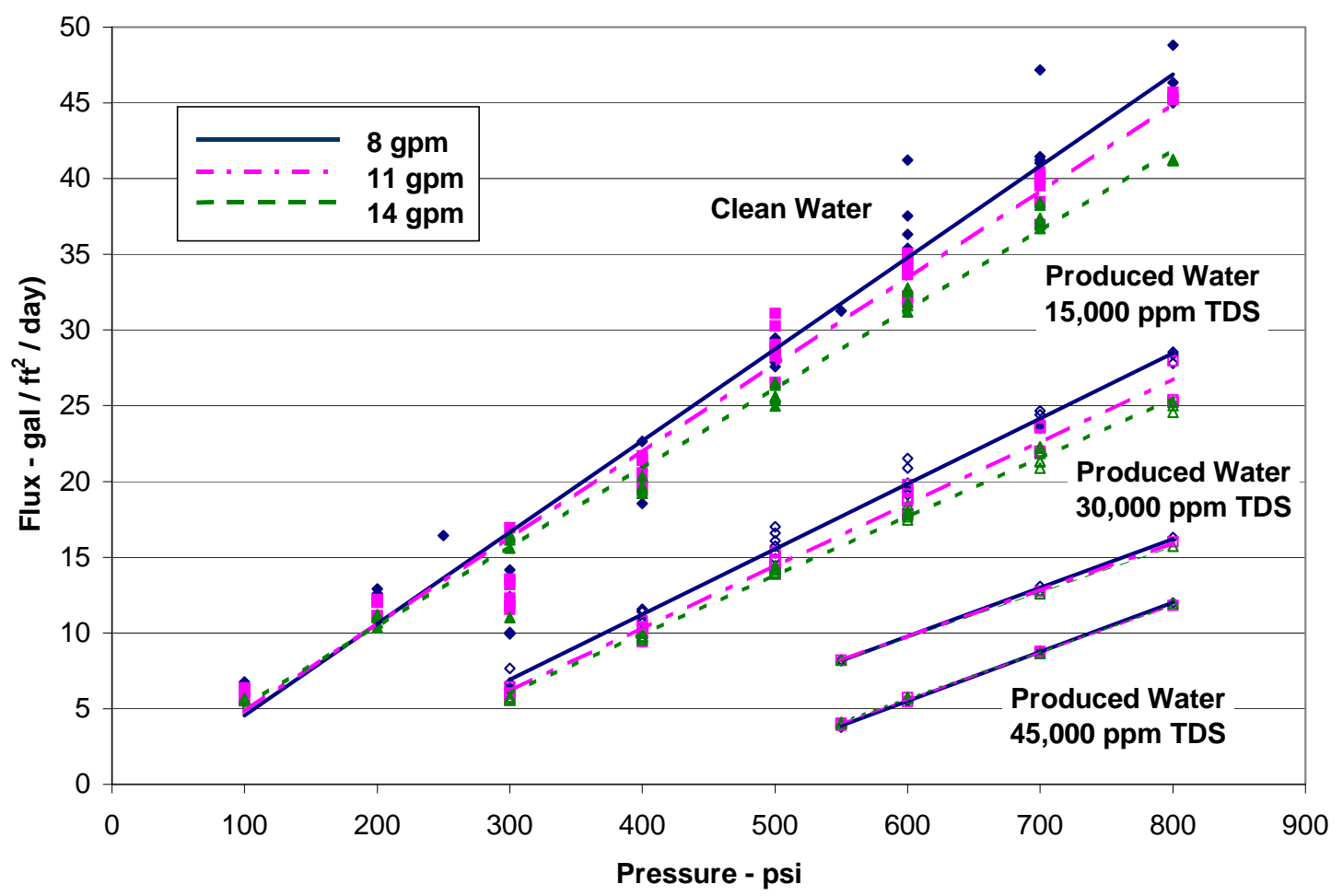

Fig. 5.19-Effect of pressure on flux with clean water and produced water $(15,000$, 30,000 and 45,000 ppm TDS) feed. (Feed flow rate = 8, 11 and 14. Flux normalized @ 95F). 


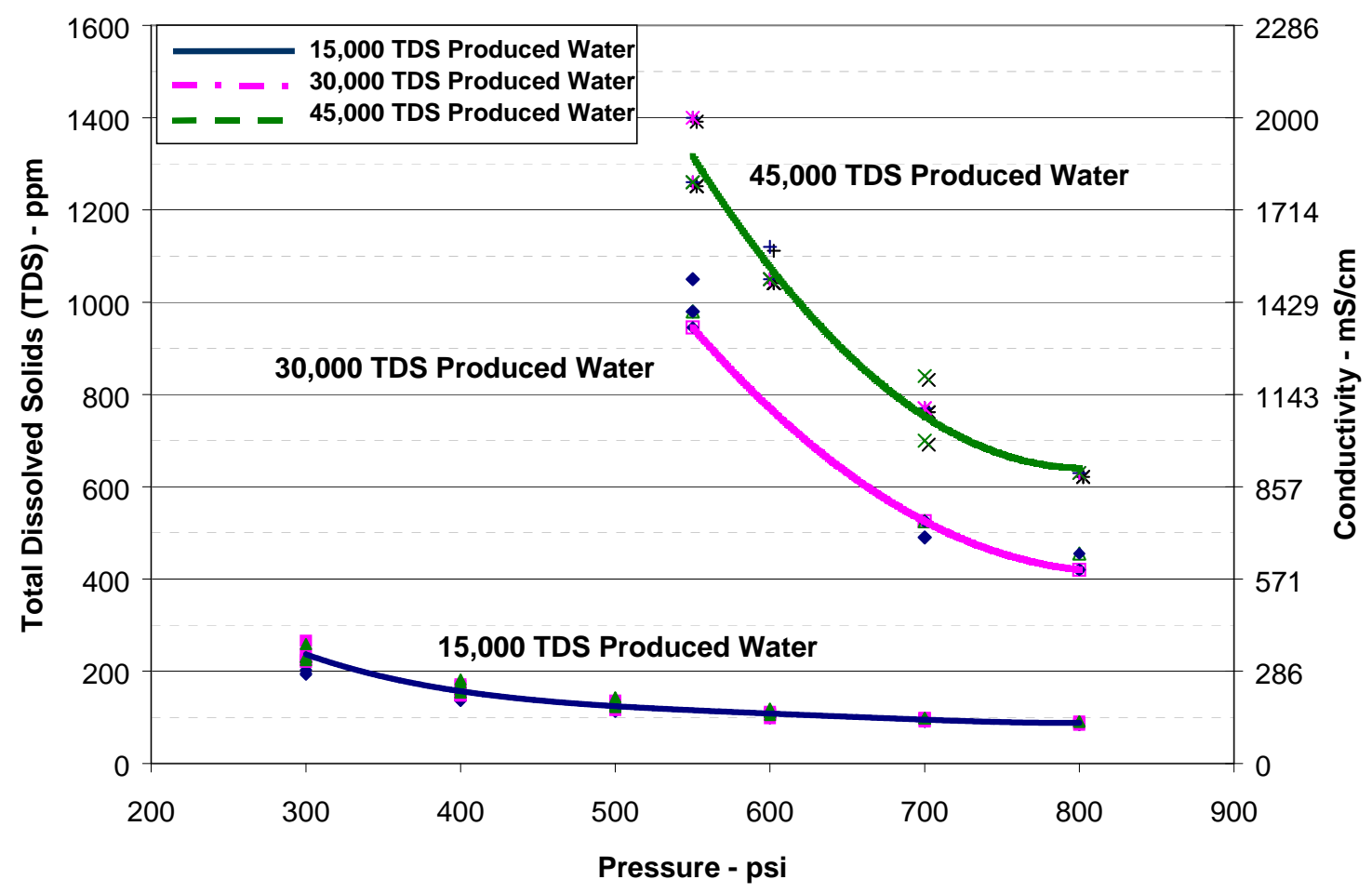

Fig. 5.20-Effect of pressure on total dissolved solids (TDS) in permeate with produced water $(15,000,30,000$ and 45,000 ppm TDS) feed. (Feed flow rate $=8,11$ and $14 \mathrm{gpm})$.

From Fig. 5.20 we can also approximately find the amount of produced solids that will be in the permeate stream, at a fixed pressure, for produced water of a concentration different than experimented with. This can be done by linear interpolation between the pressure vs. TDS curves. 


\subsubsection{Rejection of Hydrocarbons by SWC-1-4040}

Rejection of hydrocarbons by the SWC-1-4040 membrane with produced water feed containing 40, 80 and 120 ppmC TOC was studied. The applied transmembrane pressure ranged from 300 to 800 psi and 8, 11 and 14 gpm feed flow rate was used. It was observed for all pressures, feed flow rates, feed TDS concentrations, and feed TOC concentrations, the amount of TOC present in the permeate was less than 2 ppmC TOC. 2 ppmC TOC was the minimum equipment TOC detection limit for the equipment that used to measure the TOC concentration. Table 5.6 summarizes the results of TOC analysis for the feed and permeate stream.

\section{TABLE 5.6-REJECTION OF HYDROCARBONS BY THE SWC-1-4040 MEMBRANE WITH DIFFERENT FEED CONCENTRATIONS, FLOW RATES AND PRESSURES.}

\begin{tabular}{|l|c|c|c|}
\hline $\begin{array}{c}\text { Feed TDS Concentration } \\
\text { and Feed Flow Rate }\end{array}$ & $\begin{array}{c}\text { Applied Pressure } \\
\text { (psi) }\end{array}$ & $\begin{array}{c}\text { TOC in Feed } \\
\text { (ppmC TOC) }\end{array}$ & $\begin{array}{c}\text { TOc in Permeate } \\
\text { (ppmC TOC) }\end{array}$ \\
\hline 15,000 ppm TDS, $8 \mathrm{gpm}$ & $300-800$ & 40 & 2 \\
\hline $15,000 \mathrm{ppm}$ TDS, $11 \mathrm{gpm}$ & $300-800$ & 40 & 2 \\
\hline $15,000 \mathrm{ppm}$ TDS, $14 \mathrm{gpm}$ & $300-800$ & 40 & 2 \\
\hline $30,000 \mathrm{ppm}$ TDS, $8 \mathrm{gpm}$ & $550-800$ & 80 & 2 \\
\hline $30,000 \mathrm{ppm}$ TDS, $11 \mathrm{gpm}$ & $550-800$ & 80 & 2 \\
\hline $30,000 \mathrm{ppm}$ TDS, $14 \mathrm{gpm}$ & $550-800$ & 80 & 2 \\
\hline $45,000 \mathrm{ppm}$ TDS, $8 \mathrm{gpm}$ & $550-800$ & 120 & 2 \\
\hline $45,000 \mathrm{ppm}$ TDS, $11 \mathrm{gpm}$ & $550-800$ & 120 & 2 \\
\hline $45,000 \mathrm{ppm}$ TDS, $14 \mathrm{gpm}$ & $550-800$ & 120 & 2 \\
\hline
\end{tabular}

Primary application of SWC-1-4040 membrane is the desalination of produced water, not hydrocarbon removal. The hydrocarbons present in the produced water are to be removed in the pretreatment steps, before the produced water is passed through the membrane. The aim of this study was to determine if the membrane could reject the hydrocarbons if some of them managed to escape in the pretreatment process and how much hydrocarbons would be present in the permeate. Hydrocarbons were present in different concentrations for all the experiments performed on the SWC-1-4040 membrane to determine how the membrane would perform under these circumstances.

\subsubsection{Optimization of Operating Parameters for 15,000 ppm TDS Produced Water}

This project aims to treat and beneficially use produced water in the west Texas region. Most mature fields in west Texas have produced water with dissolved solids in the range 
of $10,000 \mathrm{ppm}$ to $15,000 \mathrm{ppm}$ TDS. Due to this reason optimization of operating parameters was done for produced water with 15,000 ppm TDS concentration.

Optimization of operating parameters consists of determining the membrane operating pressure, temperature and feed flow rate across the membrane needed to obtain permeate of fresh irrigation water quality, which is defined by the TCEQ as water with less than 500 ppm dissolved solids.

Due to membrane fouling concerns the manufacturer suggests a maximum recovery of $10 \%$ per membrane element with 30,000 ppm TDS salt water for SWC-1-4040 membrane. Between 30-50\% total recovery is required for treatment of 15,000 ppm TDS produced water for the process to be economically feasible. But we are limited to maximum 17\% recovery at $8 \mathrm{gpm}$ at 800 psi for 15,000 ppm TDS water. Recovery also plays an important part in concentration polarization and higher recovery per element means a higher operating pressure and more chances of fouling.

On the other hand, feed flow rate needs to be kept at an optimum level because of energy requirements and recovery. In addition the pressures of the system should be as low as possible due to power requirements and equipment limitations. Finally for high-pressure operations the equipment becomes more expensive (high pressure pumps and plumbing and fittings).

Energy required per gallon permeate obtained needs to be kept as low as possible. Higher feed flow rate provides a self-cleaning effect across the membrane and reduces concentration polarization.

The fouling of membrane reduces the flux and the recovery in addition to increase in the salt passage across the membrane. Each membrane cleaning reduces the effectiveness of the surface and results in the reduction of selectivity for TDS.

To overcome these problems operating pressure has to be increased with time to obtain the permeate of same quality or on the other hand more TDS in the permeate and lower flux should be accepted. In practical applications the system may be sized to allow increased pressures due to reduction in membrane flux and selectivity. However, once the practical limitations are reached the membrane must be replaced.

Energy consumed per gallon of permeate obtained at the selected feed flow rates of 8, 11 and 14 gpm, as the pressure is changed for the 15,000 ppm TDS feed is shown in Fig. 5.21. It is seen from the figure that the energy consumed per gallon of permeate processed goes down as the pressure is increased from 300 psi to 800 psi for all feed flow rates. From 500 to 800 psi operating pressure, the energy consumed per gallon permeate recovered becomes nearly constant, at a fixed feed flow rate for the selected feed flow rates of 8,11 and 14 gpm.

It is also observed from Fig. 5.21 that the energy requirements are the least for $8 \mathrm{gpm}$ feed flow rate per gallon of permeate processed, at a fixed pressure. This energy to 
requirement increases as the feed flow rate is increased from 8 gpm to $11 \mathrm{gpm}$ and to 14 gpm at a fixed pressure.

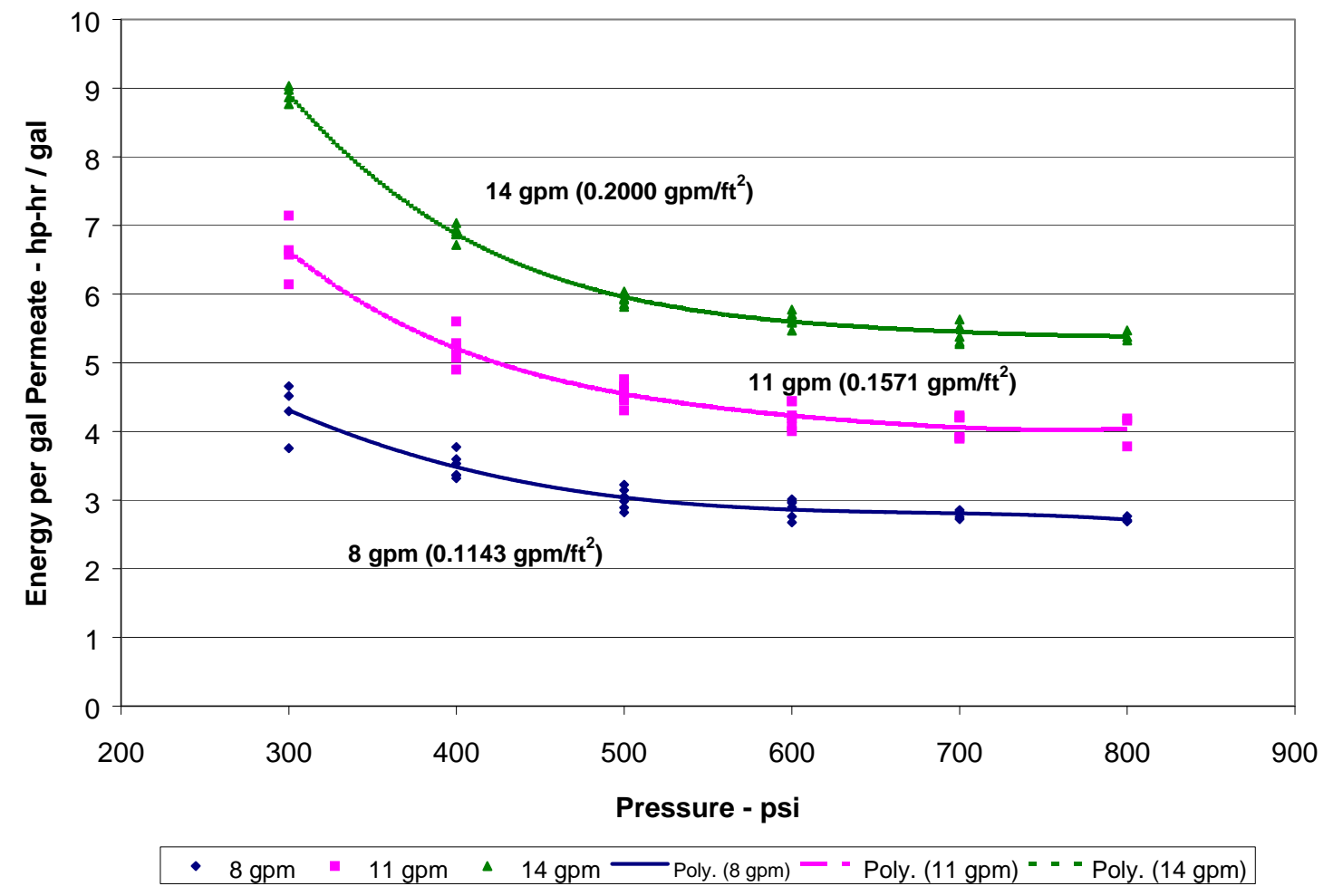

Fig. 5.21-Effect of pressure on energy required per gallon permeate obtained with 15,000 ppm TDS produced water feed. (Feed flow rate $=8,11$ and $14 \mathrm{gpm}$ ).

Taking all the above factors into consideration it was decided to operate the membrane at an operating pressure of $550 \mathrm{psi}$ and a feed flow rate of $10 \mathrm{gpm}$ for the produced water feed of 15,000 ppm TDS and $40 \mathrm{ppmC}$ TOC. At this pressure and feed flow rate we have enough reserve pressure to boost up the operating pressure to up 700 psi with time, as the membrane becomes old and salt passage increases and flux decreases. This would allow us to have permeate of the desired quality with an acceptable flux. As seen from Fig. 5.21 the energy consumed per gallon of permeate obtained will be minimal at 550 psi pressure and 10 gpm feed flow rate for the desired permeate quality and equipment limitations.

At 550 psi operating pressure and 10 gpm feed flow rate we would get a maximum flux of about 15 GFD and $9 \%$ recovery across the first membrane. The salt concentration in the permeate would be about $150 \mathrm{ppm}$ TDS. If $50 \%$ recovery is wanted the feed at the last membrane would have about 30,000 ppm TDS and the permeate obtained at 550 psi and $10 \mathrm{gpm}$ will have about $900 \mathrm{ppm}$ TDS. This permeate is going to blend with the permeate with 150 ppm TDS from the first membrane, and permeates from the other 
membranes which will have TDS concentrations between 150 and 900 ppm. Also we will have the maximum amount of permeate from the first membrane, lesser from the second and the least from the last membrane. When these permeates would blend we will have a final permeate with about 400 ppm TDS.

\subsubsection{Membrane Fouling}

Fouling and cleaning studies were done on SWC-1-4040 membrane using produced water feed of 15,000 ppm TDS and 40 ppmC TOC at a feed flow rate of $10 \mathrm{gpm}$ and at an operating transmembrane pressure of 550 psi, which were selected as described previously.

Produced water was processed through the membrane for a total of 41.5 hours (2485 minutes) of operation. Fig. 5.22 and 5.23 shows the flux across SWC-1-4040 membrane during this period of operation and Fig. 5.24 shows the salt rejection by the membrane during the fouling run. All the three figures (Figs. 5.22, 5.23 and 5.24) are divided in two parts, which are: series "Foul 1" and series "Foul 2". The reason for his is because after 685 minutes of operation there was a system upset. "Foul 1" refers to the data taken from prior to system upset and "Foul 2" refers to the data taken after system was restored to the operating conditions. 


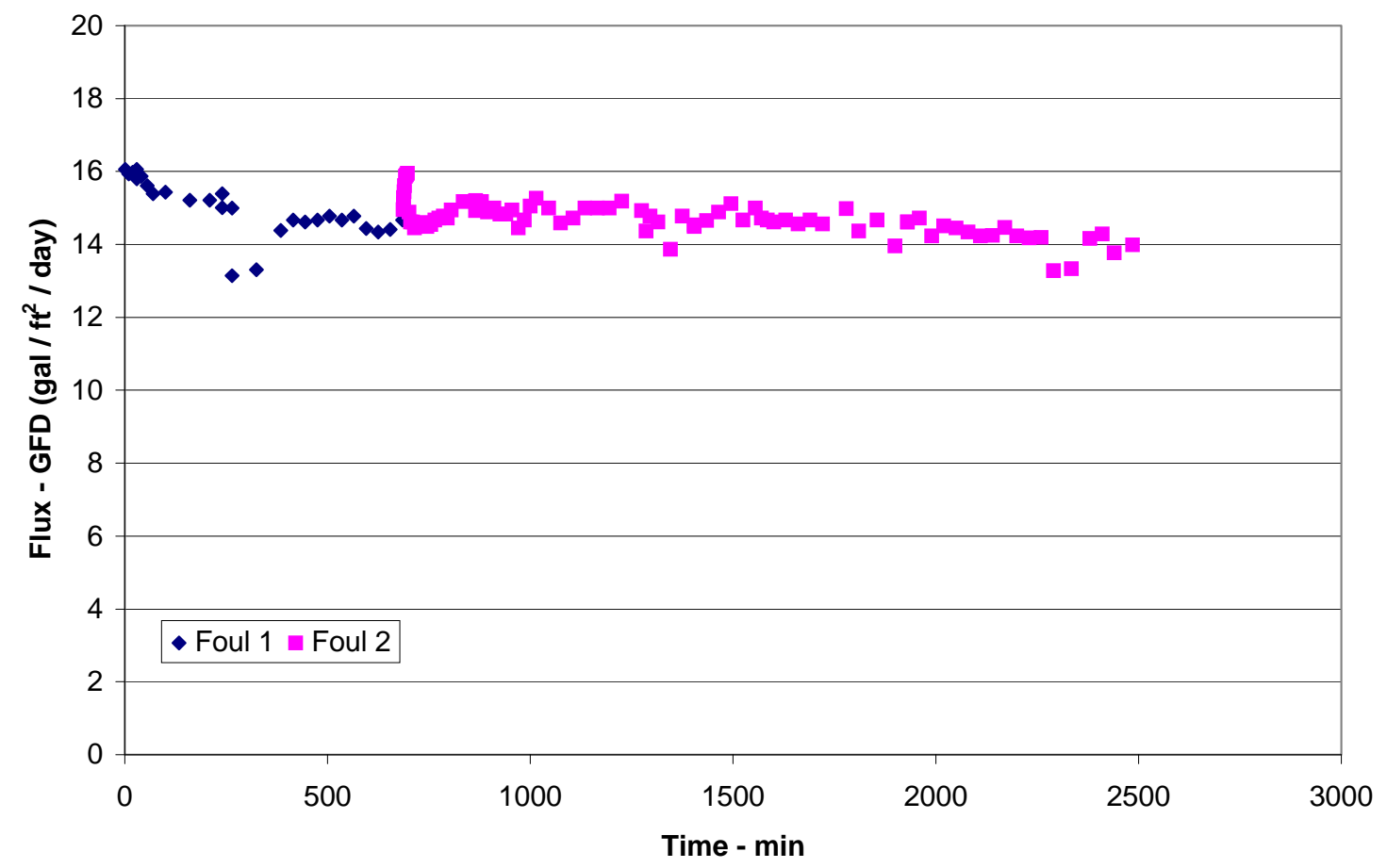

Fig 5.22-Effect of time on flux across SWC-1-4040 membrane for fouling profile. (15,000 ppm TDS and 40 ppmC TOC produced water. Flux normalized @ 95 F).

It can be seen from Figs. 5.22 and 5.23 that the flux across the membrane remained nearly constant at about 14.5 GFD during 41.5 hours (2485 minutes) of operation. This showed that there was little membrane fouling by the produced water as the produced water was processed by SWC-1-4040 membrane. It is also seen from the Fig. 5.22 that initially the flux is a little higher than 14.5 GFD for both series Foul 1 and Foul 2 but it drops down to a steady value of 14.5 GFD after a little time. There are flux values that are below the average flux of 14.5 GFD but these are due to slight differences in operating conditions (pressure or feed flow rate higher or lower than 550 psi and 10 gpm), which were corrected immediately. 


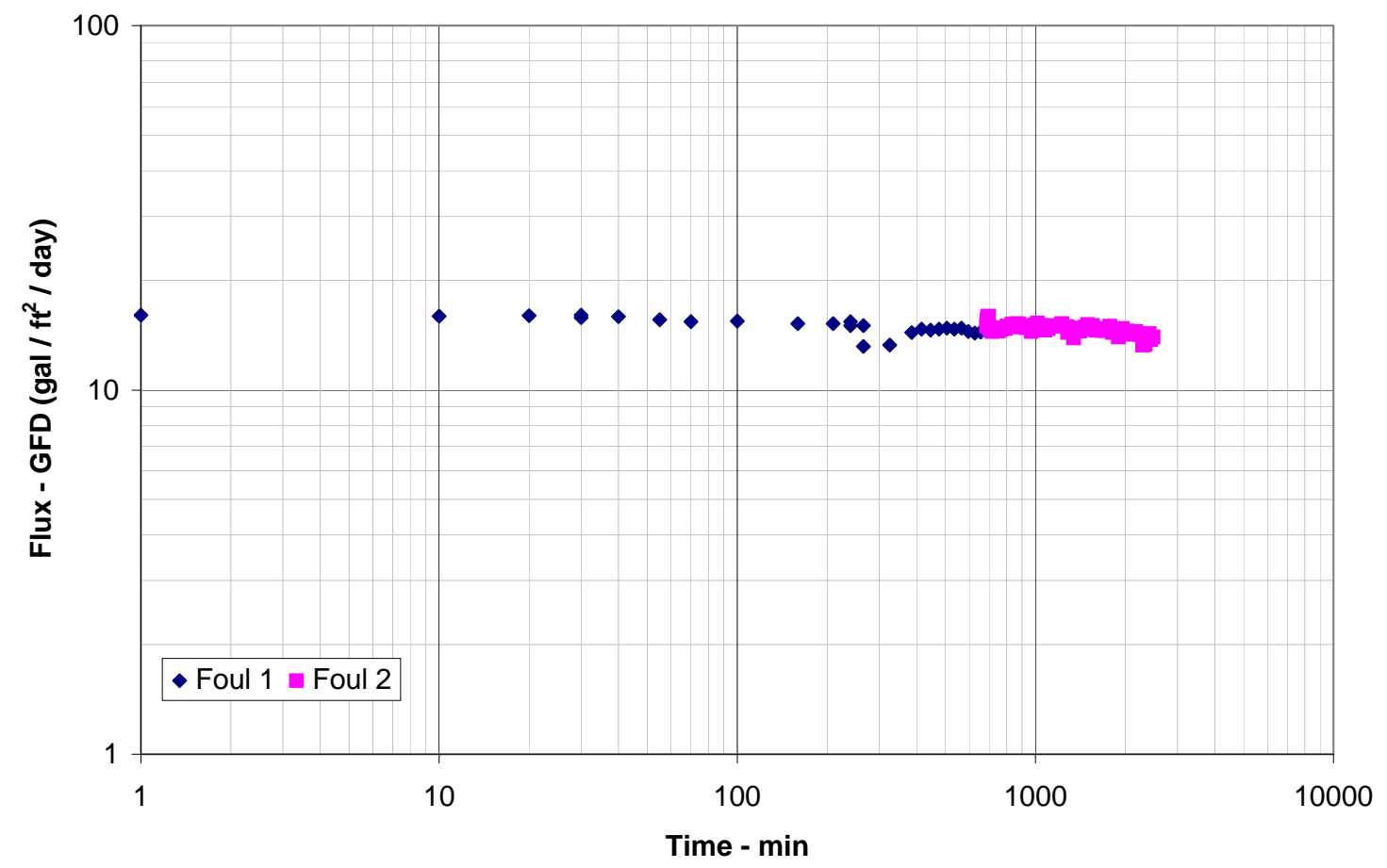

Fig 5.23-Effect of time on flux for fouling profile on log-log scale. (15,000 ppm TDS and 40 ppmC TOC produced water. Operating pressure $=550$ psi. Feed flow rate $=$ 10 gpm. Flux normalized @ 95 F).

Fig. 5.24 shows the salt rejection by SWC-1-4040 and the concentration of salts in the permeate obtained through the membrane. For the Foul 1 series it is seen that the concentration of salts in the permeate is about $115 \mathrm{ppm}$ on the average, which gives about 99.25\% salt rejection by the membrane. The series Foul 2 shows lesser salt rejection by the membrane. It shows that the salt rejection stabilized at about $99 \%$, corresponding to about 140 ppm TDS in the permeate obtained across the membrane.

The difference in the TDS in the permeates of Foul 1 and Foul 2, and the corresponding difference in the salt rejection, can be explained due to membrane cleaning done. According to Amjad ${ }^{70}$ and Kessler and Lund ${ }^{71}$ every time a membrane is cleaned, part of the membrane surface is etched away due to chemicals employed for membrane cleaning. In this case a severe membrane cleaning cycle was employed to wash out oil that had accumulated on the membrane surface due to a system upset. 


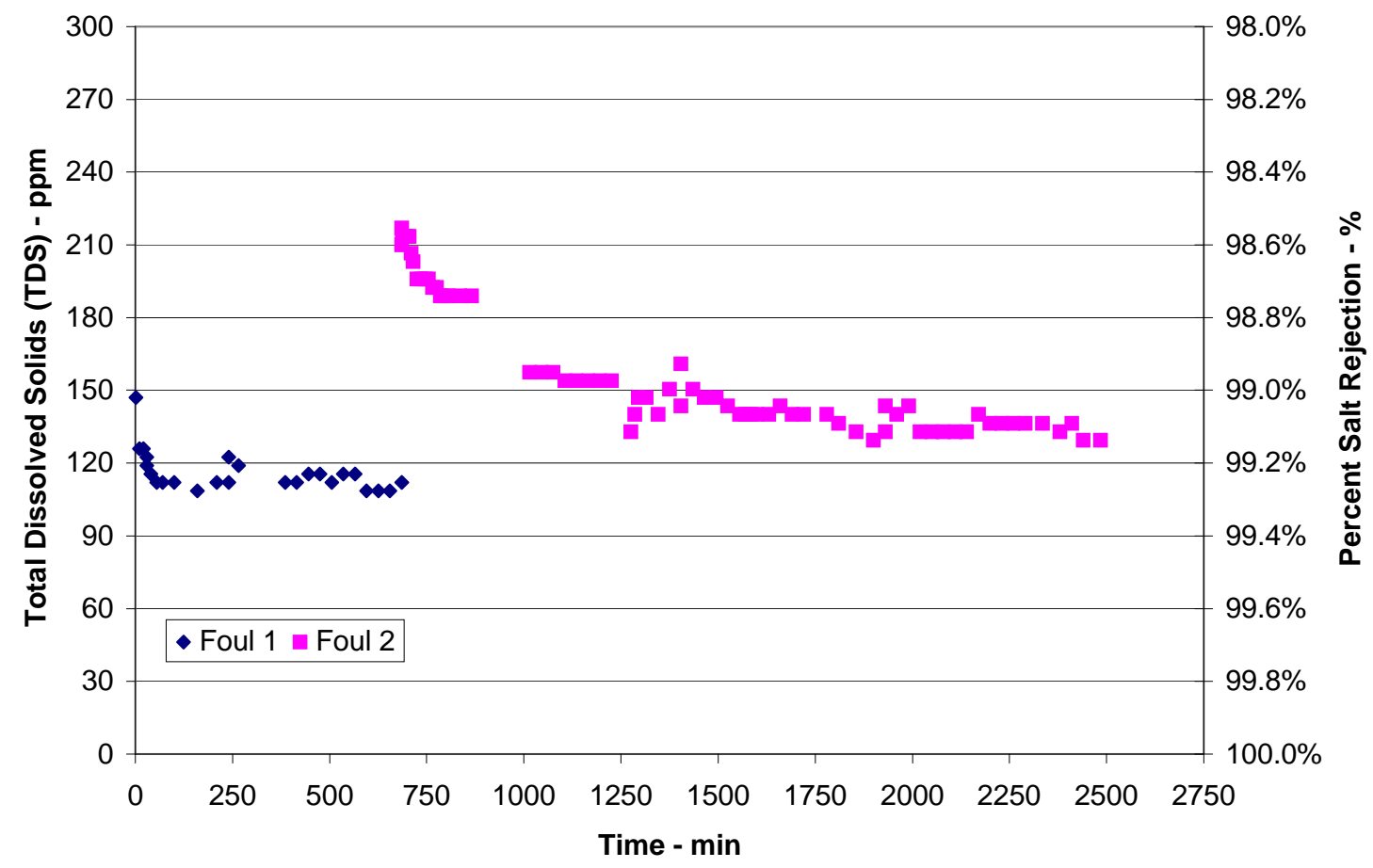

Fig. 5.24-Effect of time on salt concentration in the permeate for fouling profile. (15,000 ppm TDS and 40 ppmC TOC produced water. Operating pressure $=550$ psi. Feed flow rate $=10 \mathrm{gpm})$.

The rejection of hydrocarbons by the membrane was also observed during fouling profile. Concentration of TOC in the produced water was $40 \mathrm{ppmC}$. It was noted that during the whole period of operation the TOC concentration in the permeate obtained across the SWC-1-4040 membrane was less than 2 ppmC. Fig. 5.25 shows the TOC concentration in the permeate obtained across SWC-1-4040 membrane during the fouling profile run. 


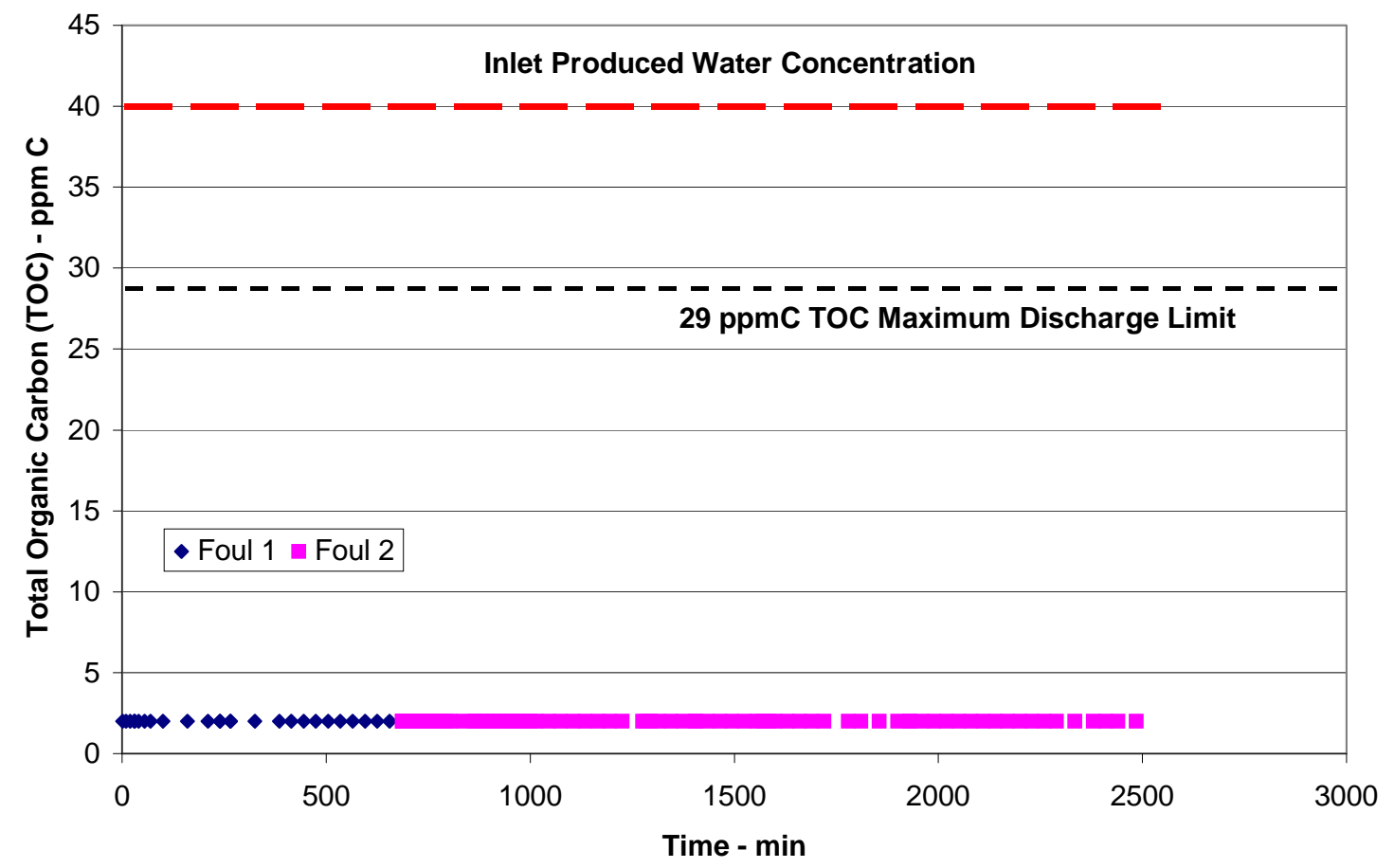

Fig. 5.25-Effect of time on TOC concentration in the permeate for fouling profile. (15,000 ppm TDS and 40 ppmC TOC produced water. Operating pressure $=550$ psi. Feed flow rate $=10 \mathrm{gpm})$.

\subsubsection{Volume Concentration Ratio (VCR)}

Fig. 5.26 shows the effect of concentrating produced water on the flux across SWC-14040 membrane at $550 \mathrm{psi}$ and $10 \mathrm{gpm}$ feed flow rate. It is seen that as the produced water is concentrated from $15,000 \mathrm{ppm}$ to $45,000 \mathrm{ppm}$ TDS, the flux across the membrane goes down from 14 GFD to about 4 GFD and the recovery decreases from $7 \%$ to $2 \%$. Fig. 5.26 also shows that as VCR increases by a factor of two, the flux decreases from 14 GFD to about 4 GFD, by a factor of 2.5 and the recovery decrease by a factor of 2.5 as well. The flux decreases linearly from 14 GFD to 4 GFD as the produced water concentration is increased from 15,000 to 45,000 ppm TDS. Similarly the recovery also decreases linearly as the produced water concentration is increased. 


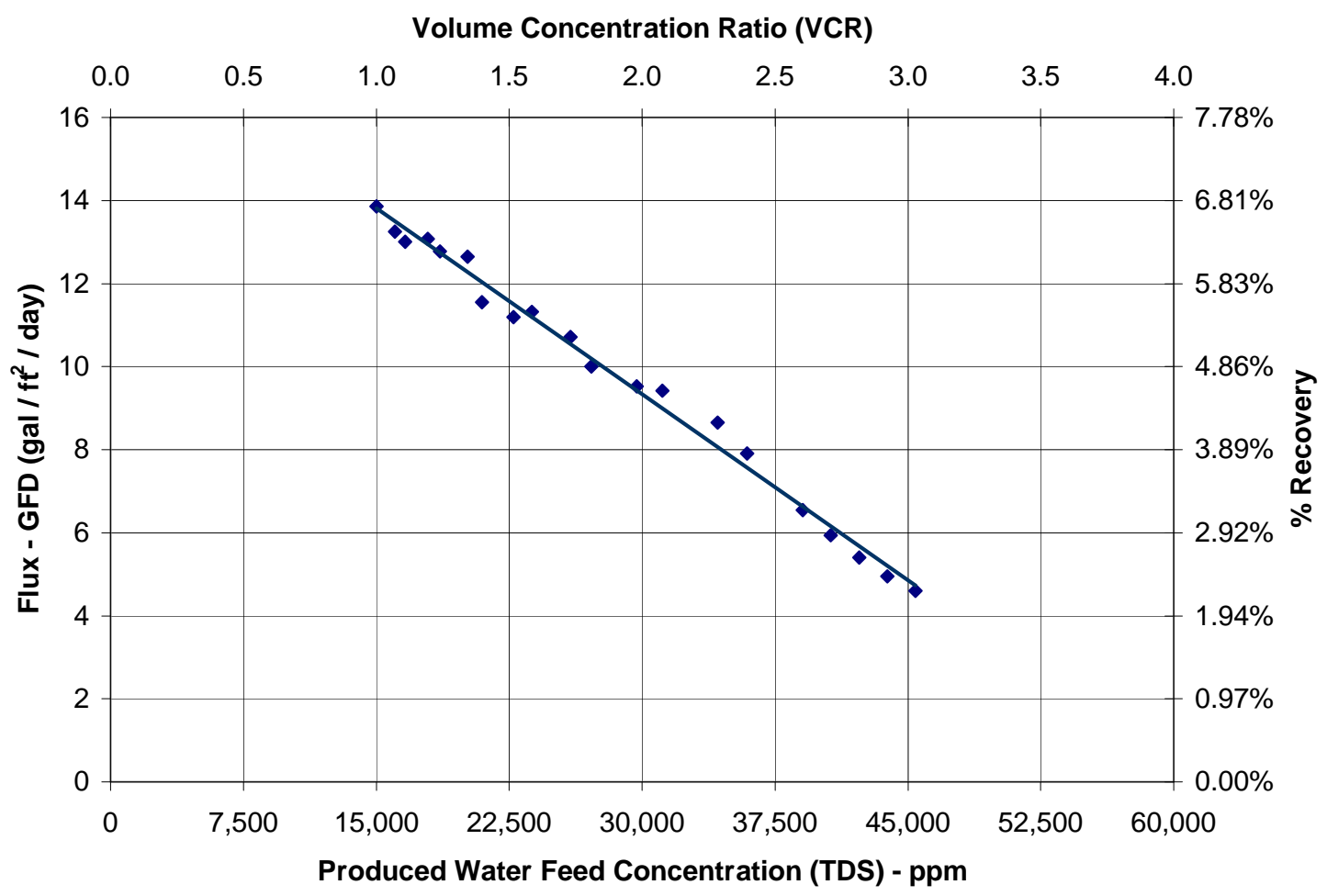

Fig. 5.26-Effect of concentrating produced water on flux. (Operating pressure $=\mathbf{5 5 0}$ psi. Feed flow rate $=10 \mathrm{gpm})$.

Fig. 5.27 shows the effect of concentrating produced water on the concentration of dissolved solids in the permeate. It is seen that as the produced water is concentrated from $15,000 \mathrm{ppm}$ to $45,000 \mathrm{ppm}$ TDS the concentration of salts in the permeate obtained across SWC-1-4040 membrane increases linearly from about 150 ppm to 1300 ppm TDS. If we look at the VCR vs. TDS in permeate it is observed that as the VCR goes up by a factor of two the amount of salts in the permeate obtained across the membrane go up by a factor of nearly eight. This shows that as produced water is concentrated, the concentration of salts in permeate obtained across the membrane will increase four times, at the same pressure and flow rate, as the produced water is concentrated one times. 


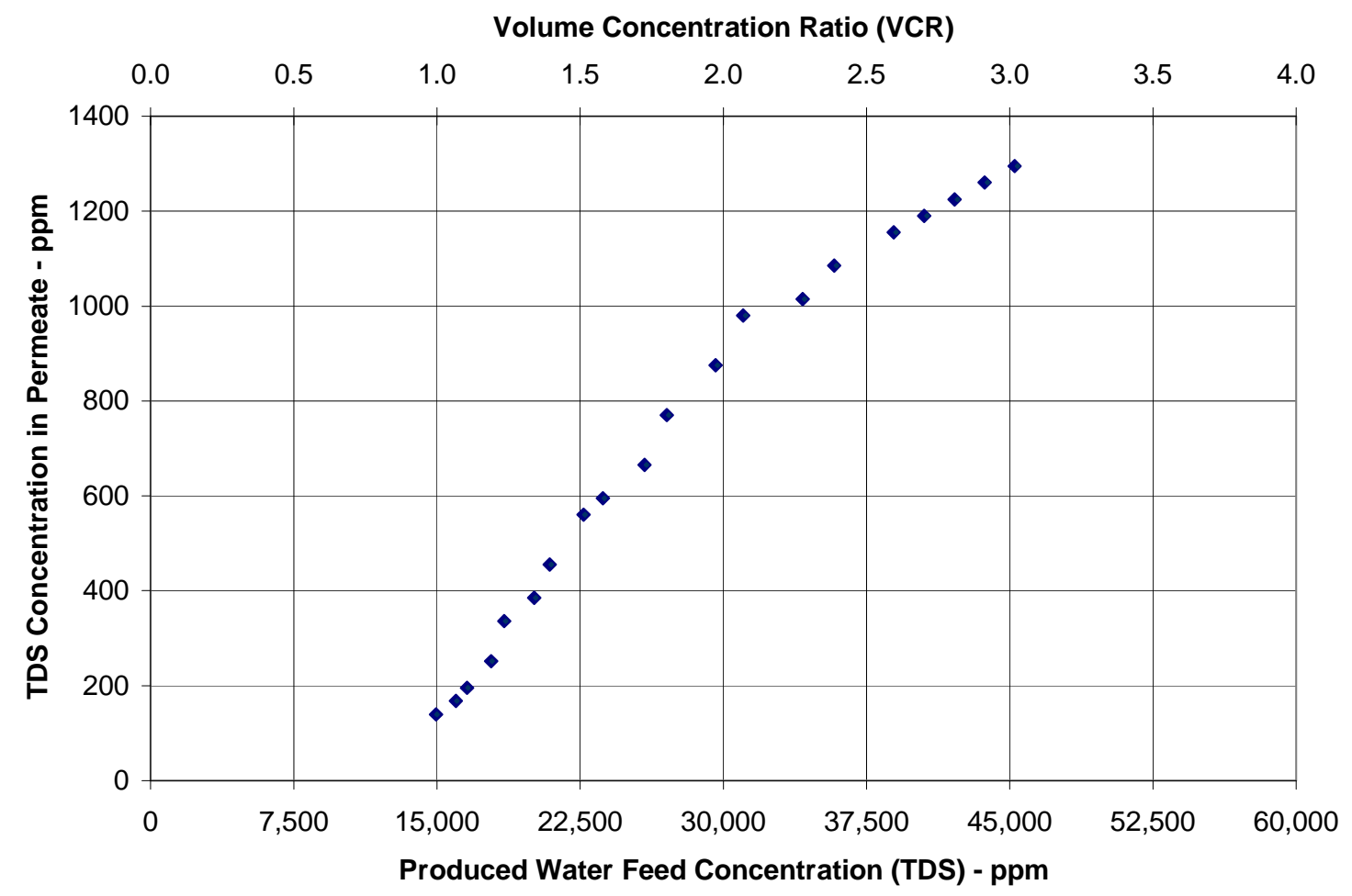

Fig. 5.27-Effect of concentrating produced water on the salt concentration in permeate. (Operating pressure $=550$ psi. Feed flow rate $=10 \mathrm{gpm})$.

From Fig. 5.26 and Fig. 5.27 we can determine the permeate flux and amount of dissolved solids that will be present in the permeate depending on how much total recovery is required from the feed and design the membrane system accordingly.

\subsubsection{Membrane Cleaning}

Clean water flux was then taken at $11 \mathrm{gpm}$ and the results are shown in Fig. 5.28. As seen from Fig. 5.28 the clean water flux at $11 \mathrm{gpm}$ after the membrane was cleaned was less than the clean water flux at 11 gpm observed with the new membrane at any fixed pressure. This result is as expected as the clean water flux after a membrane has been used to process a contaminated feed will always be less than clean water flux of a new membrane. 


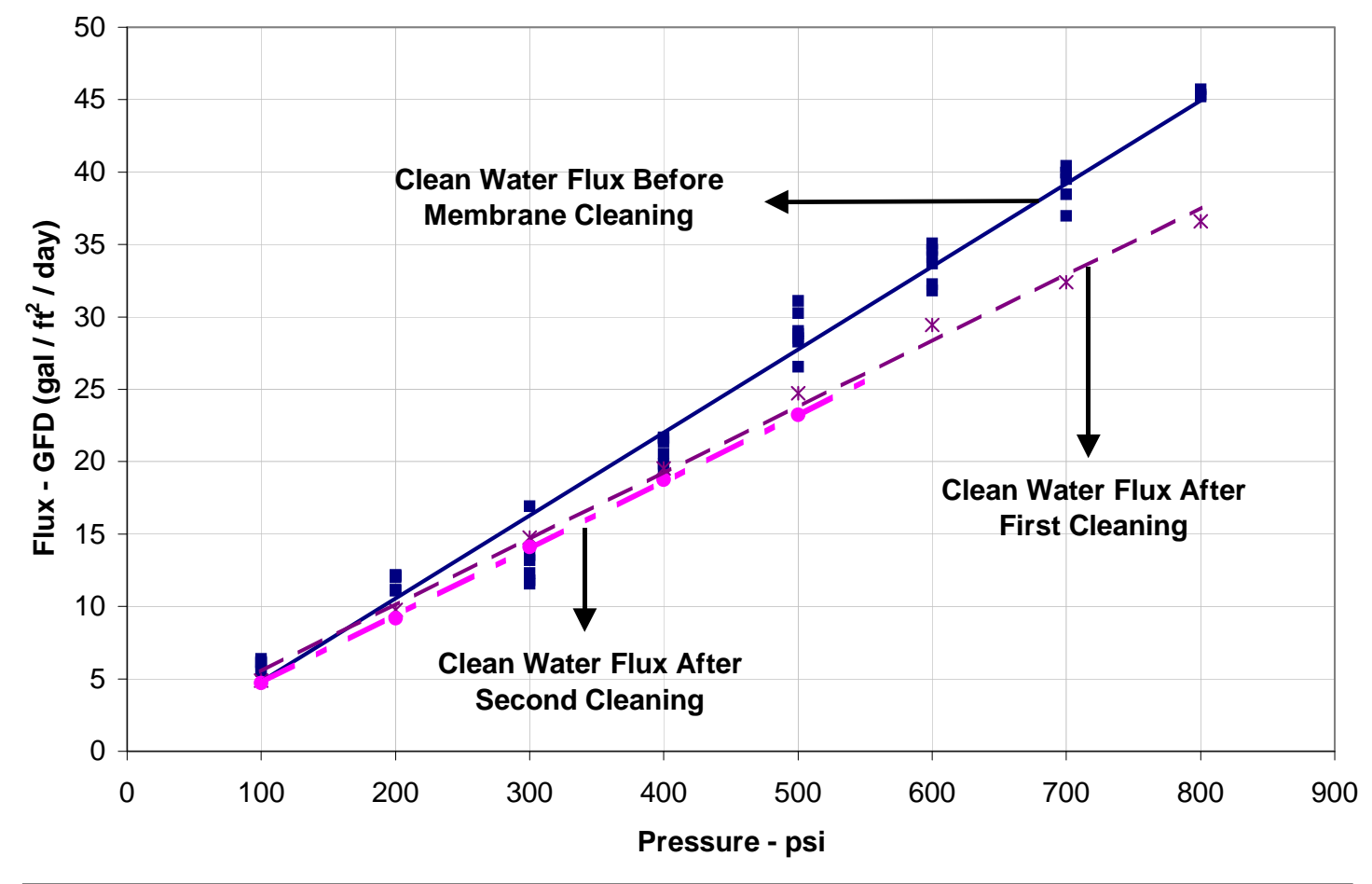

- $11 \mathrm{gpm} *$ Cleaning 1 - Cleaning 2 - Linear (11 gpm) - - Linear (Cleaning 1)

Fig. 5.28-Effect of pressure on flux with clean water feed before and after membrane cleaning. (Feed flow rate $=11 \mathrm{gpm})$.

What is more important is the comparison of flux with the same feed that was processed at the same operating conditions. Fig. 5.29 compares the flux across the SWC-1-4040 membrane for produced water of 15,000 ppm TDS and 40 ppmC TOC concentration at $11 \mathrm{gpm}$ feed flow rate before and after the membrane was cleaned. It can be seen from Fig. 5.29 that the flux across the membrane for produced water of 15,000 ppm TDS concentration at 11 gpm before and after the membrane was cleaned is nearly the same at any fixed pressure. This shows that the membrane cleaning procedure employed was effective. 


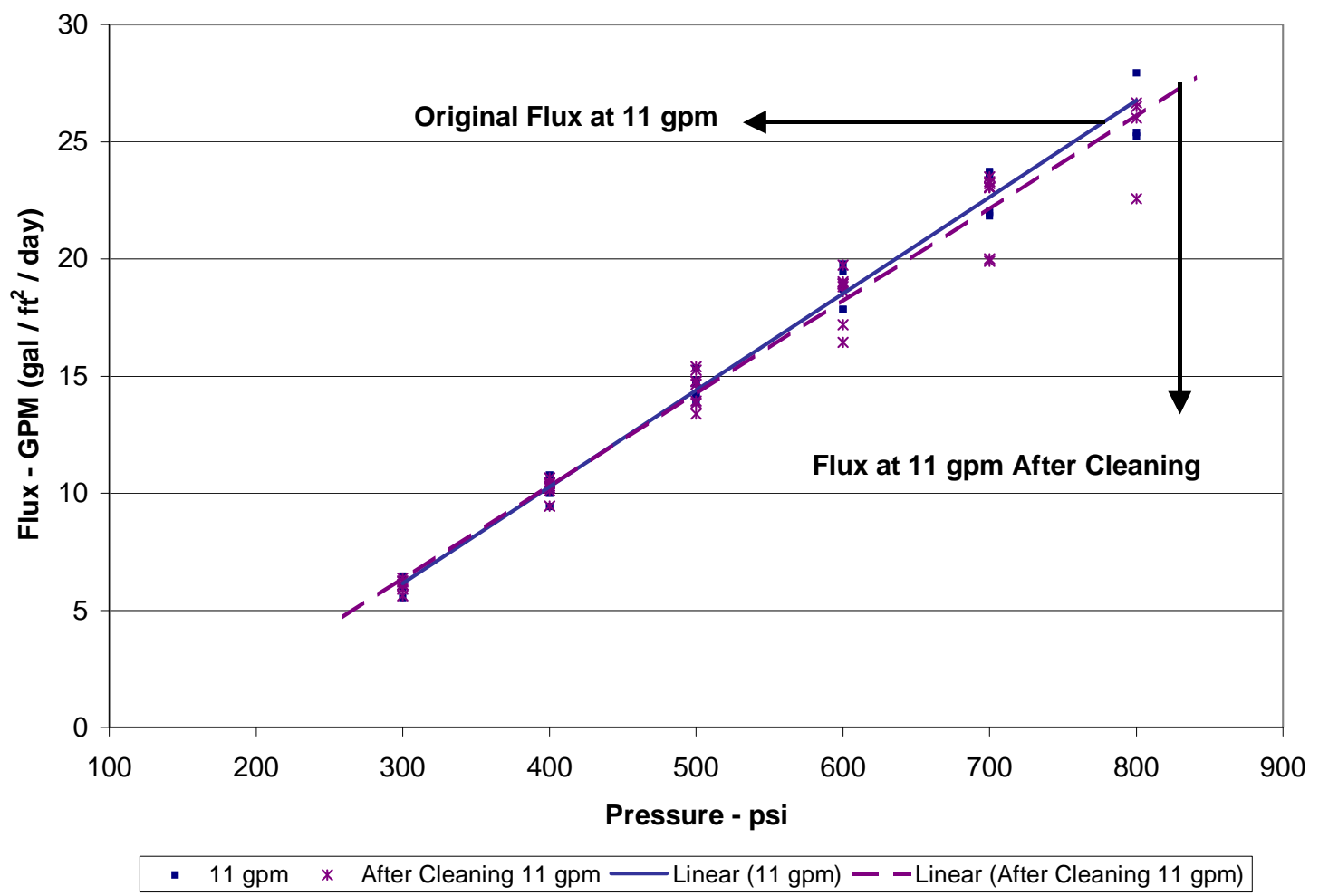

Fig. 5.29-Effect of pressure on flux with 15,000 $\mathrm{ppm}$ TDS produced water feed before and after membrane cleaning. (Feed flow rate $=11$ gpm).

Fig. 5.29 shows the effect of pressure on flux across SWC-1-4040 membrane for clean water at a feed flow rate of $11 \mathrm{gpm}$. It is observed from the figure that the clean water fluxes after the first and second membrane cleaning runs are nearly the same at any fixed pressure. This shows that the membrane cleaning method employed the second time is effective in cleaning the membrane when produced water with 15,000 ppm TDS and 40 ppmC TOC is processed by the membrane, as the clean water flux obtained across the membrane was nearly the same as the flux obtained after the first cleaning run.

Also during the fouling profile experiment the flux obtained across the membrane (Fig. 5.22) before and after the membrane was cleaned is nearly the same. The fouling experiments were done at $550 \mathrm{psi}$ operating pressure and $10 \mathrm{gpm}$ feed flow rate with a produced water feed of 15,000 ppm TDS and 40 ppmC TOC.

Fig. 5.30 shows the effect of pressure on TDS concentration in the permeate and the corresponding salt rejection across the SWC-1-4040 membrane for 15,000 ppm TDS produced water feed at a feed flow rate of $11 \mathrm{gpm}$, before and after the membrane was cleaned. It is observed that the concentration of salts in the permeate increases at the same pressure after membrane cleaning and hence the corresponding salt rejection goes down. The difference in the TDS concentration of the permeates obtained before and 
after membrane cleaning, and the corresponding difference in the salt rejection, is because every time a membrane is cleaned, part of the membrane surface is etched away due to chemicals employed for membrane cleaning as described by Amjad ${ }^{70}$ and Kessler and Lund ${ }^{71}$. As surface of the membrane is etched away the membrane becomes more porous and more salts pass through the membrane to the permeate.

Fig. 5.30 shows the effect of pressure on the concentration of TDS in the permeate obtained across the SWC-1-4040 membrane before and after membrane cleaning, for 15,000 ppm TDS produced water processed by the membrane, at a feed flow rate of 11 gpm. As seen from Fig. 5.30 the permeate obtained after membrane cleaning has nearly twice the amount of salt concentration as compared to the permeate obtained before the membrane was cleaned. However the salt rejection by the membrane is still very good.

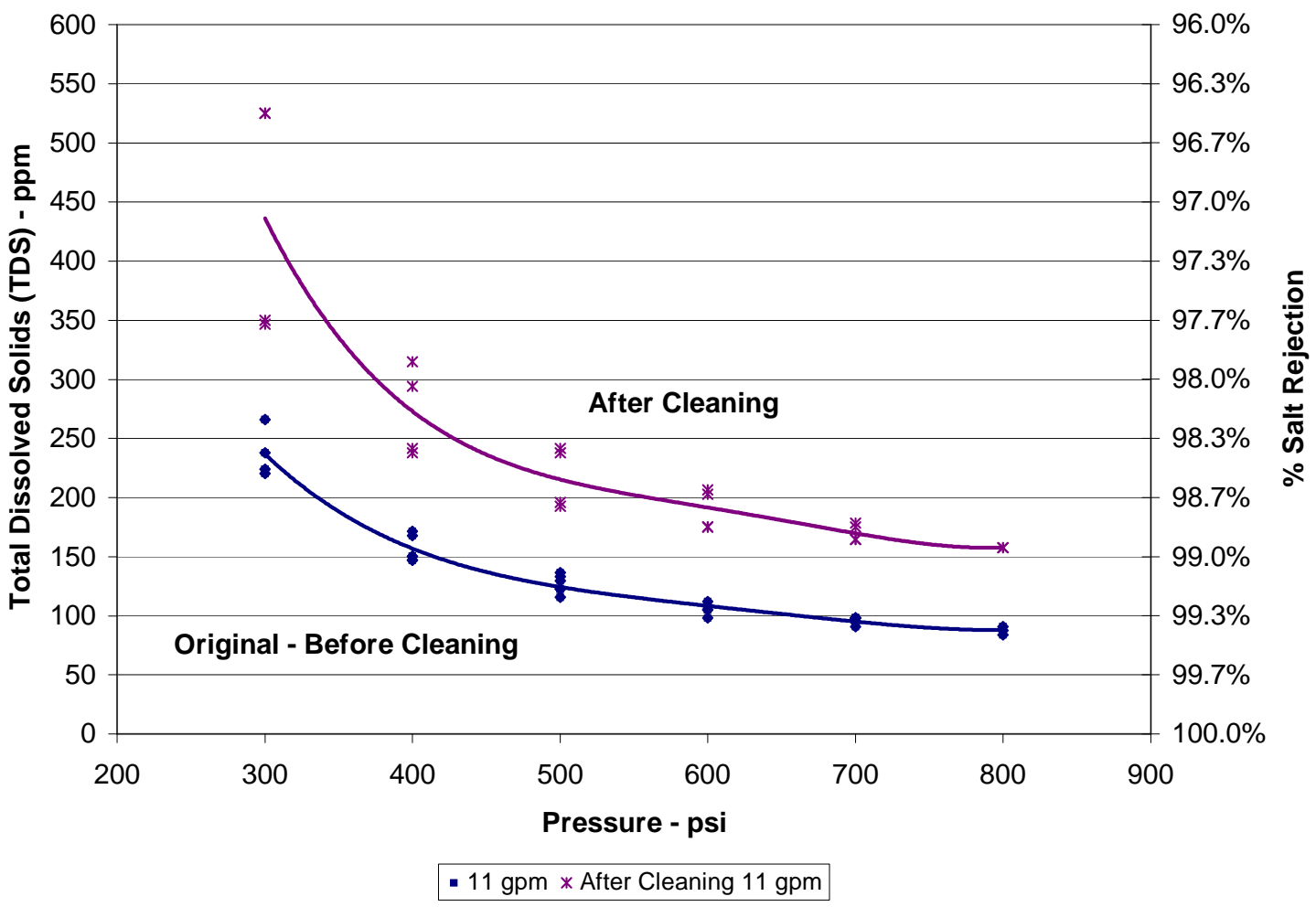

Fig. 5.30-Effect of pressure on salt concentration in permeate before and after membrane cleaning. (15,000 ppm TDS produced water feed. Feed flow rate $=11$ gpm).

At 550 psi the TDS concentrations in the permeate was $200 \mathrm{ppm}$ and the corresponding salt rejection was about $98.7 \%$ after the membrane was cleaned and the and permeate TDS concentration was $120 \mathrm{ppm}$ and $99.2 \%$ salt rejection before membrane cleaning at 
the same pressure. At 800 psi operating pressure, salt rejection was $99.4 \%$ with $90 \mathrm{ppm}$ TDS in the permeate before membrane cleaning, and $160 \mathrm{ppm}$ TDS in the permeate corresponding to $98.9 \%$ salt rejection by the membrane after membrane cleaning. This shows that there is only about $0.5 \%$ difference in salt rejection before and after the membrane was cleaned which is still a very good salt rejection.

It should be noted is that this membrane cleaning cycle was very aggressive as the membrane was completely fouled by the oil that leaked into the system. Normally this aggressive membrane cleaning run would not be required until and unless there was a big system upset and the membrane got fouled by excessive amounts of oil present in the feed. This was demonstrated later on when the membrane was cleaned prior to storage after all the experiments had been performed. 


\section{CHAPTER VI ECONOMICS OF WATER TREATMENT}

\section{Introduction}

Economics of produced water treatment depends on many factors. These factors include the amount of suspended and dissolved hydrocarbons present in the produced water, amount of suspended and dissolved solids (salts) present in the produced water. Cost of treating the produced water also depends on the final quality of the permeate (treated water) that is required by treating the produced water (final TDS in the produced water).

One of the most important factors affecting the cost of treating the produced water is the amount of total recovery from produced water that is required. As the amount of recovery is increased the operating and the capital costs go up because of higher pressures involved for higher recoveries (as the equipment becomes more expensive). But at the same time the operating and capital cost per gallon of water treated/recovered may go down. There is a fine balance involved in deciding the amount of water to be recovered and the minimum treated water price. This involves a lot of optimization process and actual field testing of the water treatment module to determine the actual operating conditions for most economical treatment price for produced water treatment.

Results of water treatment costs for produced water with of 15,000 ppm total dissolved solids (TDS) and about 200 ppmC TOC (hydrocarbons) are presented in this chapter. These water treatment costs are based on two scenarios:

a) A large mobile produced water treatment unit with a maximum feed flow rate capacity of 14,000 gallons per day with 50\% recovery (7,000 gallons per day permeate/treated water rate).

b) A smaller mobile produced water treatment unit with a maximum feed flow rate capacity of 6,000 gallons per day with 50\% recovery (3,000 gallons per day permeate/treated water rate).

These two scenarios have been further subdivided in two cases. These two cases are that after the first stage pretreatment, before the water is passed through the organoclay, the amount of hydrocarbons present in the produced water is reduced either to $80 \mathrm{ppmC}$ TOC or 30 ppmC TOC.

The total water treatment cost consists of capital cost per gallon treated produced water (permeate) and operating cost per gallon treated produced water (permeate). The operating costs are based on the results of the experiments conducted. 


\section{Capital Costs}

Table 6.1 gives the capital costs involved in assembling the produced water treatment units based on produced water feed flow rates of 14,000 and 6,000 gpd (gallons per day) respectively. Costs of these units are based on existing retail market price of the equipment, and it is assumed that all the components are purchased individually and then assembled to manufacture the water treatment unit. These prices are for mobile pilot field water treatment units and not for commercial units. If these units are manufactured commercially it is expected that the price would go down.

The primary oil/water separation equipment consists of one of the traditional oil/water separation equipments that are used in the oil field. This may include a conventional API oil/water separator, plate separator, hydrocyclone, air sparged hydrocyclone, centrifuge, or one of the other equipments that are discussed in earlier. The organoclay equipment includes a column of activated carbon for the removal of any final remaining dissolved hydrocarbons (BTEX) that may be present in the treated water after it is treated by the membranes.

\section{1-CAPITAL COST FOR PRODUCED WATER TREATMENT UNITS FOR ,,000 AND 6,000 GPD PRODUCED WATER TREATMENT UNITS.}

\begin{tabular}{|l|c|c|}
\hline Produced Water Flow Rate & $\begin{array}{c}14000 \mathrm{gpd} \\
(9.72 \mathrm{gpm})\end{array}$ & $\begin{array}{c}6000 \mathrm{gpd} \\
(4.17 \mathrm{gpm})\end{array}$ \\
\hline Capital Investment & & \\
\hline Primary Oil/Water Separation Equipment & $\$ 18,000$ & $\$ 12,000$ \\
\hline Organoclay Equipment (+ Activated Carbon) & $\$ 12,000$ & $\$ 8,000$ \\
\hline Membrane Unit R/O & $\$ 55,000$ & $\$ 45,000$ \\
\hline Instrumentation \& Control & $\$ 10,000$ & $\$ 10,000$ \\
\hline Miscellaneous & $\$ 0$ & $\$ 0$ \\
\hline Total Capital Investment & $\$ 95,000$ & $\$ 75,000$ \\
\hline
\end{tabular}

Capital price for desalination of the produced water is based on using six 4x40" spiral Hydranautics reverse osmosis membranes for the 14,000 gpd treatment unit, and six 2.5x40" spiral Hydraunatics RO membranes for the 6,000 gpd treatment unit. Membrane surface area for the 4 " membrane is $70 \mathrm{ft}^{2}$ per element and $40 \mathrm{ft}^{2}$ per element for 2.5 ” membrane.

Instrumentation and controls refers to all the controls and instrumentation that are needed for automation, data collection (pressure, temperature, flow rates, weather data, etc), and 
data transmission from field to office. Delivery system consists of transporting the treated water from the water treatment unit to the actual point of application within an area of 1 acre around the mobile water treatment unit.

Table 6.2 gives the capital cost of treating produced water on per gallon (bbl) treated water (permeate) based on amortization of capital investment over 3, 5, 7 and 10 year periods. Straight-line amortization schedule has been used to calculate the costs for different time periods. The capital cost for both the 14,000 gpd and 6,000 gpd units has been calculated.

\section{E 6.2-CAPITAL COST PER GALLON (BBL) TREATED WATER ASSUMING IIZATION OVER 3, 5, 7 AND 10 YEAR PERIOD FOR 14,000 AND 6,000 GPD PRODUCED WATER TREATMENT UNITS.}

\begin{tabular}{|c|c|c|c|c|c|c|c|c|}
\hline $\begin{array}{c}\text { Produced Water Flow } \\
\text { Rate }\end{array}$ & \multicolumn{4}{|c|}{14000 gpd (9.72 gpm) } & \multicolumn{4}{|c|}{6000 gpd (9.72 gpm) } \\
\hline $\begin{array}{c}\text { Treated Water } \\
\text { (Permeate) Flow Rate }\end{array}$ & \multicolumn{4}{|c|}{7000 gpd (4.86 gpm) } & \multicolumn{4}{|c|}{3000 gpd (2.08 gpm) } \\
\hline Total Capital Investment & \multicolumn{4}{|c|}{$\$ 95,000$} & \multicolumn{4}{|c|}{$\$ 75,000$} \\
\hline $\begin{array}{c}\text { Unit Life (years) } \\
\text { (amortization period) }\end{array}$ & 3 & 5 & 7 & 10 & 3 & 5 & 7 & 10 \\
\hline $\begin{array}{l}\text { Capital Cost } \\
\text { (\$/year) }\end{array}$ & 31,667 & 19,000 & 13,571 & 9,500 & 25,000 & 15,000 & 10,714 & 7,500 \\
\hline $\begin{array}{l}\text { Capital Cost } \\
\text { (\$/gal permeate) }\end{array}$ & 1.24 & 0.74 & 0.53 & 0.37 & 2.28 & 1.37 & 0.98 & 0.68 \\
\hline $\begin{array}{c}\text { Capital Cost } \\
\text { (\$/bbl permeate) }\end{array}$ & 0.52 & 0.31 & 0.22 & 0.15 & 0.95 & 0.57 & 0.41 & 0.28 \\
\hline
\end{tabular}

\section{Operating Costs}

\subsubsection{Operating Cost for Primary Oil/Water Separation (Hydrocarbon Removal)}

Table 6.3 gives operating costs for the primary removal of suspended hydrocarbons from the produced water before it is passed through the organoclay. It is assumed that the primary oil/water separation will be done using one of the conventional oil/water separation equipment, which is discussed in Chapters II and III. This equipment may consist of traditional API separator, dissolved air flotation (DAF), hydrocyclone, centrifuge, etc. 
The input hydrocarbon concentration of the produced water to the primary oil removal equipment is $200 \mathrm{ppmC}$ TOC, and the output concentration of the produced water is between 80 - 30 ppmC TOC. Operating costs for produced water feed flow rates of 14,000 gpd and 6,000 gpd and 50\% recovery have been calculated. The results are given in Table 6.3.

\begin{tabular}{|c|c|c|}
\hline $\begin{array}{r}\text { TABLE 6.3-OPERATING COS } \\
\text { (REMOVAL OF HYDROCARBONS } \\
6,000 \text { GPD PRODUC }\end{array}$ & $\begin{array}{l}\text { R PRIMARY OIL/WAT } \\
\text { OM PRODUCED WAT } \\
\text { WATER TREATMENT }\end{array}$ & $\begin{array}{l}\text { R SEPARATION } \\
\text { R) FOR 14,000 AND } \\
\text { JITS. }\end{array}$ \\
\hline Produced Water Flow Rate & 14000 gpd (9.72 gpm) & $6000 \mathrm{gpd}(4.17 \mathrm{gpm})$ \\
\hline Treated Water (Permeate) Flow Rate & 7000 gpd (4.86 gpm) & $3000 \mathrm{gpd}(2.08 \mathrm{gpm})$ \\
\hline Electricity Cost & \$0.1/Kwatt-hr & \$0.1 /KWatt-hr \\
\hline Pump Pressure & 5 psi & 5 psi \\
\hline Other Motor Power & $1 \mathrm{hp}$ & $1 \mathrm{hp}$ \\
\hline \multirow{2}{*}{ Pretreatment Power Requirements } & $1.04 \mathrm{hp}$ & $1.02 \mathrm{hp}$ \\
\hline & 0.78 Kwatt & 0.76 Kwatt \\
\hline \multirow{2}{*}{ Electricity Cost } & $0.03 \$ / g a l$ perm & $0.06 \$ /$ gal perm \\
\hline & $1.12 \$ / b b l$ perm & $2.55 \$ / b b l$ perm \\
\hline \multirow{2}{*}{$\begin{array}{l}\text { Total Operating Costs - Primary } \\
\text { Oil/Water Separation }\end{array}$} & $0.03 \$ / g a l$ & $0.06 \$ / g a l$ \\
\hline & 1.12 \$/bbl perm & $2.55 \$ / b b l$ perm \\
\hline
\end{tabular}

\subsubsection{Operating Cost for Treating Produced Water with Organoclay}

Table 6.4 gives the calculation details for treating produced water with organoclay for the removal of hydrocarbons from the produced water. Calculations are based on produced water being passed through two containers of organoclay with 5 minutes resonance time with organoclay in each container. Produced water feed flow rates of 14,000 gpd and 6,000 gpd have been used to determine the operating costs. Additionally two more scenarios have also been considered. It is assumed that the amount hydrocarbons present in the produced water as it exits the primary oil/water separation equipment is reduced to either 80 ppmC TOC or 30 ppmC TOC. Operating costs using both these hydrocarbon concentrations at the inlet to the organoclay have been calculated for the two produced 
water feed flow rates. The hydrocarbon concentration of the produced water at the exit of the organoclay is assumed to be 3 ppmC TOC.

The details of the cost calculations are provided in Table 6.4. Cost of organoclay used for these calculations is $\$ 2 / \mathrm{lb}$ and the density of the organoclay is $46 \mathrm{lb} / \mathrm{ft}^{3}$.

\subsubsection{Operating Cost for Membranes}

Table 6.5 lists the operating cost for membranes for produced water feed flow rate of 14,000 gpd and 6,000 gpd. It is assumed that the membranes are operated at 700 psi operating pressure and recovery from for $15,000 \mathrm{ppm}$ TDS produced water is $50 \%$. The recovered treated water (permeate) is less than 500 ppm TDS based on the experimental results obtained earlier. Operating costs for the membranes are based on the experimental results of flux, recoveries, salt rejection and fouling experiments conducted.

\subsubsection{Operating Costs for Water Delivery System}

Table 6.6 gives the operating costs for the treated water delivery system. Operating costs for the delivery system consists of transporting the treated water from the water treatment unit to the actual point of application within an area of 1 acre around the mobile water treatment unit for irrigation purposes.

\section{TABLE 6.4-OPERATING COSTS FOR PRODUCED WATER TREATMENT WITH ORG FOR 14,000 AND 6,000 GPD PRODUCED WATER TREATMENT UNITS.}

\begin{tabular}{|l|c|c|c|c|}
\hline Produced Water Flow Rate & \multicolumn{2}{|c|}{$14000 \mathrm{gpd}(9.72 \mathrm{gpm})$} & $6000 \mathrm{gpd}(4.17 \mathrm{gpm})$ \\
\hline $\begin{array}{l}\text { Treated Water (Permeate) } \\
\text { Flow Rate }\end{array}$ & \multicolumn{2}{|c|}{$7000 \mathrm{gpd}(4.86 \mathrm{gpm})$} & $3000 \mathrm{gpd}(2.08 \mathrm{gpm})$ \\
\hline Electricity Cost & \multicolumn{2}{|c|}{$0.1 \$ / \mathrm{KWatt}-\mathrm{hr}$} & \multicolumn{2}{|c|}{$0.1 \$ / \mathrm{KWatt}-\mathrm{hr}$} \\
\hline \multirow{2}{*}{ Pump Pressure } & \multicolumn{2}{|c|}{$10 \mathrm{psi}$} & \multicolumn{2}{c|}{$10 \mathrm{psi}$} \\
\hline $\begin{array}{l}\text { TOC in Produced Water } \\
\text { (pre-treated) }\end{array}$ & $30 \mathrm{ppmC}$ & $80 \mathrm{ppmC}$ & $30 \mathrm{ppmC}$ & $80 \mathrm{ppmC}$ \\
\hline \multirow{2}{*}{$\begin{array}{l}\text { TOC removed by } \\
\text { Organoclay }\end{array}$} & $27 \mathrm{ppmC}$ & $77 \mathrm{ppmC}$ & $27 \mathrm{ppmC}$ & $77 \mathrm{ppmC}$ \\
\cline { 2 - 5 } & $0.0002 \mathrm{lb} / \mathrm{gal}$ & $0.0006 \mathrm{lb} / \mathrm{gal}$ & $0.0002 \mathrm{lb} / \mathrm{gal}$ & $0.0006 \mathrm{lb} / \mathrm{gal}$ \\
\cline { 2 - 5 } & $0.0095 \mathrm{lb} / \mathrm{bbl}$ & $0.0270 \mathrm{lb} / \mathrm{bbl}$ & $0.0095 \mathrm{lb} / \mathrm{bbl}$ & $0.0270 \mathrm{lb} / \mathrm{bbl}$ \\
\cline { 2 - 5 } Fluid Volume in Tank & $3.1545 \mathrm{lb} / \mathrm{day}$ & $8.9963 \mathrm{lb} / \mathrm{day}$ & $1.3519 \mathrm{lb} / \mathrm{day}$ & $3.8555 \mathrm{lb} / \mathrm{day}$ \\
\hline $\begin{array}{l}\text { Tank Volume (assuming } \\
25 \% \text { porosity) }\end{array}$ & $97.22 \mathrm{gal}$ & $97.22 \mathrm{gal}$ & $41.67 \mathrm{gal}$ & $41.67 \mathrm{gal}$ \\
\hline Organoclay Volume in Tank & $388.89 \mathrm{gal}$ & $388.89 \mathrm{gal}$ & $166.67 \mathrm{gal}$ & $166.67 \mathrm{gal}$ \\
\hline Weight of Organoclay & $291.67 \mathrm{gal}$ & $291.67 \mathrm{gal}$ & $125.00 \mathrm{gal}$ & $125.00 \mathrm{gal}$ \\
\hline
\end{tabular}


Burnett \& Siddiqui. “Recovery of Fresh Water Resources

\begin{tabular}{|c|c|c|c|c|}
\hline $\begin{array}{l}\text { Weight of Hydrocarbons } \\
\text { held by Organoclay } \\
\text { ( } 50 \% \text { of its weight) }\end{array}$ & $896.77 \mathrm{lb}$ & $896.77 \mathrm{lb}$ & $384.33 \mathrm{lb}$ & $384.33 \mathrm{lb}$ \\
\hline $\begin{array}{l}\text { Change out Time for } \\
\text { Organoclay }\end{array}$ & 284.28 days & 99.68 days & 284.28 days & 99.68 days \\
\hline No. of change outs required & 1.28 per year & 3.66 per year & 1.28 per year & 3.66 per year \\
\hline Cost of Organoclay & $\$ 12.62$ /day & $\$ 35.99$ /day & $\$ 5.41$ /day & $\$ 15.42$ /day \\
\hline \multirow{2}{*}{ Organoclay Power } & $0.079 \mathrm{hp}$ & $0.079 \mathrm{hp}$ & $0.034 \mathrm{hp}$ & $0.034 \mathrm{hp}$ \\
\hline & 0.059 Kwatt & 0.059 Kwatt & 0.025 Kwatt & 0.025 Kwatt \\
\hline \multirow{2}{*}{$\begin{array}{l}\text { Electricity Cost - } \\
\text { Organoclay }\end{array}$} & $\begin{array}{l}0.002 \$ / g a l \\
\text { perm }\end{array}$ & $\begin{array}{l}0.002 \$ / g a l \\
\text { perm }\end{array}$ & $\begin{array}{l}0.002 \$ / g a l \\
\text { perm }\end{array}$ & $\begin{array}{l}0.002 \$ / g a l \\
\text { perm }\end{array}$ \\
\hline & $\begin{array}{l}0.0846 \$ / b b l \\
\text { perm }\end{array}$ & $\begin{array}{l}0.0846 \$ / \mathrm{bbl} \\
\text { perm }\end{array}$ & $\begin{array}{l}0.0846 \$ / \mathrm{bbl} \\
\text { perm }\end{array}$ & $\begin{array}{l}0.0846 \$ / b b l \\
\text { perm }\end{array}$ \\
\hline \multirow{2}{*}{ Organoclay Cost } & $0.18 \$ /$ gal perm & $0.51 \$ /$ gal perm & $0.18 \$ /$ gal perm & $0.51 \$ / g a l$ perm \\
\hline & $7.57 \$ / \mathrm{bbl}$ perm & $\begin{array}{l}21.59 \$ / b b l \\
\text { perm }\end{array}$ & 7.57 థ/bbl perm & $\begin{array}{l}21.59 \$ / b b l \\
\text { perm }\end{array}$ \\
\hline \multirow{2}{*}{$\begin{array}{l}\text { Total Operating Cost - } \\
\text { Organoclay }\end{array}$} & $0.18 \$ /$ gal perm & $0.52 \$ /$ gal perm & $0.18 \$ /$ gal perm & $0.52 \$ / g a l$ perm \\
\hline & $7.66 \$ / \mathrm{bbl}$ perm & $\begin{array}{l}21.68 \$ / b b l \\
\text { perm }\end{array}$ & $7.66 \$ / \mathrm{bbl}$ perm & $\begin{array}{l}21.68 \$ / b b l \\
\text { perm }\end{array}$ \\
\hline
\end{tabular}

TABLE 6.5-OPERATING COSTS FOR MEMBRANES FOR 14,000 AND 6,000 GPD PRODUCED WATER TREATMENT UNITS.

\begin{tabular}{|l|c|c|}
\hline Produced Water Flow Rate & $14000 \mathrm{gpd}(9.72 \mathrm{gpm})$ & $6000 \mathrm{gpd}(4.17 \mathrm{gpm})$ \\
\hline Treated Water (Permeate) Flow Rate & $7000 \mathrm{gpd}(4.86 \mathrm{gpm})$ & $3000 \mathrm{gpd}(2.08 \mathrm{gpm})$ \\
\hline Membrane Operating Pressure & $700 \mathrm{psi}$ & $700 \mathrm{psi}$ \\
\hline Electricity Cost & $\$ 0.1 / \mathrm{KWatt}-\mathrm{hr}$ & $\$ 0.1 / \mathrm{KWatt}-\mathrm{hr}$ \\
\hline Membrane life, years & 0.5 & 0.5 \\
\hline Membrane cost, \$/element & 400 & 250 \\
\hline Number of elements & 6 & 6 \\
\hline Cost of Chemicals (\$/gal) & 0.001 & 0.001 \\
\hline Pump Power & $5.51 \mathrm{hp}$ & $2.36 \mathrm{hp}$ \\
\hline Membrane Cost & $\$ 13.15 / \mathrm{day}$ & $\$ 8.22 / \mathrm{day}$ \\
\cline { 2 - 4 } & $0.19 \$ / \mathrm{gal}$ perm & 0.27 \$/gal perm \\
\hline
\end{tabular}


Burnett \& Siddiqui. “Recovery of Fresh Water Resources

\begin{tabular}{|c|c|c|}
\hline & 7.89 \$/bbl perm & 11.51 \$/bbl perm \\
\hline \multirow{3}{*}{ Water Chemical Costs } & \$14 /day & \$6 /day \\
\hline & $0.20 \$ / g a l$ perm & $0.20 \$ /$ gal perm \\
\hline & 8.40 \$/bbl perm & $8.40 \$ / b b l$ perm \\
\hline \multirow{2}{*}{ Membrane Power } & 0.0019 hp & $0.0027 \mathrm{hp}$ \\
\hline & $0.0789 \mathrm{Kwatt}$ & $0.1151 \mathrm{Kwatt}$ \\
\hline \multirow{2}{*}{ Electricity Cost } & $0.14 \$ /$ gal perm & $0.14 \$ / g a l$ perm \\
\hline & 5.92 థ/bbl perm & $5.92 \$ / b b l$ perm \\
\hline \multirow{2}{*}{ Total Operating Cost - Membrane } & $0.53 \$ / g a l$ perm & $0.62 \$ / g a l$ perm \\
\hline & $22.21 \$ / b b l$ perm & $25.83 \$ / \mathrm{bbl}$ perm \\
\hline
\end{tabular}




\section{TABLE 6.6. OPERATING COSTS FOR TREATED WATER (PERMEATE) DELIVERY SYSTEM FOR 14,000 AND 6,000 GPD PRODUCED WATER TREATMENT UNITS.}

\begin{tabular}{|c|c|c|}
\hline Produced Water Flow Rate & 14000 gpd (9.72 gpm) & 6000 gpd (4.17 gpm) \\
\hline Treated Water (Permeate) Flow Rate & 7000 gpd (4.86 gpm) & 3000 gpd (2.08 gpm) \\
\hline Electricity Cost & $\$ 0.1 / K w a t t-h r$ & \$0.1/Kwatt-hr \\
\hline Pump Pressure & 25 psi & 25 psi \\
\hline Irrigation Power Requirements & $0.098 \mathrm{hp}$ (0.073 KWatt) & $0.042 \mathrm{hp}$ (0.031 KWatt) \\
\hline \multirow{2}{*}{ Electricity Cost } & $0.0025 \$ / g a l$ perm & $0.0025 \$ / g a l$ perm \\
\hline & 0.1058 \$/bbl perm & $0.1058 \$ / \mathrm{bbl}$ perm \\
\hline \multirow{2}{*}{ Total Operating Costs - Delivery } & $0.0025 \$ / g a l$ & $0.0025 \$ / g a l$ \\
\hline & 0.106 \$/bbl perm & $0.106 \$ / b b l$ perm \\
\hline
\end{tabular}

\subsubsection{Total Operating Costs for Produced Water Treatment}

Table 6.7 gives the total operating cost for treating produced water with 15,000 ppm TDS and 200 ppmC TOC to primary irrigation quality water (less than 500 ppm TDS). Operating costs for 14,000 gpd and 6,000 gpd produced water treatment units are presented assuming recover of $50 \%$ ( $50 \%$ of the produced water is treated). The costs is further broken down for two more cases each, assuming $80 \mathrm{ppmC}$ TOC and $30 \mathrm{ppmC}$ TOC hydrocarbon concentration at the inlet to the organoclay.

It is seen that the total operating cost for treating the produced water ranges between 0.74

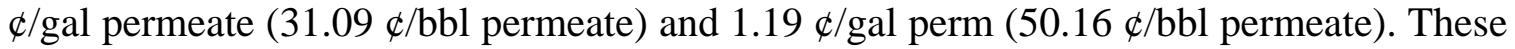
operating costs can be further reduced if more treated water (permeate) is recovered from the produced water.

TABLE 6.7. TOTAL OPERATING COST FOR WATER TREATMENT FOR 14,000 AND 6,000 GPD PRODUCED WATER TREATMENT UNITS.

Flow rate (Produced Water)

14000 gpd (9.72 gpm)

6000 gpd (9.72 gpm) 
Burnett \& Siddiqui. “Recovery of Fresh Water Resources

\begin{tabular}{|c|c|c|c|c|}
\hline $\begin{array}{l}\text { Treated Water } \\
\text { (Permeate) Flow rate }\end{array}$ & \multicolumn{2}{|c|}{7000 gpd (4.86 gpm) } & \multicolumn{2}{|c|}{3000 gpd (2.08 gpm) } \\
\hline Electricity Cost & \multicolumn{2}{|c|}{$0.1 \$ /$ Kwatt-hr } & \multicolumn{2}{|c|}{$0.1 \$ / K W a t t-h r$} \\
\hline $\begin{array}{l}\text { TOC in Produced } \\
\text { Water (pre-treated) }\end{array}$ & 30 ppmC & 80 ppmC & 30 ppmC & 80 ppmC \\
\hline \multirow{2}{*}{$\begin{array}{l}\text { Primary Oil/water } \\
\text { Separation Operating } \\
\text { Costs }\end{array}$} & $0.027 \begin{array}{c}\$ / g a l \\
\text { perm }\end{array}$ & $0.027 \begin{array}{c}\$ / g a l \\
\text { perm }\end{array}$ & $0.061 \begin{array}{l}\$ / g a l \\
\text { perm }\end{array}$ & $0.061 \begin{array}{c}\text { \$/gal } \\
\text { perm }\end{array}$ \\
\hline & $1.117 \begin{array}{c}\mathrm{\Phi} / \mathrm{bbl} \\
\text { perm }\end{array}$ & $1.117 \mathrm{p} / \mathrm{bbl}$ & $2.549 \begin{array}{l}\Phi / b b l \\
\text { perm }\end{array}$ & $2.549 \begin{array}{l}\mathrm{Q} / \mathrm{bbl} \\
\text { perm }\end{array}$ \\
\hline \multirow{2}{*}{$\begin{array}{l}\text { Operating Costs } \\
\text { Organoclay }\end{array}$} & 0.182 perm. & $0.516 \begin{array}{l}\$ / g a l \\
\text { perm }\end{array}$ & $0.182 \begin{array}{l}\Phi / g a l \\
\text { perm }\end{array}$ & $0.516 \begin{array}{c}\$ / g a l \\
\text { perm }\end{array}$ \\
\hline & $7.65 \stackrel{\$ / b b l}{\text { perm }}$ & $21.67 \begin{array}{c}\mathrm{\Phi} / \mathrm{bbl} \\
\text { perm }\end{array}$ & $7.65 \stackrel{\$ / b b l}{\text { perm }}$ & $21.67 \begin{array}{c}\mathrm{\Phi} / \mathrm{bbl} \\
\text { perm }\end{array}$ \\
\hline \multirow{2}{*}{$\begin{array}{l}\text { Membrane Operating } \\
\text { Cost }\end{array}$} & $0.529 \begin{array}{l}\$ / \text { gal } \\
\text { perm }\end{array}$ & $0.529 \begin{array}{c}\$ / g a l \\
\text { perm }\end{array}$ & $0.615 \begin{array}{l}\text { \$/gal } \\
\text { perm }\end{array}$ & $0.615_{\text {perm }}^{\Phi / g a l}$ \\
\hline & $22.21 \begin{array}{c}\Phi / g a l \\
\text { perm }\end{array}$ & $22.21 \begin{array}{c}\Phi / g a l \\
\text { perm }\end{array}$ & $25.83 \begin{array}{l}\text { \$/gal } \\
\text { perm }\end{array}$ & $25.83 \begin{array}{c}\Phi / g a l \\
\text { perm }\end{array}$ \\
\hline \multirow{2}{*}{$\begin{array}{l}\text { Delivery Operating } \\
\text { Costs }\end{array}$} & $0.003 \begin{array}{c}\$ / g a l \\
\text { perm }\end{array}$ & $0.003 \begin{array}{c}\$ / g a l \\
\text { perm }\end{array}$ & $0.003 \begin{array}{l}\$ / \text { gal } \\
\text { perm }\end{array}$ & $0.003 \begin{array}{c}\Phi / g a l \\
\text { perm }\end{array}$ \\
\hline & $0.106 \underset{\text { perm }}{\Phi / g a l}$ & $0.106 \begin{array}{c}\text { \$/gal } \\
\text { perm }\end{array}$ & $0.106 \begin{array}{c}\text { \$/gal } \\
\text { perm }\end{array}$ & $0.106 \underset{\text { perm }}{\Phi / \text { gal }}$ \\
\hline \multirow{2}{*}{ Total Operating Cost } & $0.74 \begin{array}{l}\text { \$/gal } \\
\text { perm }\end{array}$ & $1.07 \begin{array}{l}\$ / \text { gal } \\
\text { perm }\end{array}$ & $0.86 \begin{array}{l}\$ / \text { gal } \\
\text { perm }\end{array}$ & $1.19 \begin{array}{l}\Phi / g a l \\
\text { perm }\end{array}$ \\
\hline & $31.09 \begin{array}{l}\$ / \text { gal } \\
\text { perm }\end{array}$ & $45.11 \begin{array}{l}\Phi / g a l \\
\text { perm }\end{array}$ & $36.14 \begin{array}{l}\Phi / g a l \\
\text { perm }\end{array}$ & $50.16 \underset{\text { perm }}{\Phi / \text { gal }}$ \\
\hline
\end{tabular}




\section{Total Water Treatment Costs}

Table 6.8 gives the total cost for treating 15,000 ppm TDS produced water to primary irrigation quality water. It is seen that for a 3-year amortization schedule the cost of treating water is the highest in all cases and is uneconomical. 3-year life for the water treatment unit is very small. It is expected that the water treatment unit will be functional for at least a period of 5 years, assuming it is compared to an ordinary automobile. On the other hand if the water treatment unit is compared to any normal industrial equipment, the life of the mobile unit can be approximated to 10 years.

For a life time of 5 years the cheapest water treatment cost per gallon permeate obtained is $1.48 / \mathrm{gal}$ permeate ( $\$ 0.6233 / \mathrm{bbl}$ permeate) for the 14,000 gpd water treatment unit and 30 ppmC TOC hydrocarbon concentration at the inlet of the organoclay. For the 6,000 gpd mobile unit, the water treatment cost is 3.48 \$/gal permeate $(\$ 1.4605 / \mathrm{bbl}$ permeate) for 80 ppmC TOC hydrocarbon concentration at the organoclay inlet.

Water treatment cost for 14,000 gpd and 6,000 gpd water treatment units, for 10 year unit life, is between $1.11 \$$ /gal permeate ( $\$ 0.4671 / \mathrm{bbl}$ permeate) and $1.88 \mathrm{\$} /$ gal permeate ( $\$ 0.7893 / \mathrm{bbl}$ permeate). The most economical water treatment cost for produced water is $1.11 \mathrm{\$} /$ gal permeate ( $\$ 0.4671 / \mathrm{bbl}$ permeate), for the 14,000 gpd water treatment unit (30 ppmC TOC hydrocarbon concentration at organoclay inlet).

If we compare the price of treating produced water to agricultural water quality with the re-injection cost of produced water then this may not be feasible as the water injection costs may be quite cheap. How ever if the disposal cost of produced water is between $\$ 0.5-1.5 / \mathrm{bbl}$ than the treatment of produced water becomes economically feasible. Also another important factor to be considered is the dollar added value the treated produced water will have for the oil field operations and the community. 


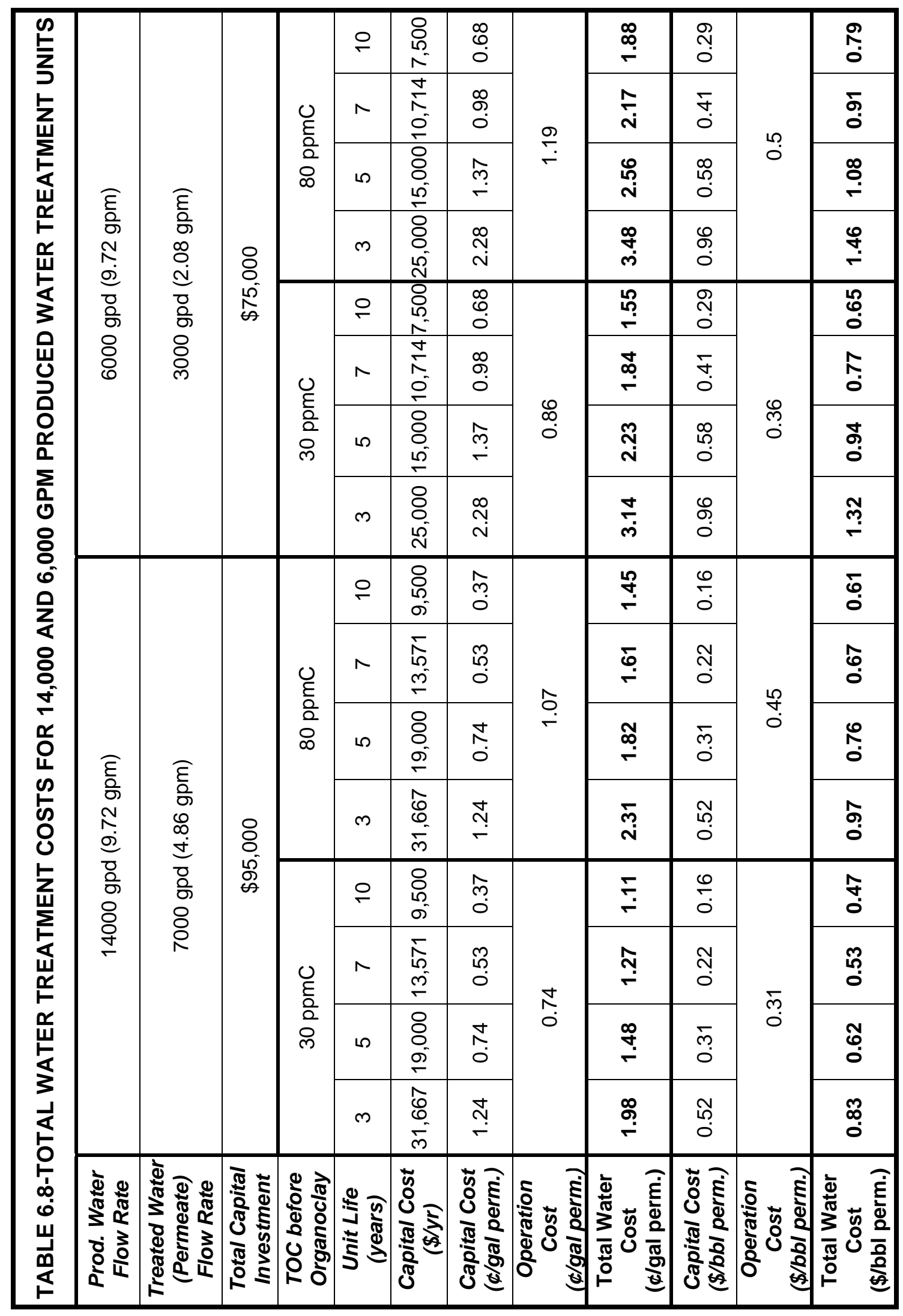


The added value will come from the beneficial use the treated produced water will have. This treated water can be used for horticulture, rangeland and ecological restoration. Table 6.9 gives a quick comparison of the treated produced water with some common products that are used every day.

\begin{tabular}{|c|c|}
\hline \multicolumn{2}{|c|}{ TABLE 6.9-A QUICK COMPARISON OF SOME COMMON PRODUCTS. } \\
\hline Product & Price \\
\hline Treated Produced Water & $\begin{array}{c}\$ 0.0198-0.0348 / \mathrm{gal} \\
(\$ 0.8315-1.4605 / \mathrm{bbl}) .\end{array}$ \\
\hline Filtered Water at Grocery Store & $\$ 0.25 / \mathrm{gal}(\$ 10.5 / \mathrm{bbl})$ \\
\hline Bottle of Aquifina / Dasani etc. & $\begin{array}{c}\$ 0.5 / \mathrm{half} \text { lit bottle } \\
(\$ 3.78 / \mathrm{gal}, \$ 158 / \mathrm{bbl})\end{array}$ \\
\hline Milk & $\$ 2.0-3.0 / \mathrm{gal}(\$ 84-126 / \mathrm{bbl})$ \\
\hline Coke / Pepsi & $\$ 1.5 / \mathrm{gal}(\$ 63 / \mathrm{bbl})$ \\
\hline Municipal Water & $\$ 0.11 / \mathrm{bbl}$ \\
\hline Oil & $\$ 50-55 / \mathrm{bbl}$ \\
\hline
\end{tabular}

Incentives also need to be given by the government in the form of tax benefits to the companies who choose to treat produced water and use this water beneficially. Thousands of dollars are spent each year by different government agencies on restoring rangelands and saving endangered wildlife. These efforts are stalled by the lack of water as in the case of "Pub Fish" in Pecos River in west Texas, which is on the verge of extinction. Availability of fresh water can speed up these recovery efforts by up to ten times. Monetary savings can be derived from the reduced time period to complete these restoration projects by the availability of fresh water by the government. If these savings can be passed on to operators who choose to treat water then this will be an added incentive for companies to look in better and more economical means of treating produced water.

Similarly communities can use the treated produced water to set up cottage industry that cannot be set due to shortage of water resources, and develop economically (as in the case of west Texas and other arid areas). The best solution on using this treated water is to let the communities themselves decide how they want to use the treated water at the price that this water can be provided to the community. This will automatically provide the highest dollar value added to the treated produced water (fresh water), as market forces will be driving the best possible use of the treated water.

However individual economic analysis needs to be done by individual companies and communities on the economic benefits that the treated water will have for them. In 
Burnett \& Siddiqui. “Recovery of Fresh Water Resources

conclusion, treatment and beneficial use of produced water is the key to sustainable development for the oil and gas industry. 


\section{CHAPTER VII}

\section{CONCLUSIONS AND RECOMMENDATIONS}

\section{Conclusions}

\subsubsection{Centrifuge}

The hydrocarbon removal efficiency of both the CINC V-02 and V-05 centrifuges was less than expected. Although CINC centrifuges perform well in other oil/water separation applications, as documented by the manufacturer, the centrifuge did not perform well for the applications of this project. It was decided not to use the CINC centrifuge as part of the water treatment process train. The V-05 centrifuge was only used in the lab for the pretreatment of the produced water for the membranes. Other method for the removal of suspended hydrocarbons from the produced water as discussed in the literature review section should be investigated and used.

\subsubsection{Organoclay}

The produced water with 80 ppmC TOC hydrocarbon concentration was run through the ET-1 organoclay packed cell for 24 hours. During the 24 hour test period, the TOC concentration of the produced water at the outlet remained below $20 \mathrm{ppmC}$ TOC. The hydrocarbon removal efficiency of the ET-1 organoclay from the produced water was about $75 \%$. This suggests that the ET-1 organoclay is effective in taking out the organics from produced water when the resonance time is kept between 3-6 minutes.

There were about 20 ppmC TOC hydrocarbons still present in the produced water exiting the organoclay cell. To remove these hydrocarbons another container of organoclay should be used in series to remove the hydrocarbons to the minimum level.

\subsubsection{Membrane Selection for the Removal of Hydrocarbons}

Produced water with hydrocarbon concentration of $110 \mathrm{ppmC}$ TOC and 45,000 ppm TDS, was run through the selected membranes at their respective operating conditions. The amount of organics present in the produced water after passing through \# 19, AH1347, AH1373, FP100, FP200 and AFC30 membranes was above the required maximum allowable discharge limit of 29 ppmC. Hence these membranes were ineffective in reducing the hydrocarbon concentration in the produced water to the required level.

Although salt rejection from the produced water by FP100, FP200, \# 19, AH1347 and AH1373 membranes was quite similar (about 42,5000 ppm TDS, 5.5\% salt rejection) and the TOC rejection levels varied a little, there was a big difference in the flux obtained 
across the membranes at these rejection levels. This shows that the salt rejection and the TOC rejection of by different membranes can be quite similar but the flux across the membrane can be very different from one membrane to the other. This is one of the reasons why proper selection of the membrane is a difficult procedure.

Based on the experimental results it was decided not to use any of the selected membranes for the removal of hydrocarbons from the produced water. It was decided that the hydrocarbons should be removed from the produced water using a combination of organoclay with one of the other oil/water separation techniques discussed literature review section for the pilot treatment unit.

Although there have been developments in the removal of hydrocarbons from produced water by membranes and new membranes are available for this purpose, but the costs associated with the use of these new membranes does not justify the use of these membranes for this project. The use of these membranes for the removal of hydrocarbons is justified by the volumes of produced water to be processed and other operational limitations such as weight of equipment, footprint of equipment, etc. 


\subsubsection{Membrane Selection for the Desalination of Produced Water}

The selection of the membranes for the treatment of the produced water is not an easy process. Membranes that give high flux may not give high salt rejection or hydrocarbon rejection. Similarly membranes that have high salt rejection characteristics have a low flux. Also membranes that give high salt rejections may not give high hydrocarbon rejection.

Flux obtained across AFC80 membrane was small compared to the salt rejection by the membrane. This flux would have been acceptable if the salt rejection by AFC80 was higher. AFC80 was able to remove the hydrocarbons concentration below the maximum allowable discharge limit of 29 ppmC TOC.

Salt rejection by AFC99 membrane was according to the membrane specifications but the flux across the membrane was very low. AFC99 was able to remove the organics from the produced water below the required levels. However AFC99 showed problems with handling the produced water with hydrocarbons in it. It was seen that the flux across AFC99 decreased very quickly over a short period of time while processing produced water, showing that it had fouling problems.

SWC-1-4040 gave the best salt rejection characteristics and a good flux at the same time. Hydrocarbon removal efficiency of SWC-1-4040 very good as it was able to remove the organics from the produced water below the maximum allowable limit of $29 \mathrm{ppmC}$ TOC. At the same time SWC-1-4040 membrane did not show any severe fouling problems during the screening process as AFC99 did.

AFC80, AFC99 and SWC-1-4040 are all desalination membranes and not meant for the removal of organics. The reason for running organics through these membranes was to establish that if there was a system upset or breakdown, would these membranes be able to handle the organics without any damage to the membranes and reject the hydrocarbons in the permeate below 29 ppmC TOC level.

Based on the results of the membrane screening experiments it was decided to use SWC1-4040 for the desalination of produced water and further tests were performed on this membrane.

\subsubsection{Experiments With SWC-1-4040}

Some initial membrane compaction was observed during the first pressure increase run with the SWC-1-4040 membrane. After that no more membrane compaction was observed. It was observed that exists a linear relationship between the applied pressure and the flux, and applied pressure and recovery for the SWC-1-4040 membrane. As the pressure was increased the flux and the corresponding recovery across the membrane 
increased, at constant flow rates of 8, 11 and $14 \mathrm{gpm}$, for the clean water as well as for produced water with different concentration of dissolved solids.

With clean water and produced water with 15,000 ppm it was observed that at any constant pressure, the flux decreased with increase in the feed flow rate across the membrane. The difference in the flux was more obvious as pressure was increased. For the 30,000 ppm and 45,000 ppm TDS produced water feed the flux at different feed flow rates remained constant at any fixed pressure. This showed that as the feed increases in total dissolved solids (salt) concentration, difference in flux obtained at different flow rates will become smaller, at a constant pressure, and will eventually become the same at all flow rates.

Maximum recovery across the SWC-1-4040 membrane was with clean water is about $28.0 \%$. This corresponded to the maximum flux of approximately $47 \mathrm{GFD}\left(\mathrm{gal} / \mathrm{ft}^{2} / \mathrm{day}\right)$ at a feed flow rate of $8 \mathrm{gpm}$ and 800 psi pressure. For 15,000 ppm TDS produced water the maximum permeate flux obtained across the membrane was about $28 \mathrm{GFD}$ (gal/ft ${ }^{2} /$ day) corresponding to $17.0 \%$ recovery at a pressure of 800 psi and 8 gpm feed flow rate. Maximum flux obtained with 30,000 ppm TDS produced water was 16.30 GFD at $8 \mathrm{gpm}$ feed flow rate and the corresponding maximum recovery was $9.9 \%$. For the $45,000 \mathrm{ppm}$ TDS produced water the flux remains identical at all the selected feed flow rates at any fixed pressure. Maximum flux was about 11.9 GFD at 800 psi and the maximum recovery is $7.3 \%$ at 8 gpm feed flow rate.

As the concentration of dissolved solids (salts) in the feed is increased the flux across the SWC-1-4040 membrane becomes less at any fixed pressure. It is also observed that as the concentration of salts increases in the water the minimum pressure to obtain permeate flow across the SWC-1-4040 membrane also increases and the membrane has to be operated at higher pressures. The relationship between pressure and flux is linear for all concentrations of feed and flux increases as the pressure is increased.

It is observed that for all concentration produced water feeds as the pressure is increased the TDS concentration in the permeate decreases. It was also observed that as the salt concentration in the produced water is increased, the amount of solids passing through the membrane into the permeate also increases at any fixed pressure.

Maximum salt rejection for 15,000 ppm TDS produced water was about $99.4 \%$ at 800 psi pressure and 8 gpm feed flow rate. This corresponds to approximately $85 \mathrm{ppm}$ TDS in the permeate. The minimum TDS concentration in the permeate of 30,000 TDS produced water is about $430 \mathrm{ppm}$ TDS corresponding to $98.6 \%$ salt rejection at $800 \mathrm{psi}$. The minimum TDS concentration in the permeate is of 45,000 TDS produced water was about $640 \mathrm{ppm}$ TDS corresponding to $98.6 \%$ salt rejection at $800 \mathrm{psi}$.

At 550 psi the TDS concentration is about 1000 ppm for 30,000 ppm TDS produced water. This corresponds to about $96.5 \%$ salt rejection. For the 45,000 ppm TDS produced water salt concentration in the permeate is about $1400 \mathrm{ppm}$ TDS corresponding to about $96.8 \%$ salt rejection. The quality of all the permeated water for the 15,000 ppm TDS 
produced water at all the selected pressures and flow rates is within the fresh water quality standards i.e. less than 500 ppm TDS.

SWC-1-4040 membrane rejected hydrocarbons from 40 ppmC TOC in the produced water to below 2 ppmC TOC in the permeate at all pressures and flow rates. For produced water feed with concentration of salts other than experimented with, the flux across the membrane at any pressure may be found by linear interpolation using Fig. .5.19. This will give an approximate working value of the flux at the desired pressure. Similarly flux for feed flow rates other then the ones experimented with, can also be found by interpolation from Fig. 5.19.

Similarly the concentration of total dissolved solids (salts) that will be in the permeate stream, at any fixed pressure, for produced water of different TDS concentration than the ones experimented with, can be approximated from Fig. 5.20. This can be done by linear interpolation between the pressure versus TDS curves

\subsubsection{Optimization of Operating Parameters}

Based on the energy consumed per gallon of permeate (treated water) obtained and other parameters and considerations as discussed earlier, it was decided to do the fouling profile and volume concentrate ratio (VCR) experiments at 550 psi operating pressure and $10 \mathrm{gpm}$ produced water feed flow rate with produced water of 15,000 ppm total dissolved solids (TDS) and 40 ppmC TOC hydrocarbon concentration. This feed flow rate was chosen because it is expected that the mobile water treatment units would be operating at this produced water feed flow rate. The energy consumed per gallon permeate obtained becomes nearly constant for pressures above $550 \mathrm{psi}$, as the increase in the energy demand with increase in the operating pressure is offset by increased flux across the membrane (increased recovery across the membrane).

During the 41 hour (2485 minute) fouling study, the flux across the SWC-1-4040 membrane remained nearly constant at about 14.5 GFD. This showed that there was little membrane fouling by the produced water as the produced water was processed by SWC1-4040 membrane.

From the VCR experiments we conclude that the flux and recovery by SWC-1-4040 membrane decreases linearly as the produced water is concentrated. As the VCR increases by a factor of two, the flux decreases from 14 GFD to about 4 GFD, by a factor of 2.5 and the recovery decrease by a factor of 2.5 as well for the 15,000 ppm TDS produced water.

As the produced water is concentrated from $15,000 \mathrm{ppm}$ to $45,000 \mathrm{ppm}$ TDS the concentration of salts in the permeate obtained across SWC-1-4040 membrane increases linearly from about $150 \mathrm{ppm}$ to $1300 \mathrm{ppm}$ TDS. As the VCR goes up by a factor of two the amount of salts in the permeate obtained across the membrane go up by a factor of nearly eight. This shows that as produced water is concentrated, the concentration of salts 
in permeate obtained across the membrane will increase four times, at the same pressure and flow rate, as the produced water is concentrated one times.

Using the VCR profile we can design the membrane system depending on how much total recovery is required from the feed. The permeate flux and amount of dissolved solids that will be present in the permeate can be determined from the VCR experiment.

After about 11.5 hours (685 minutes) of operation during the fouling study experiment there was a system upset and the membrane got fouled. The membrane was cleaned aggressively before operation was resumed. The flux across the membrane was the same before and after the cleaning. However there is a difference in the concentration of salts in the permeate before and after the membrane was cleaned. Before the membrane cleaning the TDS concentration in the permeate was about $115 \mathrm{ppm}$ on the average, which gives about $99.25 \%$ salt rejection by the membrane. After the membrane cleaning, salt rejection by the membrane was about 99\%, corresponding to about 140 ppm TDS in the permeate obtained across the membrane.

This proves that every time the membrane is cleaned, salt passage across the membrane will increase as the membrane is etched away due to the chemicals employed for membrane cleaning.

Regular membrane cleaning can be done using "Big Red" commercial detergent and $\mathrm{NaOH}$ as described and the flux across the membrane can be restored. If the membrane gets severely fouled due to a system upset by excessive amounts of oil in the produced water an aggressive membrane cleaning protocol can be employed. The membrane may be cleaned and flux restored using a combination of "Big Red", $\mathrm{NaOH}$ and the enzyme based detergent "Ter-A-Zyme". This was demonstrated when the membrane got fouled by a system upset with more than 1000 ppmC TOC oil present in the produced water

\subsubsection{Economics of Water Treatment Process}

An economic analysis was done to predict the water treatment costs for treating produced water with 15,000 ppm TDS and 200 ppmC TOC, based on using the technologies discussed. Two units with 14,000and 6,000 gal/day produced water feed with 50\% recovery (7,000 gpd and 3,000 gpd) were considered, with $30 \mathrm{ppmC}$ and $80 \mathrm{ppmC}$ hydrocarbon concentration at the inlet of organoclay.

Amortization schedules of 3, 5, 7 and 10 years was considered for the capital investment (cost of the mobile water treatment unit). Cost for treating water over a five year unit life (if the water treatment unit life is compared to an ordinary automobile) range between $\$ 0.5$ /bbl treated water and $\$ 1.5 / \mathrm{bbl}$ treated water for the 14,000 gpd and 6,000 gpd water treatment units. For ten year unit life the water treatment costs are predicted to be between $\$ 0.5 / \mathrm{bbl}$ treated water and $\$ 0.79 / \mathrm{bbl}$ treated water These costs of treating produced water become economically feasible whenever the cost of disposing produced water is in this range. Also another important factor to be 
considered is the dollar added value the treated produced water will have for the oil field operations and the community. However individual economic analysis needs to be done by individual companies and communities on the economic benefits that the treated water will have for them.

\subsubsection{Summary of Conclusions}

We can assemble a water treatment process train from the technologies that we tested to treat produced water. Alternates to centrifuges such as hydrocyclones need to be assessed. Work needs to be done on the organoclay to determine its break through point for the adsorption of TOC from produced water.

We can assemble a water treatment process train to treat the produced water to primary agricultural water quality standards (less than 500 ppm TDS and less than 2 ppm TOC ) from the technologies that we tested to treat produced water. Alternates to CINC centrifuge, such as hydrocyclones, separators, dissolved air flotation, etc., or other traditional technologies, need to be assed.

Organoclay proved to be effective in removing the hydrocarbon concentration of the produced water to below the required EPA regulatory limit of 29 ppmC TOC. Different membranes assessed for TOC removal did not prove to be effective in removing the hydrocarbons to the desired level.

For the desalination of produced water SWC-1-4040 membrane was selected as it gave the best combination of flux, recovery and salt rejection characteristics as well as hydrocarbon rejection if there was a system upset.

Produced water of $15,000,30,000$ and $45,000 \mathrm{ppm}$ TDS was processed through the SWC-1-4040 membrane. SWC-1-4040 membrane was effective in desalinating the produced water to levels acceptable for irrigation purposes. However, the initial total dissolved solids present in the produced water limit the maximum recovery that can be obtained using the SWC-1-4040 membrane. As the amount of TDS in the produced water increases the total recovery from the produced water decreases, as well as the flux across the membrane.

Fouling studies indicated that there exist little fouling problems associated with processing produced water of 15,000 ppm TDS. The cleaning regime employed showed that the SWC-1-4040 membrane can be cleaned successfully and flux restored to previous values. In case of severe fouling the membrane can still be cleaned using an aggressive cleaning cycle and the original flux restored, but at the expense of increased salt passage across the membrane.

A brief economic analysis was done to determine the water treatment costs. This included calculating the capital costs for building the water treatment units and the operational costs for the water treatment. The costs calculated were based on treating produced water 
with 15,000 ppm TDS and 50\% recovery. Costs were calculated for different scenarios as discussed earlier. Total water treatment casts varied in the range of $\$ 0.50$ to $\$ 1.50 / \mathrm{bbl}$ treated water. This simple economic analysis shows that the cost of treating produced water can be competitive and justified where produced water disposal costs can be avoided.

\section{Recommendations}

Work still needs to be done on the pretreatment of produced water for the removal of hydrocarbons before the produced water is passed through the membranes. As discussed previously, CINC centrifuge was not efficient in removing hydrocarbons from the produced water. Efficiency of alternate technologies to remove hydrocarbons from the produced water should be studied. Some of these technologies such as hydrocyclones, air-sparged hydrocyclones, coalescing plate separators, etc., have been discussed earlier in literature review.

Field tests need to be conducted with the water treatment unit to see how it performs over a long time period. The organoclay is going to be used in the polishing stage for the produced water before it is passed through the membranes, so that the membranes are not fouled by the organics. It is however not known that for what period of time (how long) will the organoclay be effective in removing the hydrocarbons from the produced water. Adsorption capacity of the organoclay needs to be studied and the breakthrough time for the organoclay needs to be determined. Also how the organoclay will behave if there is system upset and surge in the hydrocarbons in the produced water needs to be determined. To determine all these criteria field tests need to be performed.

SWC-1-4040 membrane performed well in the lab experiments. Field tests need to be performed on the membrane to assess its fouling, salt rejection and flux characteristics in the field with different kinds of produced water over a long period of time to determine the membranes proper life and efficiency.

This is an ongoing project with room for continuous improvement as new and better technologies are developed, both in the field of oil/water separations and membranes. Different companies are developing new membranes with better flux and salt rejection characteristics and lower power requirements. Their use and performance should be investigated. New and alternate oil/water separation techniques are also available. These should also be looked into.

This research project is envisioned to be the basis for justification that produced water is a resource rather than a waste. Produced water can be economically treated to irrigation quality water and be an important component of sustainable development of the communities where oil and gas industry operates. 


\section{REFERENCES}

1. “Oil and Gas Production Statistics for Texas for the Year 2000," Texas Railroad Commission, Austin, Texas (2001).

2. Lyngbeak, M. E. and Blidegn, L, H.: "Produced Water Management” paper SPE 23312 presented at the 1991 First International Conference on Health, Safety and Environment held in The Hague, Netherlands, 10-14 November.

3. Ukpohor, T. O.: "Produced Water: Environmental Issues/ Technological Solution of the Nigeria Depletion Era” paper SPE 71437 presented at the 2001 SPE Annual Technical Conference \& Exhibition held in New Orleans, Louisiana, 30 September-3 October.

4. Lawrence, A. W., Miller, J. A. and Miles, D. L.: “An Evaluation of Produced Water Management Options in the Natural Gas Production Industry” paper SPE 26004 presented at the 1993 SPE/EPA Exploration and Production Environment Conference held at San Antonio, Texas, 7-10 March.

5. Lawrence, A. W. et al.: "Regional Assessment of Produced Water Treatment and Disposal Practices and Research Needs,” paper SPE 29729 presented at the 1995 SPE/EPA Exploration \& Production Environmental Conference held in Houston, 2729 March.

6. Kjos, T., Michelet, J. F. and Kleppe, J.: “Down-Hole Water-Oil Separation and Water Re-injection Through Well Branches” paper SPE 30518 presented at the 1995 SPE Annual Technical Conference \& Exhibition held in Dallas, 22-25 October.

7. Willde, D. I., Kennedy, W. L. and Tracy, K. F.: "Produced Water Disposal - A Learning Curve in Yemen” paper SPE 35030 presented at the 1996 SPE Formation Damage Symposium held at Lafayette, Louisiana, 14-15 February.

8. Evans, R.: “Decision Analysis for Integrated Reservoir Management” paper SPE 65148 presented at the 2000 SPE European Petroleum Conference held in Paris, France, 24-25 October.

9. Khatib, Z. I.: "Handling, Treatment, and Disposal of Produced Water in the Offshore Oil Industry,” paper SPE 48992 presented at the 1998 SPE Annual Technical Conference \& Exhibition in New Orleans, 27-30 September.

10. Evans, P. and Robinson, K.: "Produced Water Management - Reservoir and Facilities Engineering Aspects” paper SPE 53254 presented at the 1999 SPE Middle East Oil Show held in Bahrain, 20-23 February. 
11. Johnsen S., Frost, T. K., Hjelsvold, M. and Utvik, T. R.: “The Environmental Impact Factor - A proposed Tool For Produced Water Impact Reduction, Management and Regulation” paper SPE 61178 presented at the 2000 SPE International Conference on Health, Safety, and the Environment in Oil and Gas Exploration and Production held in Stavanger, Norway, 26-28 June.

12. Evans, R.: "Produced Water Management Strategy With the Aid of Decision Analysis” paper SPE 66543 presented at the 2001 SPE/EPA/DOE Exploration and Production Environmental Conference held in San Antonio, Texas, 26-28 February.

13. Georgie, W. J., Sell, D. and Baker, M. J.: "Establishing Best Practicable Environmental Option Practice for Produced Water Management in the Gas and Oil Production Facilities" paper SPE 66545 presented at the 2001 SPE/EPA/DOE Exploration and Production Environmental Conference held in San Antonio, Texas, 26-28 February.

14. Priatna, R., Pertamina, B. P. and Wusono, S. B.: “Application of Produced Water Technology Practices in Indonesia Upstream Petroleum Industry” paper SPE 68715 presented at the 2001 SPE Asia Pacific Oil and Gas Conference held in Jakarta, Indonesia, 17-19 April.

15. Matthews, C. M., Chachula, R., Peachey, B. R. and Solanki, S.C.: “Application of Downhole Oil/Water Separation Systems in the Alliance Field” paper SPE 35817 presented at the 1995 Third International Conference on Health, Safety \& Environment in Oil \& Gas Exploration and Production held in New Orleans, 9-12 June.

16. Shaw, C.: "Downhole Separation as a Strategic Water and Environmental Management Tool” paper SPE 61186 presented at the 2000 SPE International Conference on Health, Safety, and the Environment in Oil and Gas Exploration and Production held in Stavanger, Norway, 26-28 June.

17. Blanco, A. E. and Davies, D. R.: “Technical \& Economic Application Guidelines for Downhole Oil-Water Separation Technology” paper SPE 67182 presented at the 2001 SPE Production and Operations Symposium held in Oklahoma City, 24-27 March.

18. Farid, E. E. and Nour, M. H.: "Subsurface Brine Injection: Proactive Approach to Close the Produced Water Loop in the Western Desert of Egypt” paper SPE 35875 presented at the 1996 International Conference on Health, Safety \& Environment held in New Orleans, 9-12 June.

19. Schneider, B. and Freeman, D.: "The Use of Brine as an Injection Fluid to Reduce Disposal Cost and Increase Gas Production” paper SPE 65615 presented at the at the 2000 SPE Eastern Regional Meeting held in Morgantown, West Virginia, 17-19 October. 
20. Hoffman, H. W.: “Texas Water Reuse Update” presented at the $199825^{\text {th }}$ Water for Texas Conference held in Houston, 3-5 December.

21. Zinberg, M. B., Nenasheva, M. N. and Gafarov, N. A.: "Cost Effective Modular Unit for Cleaning Oil and Gas Field Waste Water" paper SPE 36037 presented at the 1996 International Conference on Health, Safety and Environment held in New Orleans, 912 June.

22. Miller, J. A., Lawerence, A. W., Hickey, R. F. and Hayes, T. D.: "Pilot Plant Treatment for Natural Gas Produced Waters to Meet Beneficial Use Discharge Requirements” paper SPE 37903 presented at the 1997 SPE/EPA Exploration and Production Environmental Conference held in Dallas, 3-5 March.

23. Doran, G. F. et al.: "Evaluation of Technologies to Treat Oil Field Produced Water to Drinking Water or Reuse Quality" paper SPE 38830 presented at the 1997 SPE Annual Technical Conference \& Exhibition held in San Antonio, Texas, 5-6 October.

24. Settle, T., Mollock, G. N. and Hinchman, R.: "Engineering the Use of Green Plants to Reduce Produced Water Disposal Volume” paper SPE 39763 presented at the 1998 SPE Permian Basin Oil and Gas Recovery Conference held in Midland, Texas, 25-27 March.

25. Doran, G. F. et al.: "Pilot Study Results to Convert Oil Field Produced Water to Drinking Water or Reuse Quality" paper SPE 49124 presented at the 1998 SPE Annual Technical Conference \& Exhibition held in New Orleans, 27-30 September.

26. Doran, G. F. et al.: "Pilot Study Results to Convert Oil Field Produced Water to Drinking Water or Reuse Quality" paper SPE 54110 presented at the 1999 SPE International Thermal Operations and Heavy Oil Symposium held in Bakersfield, 1719 March.

27. Gurden, C. and Cramwinckel, J.: "Application of Reedbed Technology in Production Water Management” paper SPE 61180 presented at the 2000 SPE International Conference on Health, Safety, and the Environment in Oil and Gas Exploration and Production held in Stavanger, Norway, 26-28 June.

28. Koseoglu, S.: "Fundamentals, New Developments and Pilot Plant Demonstrations" paper presented at the 2000 Annual Short Course on Membrane Technology held in Houston, 20-24 March.

29. Cheryan, M., Ultra-filtration and Micro-filtration Handbook, Technomic Publishing Company, Inc., Lancaster, PA (1998).

30. Koseoglu, S.: "Fundamentals, New Developments and Pilot Plant Demonstrations" paper presented at the 2001 Practical Short Course on Membrane Technology held in College Station, Texas, 25-29 March. 
31. Marinello, S. A., Lyon, F. L. and Ballantine, W. T.: "Disposal of E \& P Waste by Injection: An Assessment of Technology and Regulatory Impacts” paper SPE 66521 presented at the 2001 SPE/EPA/DOE Exploration and Production Environmental Conference held in San Antonio, Texas, 26-28 February.

32. Hamid, S. and Yeo, W. N.: "Effluent Water Quality Improvement” paper SPE 27316 presented at the 1994 Second International Conference on Health, Safety and Environment in Oil and Gas Exploration and Production held Jakarta, Indonesia, 2527 January.

33. Garland, E. M.: "Produced Water in the North Sea: A Threat for the Environment or a Threat for the Industry?” paper SPE 46706 presented at the 1998 SPE International Conference on Health, Safety and Environment in Oil and Gas Exploration and Production held in Caracas, Venezuela, 7-10 June.

34. World Commission on Environment and Development: Our Common Future, Oxford University Press, Oxford, 1987.

35. Hargis, P. D.: "Balancing Sustainable Offshore Production With Onshore Social and Environmental Issues in Central California” paper SPE 61109 presented at the 2000 SPE International Conference on Health, Safety, and the Environment in Oil and Gas Exploration and Production held in Stavanger, Norway, 26-28 June.

36. Holgate, M. J. et al.: "Prioritising Environmental Investment Through Sustainable Development Targets" paper SPE 61108 presented at the 2000 SPE International Conference on Health, Safety, and the Environment in Oil and Gas Exploration and Production held in Stavanger, Norway, 26-28 June.

37. Bradley, A. S. and Hartog, J. J.: "Sustainable Development - Implementation Strategy for a Global Exploration and Production Business” paper SPE 61106 presented at the 2000 SPE International Conference on Health, Safety, and the Environment in Oil and Gas Exploration and Production held in Stavanger, Norway, 26-28 June.

38. Allam, H.: “Introducing Sustainability into Your Business Plan” paper SPE 61105 presented at the 2000 SPE International Conference on Health, Safety, and the Environment in Oil and Gas Exploration and Production held in Stavanger, Norway, 26-28 June.

39. Daza, D. S. et al.: "Environmental Land-Use for Hydrocarbon Exploration and Exploitation in Colombia” paper SPE 61281 presented at the 2000 SPE International Conference on Health, Safety, and the Environment in Oil and Gas Exploration and Production held in Stavanger, Norway, 26-28 June.

40. Wolff, R. et al.: “Indicators for Sustainable Development” paper SPE 61320 presented at the 2000 SPE International Conference on Health, Safety, and the 
Environment in Oil and Gas Exploration and Production held in Stavanger, Norway, 26-28 June.

41. Abbott, R. E. and Unruh, G. L.: "Sustainable Growth Journey” paper SPE 68696 presented at the 2001 SPE/EPA/DOE Exploration and Production Environmental Conference held in San Antonio, Texas, 26-28 February.

42. Browne, B.: “Strategies for Sustainable Development” paper SPE 46701 presented at the 1998 SPE International Conference on Health, Safety and Environment in Oil and Gas Exploration and Production held in Caracas, Venezuela, 7-10 June.

43. Bradley, A. S. and Hartog, J. J.: "Sustainable Development - How to Assess Your Contribution?” paper SPE 46878 presented at the 1998 SPE International Conference on Health, Safety and Environment in Oil and Gas Exploration and Production held in Caracas, Venezuela, 7-10 June.

44. Skov, A. M.: “National Health, Wealth, and Energy Use” paper SPE 52942 presented at the 1999 SPE Hydrocarbon Economics and Evaluation Symposium held in Dallas, Texas, 20-23 March.

45. U.S. Environmental Protection Agency (EPA), CFR Title 40: Protection of Environment, Chapter I - Part 435, http://www.epa.gov/epahome/cfr40toc.htm, 30 September 2002.

46. Hughes, S.W. and Sehsuvaroglu, S. A.: "Produced Water Treatment Technologies: A Case Study” paper SPE 27131 presented at the 1994 Second International Conference on Health, Safety, and the Environment in Oil and Gas Exploration and Production held in Jakarta, 25-27 January.

47. Ditria, J.C. and Hoyack, M. E.: “The Separation of Solids and Liquids With Hydrocyclone-Based Technology for Water Treatment and Crude Processing " paper SPE 28815 presented at the 1994 SPE Asia Pacific Oil and Gas Conference, Melbourne, Australia, 7-10 November.

48. Khatib, Z. I., Faucher, M. S. and Sellman, E. L.: "Field Evaluation of Disc-Stack Centrifuges for Separating Oil/Water Emulsions on Offshore Platforms” paper SPE 30674 presented at the 1995 SPE Annual Technical Conference \& Exhibition held in Dallas, 22-25 October.

49. Kenaway, F. A. et al.: "Produced Water Treatment Technology, A Study of Oil/Water Separation in Gravity Type Cross Flow Pack Separators for Qualitative Separation” paper SPE 36056 presented at the 1996 International Conference on Health, Safety \& Environment held in New Orleans, 9-12 June. 
50. Delgado, A. and Lee, H. M.: “The Chronology of Water-Oil Handling” paper SPE 39878 presented at the 1993 SPE International Petroleum Conference held in Mexico, March 3-5.

51. Bansal, K. M. and Caudle, D. D.: "Interferences With Produced Water Treatment for Dispersed Oil Removal” paper SPE 46576 presented at the 1998 SPE International Conference on Health, Safety and Environment in Oil and Gas Exploration and Production held in Caracas, Venezuela, 7-10 June.

52. Wim, M. G. T. et al.: “Comparison of Plate Separator, Centrifuge and Hydrocyclone” paper SPE 48870 presented at the 1998 SPE International Conference held in Beijing, China, 2-6 November.

53. Finborud, A. et al.: "New Method for Improving Oil Droplet Growth for Separation Enhancement" paper SPE 56643 presented at the 1999 SPE Annual Technical Conference \& Exhibition held in Houston, 3-6 October.

54. Arnold, K. E. and Ferguson, P. L.: “Designing Tomorrow's Compact Separation Train” paper SPE 56644 presented at the 1999 SPE Annual Technical Conference \& Exhibition held in Houston, 3-6 October.

55. Meikrantz, D. H. et al.: “Advances in Liquid/Liquid Centrifuge Design Provide New Options for Petroleum Production” paper SPE 56709 presented at the 1999 SPE Annual Technical Conference \& Exhibition held in Houston, 3-6 October.

56. Sinker, A. B., Humphris, M. and Wayth, N.: "Enhanced Deoiling Hydrocyclone Performance Without Resorting to Chemicals,” paper SPE 56969 presented at the 1999 SPE Offshore Europe Conference held in Aberdeen, Scotland, 7-9 September.

57. Doyle, D. H. and Brown, A. B.: "Produced Water Treatment and Hydrocarbon Removal With Organoclay” paper SPE 63100 presented at the 2000 SPE Annual Technical Conference \& Exhibition and Exhibition held in Dallas, Texas, 1-4 October.

58. Stroder, S. M. and Wolfenberg, E. E.: "Hydrocyclone Separation: A Preferred Means of Water Separation and Handling in Oilfield Production " paper SPE 27671 presented at the 1994 SPE Permian Basin Oil and Gas Recovery Conference held in Midland, Texas, 1-8 March.

59. Gomez C. et al.: “Oil-Water Separation in Liquid-Liquid Hydrocyclones (LLHC) Experiment and Modeling” paper SPE 71538 presented at the 2001 SPE Annual Technical Conference \& Exhibition held in New Orleans, 30 September-3 October.

60. Nnabuihe, L.: "Novel Compact Oil/Water Separator Tested in Nimr" paper SPE 68150 presented at the 2001 SPE Middle East Oil Show held in Bahrain, 17-20 March. 
61. Buarki, M. I., Tabtabai, I., Hatabata, H. and Konishi, Y.: "Treatment of Produced Water Utilizing Ceramic Technology: Field Trail” paper SPE 71469 presented at the 2001 SPE Annual Technical Conference \& Exhibition held in New Orleans, 30 September -3 October.

62. Miller, J.: “"ASH” Air Sparged Hydrocyclone Technologies,” Environmental Engineering Graduate Program Research Projects, University of Utah, http://www.mines.utah.edu/enveng/treat/, 01 August 2001.

63. Boysen, J. E. et al.: “The Current Status of Commercial Deployment of the Freeze Thaw Evaporation Treatment of Produced Water” paper SPE 52700 presented at the 1999 SPE/EPA Exploration and Production Environmental Conference held in Austin, Texas, 1-3 March.

64. Khatib, Z. I., McMillen, S. and Wilkinson, J. B.: "Summary of Cooperative Research Projects conducted by the Petroleum Environmental Research Forum,” paper SPE 66563 presented at the 2001 SPE/EPA/DOE Exploration and Production Environmental Conference, held in San Antonio, Texas, 26-28 February.

65. Pars, H. M. and Meijer, D. T.: "Removal of Dissolved Hydrocarbons From Production Water by Macro Porous Polymer Extraction (MPPE)” paper SPE 46577 presented at the 1998 SPE International Conference on Health, Safety and Environment in Oil and Gas Exploration and Production held in Caracas, Venezuela, 7-10 June.

66. Amjad, Z. (Ed.): Reverse Osmosis: Membrane Technology, Water Chemistry, and Industrial Applications, Van Nostrand Reinhold, New York (1993). 
Recovery of Fresh Water Resources from Desalination of Brine Produced during Oil and Gas Production Operations

Section 2

Field Demonstration of Produced Brine Treatment and Re-Use for Beneficial Purposes
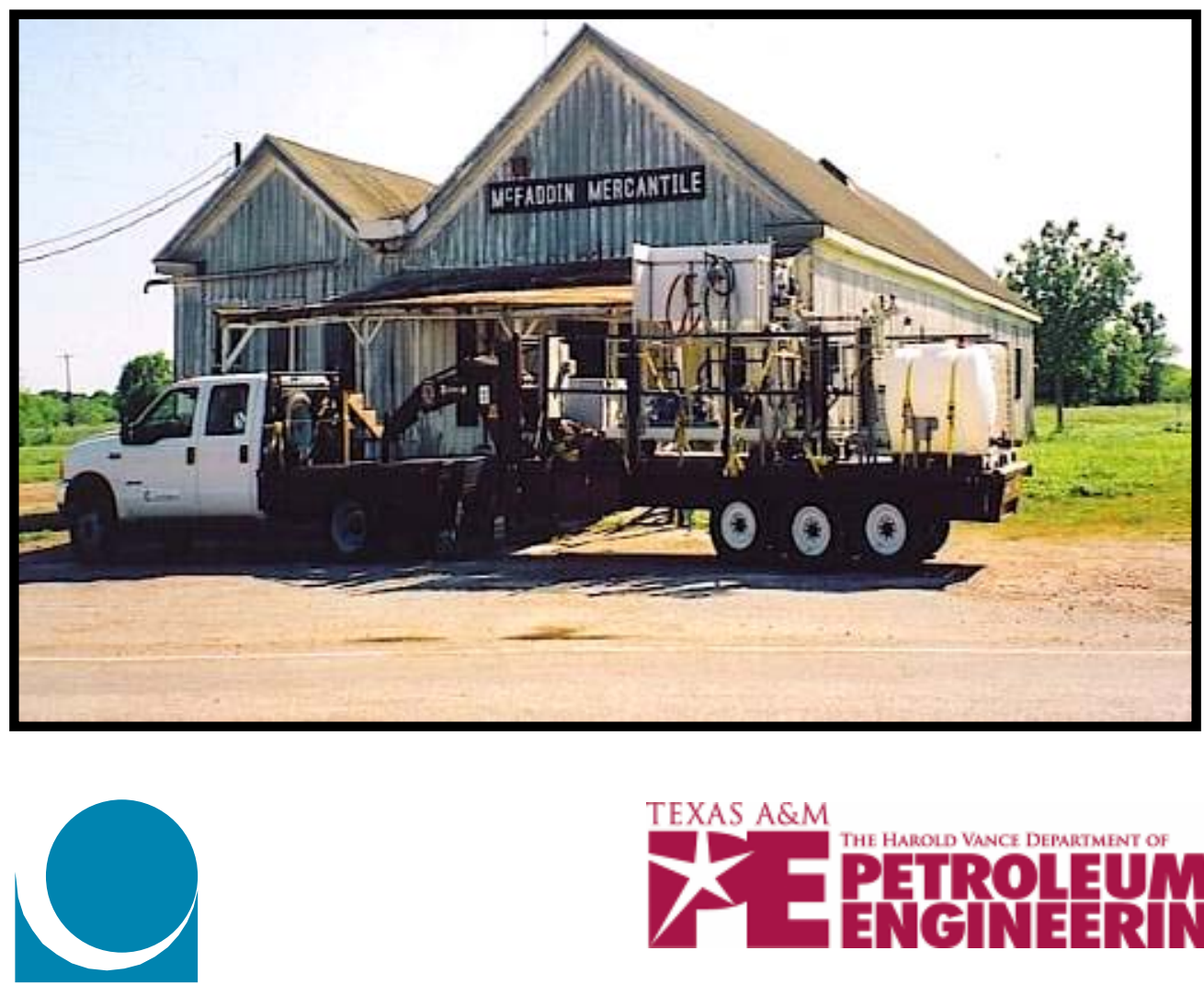

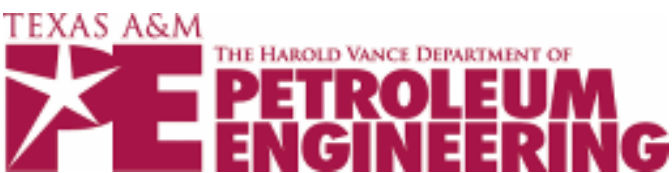




\section{Table of Contents}

BASICS OF PRODUCED WATER MANAGEMENT ................................................. 131

Water Production in Onshore Oil and Gas Operations in Texas ..................................... 131

Water Produced During Drilling Operations ............................................................... 131

Water Produced from Well Fracturing Operations.......................................................... 132

Water Produced During Production Operations …………............................................. 133

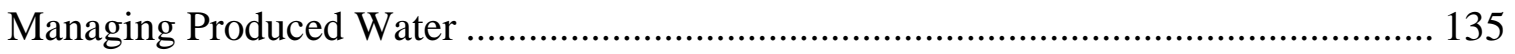

Produced Water Volumes and Composition................................................................ 135

Brackish Water Produced in Texas Oil and Gas Wells ................................................. 136

Uncertainties with Regulatory Issues......................................................................... 142

Costs of Managing Produced Water ............................................................................. 142

POTENTIAL FOR THE DESALINATION OF PRODUCED BRINE .......................... 143

Produced water desalination (PWDS) technology........................................................... 143

Reverse Osmosis Desalination for Oil Field Brine ......................................................... 144

Pre-Treatment of Oil Field Brine................................................................................. 145

Disposal of Materials Removed from Brine during Desalination ................................... 146

Costs of Reverse Osmosis Desalination of Oil Field Brine.............................................. 148

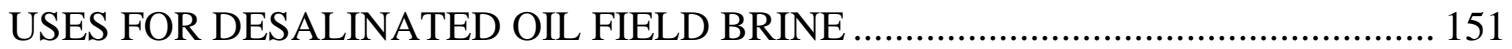

Beneficial Use of Desalinated Oil Field Brine …………........................................... 151

Potable Uses ....................................................................................................... 152

Discharge to Supplement In-Stream Flow or Rangeland Habitat Enhancement............. 153

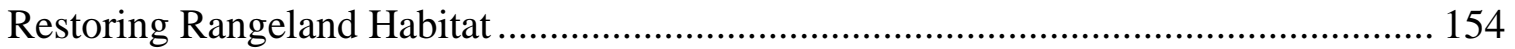

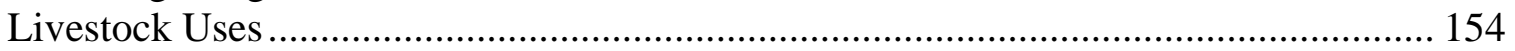

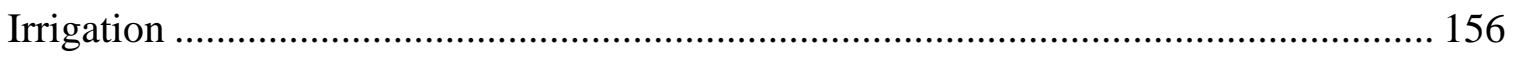

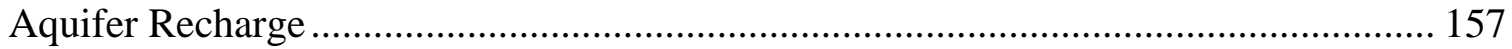

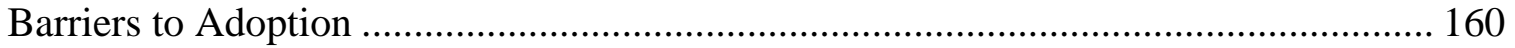

General Regulatory Requirements ............................................................................. 161

WATER RESOURCES ASSOCIATED WITH UNCONVENTIONAL O\&G

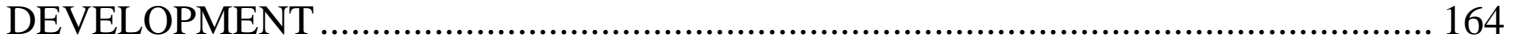

Water Resources Used in Energy Production.......................................................... 165

The Social Cost of Energy Production............................................................................ 167

RECOMMENDATIONS FOR THE ADVANCEMENT OF DESALINATION

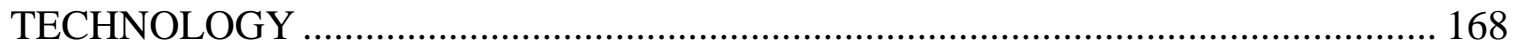

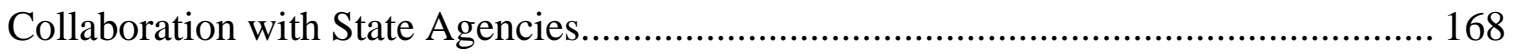

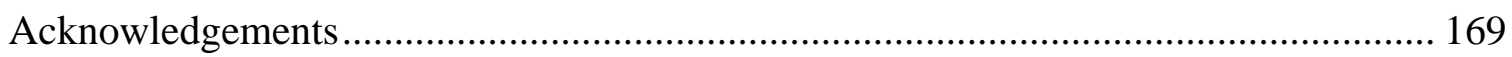

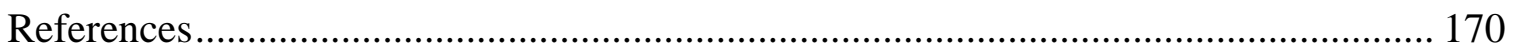




\section{List of Figures and Tables (Tables in Bold Font)}

Figure 1 Unconventional resource coal bed methane basins for the onshore U.S. [48].

Figure 2. Oil field produced water volume trends .................................................... 134

Table 1. Injection Wells Example (Montgomery County Texas) ..................................... 135

Figure 3. Location of active gas wells in Texas. ................................................................ 137

Figure 4. Distribution of produced water sites in Texas. ............................................. 138

Figure 5. Brackish Produced Water Locations......................................................... 139

Figure 6. Saline Produced Water Sites ...................................................................................... 140

Figure 7. Hyper-Saline Produced Water Sites ........................................................ 141

Table 2. Costs of Produced Water Disposal .................................................................... 19

Figure 8. New MEDRC research program in thin film membrane technology............ 144

Table 3. Pre-Treatment Costs: Removing Contaminants from Waste Water ....................... 146

Figure 9 Example of one of the water ways classified by EPA as “Impaired".............. 148

Figure 10. The A\&M Mobile Desalination Unit........................................................ 149

Table 4. Representative power costs of desalination of oil field brine .............................. 150

Factors contributing to the degree of public acceptance of water reuse ........................ 151

Table 5 Guide to the Use of Saline Waters for Livestock and Poultry............................... 155

Figure 11 Distribution of brackish produced water sites in the USGS database for Texas........................................................................................................................... 159

Figure 12 shows an overlay of BPW production near surface waterways with impaired quality.......................................................................................................................... 160

Table 6 Injection Well Class for Concentrate Injection under Different Scenarios ............. 162

Figure 13. Unconventional Shale Gas Resources in the U.S .......................................... 164

Figure 14 Gas production forecasts for the lower 48 states and Canadian Fields [48] 165

Figure 15 is a photograph of a fracturing operation in the Barnett Shale................... 166

Table 7. Composition of Typical Flow Back Water from Barnett Shale [49] ..................... 166 


\section{Recovery of Fresh Water Resources from Desalination of Brine Produced during Oil and Gas Production Operations}

\section{Executive Summary}

This is the second section of the Texas A\&M Advanced Desalination Program.

This section provides a comprehensive description of what is involved in the desalination of oil field produced brine and the technical developments and regulatory changes needed to make the concept a commercial reality. It contains three sections related to "conventional" produced water treatment: (1) the basics of produced water management, (2) the potential for desalination of produced brine in order to make the resource more useful and available in areas of limited fresh water availability, and (3) the potential beneficial uses of produced water for other than oil production operations.

One way to reduce the impact of $O \& G$ operations is to treat produced brine by desalination. The main body of the report contains information showing where oil field brine is produced, its composition, and the volume available for treatment and desalination. This collection of information all relates to what the oil and gas industry refers to as "produced water management". It is a critical issue for the industry as produced water accounts for more than $80 \%$ of all the byproducts produced in oil and gas exploration and production. The expense of handling unwanted waste fluids draws scarce capital away for the development of new petroleum resources, decreases the economic lifetimes of existing oil and gas reservoirs, and makes environmental compliance more expensive to achieve.

More than 200 million barrels of produced water are generated worldwide each day; this adds up to more than 75 billion barrels per year. For the United States, the American Petroleum Institute estimated about 18 billion barrels per year were generated from onshore wells in 1995, and similar volumes are generated today. Offshore wells in the United States generate several hundred million barrels of produced water per year. Internationally, three barrels of water are produced for each barrel of oil. Production in the United States is more mature; the U.S average is about 7 barrels of water per barrel of oil. Closer to home, in Texas the Permian Basin produces more than 9 barrels of water per barrel of oil and represents more than 400 million gallons of water per day processed and re-injected.

The report contains a fourth section, "Water Issues Associated with Unconventional O\&G Development," introducing a new issue related to water utilized in the recovery of oil and gas from unconventional resources. This is an emerging industry in Texas requiring large amounts of water resources, most of which cannot be recovered with present technology. This new source of energy from unconventional resources is expected to represent almost 50\% of the natural gas produced in the United States in the next 25 years. Texas has the opportunity to be in the forefront of technology developed to achieve this by sustainable economic development. However, this new "face of the O\&G industry" is even more dependent on water resources than traditional operations. It also tends to be more intrusive and can negatively impact sensitive environmental areas and 
local community areas if not integrated into managed processes for change that govern economic development in the state.

The emergence of energy dependence on unconventional gas reserves has not been fully realized by either the public or policy makers. Unconventional gas development represents an important natural resource in Texas that will require significant amounts of water. Technology advancements in gas well fracturing technology in the Barnett Shale has created a drilling "boom" in North Texas To put the issue into perspective, drilling, completion and fracturing operations in a few Texas counties are using more fresh water daily than a small city. Essentially all of this water is then disposed of in deep wells and removed from the normal, natural water cycle.

Most of the byproduct water from oil and gas (O\&G) activity is highly saline brine and in conventional oil fields is generally used for oil recovery. However, there are significant opportunities to use the less saline (brackish water) produced water for other purposes, especially if desalinated. Most of the beneficial uses of produced water require the purification of the resource (and the disposal of the waste products generated). The practice of desalinating oil field brine has been the focus of study for Texas A\&M University for several years and that effort has provided information on the affordability of such technology. Information is provided on the cost effectiveness of desalination and the costs of reverse osmosis (RO) desalination technology (the preferred treatment). Forecasts of future cost savings are reported based on potential future changes in regulatory requirements and in availability of new technology.

This study addresses the potential uses for the fresh water resource recovered from desalination, including use in agriculture, livestock, and rangeland restoration. Waterways in Texas where stream flow augmentation would benefit fish and wildlife are shown. Other uses for the water are addressed, including industrial use, and the potential for supplementing municipal water resources during periods of water scarcity. The report also describes disposal of the byproducts of desalination back into the oil and gas formations from where it was produced. 


\section{Recovery of Fresh Water Resources from Desalination of Brine Produced during Oil and Gas Production Operations}

This report discusses the feasibility of treating brine from oil and gas operations to make it usable for beneficial purposes. A separate section on unconventional oil and gas operations discusses the increased demand for water resources and the need for recovery of fresh water and re-use of brine byproducts from this activity. The study was conducted by the Department of Petroleum Engineering and the Texas Water Resources Institute at Texas A\&M University, College Station Texas and CH2M Hill Company. This is the second section to be prepared describing the six-year research program conducted at Texas A\&M University. Funds for the program were made available through grant U.S. DOE DE-PS26-02NT41613-11 and from the GPRI joint venture on Advanced Desalination Technology.

\section{Motivation for the Research}

Texas has long been one of the top petroleum producing states in the nation. As fields have matured, more brine water is produced along with the petroleum resource. More brine water is being re-injected as well, to sustain production, prevent subsidence, and to dispose of excess produced brine. Texas has long been struggling with a lack of water resources and as the population of the state grows, more demand is being placed upon surface and ground water sources of fresh water. As these issues become more important, more attention is turning to recovery of fresh water from these brine byproducts of O\&G activity.

Unfortunately, produced brine cannot be used without treatment to remove harmful substances. Untreated produced brine has contaminants that make it unpalatable for humans or livestock. Re-injection of the brine back into the formation from where it was produced has been the least expensive, hence preferred disposal method for brines. Other issues include:

(1) Desalination of wastewater such as oil field brine can be expensive.

(2) Oil and gas companies are not water providers.

(3) Less expensive surface and ground water has provided adequate supplies of fresh water for communities, livestock and agriculture interests.

Most of these issues are the result of the characteristics of oil field brine. Large quantities of produced water are brought to the surface in Texas as a result of various natural resource extraction activities. The composition of this produced fluid is dependent on whether crude oil or natural gas is being produced and generally includes a mixture of either liquid or gaseous hydrocarbons, produced water, dissolved or suspended solids, produced solids such as sand or silt, and injected fluids and additives that may have been placed in the formation as a result of exploration and production activities.

The Texas Water Development Board is seeking to determine whether desalination of 
produced brine offers promise as a source of fresh water resources. Research is currently underway at a number of companies to assess the economic and technological feasibility of desalting this product water to develop water of sufficient quality to meet certain local water supply needs and to allow consideration of disposal options other than well injection. At Texas A\&M University, a team of scientists and engineers is working on this concept and is working to further the technology and put it into commercial practice.

Specific research needs are harder to prioritize. For the past three years A\&M has worked to find technologies to employ in desalination and to outline ways to establish a value for the resource that is recovered by this treatment. The research has found that the technology is available to desalinate certain brines produced in petroleum operations [1]. However, that technology needs to be improved, the value of fresh water and local water supply needs must be established, and the environmental and regulatory issues associated with beneficial use must be addressed.

\section{BASICS OF PRODUCED WATER MANAGEMENT}

\section{Water Production in Onshore Oil and Gas Operations in Texas}

In the oil and gas industry, standard water management operations include handling large volumes of water, both fresh water and brine water [2]. Drilling operations (onshore Texas) for the most part employ water-based drill fluids for well construction. In addition, well completions including fracturing operations use very large amounts of water, some of which may be fresh water when injected downhole, but are mixed with formation fluids when flowing back to the surface. Finally, production operations use produced brine to enhance petroleum production and maintain reservoir pressure. Different well operations require different water management strategies to minimize waste and to protect the environment. Generally water needs and issues can be grouped into two categories, drilling and completion, including stimulation (fracturing) operations, and production operations. These are discussed in the following sections.

\section{Water Produced During Drilling Operations}

Drill fluids are specially formulated materials containing chemicals, solids, and rheological control agents designed to drill through rock matrices and return drill cuttings to the surface for discharge. Drilling fluid companies have specialists whose job it is to manage drill waste in E\&P operations, and under most conditions, excess water production has not been an issue at the well site. High performance drilling fluids, materials that are designed for low damage, high temperature, maximum wellbore stability etc, are so costly that most service companies return the used fluid back to the service facility where it is reconstituted and used again. Typically only about $2 \%$ of the volume of drilling fluids is lost or discharged in drill cuttings waste.

More and more frequently oil and gas operators find that environmental issues are one of the key factors to consider when preserving the environment in an area without disrupting the lives of nearby communities. New technology is being developed to allow fluid handling systems to be designed as a zero-discharge operation. Many of these techniques have been developed for the offshore industry [3].

The main byproducts from drilling operations are re-injected. However, some practices 
recover water from drilling operations in ways that allow waste disposal in an environmentally sound way. Waste recycling, bio-treatment, and temporary offsite treatment and disposal are the options in a waste-management strategy. In Venezuela's Orinoco Basin it was reported [4] that during 5 years of operation, a total of approximately $41.5 \times 104 \mathrm{~m} 3$ (greater than $100 \mathrm{MM}$ lbs per year) of exploration and production (E\&P) waste were handled and disposed of successfully without harm to the environment.

In Texas, "zero discharge" operations at well sites are the normal operating practices. The most important factor when considering drilling practices is that drill operations offer a potential use of recovered water from other oil field operations.

\section{Water Produced from Well Fracturing Operations}

There is another way to obtain fresh water resources from O\&G activity - to reduce the volume of water used in drilling operations and in particular fracturing operations. In the past 5 years, a new drilling boom has begun in North Texas in a development known as the "Barnett Shale". The resource $[5,6]$ is a gas play that has become an economic drilling target because of advancements in fracturing technology. The reservoir was originally developed in Wise and Denton County Texas but has trended southward into Johnson County and neighboring areas. Figure 1 shows the spatial location of the development. The expected gas reserves in the Barnett Shale keep increasing with the most recent projection by the USGS (United States Geological Society) having been estimated at 26.2 tcf $[7,8]$. Currently there are over 3,500 producing wells in the Basin.

The magnitude of the O\&G development puts the Barnett Shale as the largest gas development in the lower 48 states and rivals the North Slope of potential gas resources. (At a natural gas price of $\$ 5.00$ per MCF (million cubic ft.) this resource represents almost $\$ 140$ billion.). Tax revenues received by Tarrant, Denton and Wise County Texas are more than a billion dollars a year [7]

The technology of massive shale fracturing with fresh water has been adopted by all of the operators in the Shale and geologists believe that this trend is a long term shift in O\&G production in Texas as the Barnett Shale play extends southwest with new shale resources being investigated in West Texas (Woodford Shale) [5, 6] and in East Texas and Western Arkansas (Fayetteville Shale) [9]. If these new resources are to be exploited, then significant water resources will be used for fracturing operations.

Barnett Shale fracturing operations utilize massive hydraulic fracturing stages in horizontal wells, each stage being separated from the previous one. Wells in Johnson County (Spring 2006) are being fractured with more than 5 million gallons of water. This water, for the most part, is coming from surface water supplies and municipal sources. While the communities involved are making a profit selling the water at residential rates, the residents of the community are upset because of this apparently profligate water use for $O \& G$ operations while their cities are on restricted water use because of the drought.

The water use issue is made critical because ALL of the water used in fracturing operations must be transported in by trucks prior to a fracture treatment, and then transported away for disposal afterwards. For the most part, these vehicles travel county and local roads sharing space with normal traffic. A single well will have more than 100 
water-haulers servicing the well during fracture stimulation. A multi-stage well fracturing operation represents the daily water use of Cleburne, the county seat of Johnson County, Texas all delivered and removed by truck transport.

\section{U.S. COALBED GAS RESOURCES}

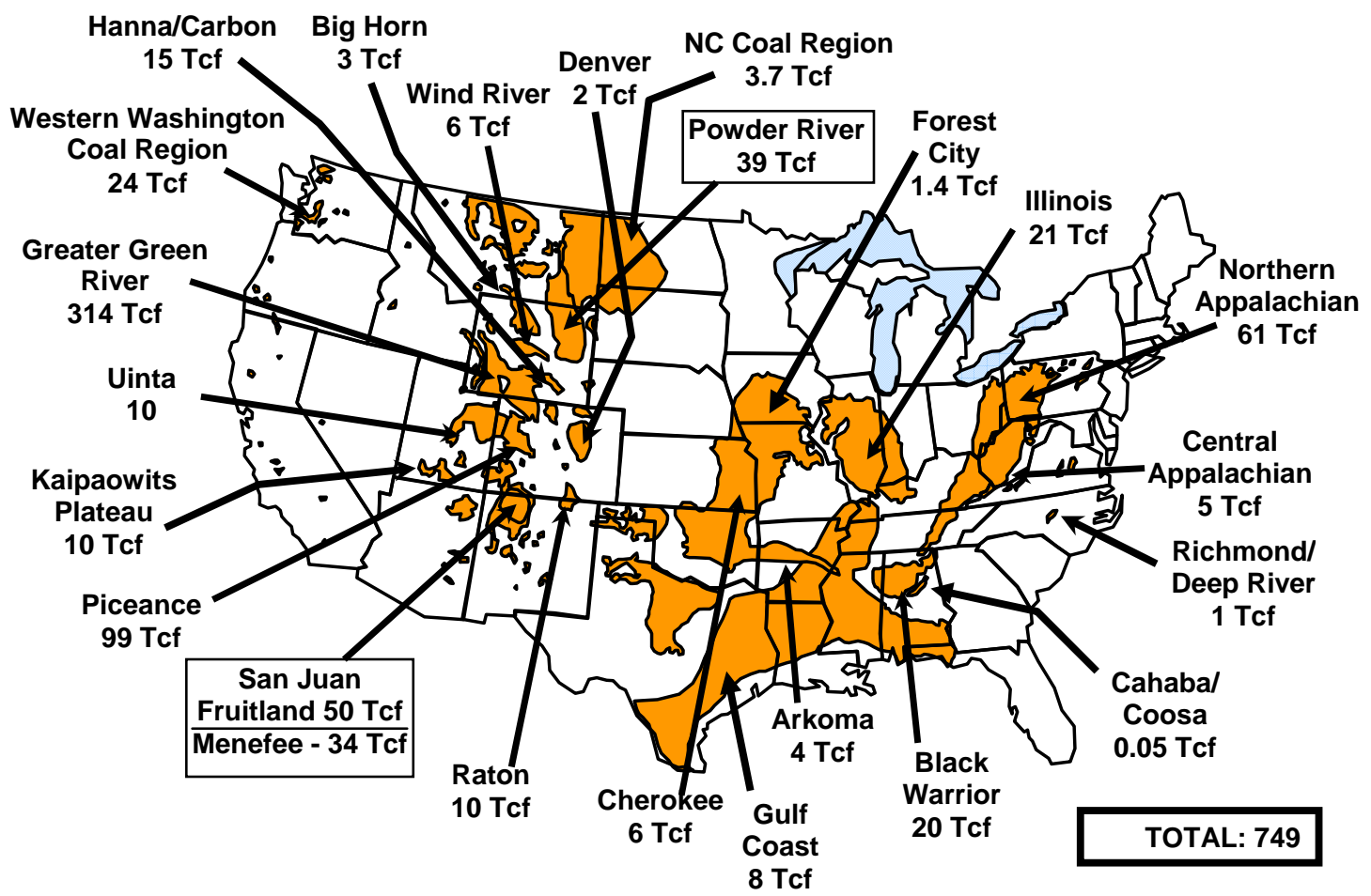

Figure 1 shows unconventional resource coal bed methane basins for the onshore U.S. Currently gas production from unconventional sources, including CBNG, accounts for almost $15 \%$ of daily U.S. production [58].

A number of groups are studying ways to re-use fracture return brine in subsequent operations. As of early 2006, no commercial operations have been established.

\section{Water Produced During Production Operations}

Oil and gas operations on leases that have been on production for extended time produce copious amounts of brine water along with the associated oil and gas. Produced water, (any water that is present in a reservoir with the hydrocarbon resource) is produced to the surface with the crude oil or natural gas. Not only in Texas, but world-wide, the oil and gas industry is experiencing increased volume of produced water handled in both onshore and offshore petroleum production operations. The resulting operational costs and environmental issues are a major concern, especially with the possibility of further reduction in the oil content allowed in the discharged water (offshore operations), as well as the fact that produced water contains a number of undesirable toxic components.

Figure 2 shows a slide from Shell Oil Company on that company's production of brine worldwide in the past decade [10]. On average, Shell's operating units re-inject 55\% of 
produced water and discharge the remainder to the environment. Practically all of the produced water must be treated to remove harmful contaminants. Treatment and disposal costs for Shell are greater than $\$ 400$ million annually. According to Shell's Zara Khatib, disposal can cost from $\$ .50$ to $\$ 50$ per 1,000 gallons of water handled [11].

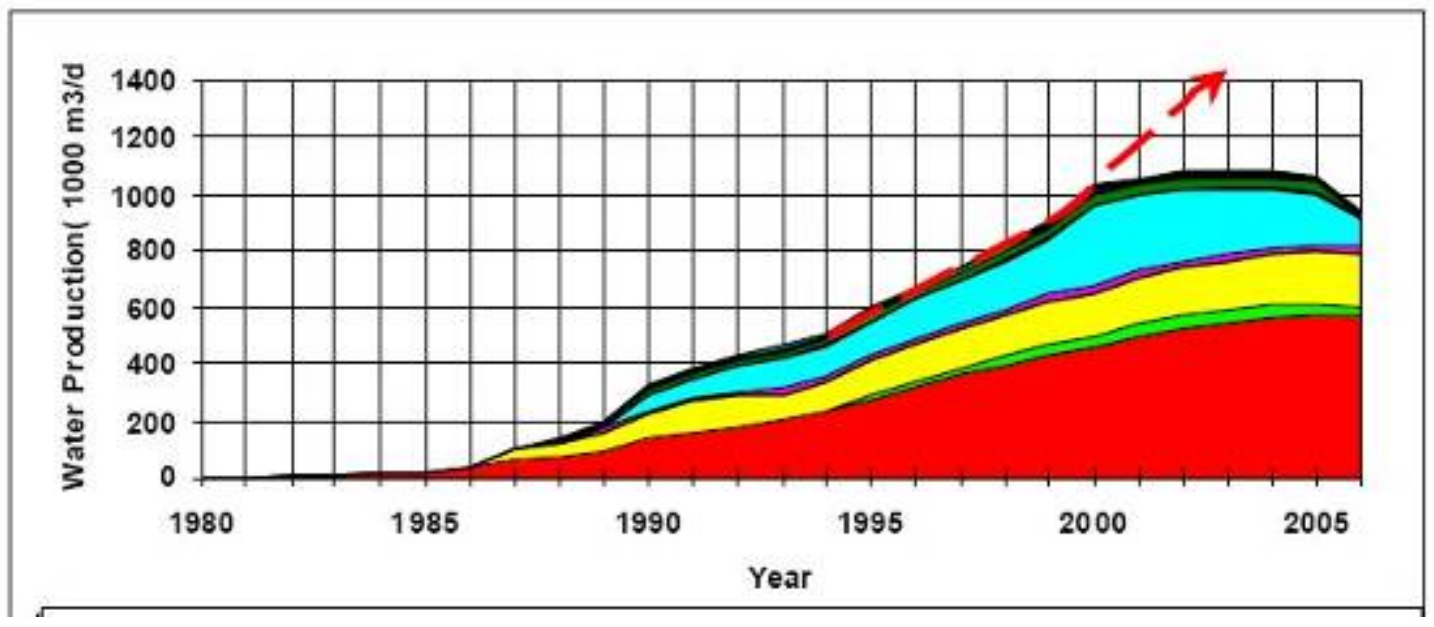

Figure 2. Oil field produced water volume trends

The chart shows each of the five major operating areas for Shell Oil. $(1,000 \mathrm{~m} 3=6289$ bbls). The trend increases in each of the areas until (assumed) new technology can intervene.

For the United States, the U.S. Department of Energy estimated more than 18 billion barrels per year were generated from onshore wells in 2000, and similar volumes are generated today [12]. Offshore wells in the United States generate several hundred million barrels per year of produced water. Internationally, three barrels of water are produced for each barrel of oil. Production in the United States is more mature; the U.S average is about 7 barrels of water per barrel of oil. Closer to home, in Texas the Permian Basin averages more than 9 barrels of water per barrel of oil and represents more than 400 million gallons of water per day processed and re-injected [13]. New technology is needed to forestall these trends.

To speed up the adoption of technology, the industry has established a number of techniques for handling produced water in both mature fields and in new and planned developments $[14,15]$. These practices take into consideration the nature of the water, technology limitations, both emission to the atmosphere and discharges into the sea, nature of the discharges, safety concerns and cost, as well as establishing any environmental gains in each case. The integrated oil company Shell uses a systematic empirical ranking and indicator tool applied to the different aspects of the alternative options considered. Most operators, big and small, handle produced water management in the same way. (Most often in Texas however, the option is brine injection back into the producing formation.)

Management of water issues is a major emphasis of the DOE's Oil and Gas Environmental Program administered by the National Energy Technology Laboratory's 
National Petroleum Technology Office [16]. Water issues include several concerns: injection water, produced water (including Coalbed Natural Gas-CBNG) and its effects on the environment, treatment of waste water, and the availability of water in arid lands. NETL currently has 26 projects grouped under Water Management Approaches and Analysis, Water Management Technologies, and Coalbed Methane and Produced Water. The shared goal of all of these projects is to ensure that water produced through oil and gas development does not adversely impact the environment and that it is put to beneficial uses where possible.

\section{Managing Produced Water}

Oil and gas operators re-inject practically all their brine into leases to provide pressure maintenance* and to sustain production. Mature leases gradually end up re-cycling water until the field reaches its economic limit. Many gas fields and smaller oil leases have produced water transported to commercial salt water disposal wells. Figure 3 shows gas well distributions in Texas. Production is found in practically every county.

To handle produced water, the O\&G industry operates a large number of injection wells to re-inject the water to maintain production. All wells in Texas are regulated $[13,17]$ whether by the Texas Commission on Environmental Quality (TCEQ) or the Texas Railroad Commission (TRC) Records of where produced water is currently being disposed and practices in different regions of the state are kept by the TRC organized into oil, gas, and water production for each district in the state. That data has been combined with United States Geologic Survey (USGS) databases [19]. The USGS database is extensive, compiled in the past 50 years on formation waters to characterize the type of brine that is being produced. Additionally costs of current methods of managing produced water have been obtained from operators and from companies that transport and dispose of brines in salt water disposal wells. Additional information on formation water and produced brine is also available from the West Texas Geological Society [20].

The Texas Railroad Commission maintains a list of injection wells in all 10 of the TRC Districts [13]. The list is organized, first into Districts, then by Counties, then by identification. Table 1 below shows an example, that of injection wells in Montgomery County, Texas (TRC District 3). (TRC Districts are shown in Figure 3 in the following section.)

Table 1. Injection Wells Example (Montgomery County Texas)

$\begin{array}{lclll}\text { LEASE\# } & \text { O/G } & \text { WELL API\# } & \text { OPERATOR NAME } & \text { LEASE NAME } \\ 168471 & \mathrm{G} & \text { 1R } 33930759 & \text { BADGER ENERGY, INC. } & \text { GIBBS } \\ 000000 & \mathrm{~A} & 133930917 & \text { BADGER ENERGY, INC. } & \text { MAGNOLIA } \\ 11326 & \mathrm{O} & 2733981150 & \text { EAST TEXAS PR. MGT. - } & \text { ALEASE\# }\end{array}$

\section{Produced Water Volumes and Composition}

The volume of produced water from oil and gas wells in Texas (conventional production) is increasing yearly as fields mature and oil production decreases. A majority of the fields in Texas that are still producing petroleum exhibit slowly increasing gas-water ratios or

\footnotetext{
* Oil field terminology can be obtuse. The Society of Petroleum Engineers maintains a Glossary dedicated to the definition and interpretation of important oil field terms ${ }^{1}$.
} 
water-oil ratios. This means that the total liquid production tends to stay constant while the oil or gas volume gradually decreases. The implication for those considering the use of brine for a field is that there is little likelihood of water production ceasing, only that the field and the wells comprising the field may no longer be economical to operate. Only then is the well shut in and abandoned.

With high prices for petroleum, economic recovery of oil and gas allows O\&G operators to keep wells on production for longer and longer times. The most recent well abandonment statistics from the TRC [12] show that fewer that 3\% of the wells in Texas were abandoned in 2005. Out of 227,796 wells, 6,688 were abandoned and their permits ended.

Figure 4 shows the statewide distribution of produced brines [13]. Distribution of produced water is shown for three categories of brine. Approximately 1/3 of the sites represent brines with salinity less than 10,000 ppm TDS. This is brackish water and can be treated for only slightly more expense than brackish ground water resources in Texas. The advantage of this is that the cost of producing this water is zero (paid for by the oil and gas production). The degree of difficulty in treating this brackish water is discussed in the following section.

\section{Brackish Water Produced in Texas Oil and Gas Wells}

Many of the producing fields in Texas discharge water having less than 10,000 ppm tds. Figures 4, 5, 6, and 7 are maps of the state divided into Water Planning Districts. Each district has a number of producing wells that discharge brackish water ( $<10,000 \mathrm{ppm}$ tds), saline water (10,000 to 50,000 ppm tds), and hyper-saline water ( $>50,000 \mathrm{ppm}$ tds). The locations of the fields are shown on the Figures. In addition, a list of the fields alphabetically for each county in Texas that discharge brackish water is available from Texas A\&M’s desalination project upon request

The entries on the map in Figures 5, 6, and 7 do not contain all of the information listed in the U.S.G.S. data base. The master database contains a tabular list of the sites, with partial information from each location. There is not a 1:1 correspondence of the map to the tabular list as many of the locations do not have latitude and longitude position locations. For more detailed information, the USGS database should be referenced [18]. The best source for this information for those planning studies of desalination of produced water should refer to the records of each county being considered. 


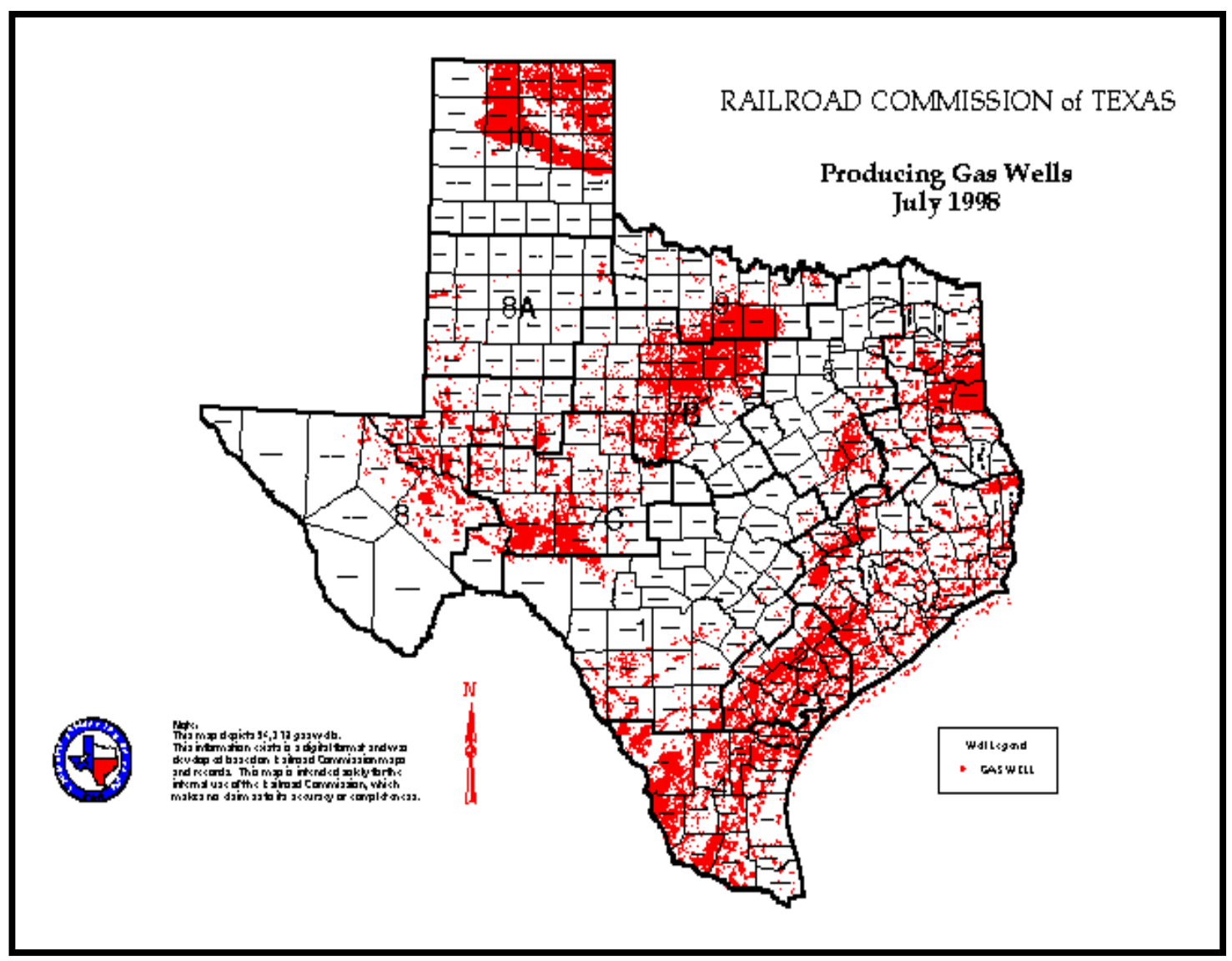

Figure 3. Location of active gas wells in Texas.

There are approximately 300,000 oil and gas wells, $2 / 3$ of these wells are on production. The majority of these wells produce water that is usually re-injected to maintain pressure and production [13].

Desalination of oil field brackish brine may be less expensive because of the disposal options available to the water treatment operator. 


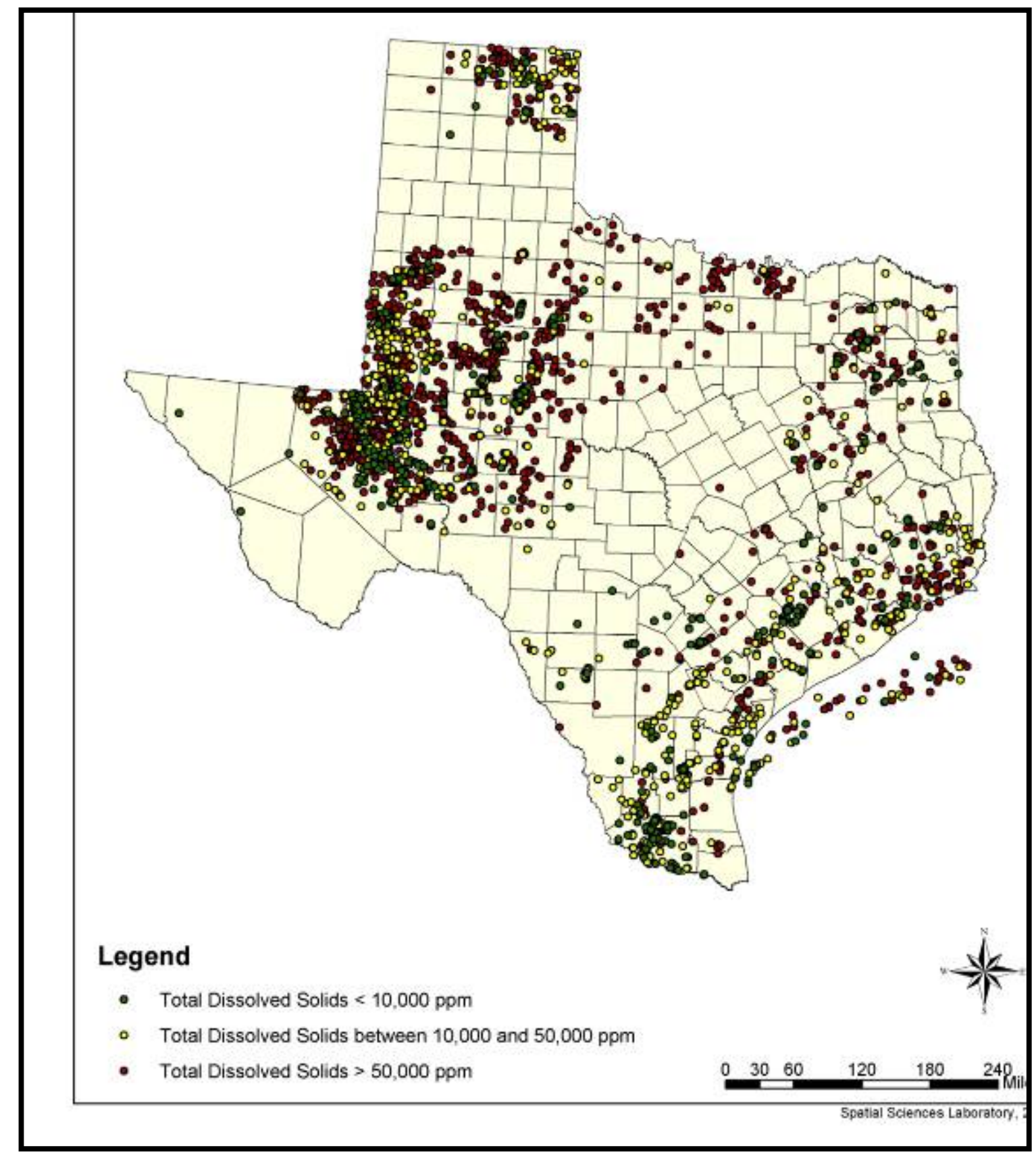

Figure 4. Distribution of produced water sites in Texas.

Approximately $1 / 3$ of the sites represent brines with salinity less than 10,000 ppm TDS and can be classified as "brackish water". Figures 5, 6 and 7 on the following pages contain well sites according to salinity superimposed on maps of the TWDB Regional Water Planning Group. 


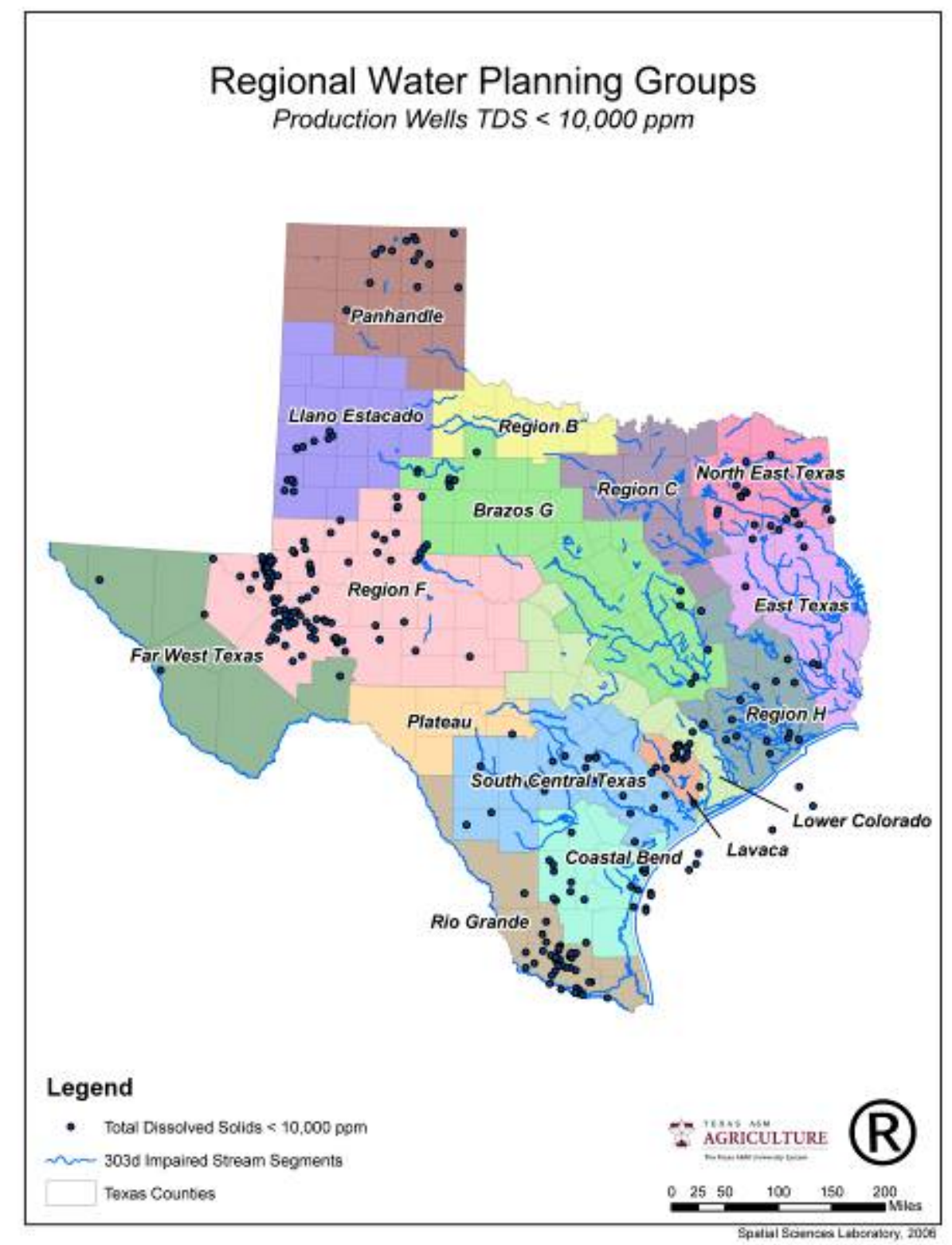

Figure 5. Brackish Produced Water Locations 


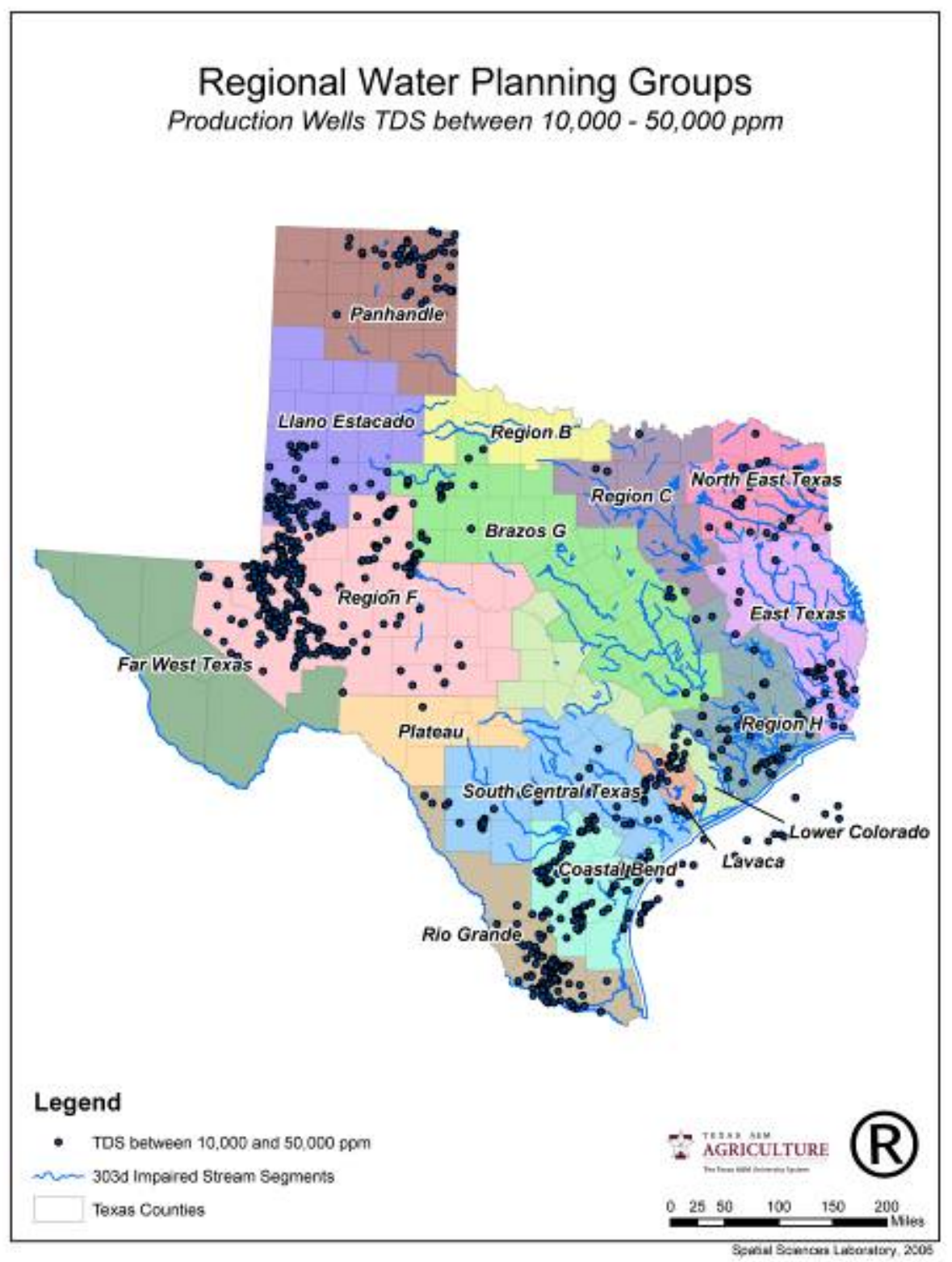

Figure 6. Saline Produced Water Sites 


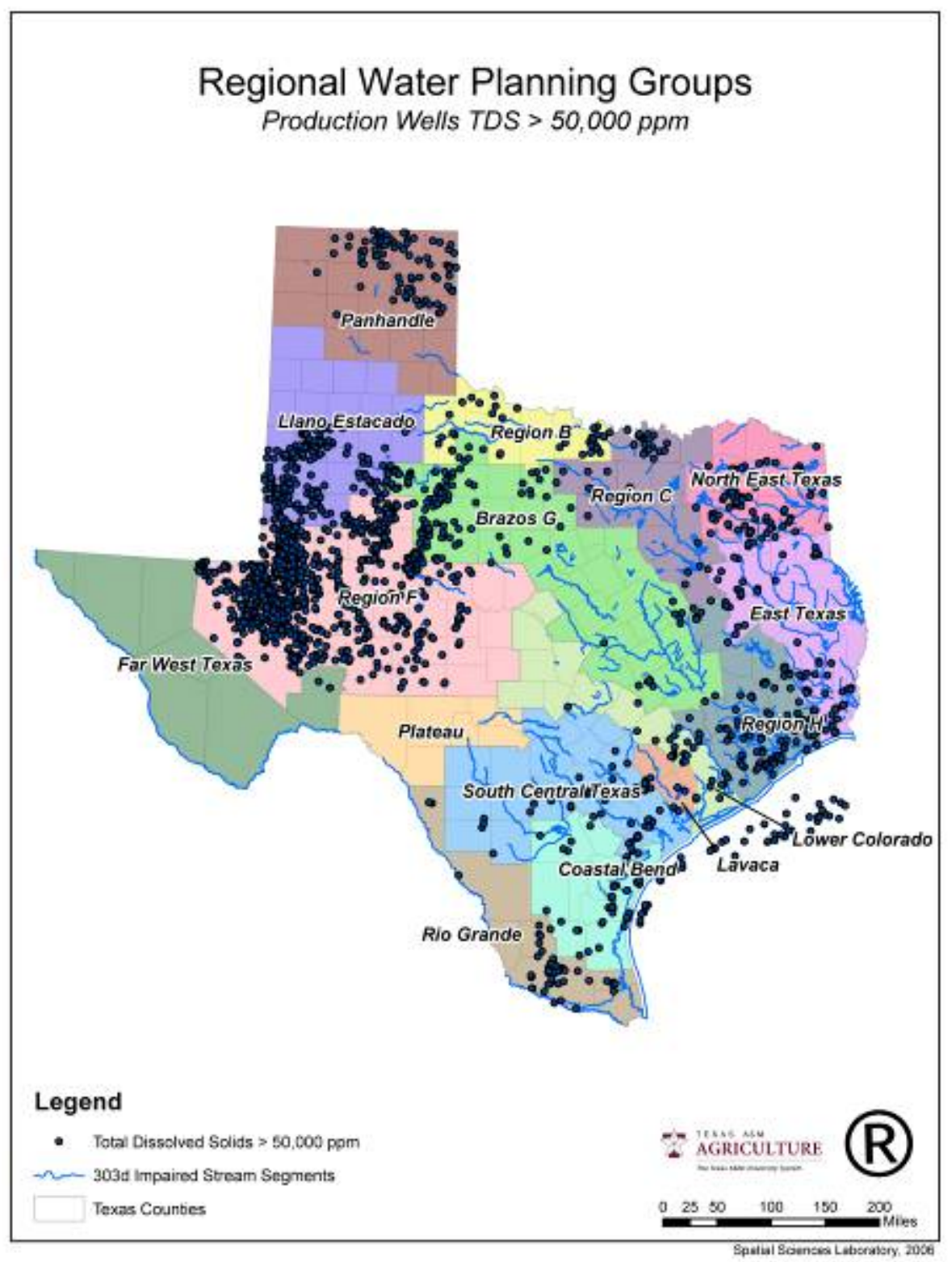

Figure 7. Hyper-Saline Produced Water Sites 
More detailed maps derived from GIS data are available uon request for each of the TWDB regional water planning regions. The solid circles represent oil or gas leases producing brine with less than 10,000 TDS brine. The database containing these locations was derived from the United States Geologic Survey database and updated with additional information from the West Texas Geological Society.

The charts also show the locations of impaired streams in Texas, a possible place where fresh water from desalination can be directed. More discussion is contained in a later section of this report.

\section{Uncertainties with Regulatory Issues}

The biggest drawback to utilizing desalination products for beneficial purposes is the environmental and regulatory issues involved. Environmentalists, regulators, industry personnel, and concerned citizens have a basic interest in how to set or negotiate environmental priorities given limited and possibly changing resources. When a new technology or process is being introduced into society, setting these priorities is a problem, especially if the technology has the potential to impact a significant part of the local community. Desalination of brackish ground water, oil field produced brine, or even seawater is one of those technologies. Burnett and Veil address these needs in their paper comparing risks of handling produced water in different manners [21].

\section{Costs of Managing Produced Water}

As stated in a previous section (page 12, "Managing Produced Water), over 95\% of produced water from conventional operations is re-injected into producing formations. The TRC website lists the permitted wells in Texas. The costs of injection of this brine will vary depending upon the field. Injection costs include the infrastructure cost to collect the water in a central facility, the cost to condition the brine for re-injection, and the cost to inject the brine back into the formation. Since the infrastructure is normally part of field development no detailed costs can be assigned to this portion of brine reinjection. As an estimate, Chevron operating company personnel in the Permian Basin estimate a cost of from $\$ 0.50$ per barrel to $\$ 1.00$ per barrel for re-injection. Table 2 illustrates three cost comparisons.

In drilling and fracturing operations, the transportation cost to delivery the brine to the well are significantly higher because the brine is transported in trucks. Brine injection well operators charge to inject the brine while the transportation companies charge by the mile to transport the brine. In the Barnett Shale play in Johnson County, Texas, the owner of a brine trucking company estimated a cost between $\$ .050$ to $\$ 1.50$ per bbl to transport brine. A representative of a salt water injection company estimated a cost of $\$ .50$ per bbl to inject the brine into a deep well formation. (Representatives of these companies requested anonymity).

Table 2 Costs of Produced Water Disposal

\begin{tabular}{|c|c|c|}
\hline Source of Brine & Transference Costs, $\$ / \mathrm{bbl}$ & $\begin{array}{l}\text { Treatment } \\
\text { costs } \$ / b b l\end{array}$ \\
\hline Drilling/completion & $\$ 0.50$ to $\$ 1.50$ & $\$ 0.50$ to $\$ 1.00$ \\
\hline Production to central facility & $\$ 0.25$ to $\$ 0.50$ & $\$ 0.50$ to $\$ 1.00$ \\
\hline $\begin{array}{l}\text { Production to battery, } \\
\text { transport to remote site }\end{array}$ & $\$ 0.50$ to $\$ 1.50$ & $\$ 0.50$ to $\$ 1.00$ \\
\hline
\end{tabular}




\section{POTENTIAL FOR THE DESALINATION OF PRODUCED BRINE}

\section{Produced water desalination (PWDS) technology}

Desalination refers to the process of removing salts from brackish water or salt water to produce potable water. It is primarily considered a technique to produce drinking water, but desalination technology has also been used to produce water for various industrial and agricultural processes. Simply put, desalination technology separates salt water into two separate streams: desalted water with a minimal concentration of dissolved salts and minerals, and a liquid containing the residual dissolved solids, referred to as the brine concentrate. For every 100 gallons of seawater, desalination can produce between 15 and 50 gallons of potable water [22, 23, 24, 25, and 26]. Depending on the type of technology used, recovery rates are even higher for brackish water. Because of this economic advantage, brackish water desalination will be the most common option in areas away from the Gulf Coast of Texas. While the average salinity of produced water in Texas from conventional oil and gas production is roughly twice as great as seawater, many fields produce significant amounts of brine that can be categorized as brackish. With respect to unconventional O\&G production, recent studies by the Environmental Protection Agency (EPA) on brine produced from coal bed methane identified reverse osmosis (RO) as the method of greatest promise. The key to RO desalination is pretreatment. Texas A\&M has performed significant research in pre-treatment and performed pilot field projects to test the A\&M technology in the field.

Desalination of highly saline brines by other technologies is also technically possible. Several different methods are available to separate salt and other solids from seawater. The two most common methods used today are thermal desalination and membrane desalination. Thermal desalination uses a very simple and natural process to separate out solids: salt water is heated to produce water vapor that is in turn condensed to form fresh water. Some of the more specific desalination technologies that depend on heat to produce water vapor include multi-stage flash distillation, multiple-effect distillation and vapor compression. Approximately half of the desalination facilities in the world use some form of thermal distillation.

The Middle East Desalination Research Center's (MEDRC) Research Advisory Council is conducting research on both thermal and membrane desalination technologies (Figure 8). Ongoing research is being funded and new research is being considered to bring these technologies closer to commercialization in this area of the world where population growth and lack of fresh water resources is even more common than in the Western U.S. 


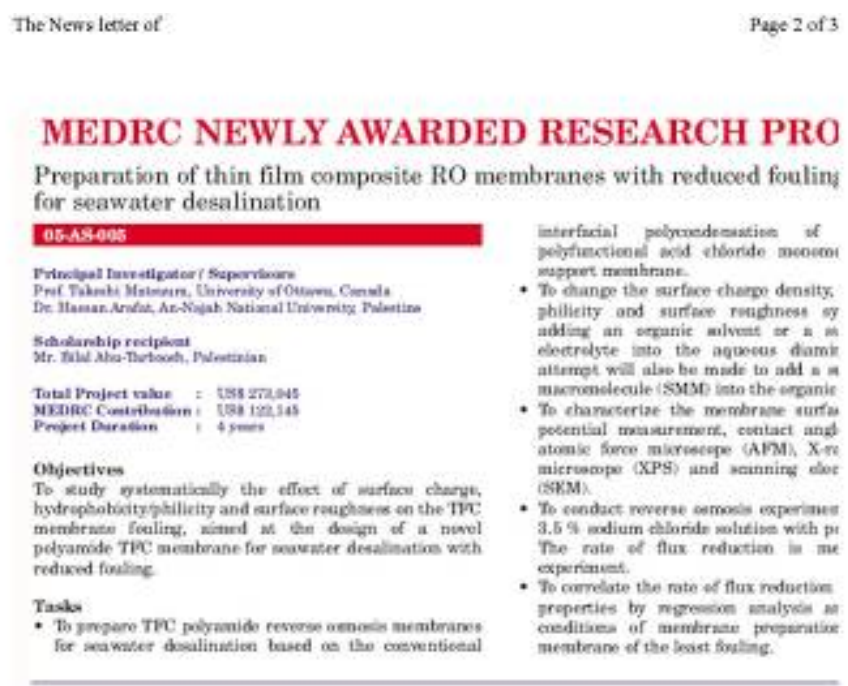

\section{New MEDRC research program in thin film membrane technology.}

Other research recently funded includes investigations into more efficient thermal desalination technology.

The MEDRC goals are:

1. Decrease the cost of desalination

2. Develop productive partnerships and cooperation

3. Develop sustainable desalination technologies

4. Improve communications in the desalination community

5. Develop human resources for application of desalination and foster international cooperation in research activities, particularly among regional experts

6. Utilize limited regional and international research resources

7. Maximize technology transfer.

The research focus in the Middle East is upon potable water systems for increased urban populations. Regardless, the advantage of oil field brine PWDS (by whatever technology) for providing fresh water resources is that the RO concentrate brine can be re-injected into petroleum formations and so utilize Class II injection wells.

Later sections in this report will address the technical, economic, and environmentally feasibility of this type of concentrate disposal.

\section{Reverse Osmosis Desalination for Oil Field Brine}

Membrane technology is the other major method used to desalinate salt water. Like thermal technology, membrane desalination is based on a simple concept: salt water is forced across a membrane, producing potable water on one side of the membrane, and leaving behind briny water on the other side. The two most common types of membrane desalination used today are electrodialysis and reverse osmosis [1]. Electrodialysis is a voltage driven process that uses an electrical current to draw salts and other solids through a membrane, leaving pure water behind. With electrodialysis, ions travel through the electrically charged membrane, which differs from reverse osmosis, where water molecules are forced through the membrane. Electrodialysis is not suited for the removal 
of dissolved organic constituents and microorganisms, which represents a serious drawback. Instead of using an electrical current, reverse osmosis membrane desalination uses high pressure to pump salt water through a semi-permeable membrane, which acts as a microscopic strainer, filtering out salts, minerals, contaminants, viruses, bacteria, pesticides and other materials. The membrane strains salt and other molecules because they are too large to fit through the microscopic pores.

The technology most adaptable to PWDS is Reverse Osmosis (RO) membrane technology. RO lends itself to scalable systems and is a commercial process. The chief difference for RO design in the oilfield is the care that must be taken with pre-treatment.

RO desalination technology has been chosen by Texas as a preferred option of providing fresh water supplies for the Gulf Coast. Cost of providing water resources have been presented by three different agencies. The Texas Water Development Board is investigating the potential for similar RO desalination, this time from brackish aquifer sources (BGW) in West Texas, where water supplies are critically low. At present however, no cost estimate for BGW desalination have been reported.

\section{Pre-Treatment of Oil Field Brine}

The oil industry refers to water pre-treatment as "water conditioning" and routinely performs this process as a necessary step to water re-injection. Since several billion gallons of water per day are re-injected, the practice of water pre-treatment is well established. A water flood engineer faces the same concerns as those who are designing membrane treatment systems. Such issues as scale removal, biofilm suppression and solids control must be handled in a cost effective manner, otherwise the injection well plugs, necessitating a costly workover.

Comparing the cost of desalinating brackish oil field brine with the costs of desalinating BGW shows that pre-treatment of the oil field brine will be more expensive, but concentrate disposal will be less expensive. Newer desalination technology is also expected to reduce these costs. Pre-treatment to accommodate saline oil field brine desalination is critical. The characteristics of the materials, particularly oily water, make pre-treatment mandatory. Several methods of oil and solids removal have been tested at the A\&M facility.

Powered centrifuges are routinely used in offshore oil production operations to remove oil and solids from water before it is discharged into sea. Siddiqui [1] tested the use of a centrifuge to reduce oil concentration from the produced water as a pre-treatment for desalination but found the power requirement to be too high. Hydrocyclone separators have been developed for more efficient oil/brine separation [27, 28, and 29]. Effective hydrocyclones impart more than $100 \mathrm{~g}$ centrifugal force at maximum efficient flow rate. Systems are best for fluids with significant density difference. Hydrocyclones work best over a narrow flow range but have proven to be effective in high pressure and medium pressure oil systems. This technology is now considered to be the most reliable for offshore applications in meeting the required level of oil for discharge. Hydrocyclones have limitations in low-pressure systems. The efficiency of oil removal with a hydrocyclone unit becomes less because there is not enough pressure in the system to drive the water. Consequently, the water has to be pumped, and as a result the produced water becomes more difficult to clean. Small oil droplets and the use of different 
chemicals make the hydrocyclone option not very effective in a number of gas condensate systems. Also, small density differences between the oil and water phase solid particles present in the feed reduced the efficiency of hydrocyclones.

Doyle [30] studied the use of organoclay for the removal of dispersed oil from water by adsorption and performed limited field tests with this technology. For onshore operation, vaporization of water using large surface area exposure of water on water ponds is another option. Boysen et al. [31] looked into the commercial feasibility of using freeze thaw and evaporation process to treat produced water. This approach may cause environmental impacts relevant to the atmosphere as well as life around the ponds.

Removal of Dissolved Oil from Produced Water: The technology for removing soluble components from produced water has improved in the past decade. The technology for removing soluble components can be based on extraction, precipitation, oxidation process, or by per-vaporation systems [29]. All these technologies require relatively large facilities to handle the large volume of produced water offshore. Most of these technologies involve the use of other chemicals and solvents, use of additional power, as well as producing a concentrated waste stream. Activated carbon has been used in the chemical industry for a long time for the removal of dissolved organics from waste streams. Some of the new technologies that are available today for the removal of dissolved hydrocarbon components from the produced water are MPPE system from Akzo Nobel (www.akzonobel.com), “Pertraction” technology (www.tno.nl) and surfactant modified zeolite microfiltration.

Table 3 contains data from a test of pre-treatment of an oily water stream with heavy biological contamination using both oil absorbent and a new type of membrane microfilter. This data was collected at Texas A\&M University using a specially designed portable unit that monitors power usage as a function of treatment type, water quality, and treatment time. Test results found that contaminants could be removed for less than $\$ 1.00$ per 1,000 gallons of raw water processed (power cost only). Power cost is typically the largest expense in membrane plant operations, thus measurement of this cost under field conditions should provide more accurate estimation of a full size facility's cost.

Table 3. Pre-Treatment Costs: Removing Contaminants from Waste Water

\begin{tabular}{|c|c|r|r|r|}
\hline $\begin{array}{c}\text { Type of Pre- } \\
\text { treatment }\end{array}$ & Kw Used & $\begin{array}{c}\text { Fresh Water } \\
\text { Produced }\end{array}$ & $\begin{array}{c}\text { Power } \\
\text { per 1,000 } \\
\text { gal }\end{array}$ & $\begin{array}{c}\text { Cost* per } \\
\mathbf{1 , 0 0 0} \text { gal }\end{array}$ \\
\hline oil + biofilm removal & 2.80 & 199.4 & 14.04 & $\$ 0.98$ \\
\hline & & & & \\
\hline oil removal & 0.94 & 99.4 & 9.46 & $\$ 0.66$ \\
\hline * = Power cost @ \$.07 per Kwh & & & \\
\hline
\end{tabular}

\section{Disposal of Materials Removed from Brine during Desalination}

Any form of desalination treatment will include some means of handling byproducts and waste removed during the purification process. In addition to brine concentrate, a desalination project may generate solid waste in the form of sand, silt and other debris found in the brine that must be filtered out before it is desalinated by the reverse osmosis membranes. The amount of solid waste generated by a large-scale desalination facility is 
considerable. At the Tampa facility, the pre-treatment process produces approximately 14 wet tons a day of organic material, suspended solids and metals found in the source water [32]. However, it is also possible to handle slurries produced from the pre-treatment process with the brine discharge directed to re-injection into the oil field. Otherwise, if pre-treatment of raw water creates solid waste, then disposal must be addressed. Quantities could be significant.

Historically, since one of the major impacts of desalination has been the problem of the disposal of the salts ("concentrate") and other materials removed from the source water, one of the advantages of oil field brine desalination processes is that these materials can be re-introduced back into the petroleum reservoir where it originated. This brine contains concentrated dissolved salts and other materials. However, in the oil and gas industry, high salinity brines are routinely injected into formations for pressure maintenance and secondary recovery by water flooding. Since water from desalination operations may be injected into these oil- and gas-containing formations, the estimated cost savings can be as much as 30\% of the cost of operating the desalination unit. This represents a significant cost savings for RO technology that offsets any added pretreatment needed for the oil field brine. Fresh water is therefore available to communities in need of this valuable resource. This opportunity for the disposal of salts and other materials from water treatment processes is being considered for a number of industries $[33,34]$ and is the subject of a study by the TWDB [35].

To illustrate the potential for disposal of brine in an oil field, the Spraberry Trend in West Texas was selected for a hypothetical brine disposal project. Spraberry reservoirs originally contained 10 billion bbls of oil in place (more than 2,000,000 $\mathrm{M}^{3}$ ). Less than $10 \%$ of this oil has been recovered [36]. The reservoirs are between 5,000 and 8,000 ft. in depth and extend over portions of Borden, Dawson, Glasscock, Martin, Midland, Reagan, Sterling, Tom Green, and Upton counties. (More than 230,000 people live in this area including the cities of Midland, Odessa, and San Angelo.) There are more than 10,000 wells in the Spraberry reservoirs many of them operating in fields which are being waterflooded. A significant number of the injection wells in the Spraberry reservoirs take water on a vacuum (no surface injection pressure). Area rainfall ranges from less than 10 " to 18" a year. All three of the major cities in this area are currently under restricted use of municipal water by households and represent potential markets for desalination facilities. There are also several waterways in the area considered "impaired". Figure 9 shows the Colorado River Headwaters watershed (No 12080002, EPA). There are numerous oil leases producing brackish brine water in this watershed and an extensive infrastructure of pipelines used to carry oil and gas to gathering facilities and pipeline connections.

Another factor favoring alternate sources of potable water in West Texas is that many communities already have infrastructure developed for recycling waste water from municipal water treatment facilities. An example is Andrews, Texas. This city recycled $100 \%$ of its discharge from municipal water treatment into landscape irrigation for public parks, golf courses and sports fields. Communities like Andrews have the resources to incorporate an additional source of water into their distribution systems if such a source was available [37].

Desalination of oil field brine has another advantage - that being a means of disposing of 
the brine concentrate. Brine re-injection into producing formations serves as an example of alternate waste brine disposal for desalination. Byproducts from desalination, regardless of the technique employed, contain concentrated dissolved salts and other materials.

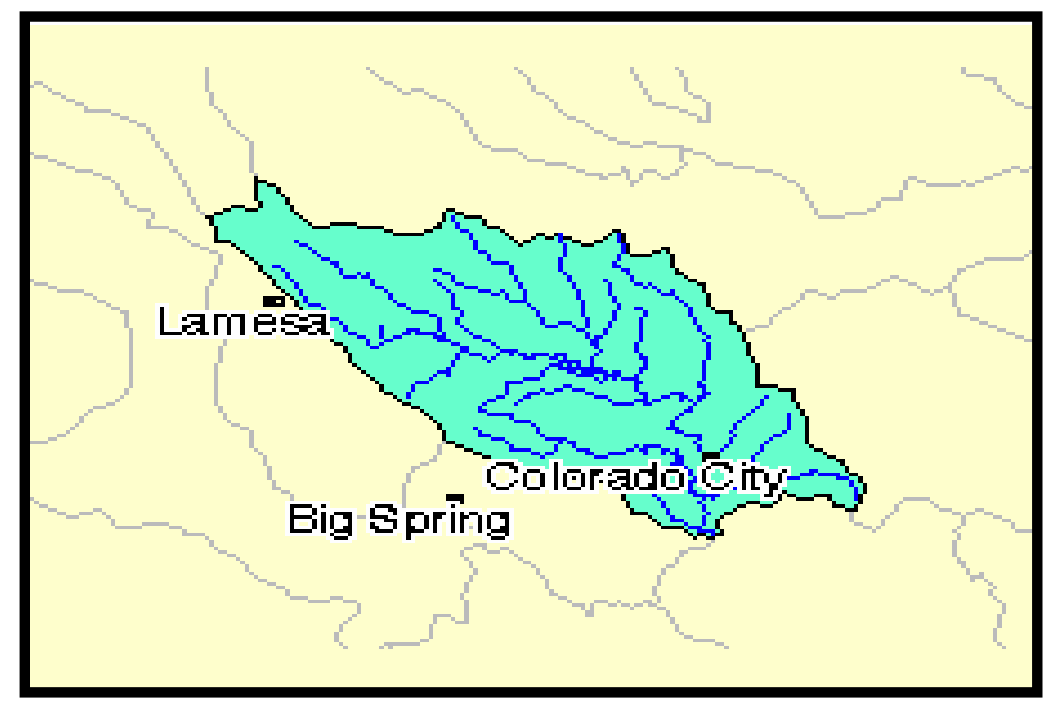

Figure 9 Example of one of the water ways classified by EPA as “impaired”.

The waterway is in the Colorado River Basin of Texas. One of the proposed uses of fresh water produced from the Spraberry Trend is stream augmentation to reduce chlorides: No 12080002, EPA.

Disposing of this brine concentrate for traditional desalination processes can represent a significant fraction of the cost of operating the unit to recover fresh water. Since in the oil and gas industry, high salinity brines are routinely injected into formations for pressure maintenance and secondary recovery by water flooding, water from desalination operations could be injected into these oil- and gas-containing formations, and the estimated cost savings are significant.

\section{Costs of Reverse Osmosis Desalination of Oil Field Brine}

The two major cost components of oil field brine desalination are (1) removal of suspended solids (pre-treatment) and (2) removal of dissolved solids (desalination). Desalination costs of saline brines are similar to conventional seawater desalination. Estimated costs for several seawater desalination facilities along the California coast range from $\$ 2.25$ to $\$ 3.70$ per 1,000 gallons (\$711 to $\$ 1171$ per acre-foot), a substantial decrease from the 1993 cost estimates of $\$ 3.17$ to $\$ 12.70$ per 1,000 gallons ( $\$ 1000$ to $\$ 4000$ per acre-foot). During the same period, the cost of water from other sources in California has steadily increased. In 1991, the Metropolitan Water District of Southern California (“MWD”) paid approximately \$27 per acre-foot for water delivered from the Colorado River and \$195 per acre-foot for water from the California Water Project. Now, MWD pays an average of $\$ 460$ per acre-foot for delivered water.

In Texas, the three proposed desalination facilities on the Gulf Coast have cost estimates ranging from $\$ 3.58$ to $\$ 4.23$ per 1,000 gallons ( $\$ 1,000$ to $\$ 1,300$ per acre-foot). These cost estimates include a "transference” cost representing the cost to deliver raw water to 
the RO facility and to deliver fresh water to existing municipal water lines [38]. The estimates also include amortization of the facility ( 25 years) and operation and maintenance costs.

The economic justification for desalination of oil field brine is entirely different than the cited examples. O\&G production savings would come from the deferred cost of disposal of the excess brine from operating facilities. Enhanced oil recovery processes also require water that must have relatively low salinity. Rather than utilize fresh water from ground water sources, the industry has tried desalination of produced water extensively. One large-scale program to desalinate brackish produced water was in Crockett County Texas [33]. Marathon Oil Company constructed and operated a facility producing 714,000 gallons per day (17,000 barrels per day) to supply feed water for steam flooding operations. The cost of the water treatment (no infrastructure costs) was reportedly less than $\$ 2.50$ per 1,000 gallons. The steam flood was projected to boost oil production in the Yates Field by more than 100,000 barrels of oil. The facility was deactivated when more advanced oil recovery technology was developed.

More recently, pilot tests of a produced water treatment by membrane technology was performed in the Burgan Field, Kuwait to test the removal of dispersed oil. Over a fivemonth period the unit operated at an oil rejection efficiency of $83 \%$ to $89 \%$. [34].

Experience has shown that membranes can be effective pre-treatment techniques and RO membranes can provide desalination at less cost than the cost of brine disposal. Testing has also shown that desalinating brackish oil field brine is more expensive that desalination of BGW but concentrate disposal will be less expensive. Newer desalination technology is also continuing its advance in the field of industrial, food, and pharmaceutical industries.

The A\&M Mobile Desalination Unit was constructed to test both pre-treatment by membranes and RO desalination at field sites. Different types of membranes are tested and RO salt rejection efficiency can be determined directly. It is equipped to run either single stage or multi-stage membrane treatments and can be configured either for parallel or series membrane flows. The unit is shown in Figure 10 in Washington County, Texas in 2006.

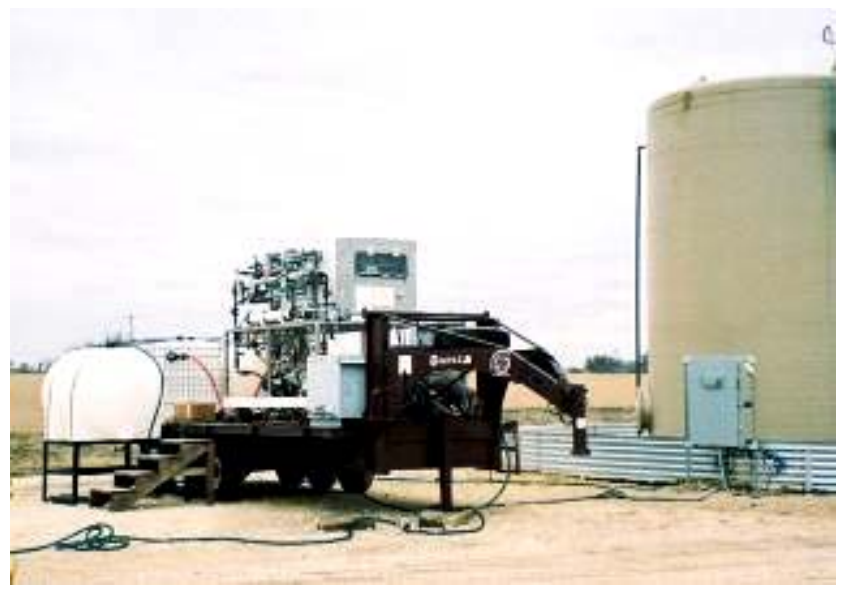

Figure 10. The A\&M Mobile Desalination Unit.

The unit is shown at a well site in Washington County, Texas in early 2006. The unit took brine from the fiberglass storage tank (shown on the right of the picture) performed pre-treatment by micro-filtration, then de-salination by RO. Fresh water was directed to the tank to the left rear of the unit. 
In addition to testing the capability of different types of membranes, the unit has power transformers to utilize oil field power and an electrical meter to measure power consumption, one of the highest cost factors in desalination. The cost of desalination is directly related to the power used to pump brine past the filters. As salinity increases, power consumption rises. Data from four different field sites are given for comparison, collected on four types of saline feed brines. Table 4 shows this comparison of electrical power costs.

Table 4. Representative power costs of desalination of oil field brine.

\begin{tabular}{|c|c|c|c|c|}
\hline \multirow[b]{2}{*}{$\begin{array}{l}\text { Salinity of Feed } \\
\text { Brine, tds (ppm) }\end{array}$} & \multicolumn{4}{|c|}{ Power Costs Kw Hr per 1,000 gal. Permeate } \\
\hline & $\begin{array}{l}\text { Pre- } \\
\text { treatment }\end{array}$ & $\begin{array}{l}\text { RO } \\
\text { desalination }\end{array}$ & $\begin{array}{c}\text { Operating } \\
\text { Cost, \$ per } \\
1,000 \text { gal. }\end{array}$ & $\begin{array}{c}\text { Operating } \\
\text { Cost, \$ per bbl }\end{array}$ \\
\hline $\begin{array}{c}\text { Contaminated } \\
\text { Surface water } \\
\sim 1,500 \text { tds. }\end{array}$ & $\$ .65$ & $\$ 1.25$ & $\$ 1.90$ & $\$ 0.08$ \\
\hline $\begin{array}{l}\text { Gas well produced } \\
\text { brine 3,600 tds. }\end{array}$ & $\$ 2.50$ & $\$ 2.00$ & $\$ 4.50$ & $\$ 0.19$ \\
\hline $\begin{array}{l}\text { Oil well produced } \\
\text { brine } \sim 50,000 \text { tds }\end{array}$ & $\$ 2.20$ & $\$ 6.00$ & $\$ 8.20$ & $\$ 0.34$ \\
\hline $\begin{array}{l}\text { Gas well produced } \\
\text { brine } ~ 35,000 \text { tds }\end{array}$ & $\$ 2.00$ (est.) & $\$ 4.20$ (est.) & $\$ 6.20$ (est.) & $\$ 0.26$ \\
\hline
\end{tabular}

The information in the Table should be used for estimates only. The prime performance monitor should be salt rejection efficiency, then operating cost. Two types of pretreatment micro-filters were used. In addition, a new low pressure RO filter was employed in the oil well test. Salt rejection efficiency of the low pressure membrane was lower than the filter used earlier.

The energy cost of operating the desalination facility represents roughly one-third of the total operating costs. Using one of the examples given in Table 4, for desalination on-site of brackish produced water from a gas well, the total operating costs would be less than $\$ 10$ per 1,000 gallons of fresh water produced ( $\$ .42$ per bbl). For comparison, the operator of the well pays approximately $\$ 1.50$ per barrel to truck the water to a commercial salt water disposal well. For this example, the field data indicate that a dedicated desalination unit on the site could reduce the water hauling volume by $50 \%$ and the total water hauling costs by almost 20\%. For this example, the land owner was offered the fresh water for no cost. Under some circumstances, the fresh water represents income to the operator. 


\section{USES FOR DESALINATED OIL FIELD BRINE}

\section{Beneficial Use of Desalinated Oil Field Brine}

Many areas of the state have water shortages and would welcome a new source of fresh water that could be used to supplement municipal supplies. Figure 11 reveals almost onethird of Texas counties have unmet water needs. Additionally TWDB anticipates a significant increase in demand for fresh water resources in the next 20 years. Accordingly, this section summarizes potential uses of water produced from oil field brine and the applicable regulations that such usage must meet.

Areas in West Texas with significant oil and gas production (and brine production) will be the most likely candidates for beneficial use of produced water. As Figure 5 shows, a significant number of produced water facilities are producing brine of less than 10,000 TDS. This represents the most affordable potential resource. To consider the feasibility of treating oil field brine, we have concentrated on this less costly opportunity, produced water which represents approximately one-third of the brine produced in Texas. The A\&M desalination project contains a list of production wells in Texas discharging brine of less than 10,000 ppm tds. The list is arranged alphabetically by county, with Field names alphabetized within a county.

Affordable desalination and supplemental use by municipalities represents a logical and beneficial use of the resource. Distribution and/or storage of desalinated water, either in surface lakes and ponds or in subsurface aquifers, are significant issues that must be considered when evaluating PWDS economics [37, 38]. Technology is available that allows pre- and post-treatment required to assimilate or blend desalinated water into the local water supply system. For example, Odessa's average daily water use has averaged 12 million gallons/day in winter and 29.5 million gallons/day in summer [39], with a peak of 34.9 million gallons used on June 26, 2002. The difference in water use in the summer is predominately landscape irrigation. Corresponding daily brine disposal in Ector, and neighboring Midland, and Winkler Counties, Texas in 2002 has been slightly more than 4,000,000 gallons of water per day according to county records, or $25 \%$ of the water used on landscape irrigation in the city. Most other areas of Texas reflect the same water usage.

Texas A\&M has been investigating the potential for rangeland and habitat restoration programs in West Texas. The results of analyses focusing on restoration of rangeland systems may provide a prioritization where habitat enhancement would be most efficient. Of significant interest will be the development of cooperative programs with other environmental agencies and introduction of the technology to determine their opinions on use and acceptance. Hand in hand with this opportunity is the potential to use desalination as a way of enhancing the quality of impaired streams in Texas. These and other uses are influenced by the public's willingness to accept the production of alternative water resources from oil and gas production. The following illustrates some of the significant concerns regarding acceptance of water reuse.

Factors contributing to the degree of public acceptance of water reuse (adapted from Hartley, 2006 [40]. indicate that U.S. public acceptance of water reuse seems to be higher when:

- Human contact is minimal. 
- Assurance of public health is clear.

- Protection of the environment is a clear benefit of the reuse.

- Promotion of water conservation is a clear benefit of the reuse.

- Cost of treatment and distribution technologies and systems is reasonable.

- Perception of wastewater as the source of reclaimed water is minimal.

- Awareness of water supply problems in the community is high.

- Role of reclaimed water in overall water supply scheme is clear.

- Perception of the quality of reclaimed water is high.

- Confidence in local management of public utilities and technologies is high.

\section{Potable Uses}

The highest level of water treatment is associated with human ingestion. The Texas Commission on Environmental Quality has responsibility for the quality of water discharged into the public sector. Water reuse for non-potable (e.g., irrigation, industrial) or indirect potable (e.g. discharge into drinking water reservoirs or supply) has continued as a topic of discussion in the United States with a focus on dry or drought impacted regions, such as Arizona, California, Colorado, and Texas; or communities experiencing substantial population and economic growth (e.g., Georgia and Florida) [2].

A significant amount of survey and case study research since the 1970s has found that the public in many of these states support the general concept of using reclaimed water for non-potable reuse initiatives [41]. Generally, constituents favor reuse that promotes water conservation, provides environmental benefits, safeguards human health, and cost effectively treats and distributes a valuable, limited resource. However, as the potential for water reuse becomes more tangible to people with proposed projects in their communities and the increased likelihood of human contact, attitudes change - "the public's support wanes" [42].

In the case of treated brine produced by oil and/or gas wells, there is an increased measure that must be overcome beyond the traditional concerns - both quality and social stigmas. Any potential for the use of treated brine from oil/gas production must meet the same permitting requirements as a municipal drinking water system by the TCEQ [41] and overcome social norms.

The applicable TCEQ Rule pertaining to public drinking water systems is TAC Chapter 290, Section 42(g). This section states that "other" treatment processes will be considered on an individual basis. Based on input from TCEQ staff, a licensed professional engineer must provide "pilot test data or data collected at similar full-scale operations" of the proposed system demonstrating that the system would meet applicable Drinking Water Standards. The pilot test must be representative of the actual operating conditions that can be expected over the course of a year, meaning the test must be done during the time of the year that would place the most strain on the treatment system. Additionally, proof of a one-year manufacturer's performance warrantee or guarantee assuring the plant will produce treated water that meets minimum state and federal drinking water standards is commonly required by the State as a condition of an operating permit. Therefore, if this water was to be used as an independent potable water source, among other drinking water standards, TDS levels must be reduced to the Environmental Protection Agency's secondary standard of $500 \mathrm{mg} / \mathrm{L}$. Permitting for waters with a TDS greater than $500 \mathrm{mg} / \mathrm{L}$ 
may be available if this water is the only potential potable resource for a community. However, if the high TDS water were to be blended with another public water supply (PWS) and then distributed, the required level of treatment could be less. The caution in this situation would relate to the salt-loading on the primary PWS infrastructure during blending.

The US National Research Council [43] released a report, "Issues in Potable Water Reuse", based on an evaluation of several existing reuse projects and the feasibility studies of Tampa and San Diego's projects. The NRC concluded that "reclaimed wastewater can be used to supplement drinking-water sources, but only as a last resort and after a thorough health and safety evaluation”. A point of contention existed in previous years regarding the discharge of RO concentrate from desalination facilities. If the saline concentrate is a waste stream, then the RO facility operator must get a permit from TCEQ for a Class 1 disposal well. However, recently [44] a tentative agreement between TCEQ and the TRC was made regarding the use of the brine concentrate in oil field brine injection wells for enhanced recovery.

\section{Discharge to Supplement In-Stream Flow or Rangeland Habitat Enhancement}

The Texas Commission on Environmental Quality (TCEQ) monitors the condition of the state surface waters, assesses the status of water quality every two years, and submits their assessment to the U.S. Environmental Protection Agency (EPA). The report is published on the TCEQ Web site as the Texas Water Quality Inventory and 303(d) List (Inventory and List). Requirements for the Inventory and List are codified in the federal Clean Water Act, Sections 305(b) and 303(d) [44]. Further requirements are set out in state law in Title 30 of the Texas Administrative Code (30 TAC), and in rules and guidance established by the TCEQ [45].

Discharges to surface water designated as Waters of the State must meet Texas Surface Water Quality Standards (TSWQS) as contained in TAC Chapter 307. Without a specific stream or amount of discharge set, it is difficult to outline all necessary regulations one must follow. Figure 12 shows the location of impaired streams with O\&G sites nearby. With proper treatment and regulatory approval, one of the uses of fresh water from desalination would be to augment stream flow. More detailed maps at higher resolution are available for each Regional Water Planning District.

The permitting process, done through the TCEQ Water Quality Division, is conditional on two key variables, the receiving stream ambient quality and the volume of the discharge. The TSWQS identify individual water quality standards for each stream in the State, and these standards are based on the use category a particular stream is assigned. A discharge, once dilution has occurred, must not hinder the water quality standards set for the receiving stream.

Most notable for brine, TCEQ Guidance Document RG-194, Procedures to Implement the Texas Water Quality Standards, provides a section entitled, "Screening Procedures and Permit Limits for Total Dissolved Solids". This document states, "Concentrations and relative ratios of dissolved minerals such as chloride and sulfate that compose total dissolved solids (TDS) will be maintained to protect existing and attainable uses” [46]. The screening procedure is applied to all domestic dischargers with an average permitted flow of 1 million gallons per day (MGD), all industrial majors, and all industrial minors that discharge process water. The screening procedure is divided into categories based on the type of receiving stream: intermittent stream, perennial stream, intermittent stream 
within three miles of a perennial stream or intermittent stream with perennial pools, lake, and bay or wide tidal river. The equations used take the following into consideration:

- TDS criterion of the receiving stream (as defined in the TSWQS)

- Harmonic mean flow of the receiving stream

- Effluent flow volume

- Effluent TDS concentration

- Effluent concentration at the edge of the human health mixing zone

For discharges to freshwater, a screening procedure is used to determine whether a total dissolved solids (TDS) permit limit or further study of the receiving water is required. If screening demonstrates elevated levels of TDS, then appropriate permit limits are calculated.

One of the potentially beneficial ways to use desalinated brine from oil field operations is to add the water to nearby streams. Waterways in Texas often fail to meet EPA standards on clean water. In the West, salinity is a problem. In the central part of the state, runoff from agricultural operations impair quality while in the Eastern part of the state, in forested watersheds, channel gradients and stream velocities are so low and water temperatures so high that low DO concentrations should not be surprising [47]. Addition of ultra-low, oxygenated fresh water into waterways with low flow can result in perceptible betterment in water quality and attendant fishery and wildlife habitat improvement.

\section{Restoring Rangeland Habitat}

Rangeland functions and processes are centered around three main variables, soils, water, and biodiversity. The successful restoration of degraded rangeland systems requires a system that, combined, addresses each of these critical characteristics and integrates management to improve the sustainability of each. The restoration of thousands of acres of degraded rangelands in the western United States will require a major effort from all who benefit from them. One of the major constraints to effectively restoring arid and semi-arid rangelands is the lack of water for establishment of vegetation. Treatment of produced water from oil and gas production could significantly benefit efforts to develop restoration strategies for arid and semi-arid rangelands throughout the western United States.

It is estimated that $4 \mathrm{MM}$ barrels of water $(150,000,000$ gal) is produced daily in Texas, equivalent to $10 \%$ of the water usage in the state, at this time little or none of it available for re-cycling. However, water alone will not provide the 'utopia' for rangeland restoration.

Degraded rangelands have undergone change due to environmental or human forces and have generally transitioned over a threshold [48] of ecological health into a state that is usually less productive, both ecologically and in terms of human benefits. To restore such degraded lands requires significant inputs outside of normal ecological succession. The use of treated produced water for the purpose of restoration in semi-arid regions provides a resource that otherwise would not be available to provide the inputs required to transition the system back across the threshold into a more productive site.

\section{Livestock Uses}

Another potential use of the brine-produced water is livestock agriculture purposes. There are very little, if any, regulations to follow; however, specific guidelines have been 
suggested for salinity and livestock uses (Table 5). If the owner of the livestock is amenable to using a water supply, he is allowed to do so. A typical rule of thumb, though, is a TDS limit of $6,000 \mathrm{mg} / \mathrm{L}$ for this purpose. This is the TDS concentration TCEQ employees use when gauging if a particular stream is suitable for livestock use. One specific managerial consideration is that livestock consuming high moisture forage (green grass) can tolerate higher levels of salinity in drinking water [49].

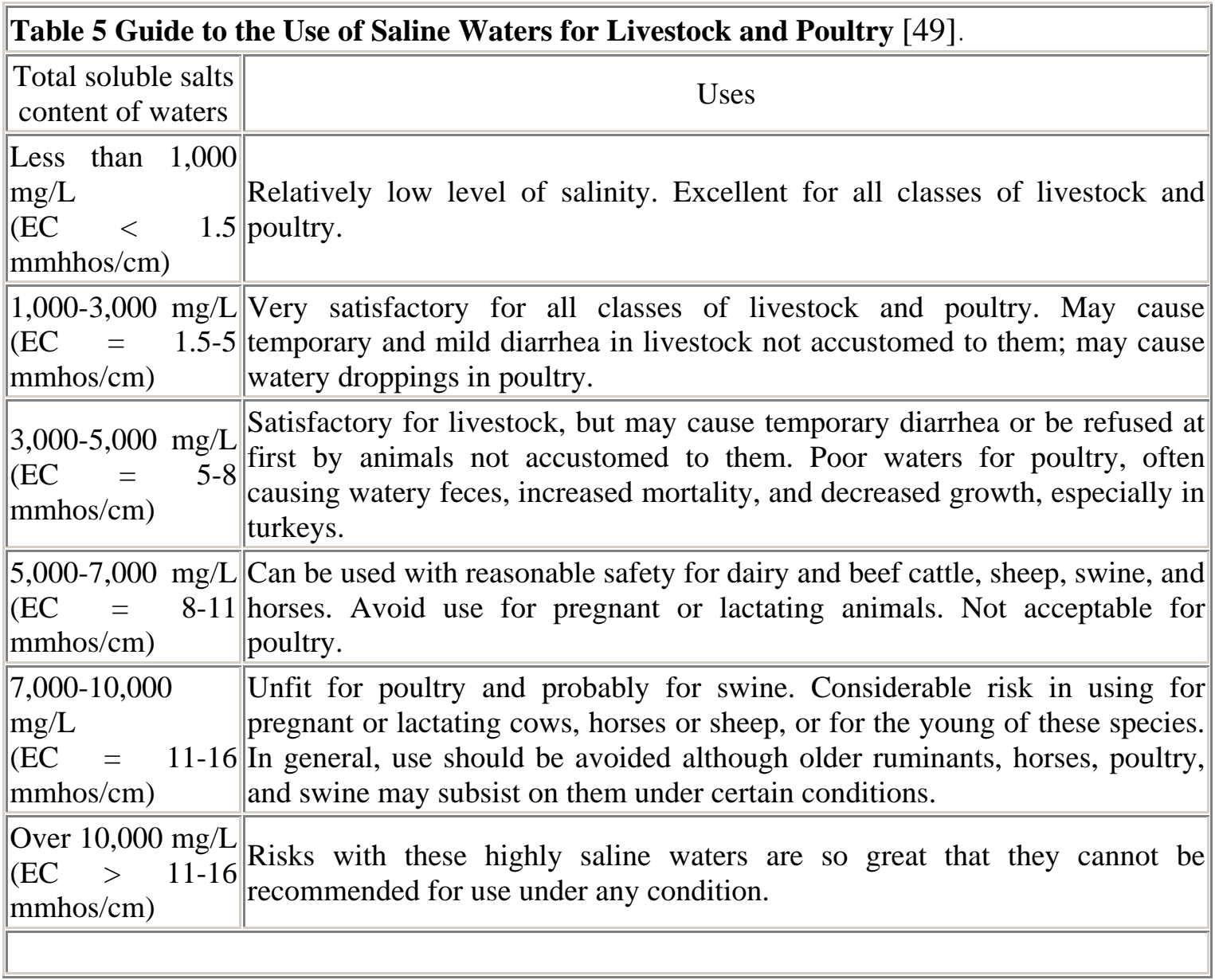

The damage of high saline water depends more on the total amount of minerals present rather than on any specific one. The ions most commonly involved in high saline waters are calcium, magnesium, sodium, bicarbonate, chloride, and sulfate. Usually chlorides are less harmful than sulfates. Magnesium chloride appears to be more injurious than calcium or sodium salts [50].

Illustrations for use of desalination of oil and gas produced water as potential livestock water shortage mitigation has been presented for Regions $\mathrm{A}, \mathrm{F}$ and $\mathrm{O}$ as a potential strategy to meet anticipated shortages in those regions.

Region A expects the largest shortages for the future to be associated with irrigation use, followed by livestock and municipal [51]. In Region A livestock water shortages were identified for Carson, Dallam, Hartley, Hutchinson, Moore, Randall, and Sherman 
counties primarily associated with confined animal feeding operations. The total water demand for livestock use within the region is expected to increase to 89,000 acre-feet by 2060, and CAFOs are expected to require roughly 82 percent of this total water use by 2060.

Regional water planning groups indicate that projected livestock water shortages will be met in a similar manner as what has been observed over the last forty years as the CAFO industry has expanded in the region; either new wells are drilled or nearby irrigated cropland is purchased (or water rights bought or leased) for its water and waste disposal. It is also possible that water allocated for irrigation use be transferred to livestock water users..

Currently, only precipitation enhancement has been addressed as a strategy for meeting potential livestock shortages. The addition of desalination of produced water may provide additional resources for water planning in Region A where logistics (social, political \& economic) and volumes are consistent with development of oilfield desalination programs.

Anticipated livestock requirements for Region $\mathrm{O}$ contain similar predictions as those of Region A. Total livestock water demand projections for the Llano Estacado Region are the sum of water demand projections for beef cattle feedlots, swine feedlots, dairies, horses, range beef cows/bulls, range beef stocker cattle, sheep, and poultry. Total livestock water use in 2000 was estimated at 37,724 ac ft [52] Total livestock water demand for the region is projected to be 70,457 ac ft/yr in 2060 .

The Region F RWPG increased the TWDB projections for the region by 32 percent to account for revised water use for different livestock categories and water use for wildlife associated with the hunting industry in the region. Livestock demand in Region $F$ is expected to remain constant at 23,060 acre-feet per year throughout the planning period [53]

Most of the livestock demand in Region $\mathrm{F}$ is for free-range livestock. In addition, Region $\mathrm{F}$ has added water to account for wildlife that relies on the same water sources as commercial livestock. Region $\mathrm{F}$ encourages individual ranchers to adopt practices that prevent the waste of water for livestock. However, the savings from these practices will be small and difficult to quantify. Therefore, livestock water conservation will not be considered in the planning process.

The use of treated produced water for livestock or rangeland habitat enhancement will, by nature, be localized due to the logistics of the water source. However, for those areas in or around producing oil and gas fields or saltwater disposal sites, desalinated oil/gas field water could be a significant input of water resources. If employed, the practice could reduce local stresses for livestock and wildlife; thus, freeing traditional resources for other uses.

\section{Irrigation}

Desalination of oil field brine (or any other impaired water) is generally too expensive to be used for irrigation of crops. An exception to this guideline would be either hydroponics irrigation of greenhouse crops or for drip irrigation of a high value crop. 
If irrigation is being used, then necessary treatment levels of water to be used for crop irrigation are driven by the salt tolerance of the crop or landscape. TCEQ Rules, TAC Chapter 309, Subchapter C (Land Disposal of Sewage Effluent) provides the following table regarding crops. Information received from the Texas A\&M Soil and Crop Sciences Department provided the following information on salinity tolerance of turf grass: Additionally, when irrigating with something considered reclaimed water, care must be taken regarding the potential for runoff to waters of the state. This can be avoided with the use of modern management practices.

\section{Aquifer Recharge}

ASR facilities have been used in the United States for over 30 years, those in Florida becoming operational in 1983. Currently, there are seven ASR facilities operating in Florida and at least twelve undergoing operational testing. The facilities are being used to inject and recover treated and untreated groundwater, partially treated surface water, and reclaimed wastewater. Some of the issues these pilots are trying to resolve include are source water quality, regional changes in aquifer flow and pressure, target storage volume (TSV) efficiency, and water quality changes.

ASR (aquifer storage \& recharge) can be used to store any type of water where water can be used later on and can be re-injected. Examples include (Adapted from Almulla [54]:

1) Potable water systems. In this case water can be stored at certain periods of the year where the demand of water is not high or there is no need to use the stored water. At high demands or in emergency, this water can be pumped out and used.

2) Reclaimed wastewater systems. In countries like United Arab Emirates, treated wastewater is used for irrigation purposes. However, in the winter there is a huge surplus in treated wastewater where in the summer there is a great shortage in irrigation water. This suggests that treated wastewater can be stored in the winter and reclaimed and used in the summer.

3) Surface-water or storm water systems. Due to rain, this runoff water can be collected in dams and directed to water storage facilities. This is an advantage in water management since currently most storm water runoff is uncontrolled and serves little more than an pollutant for waterways and surface water sources..

The combination of Aquifer Storage and Recharge in coordination with desalination facilities, referred to as DASR, is increasingly recognized as a cost-effective combination, taking advantage of the economies associated with steady operation of membrane desalination facilities, plus the large volume water storage capabilities available in ASR wells to meet seasonal variations in water demand, storing excess water in winter months when demand is low and recovering the stored water in summer months when demand is high [55].

Public confidence in water reuse projects is seemingly higher when the water is put back into natural systems such as streams and aquifers before recovery for reuse. Societal perceptions view natural systems as beneficial with respect to removal of human pathogens, the most significant concern to human health. Putting reclaimed water into the 
natural environment increases the cycle time of recycling and allows more time for biodegradation of contaminants that degrade more slowly [56, 57].

A second major advantage is the capacity for inter-seasonal and inter-year storage that natural systems provide. This is where aquifers have major advantages over surface impoundments. The capacity is very large so that matching supply and demand for recycled water, particularly for agricultural use, is not the dilemma it can be where finite active surface storage capacity is bounded by spill or running dry. Aquifers have more blurry bounds that may provide a softer landing when the system is pushed to its limits.

Finally, aquifers offer storage where there is no room for surface storage, such as in urban areas; they do not consume prime valley floors, do not harbor mosquitoes or algal blooms, including toxic cyanobacteria, and there are no evaporation losses that also increase the salinity of the remnant water $[57,58]$. One potential attraction for aquifer recharge is that it could be used for water rights transfer from party to party. Such offsets are accepted in the Columbia River Basin where a one-to one- replacement of fresh water is required for permits to be issued for new fresh water usage (59).

The major disadvantages to ASR are (1) the cost of injection of the fresh water into the underground formation and (2) the uncertainty of monitoring of water quality. Hydrologic models of water flow often do not have the precision needed to track salinity gradients or other potential contaminant contents. O\&G reservoir engineering models offer possible solutions for the latter but a cost effective ASR program is still tied to injection costs of the desalination stream. 


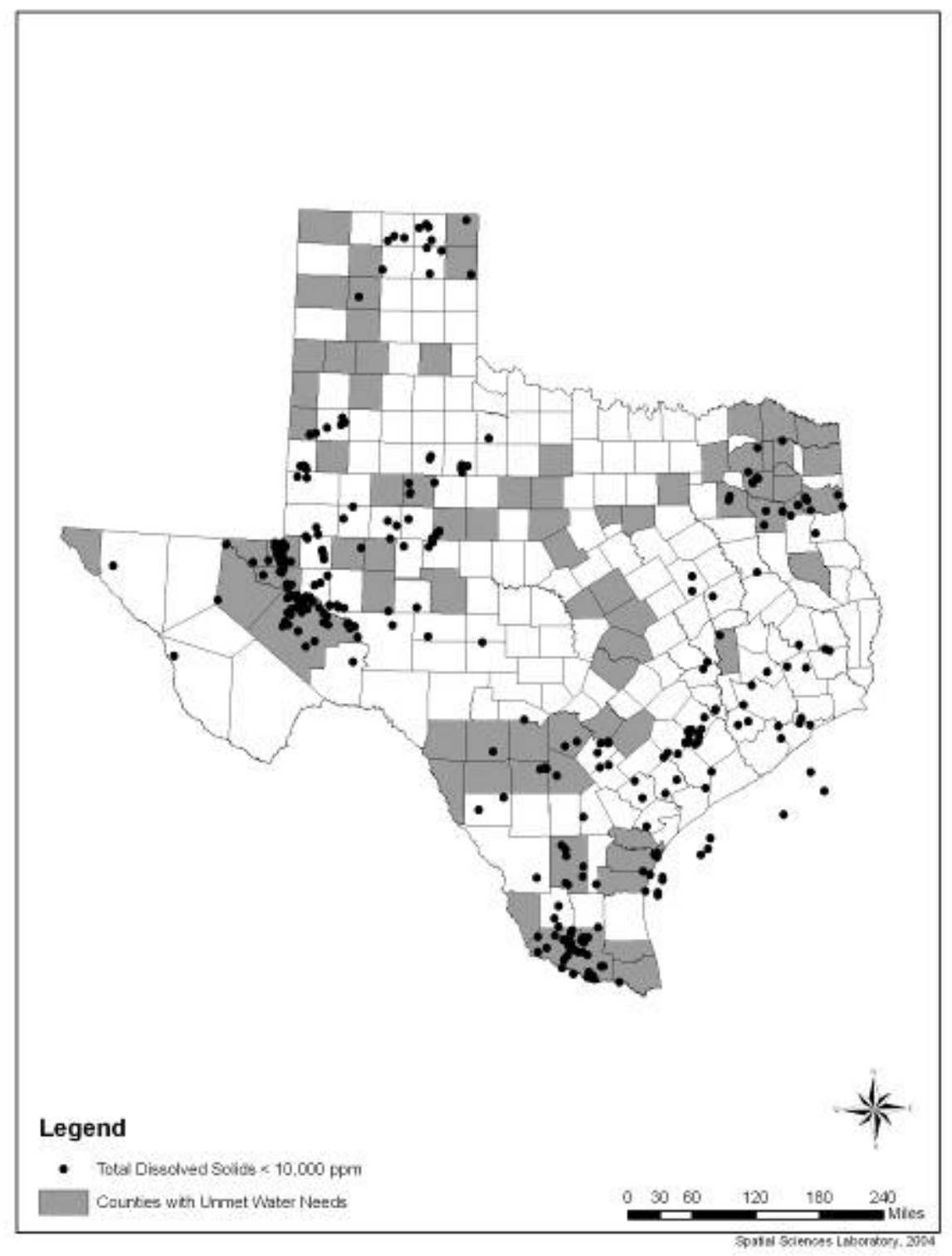

Figure 11 Distribution of brackish produced water sites in the USGS database for Texas.

The brines are shown with EPA classified counties with unmet water needs [44].

Therefore, if this water was to be used as an independent potable water source, among other drinking water standards, TDS levels must be reduced to the Environmental Protection Agency's secondary standard of $500 \mathrm{mg} / \mathrm{L}$. Permitting for waters with a TDS greater than $500 \mathrm{mg} / \mathrm{L}$ may be available if this water is the only potential potable resource for a community. However, if the high TDS water were to be blended with another public water supply (PWS) and then distributed, the required level of treatment could be less. The caution in this situation would relate to the salt-loading on the primary PWS infrastructure during blending [60].

A point of contention existed in previous years regarding the discharge of RO concentrate from desalination facilities. If the saline concentrate is a waste stream, then the RO 
facility operator must get a permit from TCEQ for a Class 1 disposal well. However, recently [45] an agreement between the TCEQ and the TRC was made regarding the use of the brine concentrate in oil field brine injection wells for enhanced recovery.

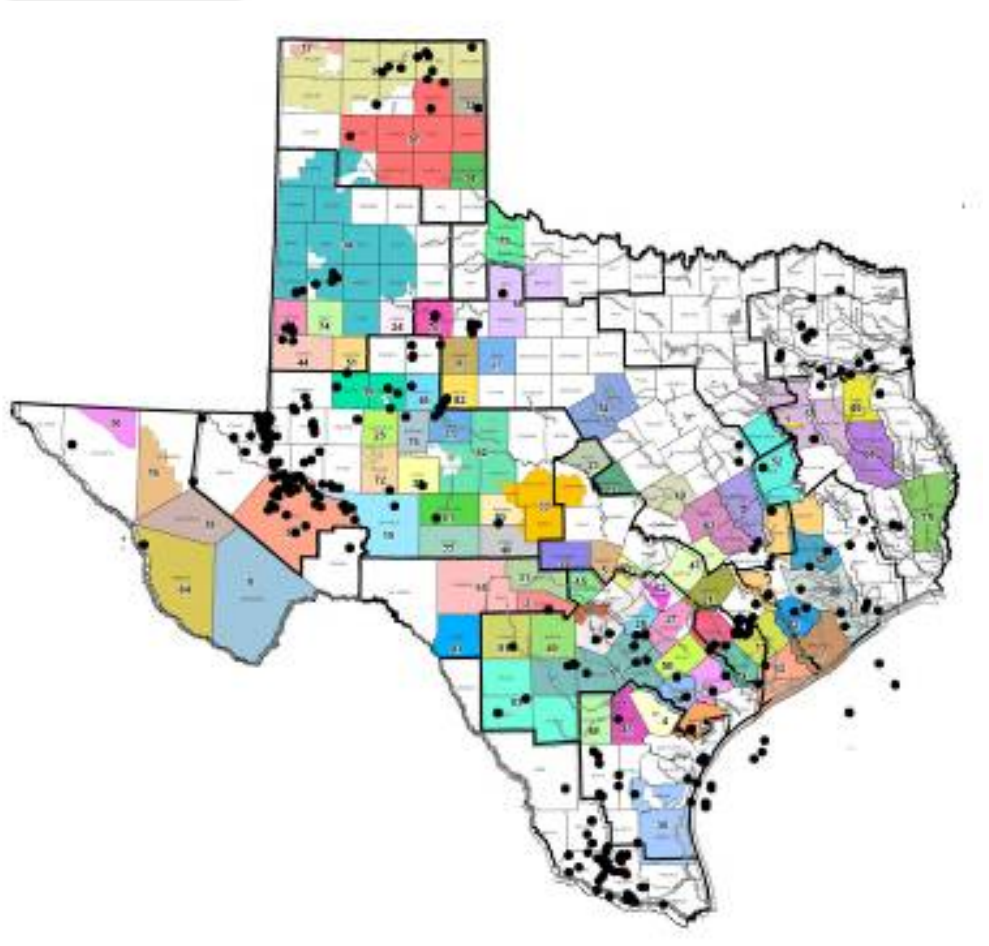

Figure 12 shows an overlay of BPW production near surface waterways with impaired quality.

Texas Water Planning Districts are shown in various colors (from TCEQ). Impaired surface waters are from U.S. Corp of Engineers. Detailed maps for each Water Planning District in the state show the impaired waterways juxtaposed with oil fields producing brine of less than 10,000 ppm tds.

\section{Barriers to Adoption}

The barriers to adoption of desalination of waste water, brackish ground water and oil field produced brine include political issues, community perception issues, and technical issues. The Governor and the TWDB have provided leadership for the State in developing desalination programs in Texas. However, lack of public funding, environmental, and regulatory issues related to desalination of produced water (and other inland saline waters) inhibit technology advancement of this resource. Public perception and acceptance of the advantages of RO desalination is unclear. Cost reduction advancements in technology are slowed by a lack of a clear "path to market" of new products and processes. Supplemental state government funding for demonstration projects (both sea water desalination and inland BGW desalination) is lacking. With these issues affecting the market for commercial development, it is clear that a more concerted effort is needed to develop new water resources from desalination, address conveyance 
issues associated with water transfer, and be prepared to meet the demand for the new resource if it were to be made available. Some selected issues are discussed below.

The Texas Commission on Environmental Quality has been working with other state agencies to streamline regulations for the permitting process for disposal in deepunderground injection wells of brine produced by desalination operations. Applicants for permits to dispose of brine from desalination in injection wells must meet the current requirements for disposing of hazardous waste in Class I injection wells, including brine from desalination if it is classified as a waste material from "either industrial or municipal facilities". Since injection wells have been used for disposal of salt water associated with oil and gas operations for almost a century, (as Class 2 wells), it is hoped that new cooperative efforts in desalination will allow deep injection wells into oil and gas fields for brine byproduct use in enhanced oil recovery operations. Recent private meetings between TCEQ and the TRC may have removed the roadblock.

Local issues that communities would identify as barriers include the perception that desalinated produced water is not pure enough for consumption by humans or livestock and that there might be environmental drawbacks to its use for plants, range, and habitat sustainability. It is suggested however, that advanced technology and an improved regulatory climate will increase the likelihood of adoption of PWDS by water use groups in the state.

\section{General Regulatory Requirements}

Desalination of sea water and brackish ground water and subsequent use by municipalities would be regulated through NPDES permitting through TCEQ [37]. Ramirez and Lee [40] describe the TPDES permitting process, including the Clean Water Act requiring every industrial or municipal facility that directly discharges pollutants into streams, lakes or the ocean to have a wastewater discharge permit. In the context of a seawater desalination facility, the TPDES permit application process would serve to ensure that discharges of brine concentrate will not have significant adverse effects on the receiving waters.

Despite the delegation of NPDES permitting authority to the State of Texas, EPA continues to exert influence over coastal activities. The Submerged Lands Act of 1953 gave coastal states title to "lands beneath navigable waters," and granted state jurisdiction over coastal waters for the "territorial sea." However, the federal government, in the Submerged Lands Act, also retained "all its navigational servitude and rights in and power of regulation and control of said lands and navigable waters for the constitutional purposes of commerce, navigation, national defense, and international affairs." Because of this, the federal government still has the ultimate authority to regulate activities involving discharges into coastal areas. The United States Supreme Court has consistently upheld the federal government's right to regulate coastal activities. Because of this and provisions of the Clean Water Act, TCEQ must provide EPA with a copy of each TPDES permit it issues, and EPA may object to any such permit issued by TCEQ. EPA also continues to have the authority to enforce any permit violations against any discharger. Moreover, a TPDES permit only lasts for a maximum of five years (although it could be less), and EPA has the right to review each permit renewal application at the end of its term. There are numerous other agencies that may be provided a draft TPDES 
permit for review depending on the nature and location of the discharge.

A TPDES permit incorporates the general requirements of the Clean Water Act, Code of Federal Regulations, Texas Water Code, and Texas Administrative Code into permit conditions specific to a particular facility's operations. When the TCEQ Wastewater Permits Section drafts a particular facility's permit, the most influential source of regulations are the Texas Surface Water Quality Standards ("TSWQS") contained in Chapter 307 of Title 30 of the Texas Administrative Code [22, 23] The specific TSWQS that would be most relevant to the permitting of a seawater desalination facility would be aesthetics, temperature, salinity and toxicity. A TPDES permit will typically contain limitations on the amount of pollutants that can be discharged, with those limitations based on technology-based standards or water quality based standards. Technology-based standards are traditionally organized by EPA-classified categories of industries. However, EPA has not yet created an industrial category for desalination, so there are no industry-wide technology-based standards. Therefore, effluent limits in a TPDES permit for a seawater desalination facility will be subject to separate issues.

The Ground Water Protection Council (http://www.gwpc.org) and its advisors are addressing this issue. Recently John Veil stated "In previous informal discussions with several state underground injection control (UIC) agencies and EPA's UIC program staff, four possible injection scenarios were identified, and the regulators offered opinions on how injected concentrate might be regulated (Table 6). The scenarios include two types of source water (brackish ground water and produced water) and two injection strategies (inject for enhanced oil recovery or inject for disposal).

\section{Table 6 Injection Well Class for Concentrate Injection under Different Scenarios}

\begin{tabular}{|c|c|c|}
\hline Source of Raw Water & $\begin{array}{l}\text { Injected for Enhanced } \\
\text { Recovery }\end{array}$ & Injected for Disposal \\
\hline Produced Water & Class II & Class II \\
\hline $\begin{array}{l}\text { Brackish/Saline } \\
\text { Water }\end{array}$ & Class II & $\begin{array}{l}\text { Not determined - regulators } \\
\text { need additional data }\end{array}$ \\
\hline
\end{tabular}

The agency representatives indicated that if the source water is produced water, disposal of the resulting concentrate could be made to a Class II well regardless of the injection strategy. They also noted that if brackish water concentrate is injected for enhanced oil recovery, the resulting well will also be a Class II well. However, they did not concur on the fourth combination - brackish ground water as source water and disposal of the concentrate via injection. Some of the regulators suggested that they would need to know the chemical constituents present in the concentrate and their levels. Based on that information, they might require Class I or Class V wells or pursue some other option.”

Source water quality is of great concern, particularly when the end use will be potable. Any system providing drinking water to more than 25 people must meet restrictions on the amount of pollutants allowed in the drinking water system. Due to the concern regarding contaminants that exist in the source water, as well as potential precipitation, fouling, and scaling of the membranes, a study conducted for the Nueces River Authority 
suggested source waters high in salt content be tested for 27 different parameters prior to the planning of a treatment facility [24].

Because the rules regarding this type of water source are not clearly defined, clarification is needed. Regulatory staff has suggested that, once a project is defined, an official letter be sent to the State to inquire about all relevant regulations and permits necessary. 


\section{WATER RESOURCES ASSOCIATED WITH UNCONVENTIONAL O\&G DEVELOPMENT}

Energy production represented by oil and gas extraction has been one of the major industries in Texas for more than 100 years. The fields that were discovered during this time are nearing their economic limit. One reason that $O \& G$ operators are interested in desalination of produced water is that it has the chance of reducing operating costs of their wells and extending their lifetimes. Within the last 10 years however, unconventional reservoirs are being brought on production as new technology makes their development economical. Most of the attention to unconventional resources has been focused on Coal Bed Natural Gas (CBNG). Figure 13 shows CBNG resources in Texas and nationwide. These resources have an estimated 750 trillion cubic $\mathrm{ft}$ of natural gas. Figure 14 shows unconventional energy trends, soon to represent more than $50 \%$ of our natural gas supply.

The increase in importance of CBNG and other unconventional resources is the result of a combination of factors - tax breaks for exploration, research funding that triggered new technology in imaging, horizontal wells, and hydraulic fracturing and high gas prices. As the figure shows, much of the energy play is in environmentally sensitive areas, in the West public lands, and in the East, in populated areas that have not experienced oil and gas "booms".

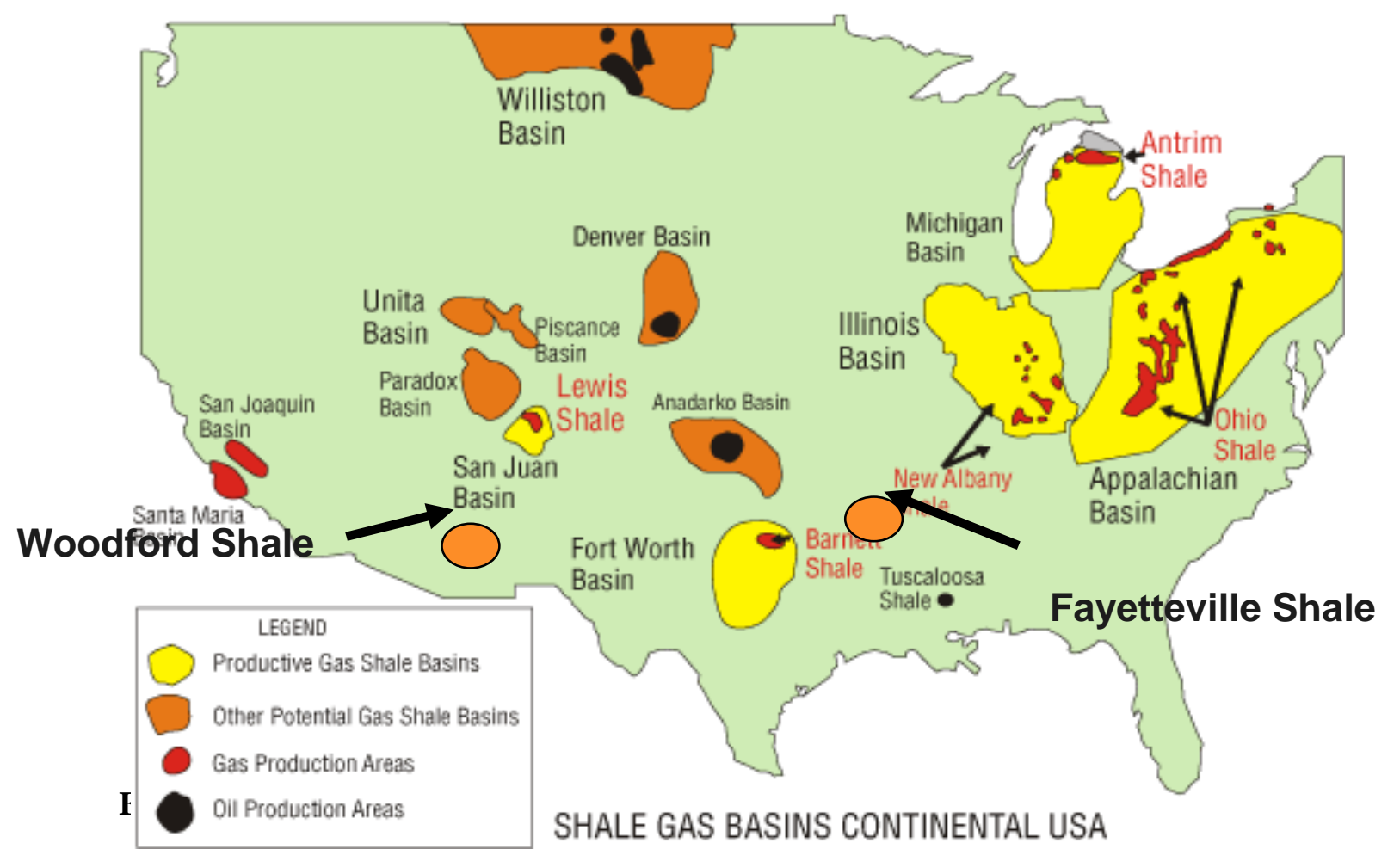

Despite the issues related to the impact of drilling in environmentally sensitive areas, and despite the needs for technology advances, most industry specialists believe that this 
source of energy for the U.S. is destined to become more and more important. Figure 14 shows a chart resulting from a study by the Petroleum Technology Council, PTTC [48]. The contribution of unconventional resources increases steadily over the next 50 years until it represents more than $50 \%$ of the U.S, natural gas needs.

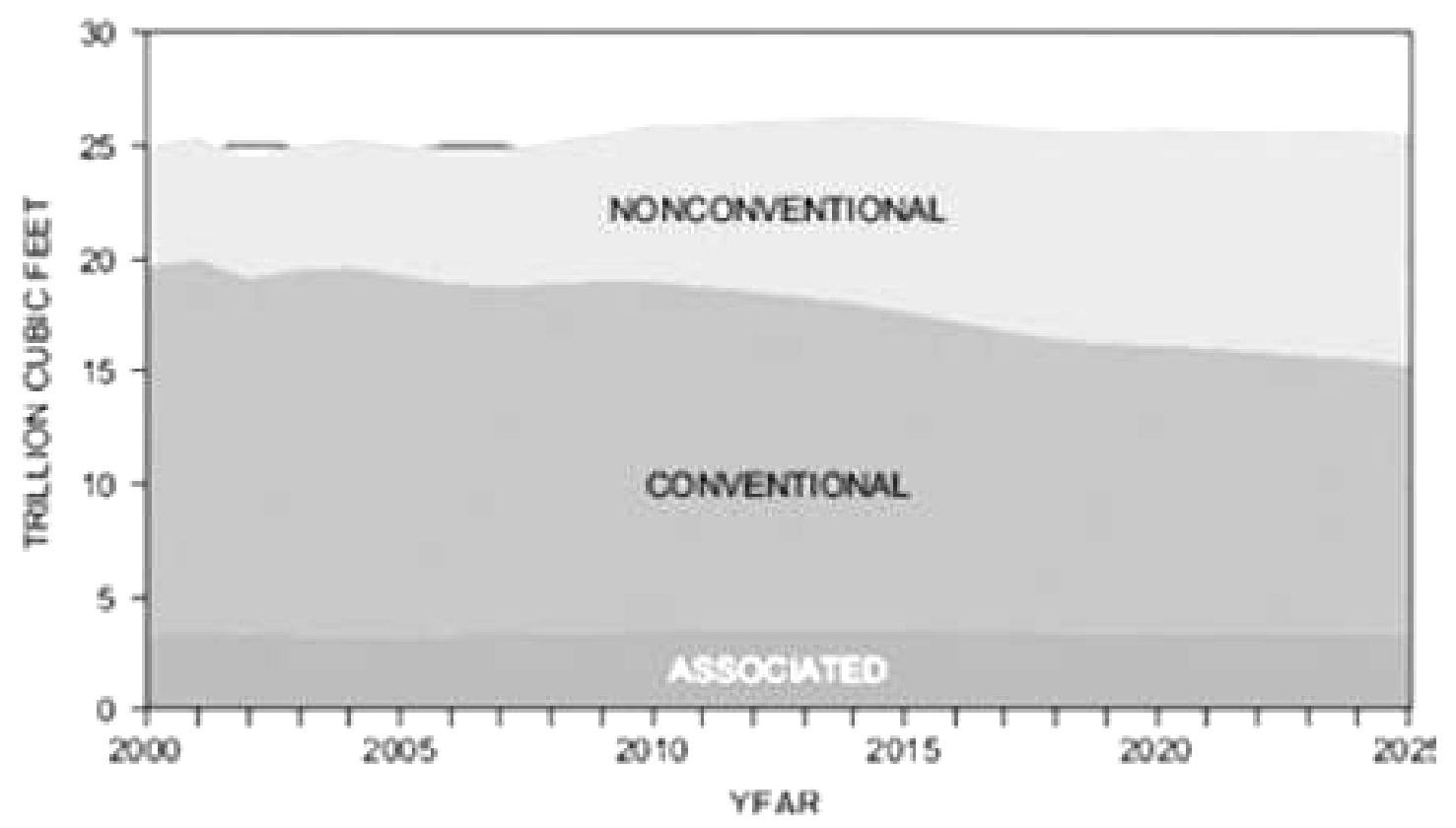

Figure 14 shows gas production forecasts for the lower 48 states and Canadian Fields for the next 20 years. Source PTTC [48]

In Texas, the most activity is in the Barnett Shale play in the North Central part of the state. In the past three years, the drilling boom in the Barnett Shale has become the most active area in the U.S. The field, the largest active gas field in Texas, now produces more than 220 Bcf of natural gas per year.

Drilling activity isn't limited to Texas however. Unconventional energy resources in Oklahoma include Hunton de-watering and coal bed methane (CBNG activity in the Arkoma and Cherokee basins). [7, 8] CBNG active in Oklahoma's Arkoma Basin produced about $70 \mathrm{Bcf}$ of gas cumulatively through mid-2003. About two-thirds of this production is from vertical wells, but horizontal production is rapidly overtaking that from vertical. Cherokee Basin CBNG cumulative production is about $45 \mathrm{Bcf}$, all from vertical wells. CBNG wells in southeast Kansas are now producing about 10 Bcf per year, and activity is strong. Arkansas CBNG production is just now beginning to increase [59].

\section{Water Resources Used in Energy Production}

The connection between unconventional energy resources and water resources is typified by the photograph in Figure 15. It shows a well fracturing operation in the Barnett Shale using fresh water from the municipality of Cleburne, Johnson County Texas. Cleburne sells water to operators at retail rates to stimulate Barnett Shale wells. A horizontal well 
fracturing operation uses on average 5 million gallons of water to create vertical fractures that intersect natural fissures in the shale. Flow back of the water, now containing mineral salts from the underground formation, occurs over a period of several days to months.

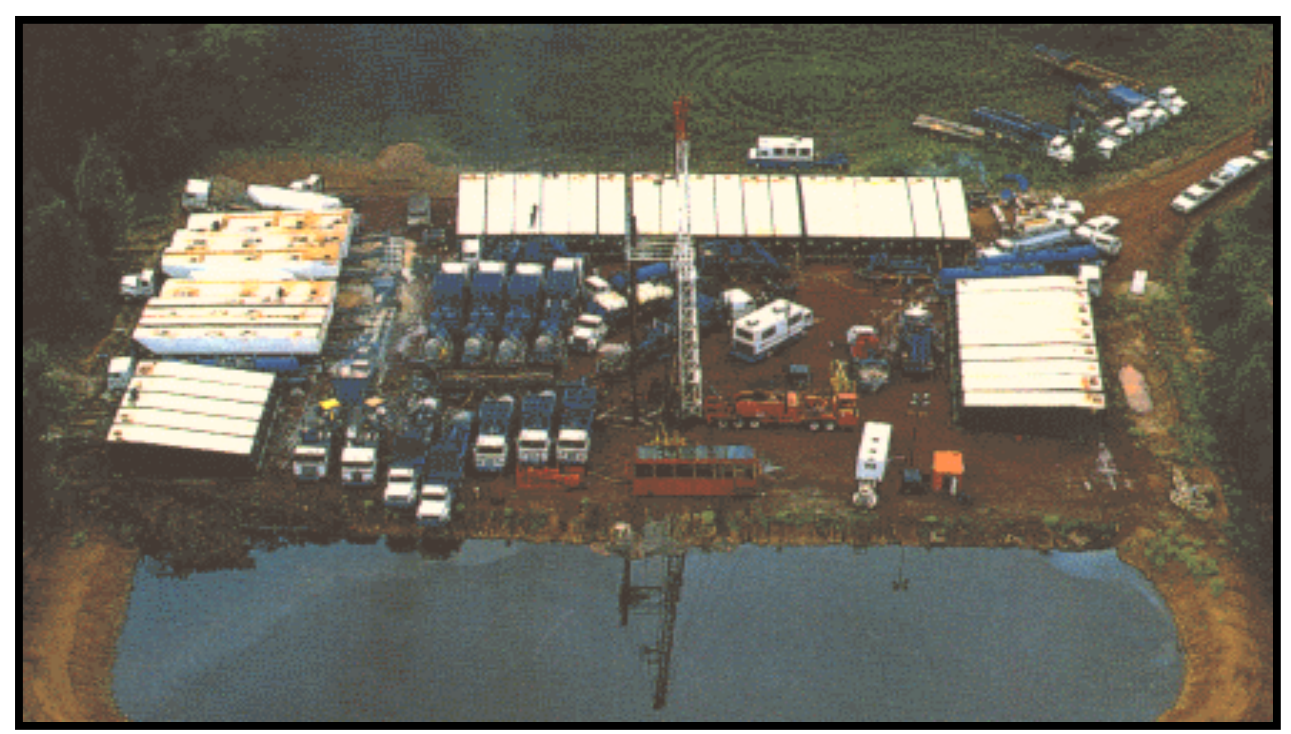

Figure 15 is a photograph of a fracturing operation in the Barnett Shale.

Flow back water must be captured in lined pits and transported to off site disposal. Salinity characteristics of this brine vary greatly, depending on the amount of flow back water, the zone that has been discharging the water, and the formation water content as a component of the fracturing water. Table 7 shows typical analytical data from water transport trucks carrying brine to off-site disposal. Total dissolved salts are in excess of $100,000 \mathrm{ppm}$. Total suspended solids (TSS) are likewise quite high averaging almost 200 ppm for transport samples and more than 15,000 for the pit sample [60]

The issue is that all of the fresh water must be transported in to the site, then all of the flow back brine stored, re-loaded in transports and trucked to disposal wells that are dozens of miles away. The brine water is then injected and lost permanently from the environmental natural water.

Table 7. Composition of Typical Flow Back Water from Barnett Shale [60] 


\begin{tabular}{|c|c|c|c|c|c|c|c|}
\hline & Flowb-1 & Prod $\mathrm{H} 2 \mathrm{O}-2$ & Truck 920 & Flowb-4 & TruckL080 & DoubW\#2 & Pit Sample \\
\hline Conductivity & 224600 & 240600 & 283000 & 225000 & 254600 & 271000 & 1410 \\
\hline Chloride & 69296 & 75254 & 87660 & 69379 & 79891 & 83781 & 150 \\
\hline Sulfate & 395 & 363 & 510 & 359 & $<40$ & 480 & 182 \\
\hline Bromide & 580 & 603 & 597 & 572 & 559 & 570 & 1.1 \\
\hline Potassium & 326 & 411 & 825 & 301 & 357.4 & 832 & 743 \\
\hline Magnesium & 1060 & 1164 & 1550 & 1070 & 999.4 & 1550 & 296 \\
\hline Silicon & 15.91 & 13 & 7.84 & 12.64 & 6.42 & 8.68 & \\
\hline Calcium & 8970 & 9982 & 13480 & 8950 & 11700 & 13460 & 287 \\
\hline Sodium & 31920 & 33480 & 36900 & 31600 & 35760 & 36760 & 505 \\
\hline Boron & 47.82 & 45 & 31 & 47 & 30.02 & 31.52 & 3.4 \\
\hline Silica & 34 & 27 & 17 & 27 & 13.7 & 18.6 & \\
\hline $\mathrm{pH}$ & 6.55 & 6 & 6.51 & 6.52 & 6.11 & 6.42 & 10.01 \\
\hline TDS & 118600 & 127800 & 152100 & 121000 & 140600 & 151400 & 1243 \\
\hline TSS & 352 & 162 & 164 & 450 & 274 & 178 & 15650 \\
\hline TPH & 136 & 74 & 27 & 1234 & 6.4 & 293 & 2.04 \\
\hline
\end{tabular}

\section{The Social Cost of Energy Production}

The issue of supplying adequate water resources for communities intersects with the need for water resources for energy production for those communities. Efforts by Texas A\&M and others to reduce the use of water in energy production and to make fresh water available for those communities is part of the process of sustainable natural resource development.

Texas, in the 21st century is becoming a different society than most adults recall growing up. In almost every county in Texas, the population is shrinking. The urban centers and the counties near the urban areas are absorbing practically $100 \%$ of the state's population growth. On the other hand, almost $100 \%$ of the population would rather live in a small community. Fewer job opportunities and inadequate socio-economic infrastructure most likely prevent even greater migration to the country.

When economic booms come to local communities, many times its leaders are unable to cope with the change. The role of state and federal government in local communities is diminishing as funds for economic development are stretched. It is becoming the responsibility of the communities themselves to take the lead in their own survival and development. Unconventional energy development brings both good and bad changes to these cities. The ability to recover water resources from energy development helps to accommodate the changes it brings.

There is new technology for developing new sources of fresh water for the community. Two examples are the desalination of brackish water from underground aquifers to make it potable, and the treatment and desalination of oil field produced water to make it usable for livestock, agriculture and industrial uses.

Studies have shown that it is extremely important that the user (defined as local community who might have a use for the water) be included in the change process that comes from adoption of this new technology. The user's interest in anyone's recommended systems is very important because these interests are the basis for the system's acceptance and adoption. 


\section{RECOMMENDATIONS FOR THE ADVANCEMENT OF DESALINATION TECHNOLOGY}

Our feasibility study recommends a number of steps to help advance desalination technology. Technology demonstrations or "road shows" could bring new concepts of pure water to communities in need. The TWDB should continue to lead by example and should encourage other State Agencies to address water needs in a comprehensive fashion and to communicate, remove paperwork barriers, and advance worthy projects.

Collaboration should not be limited to just Texas organizations. The Rio Grande Basin Initiative is one example of economic development programs that seeks new approaches to solving problems [57] common to the states of New Mexico and to Texas. A research alliance has been established that includes these two states, plus Arizona, named CHIWAWA (Consortium for Hi-Technology Investigations in Water and Wastewater) [58]. T he purpose of this initiative is to create sustainable urban and rural water supplies and protect environmental quality by conducting innovative, collaborative research, education and training programs in inland desalination technology, concentrate disposal and water resources management. A consortium including New Mexico State University, The Texas A\&M University System, The University of Texas at El Paso and two water utilities, the Cities of El Paso and Alamogordo, are pooling advanced expertise and experience in arid environment water resource management to address pressing technological, management and training issues related to inland desalination, source water characterization, and concentrate and water resources management.

Finally, the efforts to address the needs of local communities at the local level is paramount, especially in the regions of the State where fresh water resources are insufficient for current or future needs. This report on the new technology of desalination and re-use of oil field brine is only a part of the effort necessary to develop commercial programs. There must be efforts by all to communicate to the users. This involvement with the community is expected to make any proposed projects more likely to be accepted and thus support our efforts to create these new water resources more effectively.

\section{Collaboration with State Agencies}

Led by the Texas Water Resources Institute at Texas A\&M, personnel from the A\&M Look College of Engineering and the Global Petroleum Research Institute (GPRI) have worked with the Texas Railroad Commission Texas Water Development Board (TWDB) and the Texas Commission on Environmental Quality (TCEQ) to further the cause of desalination in Texas. Among a number of activities, the group has participated in the following;

Desalination Research Workshop, Austin Texas 2002, volunteer activity

Collaboration with TWDB USBR research project "Pass the Salt", volunteer activity

Collaboration with the South Central Desalination Association Workshops, 2005, San Antonio, College Station

Development of the "Future of Desalination" A\&M Workshop, August 2005,

Hosting the "Future of Desalination” A\&M Workshop August 2006 
Proposed Brackish Ground Water Desalination with Concentrate Injection into Oil Fields, BLM Proposal 2005 (funding denied)

Proposed Brackish Ground Water Desalination with Concentrate Injection into Andrews, Texas Oil Fields, (TWDB funding denied)

"Use of RO Concentrate in Oil Fields for Beneficial Use (Stripper Well Consortium Project, 2006).

Desalination of Oil Field Brine with Concentrate Injection into the Darst Field. Meeting with TCEQ and TRRC to Resolve Regulatory Issues, January 2006.

The meeting with TCEQ and the TRRC resolved a regulatory barrier to desalination of brackish ground water or oil field brine with re-injection of brine concentrate into an operating oil field.

\section{Acknowledgements}

This project, jointly funded by the U.S. Department of Energy, National Energy Technology Laboratory (No. DE-FC26-03NT15427) and the Global Petroleum Research Institute (Texas Engineering Experiment Station) Texas A\&M University

Assistance also came from members of the Texas Water Resources Institute (TWRI) who provided both guidance and information relating to GIS data.

Several consultations were conducted with members of the Texas Water Development Board and with members of the petroleum engineering faculty at Texas A\&M University. Thanks also go to the staff of Texas Railroad Commissioner Michael Williams who provided information for this study while Texas Water Resources Institute provided reference material on fresh water issues in Texas.

Special thanks go to Mr. John Veil of Argonne National Laboratory who provided insightful comments on water policy issues in the state and across the U.S. 


\section{References}

1. Siddiqui, Mustafa, "Treatment of Oil Field Brine by Desalination: A Multidisciplinary Program”, MS. Thesis Department of Petroleum Engineering, Texas A\&M University, 2002

2. Veil, John A., Puder, Markus G., Elcock, Deborah, and Edweik, Robert J., Argonne National Laboratory, Produced Water from Production of Oil and Natural Gas, U. S. DOE Contract W-31-109-Eng-38 (2004).

3. Veil, John A. "Management of Offshore Wastes in the United States," Argonne National Laboratory Washington DC 2002.

4. Melchor, A.E., de Costa, A., Rodriquez, C., and Pena, J.R., "E\&P Waste Management in the Orinoco Basin, paper SPE 78807-PA 2002, Society of Petroleum Engineers.

5. Pollastro, R.M., R.J. Hill, T.A. Ahlbrandt, R.R. Charpentier C., Cook, T.R. Klett, M.E. Henry, and C.J. Schenk, 2004, Assessment of undiscovered oil and gas resources of the Bend Arch-Fort Worth Basin Province of North-Central Texas and Southwestern Oklahoma, 2003: U.S. Geological Survey Fact Sheet 2004-3022, 2p., available online at: http://pubs.usgs.gov/fs/2004/3022/

6. Pawlewicz, Mark, "U.S. Geological Survey 1-D Burial History Modeling in the Permian Basin, Western Texas and Southeastern New Mexico,” AAPG Annual Convention, April 9-12, 2006

7. Powell, Dylan Unconventional Energy in the Southern Mid Continent Petroleum Technology Transfer Council, Network News, $1^{\text {st }}$ Quarter, 2004.

8. Busten, R. Mark., Gas Shale Tapped for Big Play,” USGS Explorer February, 2005

9. Arkansas Times Record, Ft Smith Arkansas, September 26, 2005 “More Drilling More Billing,"

10. Gould, Andrew, “Technology and Production, A View for the Future,” Keynote Address at the 35th annual Offshore Technology Conference (OTC), May 4, 2004, Houston. TX.

11. Kathib, Z. and ver Beek, P. "Water to Value-Produced Water Management for Sustainable Field Development for Mature and Green Fields,” paper SPE 73853 presented at the SPE International Conference on Health, Safety and the Environment in Exploration and Production, Kuala Lumpur, March 2002

12. Burnett, D. B. GPRI, Simms, Bart. Texas Railroad Commission, Private Conversations, May 11, 2006

13. Texas Railroad Commission Digital Information, Districts and Wells http://www.rrc.state.tx.us/divisions/og/ogmap.html

14. Barrufet, M.A. Morales, G. A. "Desalination of Produced Water Using Reverse Osmosis,” Gas Research Institute, Gas TIPS, Summer 2002, Volume 8 Number 3 pages 13-17.

15. Georgie, W. J., Sell, D., and Baker, M.J. "Establishing Best Practicable Environmental Option Practice for Produced Water Management in the Gas and Oil Production Facilities" SPE 66545, presentation at the SPE/EPA/DOE Exploration and Production Environmental Conference, San Antonio, Texas, 2628 February 2001. 
16. U. S. Department of Energy National Energy Technology Laboratory, Fossil Energy, Drilling \& Completion Research Projects, http://www.fossil.energy.gov/fred/feprograms.jsp?prog=Gas/Oil++Drilling,+Completion+and+Stimulation

17. Texas Commission on Environmental Quality, "Injection Wells, am I Regulated?”

http://www.tceq.state.tx.us/permitting/waste_permits/uic_permits/UIC_Am_I_Re gulated.html

18. Soc. Petroleum. Eng. Glossary http://www.spe.org/spe/jsp/basic/0,,1104_1710,00.html

19. United States Geological Society URL http://www.usgs.gov

20. Compendium of West Texas Oil Fields, Vol. I-VII, West Texas Geological Society, Midland TX Library Reference Shelves.

21. Burnett, D. B. and Veil, John A., "Decision and Risk Analysis Study of the Injection of Desalination Byproducts into Oil and Gas Producing Zones," paper SPE 86526 presented at the SPE Formation Damage Conference, Lafayette LA. February, 2004.

22. Marlo Berg, Water Supply Division, Public Drinking Water Section, Technical Review and Oversight Team (April 15, 2004)

23. Kelly Holligan, Water Quality Division, Wastewater Permitting Section, Industrial Permits Team (April 19, 2004)

24. HDR Engineering, Inc. Desalination for Texas Water Supply, Part A: Membrane Technologies and Costs. 2000.

25. Wilbert, M.C., Leitz, F., Abart, E., Boegli, B., and Linton, K., 1998. The desalting and Water Treatment Technology Program Report No29, 2nd Edition, U.S. Department of the Interior, Bureau of Reclamation..

26. Foundation for Water and Energy Education Columbia Basin http://www.fwee.org/c-basin.html

27. Arnold, K. E. and Ferguson, P. L.: "Designing Tomorrow's Compact Separation Train" paper SPE 56644 presented at the 1999 SPE Annual Technical Conference \& Exhibition held in Houston, 3-6 October.

28. Meikrantz, D. H. et al.: “Advances in Liquid/Liquid Centrifuge Design Provide New Options for Petroleum Production” paper SPE 56709 presented at the 1999 SPE Annual Technical Conference \& Exhibition held in Houston, 3-6 October.

29. Sinker, A. B., Humphris, M. and Wayth, N.: "Enhanced Deoiling Hydrocyclone Performance without Resorting to Chemicals," paper SPE 56969 presented at the 1999 SPE Offshore Europe Conference held in Aberdeen, 7-9 September.

30. Doyle, D. H. and Brown, A.B. "Produced Water Treatment and Hydrocarbon Removal with Organoclay,” SPE 63100 SPE Annual Conference,, 1-4 October, Dallas, Texas, 2000

31. Boysen, J.E. Harju, J.A., Shaw, G. and Hayes, T. Field Demonstration of the Freeze-Thaw/Evaporation Process for the Treatment of Produced Waters in the San Juan Basin of New Mexico SPE Paper 37904 presented at the SPE/EPA Exploration and Production Environmental Conference, Dallas, 3, Marc, 19997 
32. Tampa Bay Desalination Plant U.S.A. Water Technology. Net Report. http://www.water-technology.net/projects/tampa/

33. Dreher, K.D., Kenyon, D.E., Marathon Oil and Co.; Iwere, F.O "Heat Flow During Steam Injection Into a Fractured Carbonate Reservoir”, paper 14902-MS. SPE Enhanced Oil Recovery Symposium, 20-23 April, Tulsa, Oklahoma

34. van den Hoek, P.J., Sommerauer, G. Nnabuihe, L., and Munro, D., "Large-Scale Produced Water Re-Injection Under Fracturing Conditions in Oman”, paper SPE 87267 presented the 9 Abu Dhabi International Petroleum Exhibition and Conference held in Abu Dhabi, U.A.E., 15-18 October 2000.

35. Mace, Robert E., "Please Pass the Salt," Texas Water Development Board Study, 2002 URL http://www.twbd.state.tx.us/desalination

36. Baker, R.O.,Bora, R. Schechter, D.S., McDonals, W.H., Knight, P.L., Rounding, C., "Development of a Fracture Model for Spraberry Field, Texas USA., SPE 71635. SPE Annual Conference, 30 Sept. New Orleans, 2001.

37. Texas Commission on Environmental Quality, "Overview of Surface Water Quality in Texas: 2004 Water Quality Inventory and 303(d) List” (May 13, 2005)

38. Texas Water Development Board Study. "The Future of Desalination in Texas, December 2004”., Appendix 1.

http://www.twdb.state.tx.us/desalination/desal/index.asp

39. City of Odessa Water Utilities Department; http://www.odessa$\underline{\text { tx.gov/internet/WebSubsectionDept.asp?key }=2318}$

40. Hartley, T.W. 2006. Public perception and participation in water reuse. Desalination. 187:115-126

41. US Environmental Protection Agency Manual. 1992. Guidelines for Water Reuse, Office of Water and Office of Research and Development, EPA/625/R92/004

42. Bruvold, W.H. 1998. Public opinion on water reuse options. J. Water Pollution Control Federation, 60(1):45-50

43. US National Research Council, Issues in Potable Reuse: The Viability of Augmenting Drinking Water Supplies with Reclaimed Water. Washington DC, 1998. www.nationalacademies.org

44. Burnett, D, Knappe, B, Gruenwald, B, Seni, S., and Veil, J. "Determining Permitting Requirements for the Darst Field Water Treatment Facility," January 25, 2006. Private Meeting

45. Texas Commission on Environmental Quality “Texas Water Quality Inventory,” http://www.tceq.state.tx.us/compliance/monitoring/water/quality/data/wqm/305_ 303.html

46. TCEQ Rules Index URL http://www.tnrcc.state.tx.us/oprd/rules/indxpdf.html

47. Ice, G. and Sugden B. "Summer Dissolved Oxygen Concentrations in Forested Streams of Northern Louisiana” SJAF 27(2) 2003.

48. Milton, S. J., W., Dean, R.W., du Plessis, M.A., Siegfried, W. R., “A Conceptual Model of Arid Rangeland Degradation,” BioScience, Vol. 44, No. 2 (Feb., 1994), pp. 70-76 
49. Griffith, C. 2006. Water quality for livestock. The Samuel Roberts Nobel Foundation. http://www.noble.org/Ag/Forage/WaterQuality/index.html

50. Faries, Jr., F.C., J.M. Sweeten \& J.C. Reagor. 1998. Water quality: its relationship to livestock. Texas Cooperative Extension. L-2374

51. Panhandle Regional Planning Commission. 2006. Regional Water Plan for the Panhandle Water Planning Area. Texas Water Development Board. Austin, TX.

52. Llano Estacado Regional Water Planning Group. 2006. Llano Estacado Regional Water Plan. Texas Water Development Board. Austin, TX.

53. Region F Water Planning Group. 2006. Region F Water Plan. Texas Water Development Board. Austin, TX.

54. Almulla, A., A. Hamad, \& M. Gadalla. 2005. Aquifer storage and recovery (ASR): a strategic cost-effective facility to balance water production and demand for Sharjah. Desalination. 174:193-204

55. R. D. G. Pyne \& Jonathan B. Howard. 2004. Desalination/Aquifer Storage Recovery (DASR): a cost-effective combination for Corpus Christi, Texas. Desalination. 165:363-367.

56. Dillon, P., P. Pavelic, S. Toze, S. Rinck-Pfeiffer, R. Martin, A. Knapton \& D. Pidsley. 2006. Role of aquifer storage in water reuse. Desalination. 188:123134

57. Dillon, P. J. (Ed.), "Management of Aquifer Recharge for Sustainability,” 4th International Symposium on Artificial Recharge of Groundwater, ISAR-4, Adelaide, South Australia, 22-26 September 2002

58. "Rules Planned on Underground Injection Of Brine From Desalination Facilities in State”, Susanne Pagano, Bureau of National Affairs, Inc., Washington D.C. 2005.

59. 2006 House Bill 2860 (Water resource management in the Columbia river basin) http://www.washingtonvotes.org/Legislation.aspx?ID=43695

60. Ramirez, Kent, and Lee, Patrick, "Desalination Opportunities and Constraints", Texas Journal of the Bar, March, 2004.

61. Rio Grande Basin Initiative, "Strategies for Meeting Present and Future Water Demand in the Rio Grande Basin.” Texas a\&M University, New Mexico State University, http://riogrande.tamu.edu/

62. Michelsen, A.I. "Water Management and Desalination Research and Education Consortium - CHIWAWA”, Draft Report,

63. Petroleum Technology Transfer Council, "State-of-the-Art Technology Summary from PTTC,” Network News Volume 10, 1st Quarter, 2006..

64. Water Analysis Report, Energy Laboratories, February, 2006. C\& L Trucking, Johnson County, Texas. 